

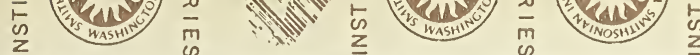

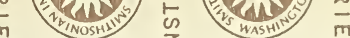

LIBRARIES SMITHSONIAN INSTITUTION NOILIIISNI
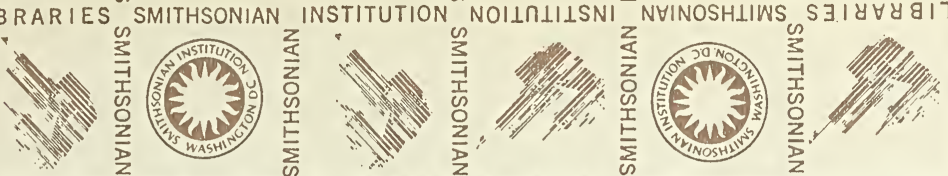

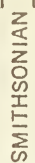
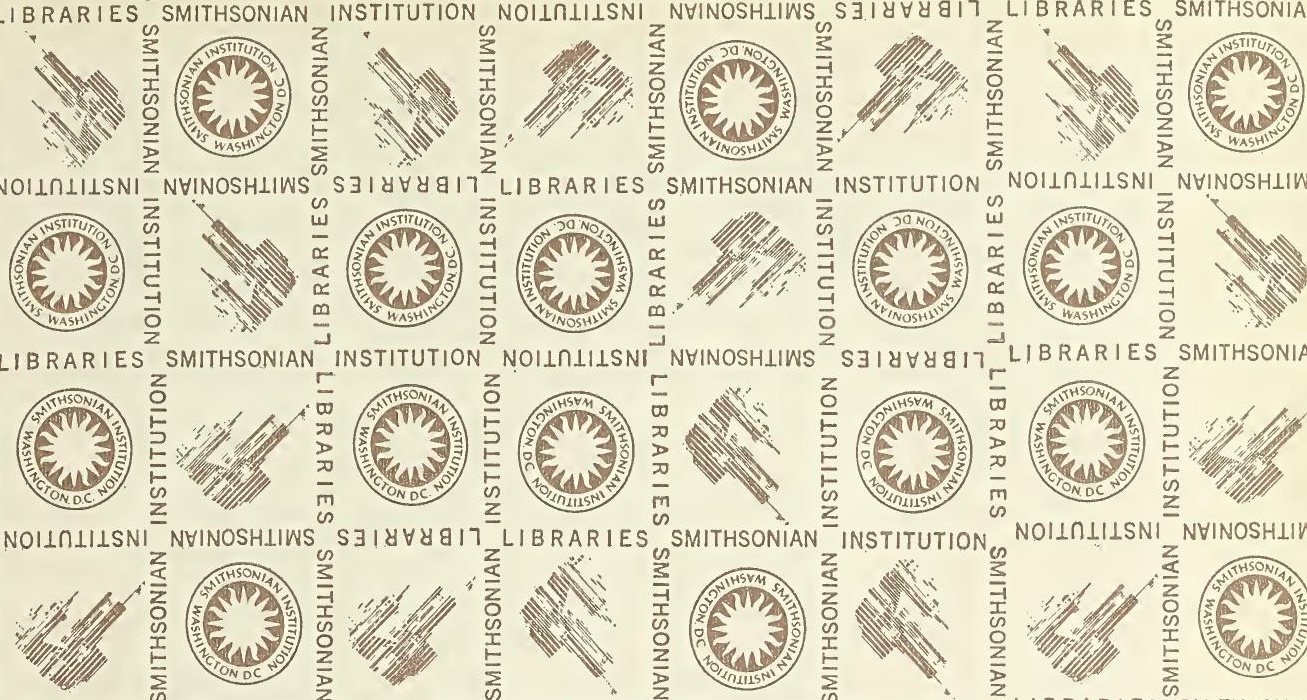

No

NOILNIILSNI
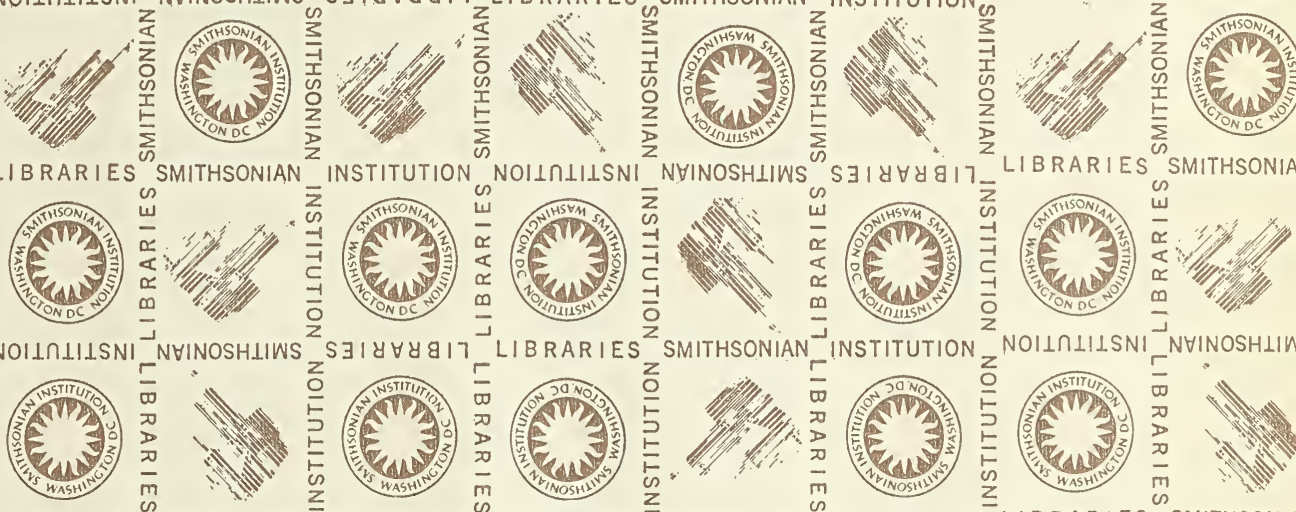

IBRARIES SMITHSONIAN
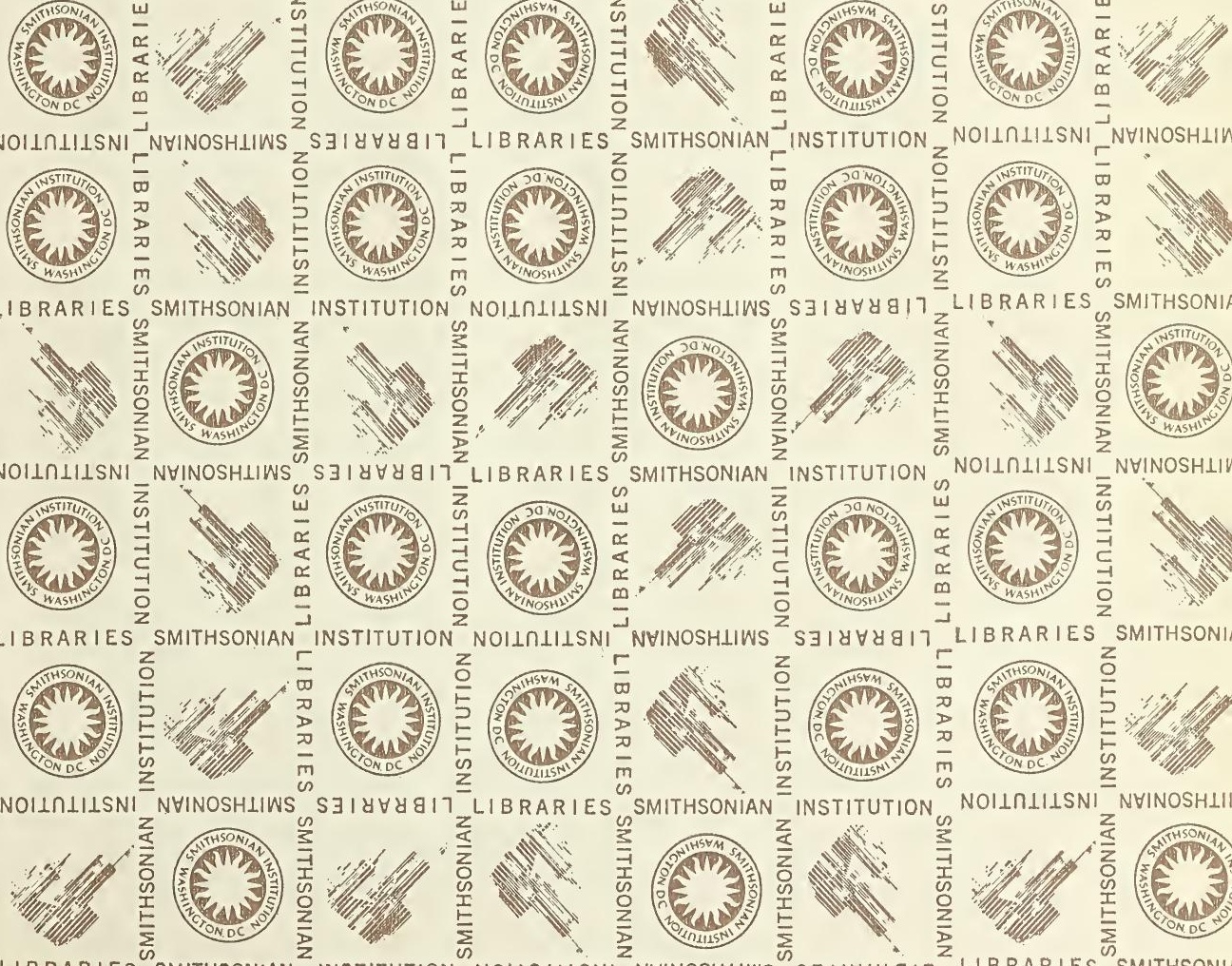



$$
\begin{aligned}
& \text { WILLIM H DALL } \\
& \text { SECIC UBRARY } \\
& \text { DIVISION GI MOLLUSS }
\end{aligned}
$$






\section{Systematisches \\ Conchyli e $n-C a b$ in e t von Martini und Chemnitz.}

In Verbindung mit

Dr. Philippi, Dr. Pfeiffer, Dr. Dunker, Dr. Römer, Clessin, Dr. Brot und Dr. v. Martens neu herausgegeben und vervollständigt

von

Dr. H. C. Kïister,

nach dessen Tode fortgesetzt von

Dr. W. Kobelt und H. C. Weinkauff.

Vierten Bandes vierte Abtheilung.

Nürnberg, 1887.

Ver lag $v \circ$ n B a u $\mathrm{r}$ \& $R$ a s p e.

(Emil Kllster). 


\title{
Das Genus
}

\section{$\mathrm{C}$ ance 11 aria}

von

Th. L öbbecke

nebst Anhang

A d $\mathrm{m}$ e $\mathrm{t} e$

von

Dr. W. Kobelt.

\author{
Niirnberg, $188 \%$. \\ Verlag von B a u $r$ \& $R$ as pe. \\ (Emil Kuster.)
}





\section{Gatiung C a n c e I l a r i a Lamarck.}

Testa ovata vel ovato-fusiformis; plerumque liris costisque sculpta, rarius fere laevis; columella plicis 2-3 magnis, supera majore, inferis minoribus, cauda brevi, labro intus plerumque lirato; operculum nullum.

Es ist kaum möglich, von der Gattung Cancellaria eine befriedigende Gesammtdiagnose zu geben, da eigentlich nur die Spindelfalten, und diese nur in einem gewissen Grade constant sind. Das Gehäuse ist meistens eiförmig oder etwas länglich, dickschalig und sehr stark sculptirt; es kommen aber auch fast spindelförmige und gethürmte Arten vor, während andere ein fast glattes und andere ein ganz dünnschaliges Gehäuse haben; viele Arten sind weit genabelt, andere wieder eng oder gar nicht; die Naht ist häufig tief und rinnenförmig, bei anderen wieder nicht. Die Mündung ist ziemlich weit, die Spindel mit meist drei starken Falten bewaffnet, von denen die oberste am stärksten ist und bei vielen Arten weit in die Mündung hinein vortritt; die zweite ist kleiner, die dritté am kleinsten. Die Aussenlippe ist innen stark gerippt, der Canal ist kurz und weit, fast nur ein Ausguss.

Das Thier ist bis jetzt noch sehr ungenau bekannt. Deshayes sagt von ihm: L'animal du C. cancellata rampe sur un pied presque aussi long que sa coquille, très mince, très aplati, et dont le bord subtronqué depasse un peu la tête. Celle ci est très elargée et fort aplatie, son bord antérieur, mince et tranchant, est courbé en segment de cercle, et c'est aux extremités de cettte courbe que s'elève de chaque côté un tentacule allongé, conique, grèle; le point oculaire est situé au côté externe de la base, ou il produit une très-legère saillie. Je n'ai jamais vu sortir de trompe de la fente buccale. Cet animal est $d u$ reste, trés-timide, rentre promptement dans sa coquille au moindre mouvement, et n'en sort que très lentement. Sa progression est lente, et en cela on ne peut le comparer aux Buccins, dont les allures sont beaucoup plus vives.

Die Adams fügen noch hinzu, dass das Thier eine kurze verkümmerte Schnauze habe und dass der Mantel ganz eingeschlossen sei und nur eine rudimentäre Siphonalfalte habe. Ihre weitere Angabe, dass eine Zungenbewaffnung nicht vorhanden sei, ist durch die sehr sorgfältige Untersuchung Troschels entschieden widerlegt worden.

IV. 4. 
In seinem Werke über das Gebiss der Schnecken im zweiten Bande Seite 45 angt Troschel: Cancellaria crenifera Sow.; das Exemplar aus dem Mus. Christians VIII in Kopenhagen, welches ich Steenstrup's Güte verdanke, stammt von den Philippinen. In einem vorstreckbaren Rüssel fand ich eine sehr kleine Mundmasse, in deren Mitte ein schmaler Längsstreifen deutlich zu sehen war, der die muskulöse Mundmasse nach hinten weit überragte. Dieser Streifen ist die Radula mit ihrer Bewaffinung. Auf ihr liegen in zwei Reihen lange, sehr dünne, bandförmige Platten, mit dem freien Ende nach vorn gerichtet. Sie haben sich in meinem Präparate in Glycerin sehr gut erhalten, sind aber meist zusammengedreht, und ihre Zahl nicht anzugeben. Auch die Länge der einzelnen Platten ist nicht genau. zu ermitteln, aber sie sind sehr lang. Ihre Breite beträgt im grössten Theile ihres Verlaufes 0, $035 \mathrm{Mm}$, gegen das freie vordere Ende verschmälern sie sich jedoch bis auf $0,01 \mathrm{Mm}$., um sich dann am abgestutzten Ende selbst wieder spatelförmig zu erweitern und eine Breite von 0,0225 $\mathrm{Mm}$. zu erreichen. Die Ecken des abgestutzten Endes sind abgerundet. Bei sehr starker Vergrösserung hat eine solche sehr dünne Lamelle jederseits am Rande eine doppelte Contourlinie. Die Fläche der Platte ist durch zwei sehr deutliche longitudinale Linien in drei Felder getheilt, von denen das mittlere etwas breiter als die seitlichen und bei durchfallendem Lichte etwas dunkler gefärbt ist; eine Folge davon, dass förmige oder saumartige Erweiterungen des Mitteltheils. - Die ganze Platte wird durch einen mittleren engen Kanal der Länge nach durchzogen. Derselbe ist in allen Theilen schwach geschlängelt, am engsten und regelmässigsten jedoch in dem schmalen Theile, bis er sich am Ende der Platte verliert. Der Kanal schlängelt sich jedoch nicht in einer Ebene, sondern verläuft in einer lang gezogenen Spirale. Die Oeffnung iselbst mit ihreni Contouren habe ich nicht wahrnehmen können; es leidet jedoch keinen Zweifel, dass eine solche vorhanden ist. Der Kanal behält überall, so weit man ihn verfolgen kann, ein gleich weites Lumen von knapp $0,0025 \mathrm{Mm}$.

Diese genauen Untersuchungen lassen keinen Zweifel zu dass die Cancellarien, wenn auch das Gebiss derselben von dem der Coniden und Pleurotomiden abweicht, mit vollem Rechte, nach Troschels Ansicht, zu den Toxoglossen gehören.

Nach Deshayes soll das Thier pflanzenfressend 'sein, aber Weinkauff bemerkt - Mittelconchylien II p. 172 - ausdrücklich, dass er Cancellaria cancellata stets auf pflanzenleerem feinsandigem Boden gedrakt habe, die Vertiefungen der Sculptur mit festanhängendem Sande ausgefüllt, als ob das Thier sich in den Sand eingrübe. Jedenfalls ist die Zungenbewaffnung eine so schwache, dass das Thier nicht sehr räuberisch sein kann. Ein Deckel ist nicht vorhanden.

C. cancellata pflegt, nach Weinkauff, beim Zurückziehen ins Gehåuse eine Quantität 
Sand mitzunehmen, welche die Mündung füllt und dem Gehäuse den Anschein gibt als sei es leer und mit Sand gefüllt.

Die Anzahl der Arten ist von den sechs, welche Lamarck kannte, in neuerer Zeit auf über hundert gestiegen, doch dürften nicht alle vor einer auf genügendes Material gestützten Untersuchung Stand halten. Leider ist es aber fast unmöglich dazu ein genügendes Material zu beschaffen, indem nahezu alle Arten zu den Seltenheiten gehören und es selbst dem eifrigsten und bemittelsten Sammler kaum möglich ist,', einzelne Exemplare aller Arten, geschweige denn Suiten von solchen zusammen zu bringen. Gerade diese Seltenheit macht Cancellaria natürlich auch zu einer Favoritgattung der Sammler und treibt die Preise zu einer unerschwinglichen Höhe. Eine nicht geringe Anzahl von Arten beruht auf einem einzigen Exemplare.

Ueber die geographische Verbreitung der Arten hat Crosse eine sehr hübsche Uebersicht gegeben (Journal de Conchyliologie IX pag. 243.) Wenn wir von den Arten der Gattung Admete absehen, die wir als eigene Gattung anerkennen, bleibt nur eine einzige Art als nicht tropisch, die mitttelmeerische Canc. cancellata, welche aber gegenwärtig ihre Hauptheimath am Senegal hat und nur im vorderen Theile des Mittelmeeres vorzukommen scheint. Die Hauptmasse der Arten findet sich um zwei Verbreitungscentren gruppirt, das eine an der tropischen Westküste Amerikas, vom Golf von Californien bis nach Peru reichend, von wo mindestens 28 Arten mit Sicherheit bekannt sind, das andere im mittleren indischen Ocean zwischen den grossen Sundainseln, Neuholland, China und Südjapan. Der atlantische Ocean ist im Vergleiche dazu sehr arm an Arten und auch in Polynesien und im indoarabischen Meere ist ihre Anzahl unverhältnissmässig geringer.

Die Systematik der Cancellarien ist verschieden aufgefasst worden. Die Adams unterscheiden, nach Abtrennung von $\mathrm{Admete}$, noch sieben Untergattungen, von denen aber zwei, A phera für C. tessellata und Massyl a für C. corrugata, nur je eine Art umfassen, während drei andere, Euclia, Narona und Merica, je vier Arten zählen, so dass die Hauptmasse auf Cancellarja s. str. und Trigonostoma entfällt. Dagegen macht Crosse mit Recht darauf aufmerksam, dass diese Untergattungen auf einzelne extreme Formen begründet sind, zwischen denen sich Uebergänge finden, so dass die Autoren selbst eine Art unter zwei verschiedenen Namen in zwei verschiedene Untergattungen gestellt haben. Er begnügt sich damit, sie in drei Unterabtheilungen: Trigonostomes, Purpuriformes und Mitriformes zu scheiden, eine Eintheilung der man sich am besten anschliessen wird, solange nicht genügende anatomische Untersuchungen vorliegen. 


\section{Cancellaria goniostoma Sowerby.}

Taf. 1. Fig. 1. 2. 11. 12.

Testa irregulariter gibboso-conica, late et profunde umbilicata, spirajbreviter gradato-turrita, solida; anfractus 7 , embryonales 2 laeves, rotundati, hyalini, sequentes superne angulati et super angulum latissime excavati, inferne contracti, transversim costati, costis rotundatis, distantibus, ad angulum nodum formantibus, lirisque spiralibus distinctis sed parum prominentibus cingulati, lineis incrementi spiralibusque clathrati; anfractus ultimus costis circa umbilicum distinctis sed haud nodiferis et parum intrantibus sculptus. Apertura trigona, sat parva, labro crasso, crenulato, marginibus callo crasso continuis, faucibus distincte liratis, columella plicis 2 superis parum prominentibus tertiaque infima obsoleta armata. Purpurascente-alba, liris castaneo-fuscis subinterrupte tinctis, in umbilico nec non ad suturam lutescente-albida; apertura alba, faucibus purpureis.

Alt. 32 diam. maj. 22 alt apert. $16,6 \mathrm{Mm}$.

$-27-\quad-22--15,5 \mathrm{Mm}$.

Cancellaria goniostoma Sowerby Proc. Zool. Soc. 1832. p. 51. Thesaurus pl. 94. fig 40

$$
\begin{array}{lll}
- & - & \text { Reeve Conch. icon sp. } 32 \\
- & - & \text { Crosse Journ. Conch. IX. p. } 230 .
\end{array}
$$

Gehäuse unregelmässig kegelförmig kugelig, weit und tief, fast durchgehend genabelt, mit treppenförmig aufgewundenem, nicht sehr hohem Gewinde, festschalig und schwer. Von den vorhandenen sieben Umgängen sind die beiden ersten (embryonalen) glatt und durchsichtig, dabei rein gerundet, die späteren sind treppenförmig aufgebaut, oben kantig, darüber weit und tief ausgehöhlt, unten zusammengezogen. Sie sind mit starken gerundeten, entferntstehenden Querrippen sculptirt, deren Zahl auf dem letzten Umgang meistens sieben beträgt; diese springen an der Kante als Knoten vor und verlaufen dann schräg nach vorn, sich gegen die Naht hin rasch verflachend; deutliche, doch nicht sonderlich starke, entfernt stehende Spiralreifen, meist nur fünf bis sechs auf dem letzten Umgang, laufen über sie hin und springen auf ihnen stärker vor; ausserdem sind noch zahlreiche, dichtstehende, feine Spirallinien vorhanden, welche mit den Anwachsstreifen zusammen eine feine Gittersculptur bewirken. Auf den oberen Umgängen stehen die Rippen wie die Leisten dichter und lassen dieselben deutlich gegittert erscheinen. An der den Nabel umgebenden Kante, welche mitunter sehr scharf ausgesprägt ist, sind die Rippen zwar noch deutlich erkennbar, schwellen aber nicht an und verlaufen sich rasch in den Nabel hinein. Die Mündung bildet ein rechtwinkliges Dreieck mit abgestutztem rechtem Winkel und leicht gebogener Hypothenuse; der Mundsaum ist dick, gezähnelt, die Ränder durch einen starken Callus vereinigt, Aussen- und Spindelrand fliessen zusammen, ohne einen Canal zu bilden, nur ein Ausguss ist erkennbar, ein eben solcher canalartiger bleibt am Aussenwinkel, der Gaumen ist scharf gerippt, die Rippen brechen kurz vor dem Rand plötzlich ab und lassen einen schmalen glatten Saum. Die senkrechte Spindel trägt zwei tief- 
atehende und darum nur wenig vorspringende Falten, darunter eine kaum angedeutete dritte.

Die Färbung ist meist gelblich weiss, mehr oder minder intensiv mit Purpur übergossen, so dass håufig nur der Nabeltrichter und einzelne Parthien über der Naht hell bleiben; bei anderen Exemplaren sind auch die Rippen ungefärbt und mitunter schrumpft die Purpurfärbung auf einzelne Flecken zusammen. Die Spiralreifen sind meistens braun gefärbt oder gegliedert, die Mündung ist weiss, der Gaumen purpurfarben.

Die beiden abgebildeten Exemplare zeigen, dass die Sculptur unbeschadet ibres Gesammtcharacters einen sehr-verschiedenen Entwicklungsgrad erreichen kann; während bei Fig. 2 die Spiralreifen kaum vortreten, springen sie bei Fig. 1 sebr erheblich vor und lassen hinter den Rippen Vertiefungen zwischen sich, welche an die Aushöhlungen hinter den Wülsten der Ranellen und Tritonen erinnern. Erheblich weiter ab steht die Fig. 11. 12 abgebildète kleine Form, die aber doch wohl noch zu C. goniostoma gerechnet werden muss, da sie in dem Gesammtcharacter der Sculptur doch vollständig mit ihr übereinstimmt und auch die Nabelbildung die gleiche ist. Allerdings ist die Färbung eine sehr auffallende, indem der letzte Umgang nur in seiner oberen Hälfte von einer braungelben breiten Binde umzogen wird, während die untere Hälfte weiss mit einem Stich in Lila bleibt; auch die Knoten an der Kante sind weiss und über ihr bleiben nur zwischen den weissen Rippen braune Flecke; die Höhe beträgt nur 18, die grösste Breite $14 \mathrm{Mm}$,

Aufenthalt an der Westküste Centralamerikas bei Panama, Mazatlan, Conchagua, S. Salvador etc.

Aus meiner Sammlung.

\section{Cancellaria brevis Sowerby.}

Taf. 1. Fig. 3. 4. 19.

Testa subglobosa, pervie sed haud late umbilicata, spira abbreviato-turifa, contabulata, anfractus 6-7 superne angulati, supra angulum profunde lateque excavati, transversim costati costis rudibus obliquis, aperturam versus interdum distantioribus, seriebus nodulorum intercedentibus, lirisque spiralibus granosis, lineis subtilibusque intercedentibus cingulati; ultimus costis circa umbilicum tumidis, in umbilico rude granosis, eumque valde coarctantibus. Apertura trigona, parvula, margine incrassatoi, callo crasso continuo, margine externo crasso, subcrenatulo, intus valde lirato; columella plicis 3 horizontalibus, tertia minima, sculpta, labio subtiliter ruguloso. Albida, castaneo vel purpureo profuse tincta, apertura luteo-albida, intus purpurea.

Alt 23, diam. $18 \mathrm{Mm}$. ait. apert. $14 \mathrm{Mm}$.

Cancellaria brevis Sowerby Proc. zool. Soc. 1832. p. 52. Thesaurus pl. 93 fig. 21.

- - - Reeve Conch. icon. sp. 40.

- $\quad$ - $\quad$ Crosse Journ. Conch. IX. p. 230. 
Gehäuse fast kugelig mit nur wenig erbabenem treppenförmigem Gewinde und durchgehendem, aber nicht weitem und durch die Rippen noch mehr 'verengtem Nabel, festschalig und schwer. Die sechs Umgänge sind wie bei der vorigen Art, treppenförmig aufgebaut, oben kantig und darüber breit ausgehöhlt; aber sie sind unter der Kante auch noch etwas gewölbt und unten nicht so eingezogen; die Rippen sind dick und knotig und verlaufen etwas schräg; bei dem vorliegendem Exemplare stehen sie auf dem letzten Umgange nach der Mündung hin weitläufiger und zwischen die letzten schieben sich Körnerreihen ein, als seien hier Rippen obsolet geworden; oben an der Kante springen die Rippen als starke Knoten vor und verlaufen auch so bis zur Naht; desgleichen springen sie unten an der Nabelkante stark vor und verengen das Lumen des Nabels, in welchem sie durch starke.Spiralleisten knotig erscheinen, sehr erheblich, ein Umstand der für die Unterscheidung von der vorigen Art sehr wichtig ist. Die Spiralsculptur besteht aus weitläufigen Reifen, welche bei dem vorliegenden Exemplar nach der Mündung hin geperlt erscheinen, und feinen Spirallinien; die Anwachsstreifen sind kaum erkennbar und damit fällt die Gitterung weg. Die Mündung ist ein rechtwinkliges Dreieck mit abgerundeten Ecken, der dicke Mundrand ist durch einen Callus auf der Mündungswand zusammenhängend und auch unten am Ausguss nicht unterbrochen; der Gaumen ist scharf gerippt mit glattem Saum; auch die Spindelplatte zeigt eine gerunzelte Sculptur; die beiden oberen Spindelfalten sind horizontal und laufen bis fast zum Rand der Spindelplatte, die dritte ist kaum entwickelt.

Die Färbung ist weisslich mit braunen oder purpurfarbenen Flecken, im allgemeinen, wie es scheint, heller als bei der vorigen Art, die Mündung weissgelb mit schmalem fleischrothem Saum und purpurfarbenem Gaumen.

Ausser dem Fig. 3. 4. abgebildeten typischen Exemplar liegt noch das kleine Fig. 19 abgebildete vor, welches der Mündung nach, trotz seiner geringen Höhe von nur 14 Mm., als ausgewachsen betrachtet werden muss. Es ist ausgezeichnet erhalten, zweifellos nicht gerollt, rein weiss mit nur wenigen Fleckenspuren da, wo die Reifen über die Rippen laufen, und über der Kante, die Rippen sind schwächer und springen besonders an der Nabelkante nicht so weit vor als beim Typus, darin gewissermassen einen Uebergang zu C. goniostoma bildend.

Aufenthalt bei Puerto Potrero und St. Elena in Westcolumbien.

Aus meiner Sammlung.

Anmerkung Ob sich diese Art bei einigermassen reichlichem Material von der vorigen wird getrennt halten lassen, ist mir sebr fraglich; der einzige Unterschied liegt in der bauchigeren, kürzeren Gestalt und dem durch die Rippen erheblich verengten Nabel. 


\section{Cancellaria rigida Sowerby.}

Taf. 1. Fig. 5-8.

Testa irregulariter ovata, umbilico infundibuliformi, sed mox coarctato, spira rontabulata, breviter turrita; anfractus 6 , embryonales rotundati, laeves, minimi, caeteri superne acute angalati, supra angulum late excavati, inferne convexiusculi, tertius et quartus costis lirisque subaequalibus cancellati, quintus costis numerosis sed majoribus, ad angulum tuberculatis liris striisque spiralibus subgranosis sculptus; anfractus ultimus costis distantibus, subtilibus, ad angulum tuberculatis et supra lamelliformibus, ad cristam umbilicalem compressis et mox evanescentibus $7-8$ armatus, liris majoribus sat distantibus granosis regulariter dispositis, lirisque minoribus et striis spiralibus munitus. Apertura oblique trigona, ad basin sinu profundo dextrorso, recurvo fere canaliculata, margine incrassato, callo parietali tenui vix continuo, columella regulariter excavata, plicis tribus, supera horizontali, inferis obliquis munita, faucibus liratis. Albida vel luteo-spadicea, maculis castaneis supra angulum inter costas et plerumque seriebus 2 macularum spiraliter ornata, apertura alba, intus fuscescens.

Alt 24, diam. maj. 20 , alt apert $14 \mathrm{Mm}$.

- 23 - 18 - $13 \mathrm{Mm}$.

Cancellaria rigida s'owerby Proc. zool. Soc. 1882 p. 53.

- costata Sowerby Thesaurus T. 95 f. 60.61 .

- rigida Reeve Conch. icon. sp. 33.

- - Crosse Journ. Conch. IX p. 230.

Gehäuse unregelmässig eiförmig, weniger dickschalig als die vorigen Arten, trichterförmig genabelt, aber der Nabel sehr rasch verengt, so dass man den zweiten Umgang nicht mehr erkennen kann, und durch den Spindelrand der Mündung noch mehr verengt, das Gewinde treppenförmig gethürmt, doch niedrig. Von den sechs vorhandenen Umgängen sind die zwei embryonalen winzig klein, die folgenden kantig, oberseits ausgehöhlt, darunter gewölbt, der dritte und vierte erscheinen durch die dichtstehenden Rippen und die fast gleich starken Reifen gegittert, auf dem fünften überwiegen die Rippen und springen an der Kante als spitze Höcker vor. Auf dem letzten Umgang dagegen stehen die einzelnen, stark vorspringenden, ziemlich schmalen Rippen weit getrennt; es sind nur 7-8 vorhanden, die an der Kante zu runden Knoten anschwellen und oberhalb derselben zu vorspringenden Lamellen werden, welche bis zur Naht laufen ohne merklich niedriger zu werden, so dass zwischen ihnen tiefe Nischen bleiben, welche durch dunkle Flecken noch mehr hervorgehoben werden; von der Kante ab laufen sie schräg nach unten und werden auf der meist sehr deutlichen Kante, welche den Nabel umgibt, zu Lamellen, welche in den Nabel hineinlaufen, aber schnell verschwinden. Die Spiralsculptur des letzten Umganges besteht aus starken, ziemlich regelmässig und entfernt gestellten leicht gekörnelten Reifen, zwischen denen noch schwächere Reifen und feine Spirallinien laufen. Die Mündung ist unregelmässig dreieckig, unten mit einem canalartigen nach rechts gerichte- 
ten zurückgebogenen Ausguss; die Spindel ist nicht geradlinig und senkrecht, wie bei goniostoma und brevis, sondern concav ausgehöhlt, dagegen der Aussenrand von der Kante ab senkrecht. Die Ränder werden durch einen dünnen, fest angedrückten Callus verbunden, erscheinen aber nicht so zusammenhängend, wie bei den vorigen Arten; der Gaumen ist gerippt; von den drei deutlichen Falten ist die obere horizontal, die beiden unteren verlaufen schräg. - Die Färbung ist weiss bis hell braungelb mit dreieckigen kastanienbrâunen Flecken in den Nischen über der Kante und meistens auch mit zwei Reihen dunkler Flecken auf den Rippen. Die Mündung ist weisslich, im Gaumen braun angelaufen.

Auch diese Art ist in der Sculptur recht veränderlich, wie die abgebildeten Exemplare beweisen; von den beiden vorigen Arten unterscheidet sie sofort der nach rechts gerichtete canalartig Auguss. Reeves Exemplar ist erheblich grösser als die mir vorliegenden, $33 \mathrm{Mm}$.

Aufenthalt an der Westküste von Centralamerika, bei Puerto Potrero in 13 Faden Tiefe von Cuming gedrakt.

Aus meiner Sammlung.

\section{Cancellaria contabulata Sowerby.}

Taf. 1. Fig. 9. 10.

Testa ovata, spira gradato-turrita, anguste rimato-umbilicata, parum crassa; anfractus 7, primi 2 laeves, minimi, globosi, sequentes angulati, superne late excavati, infra vix convexiusculi, ad basin contracti, costis confertis - 16-17 in anfractu ultimo - parum prominentibus, ad angulum vix tuberculatis et mox evanescentibus, ad costas subtuberculiferis sculpti, sub lente striis incrementi spiralibusque subtilissime reticulati. Apertura trigono-ovata, sublunata, inferne subcanaliculata, margine acuto, callo tenuissimo super parietem aperturalem vix continuo, externo intus mox incrassato, confertim valde lirato, supero liris 2 denticulato; columella verticalis plicis 3 distinctis obliquis armata Albida vel pallide straminea, aurantio-rufo super angulum maculata et indistincte fasciata, apertura alba faucibus fuscescentibus.

Alt. 29 , diam $20 \mathrm{Mm}$., alt. apert. $15 \mathrm{Mm}$.

Cancellaria contabulata Sowerby Conchological Illustr. fig 28. Thesaurus pl 93 fig. 23. - $\quad$ - Reeve Conch. icon. sp. 42.

- $\quad$ - Crosse Journ. Conch. IX p. 230.

Juv. = Cancellaria pusilla Sowerby Concholog. Illustr. fig. 34. Thesaurus fig. 19.

Gehäuse ziemlich eiförmig mit gethürmtem treppenförmigem Gewinde, nicht sehr dickschalig, mit ganz engem fast ritzförmigem Nabel. Von den sieben vorhandenen Windungen sind die beiden ersten embryonalen winzig klein, kugelig, glatt, durchsichtig; die übrigen sind kantig, oben breit ausgehöhlt, unter der Kante kaum gewölbt, an der Basis 
verschmälert, sie sind sculptirt mit dichtstehenden, wenig erhabenen Faltenrippen, 16-17 auf dem letzten Umgang, welche an der Kante leicht vorspringen und dann schnell verschwinden, so dass der Raum über der Kante fast glatt ist, und erscheinen regelmässig gekörnelt, da die wenig erhabenen, regelmässig angeordneten Spiralreifen, welche die ren Umgänge dichter, den letzten weitläufiger umziehen, auf den Rippen leicht anschwellen. Unter der Loupe erscheint noch eine feine Gittersculptur aus den Anwachsstreifen und feinen Spirallinien. Die Mündung ist fast dreieckig eirund, oben durch die Mündungswand ausgeschnitten, unten mit tiefem, canalartigem Ausguss, die Randinsertionen werden nur durch einen dünnen Callus verbunden. Der Aussenrand ist scharf, ungekerbt, aber innen bald verdickt und mit"scharfen, dichtstehenden Rippen sculptirt; auch auf dem Oberrand stehen zwei Leisten, welche als Zähnchen vorspringen'; die fast senkrechte Spindel trägt drei deutliche, fast gleich starke, schräge Falten.

Die Färbung ist mehr oder minder intensiv gelblich weiss; über der Kante stchen einige grosse orangefarbene Flecken, auf dem letzten Umgang sind einige orangerothe Binden angedeutet; die Mündung ist weiss, der Gaumen bräunlich.

Aufenthalt an Ceylon, auf Sandboden.

Aus meiner Sammlung.

\section{Cancellaria crenifera Sowerby.}

Taf. 1. Fig. 13-16.

Testa ovato-pyramidata, spira gradato-turrita, anguste sed profunde umbilicata, solidula, nitida; anfractus 6-7, primi embryonales laeves, apicem minimum sed exsertum exhibentes, sequentes angulati, superne late excavati, infra convexiusculi, ad basin contracti, costis pliciformibus, distantibus, obliquis, ad angulum uncinato-tuberculatis, 8-10 in anfractu ultimo, et liris numerosis parum prominulis sculpti. Apertura trigons, parum lunata, ad àngulum marginis externi nec non ad basin subcanaliculata, peristomate callo tenui vix continuo, margine supero plica intrante dentato, externo acuto, intus mox incrassato, valde lirato, columeliari plicis 3 obliquis subaequalibus munito. Alba, interstitiis lirarum livido-fuscis, aperturam versus interdum spadiceo bifasciata, fascia alba tantum mediana persistente, apertura alba, fauce fuscescente. -

Alt 27, diam 18, alt apert. $16 \mathrm{Mm}$.

- 24, - 16, - $-14 \mathrm{Mm}$.

Cancellaria crenifera Sowerby Conchol. Illustr. fig. 29. Thesaurus Pl. 96 fig. 84.86. $\begin{array}{lll}- & - & \text { Reeve Conch. icon. sp. } 2 t \\ - & - & \text { Crosse Journ. Conch. IX. p. } 230 .\end{array}$

Gehäuse eiförmig-kegelförmig mit ziemlich hoch gethürmtem Gewinde, eng aber tief genabelt, ziemlich festschalig, glänzend, aus beinahe sieben Umgängen bestehend, die bei-

IV. 4 
den obersten sind winzig klein, durchsichtig, springen aber doch stark vor, die späteren sind kantig, obenher ausgehöhlt, unter der Kante nur schwach gewölbt und unten eingezogen. Die Sculptur besteht aus schmalen, abęr ziemlich hohen, entfernt stehenden Faltenrippen, von denen auf dem letzten Umgang 8-10 stehen; dieselben springen an der Kante, namentlich nahe der Mündung in Form starker gekrümmter Stacheln vor, doch ist dieser Character nicht immer scharf ausgeprägt. Ausscrdem sind zahlreiche, ziemlich dichtstehende, wenig vortretende, aber mitunter durch besondere Färbung hervorgehobene Spiralrcifen vorhanden. Die Mündung bildet ein am Winkel nur wenig ausgeschnittenes rechtwinkliges Dreieck mit einer Art Canal am Aussenwinkel und einem canalartigem Ausguss an der Basis; die Randinsertionen sind nur durch einen schwachen Callus verbunden. Der Oberrand hat eine starke eindringende Leiste, welche am Rande zahnförmig erscheint; der Aussenrand ist scharf, aber dann rasch verdickt und mit verhälinissmässig weitläufig stehenden Rippen sculptirt, die Spindel trägt drei ziemlich gleiche schräg laufende Falten. Die Färbung ist wechselnd, weiss mit livid braunen Bisden, meistens erscheinen die Zwischenräume der Rippen bräunlich, nach der Mündung hin fliesst die Färbung zusammen und wird namentlich an den Rippen und an der Kante intensiver; mitunter entstehen so zwei breite braune Binden, welche durch eine schmälero weisse geschicden werden; der Nabel ist weiss, die Mündung weiss mit brauncm Gaumen.

Aufenthalt an den Philippinen, von Cuming in der Bucht von Manila auf sandigen Schlamm in fünf Faden Tiefe gefunden.

Aus meiner Sammlung.

\section{Cancellaria Thomasiana Crosse?}

Taf. 1. Fig. 17. 18.

„C. testa ovali-oblonga, turrita; costis distantibus, crassis, subangulatis, crenulatis, ad angulum anfractuum in angulum duplicatum productis, interstitiis laevibus; spira producta, anfractibus angulatis, ad suturam excavatis: apertura subtriangulari prope angulum posticum uniplicata, interne usque ad marginem costata, margine laevi; canali antico producto, vix excavato; columella subrugosa, triplicata, umbilico sulcato; colore pallidissime fulvo, fusco rubescente late bifasciato: variat albo." - Sow.

Cancellaria scalarina Sowerby Thes. Conch. pag. 452 pl. XCVI fig. 87.88 nec Lam. - $\quad$ - Reeve Conch. icon. sp. 25.

- Thomasiana Crosse Journal de Conchyliologie IX. p. 231.

Schale länglich eirund mit gethürmtem Gewinde, mit starken ziemlich entfernt stehenden, ziemlich kantigen Rippen sculptirt, welche am Rande leicht crenulirt erscheinen und an der Kante der Umgänge, namentlich des letzten, einen doppclten Winkel bilden Die Zwischenräume sind bei unsercm Exemplar nicht glatt, wie Sowerby angibt, sondern 
von feinen Querreifen durchzogen, die Reifen sind aber auf dem letzten Umgang nur mit der Loupe erkennbar; Sowerbys Abbildungen zeigen übrigens, dass sein Ausdruck nicht wörtlich zu nehmen ist. Das Gewinde ist gethürmt vorgezogen, und liegt fast vollständig in einer geraden Linie mit der Spindel, während es bei crenifera immer etwas nach rechts geneigt ist. Die Umgänge sind oben kantig und ausgehöhlt. Die Mündung ist ziemlich rein dreieckig; der obere gerade Theil des Mundrandes trägt innen eine Falte, der Aussenrand ist mit nicht allzu dichten, bis zum Rande durchlaufenden Rippen sculptirt; der Rand ist ungezähnelt. Der Canal ist unten vorgezogen, die spindel ist kaum ausgehöhlt und liegt zum grösseren Theile in der Achse des Gehäuses, sie trägt drei deutliche, fast gleichstarke Falten; der Nabel ist ziemlich eng, seitlich zusammengedrückt, im Inneren gefurcht. Die Färbung ist ganz blassbraun oder gelblich weiss mit zwei breiten braunen Binden, in denen man meist die etwas dunkler gefärbten Spiralreifen unterscheiden kann, an der Kante steht hinter jeder Rippe ein Fleck; die beiden braunen Binden sind auch in der Mündung erkennbar.

Aufenthalt in Westindien?

Aus meiner sammlung.

Anmerkung. Vas abgebildete Exemplar stanımt aus der Taylor'schen Sammlung und wurde mir von Sowerby als seine Cancellaria scalarina übersandt; es stimmt auch vollständig mit der Abbildung und ist ohne Zweifel Sowerbys C. scalarina. Die Frage ist uur, wie diese zu der ächten C. scalarina Lam. steht. Crosse bestreitet entschieden, dass sie mit dieser identisch sei, und hat ihr darum den neuen Namen C. Thomasiana gegeben. Lamark gibt von seiner Cancellaria scalarina folgende Diagnose:

"C. testo ovato conica, ventricosinscula, umbilicata, longitudinaliter plicata, transversim tenuissime striata, albs aut fuscescente; plicis obliquis distantibus, spira contabulata; columella triplicata. Habite les mers de l'ile de France. Mon cabinet. Elle est un peu ventrue et canaliculée à ses sutures. Cotes distantes et un peu obliques. Elle n'a rien de rude au toucher. Longueur 12 lignes et demi."

Diese Diagnose lässt sich mit der Sowerby'schen und unserem Exemplare ganz gut vereinigen. Crosse hat sich besonders daran gestossen, dass die Sowerby'sche Art glatt sein solle; die Abbildung zeigt aber deutlich Spiralreifen und bei unserem Exemplar sind dieselben auch vorhanden, aber hinter den Rippen auf dem letzten Umgang nur durch die Loupe zu erkennen. Der Nabel ist auch wie bei der Sowerby'schen Form vorhanden, allerdings nicht sehr weit, aber davon sagt auch Lamarck nichts. Lamarck nennt die Rippen distantes, gibt aber nicht an, wie viele auf dem Umgang stehen, so dass sich ein haltbarer Unterschied daraus nicht ableiten lässt. Crosse betont endlich, dass Lamarck die Zeichnung nicht unerwähnt gelassen haben würde, aber Sowerby bildet fig. 87 auch ein weisses Exemplar ab. Es bleibt somit nur der Unterschied im Vaterlande. Lamarek gibt He de France an; Sowerby Westindien. Ob man darauf hin die beiden Formen trennen soll weiss ich nicht recht. Einstweilen mag die Art unter dem Crosse'schen Namen gehen, bis sich mit reicherem Iraterial von sicheren Fundorten die Frage endgültig entscheiden lïsst. 


\section{Cancellaria Reeveana Crosse.}

Taf. 2. Fig. 1-9.

Testa ovato-acuminata, obtecte perforata, solida, ponderosa, spira plus minusve acurninata, anfractus $7-8$, primi $11 / 2$ apicem laevem formantes, sequentes convexi, sutura plus minuswe canaliculata discreti, costis obliquis subtilibus aequalibus, ad suturam prominentibus sculpti lirisque spiralibus vix minoribus, ad intersectiones noduliformibus distincte decussati. Apertura ovato-acuminata, alba vel pallide rosacea, faucibus liratis, margine leviter denticulato, columella plicis tribus crassis armata, (supera majore subhorizontali, media obliqua, infera ad marginem canalis sita contorta), et callo, superne tenui et late expanso, inferne crasso et rugis obliquis munito obtecta. Albida fasciis tribus pallide fulvis varie cingulata, interdum fere unicolor.

Alt 47, diam. 24,5 Mm.

Cancellaria elegans Sowerby Thesaurus pl. 93 fig. $36-$ pl. 96 fig. 104 nec Desh. - $\quad$ - Reeve Conch. icon. sp. 12

- Reevean a Crosse Journal de Conchyl. IX p. 237.

Varietas subsinensis m., sutura haud canaliculata (Fig. 3).

Varietas laticosta m., gracilior, exumbilicata, costulis distantibus regularibus sculpta, (Fig. 7-9).

Gehäuse spitzeiförmig, der Nabel bis auf ein kleines, von vorn nicht sichtbares Loch überdeckt, festschalig und schwer; das Gewinde ist spitz und mehr oder minder hoch und schlank. Von den 7-8 Umgängen sind die $1 \frac{1}{2}$ ersten glatt und bilden einen kleinen glatten Apex; die folgenden sind gewölbt, durch eine deutliche tiefe nach unten mehr oder minder rinnenförmig werdende Naht geschieden, mit sehr zahlreichen, nahezu gleichen, feinen, schrägen Rippen sculptirt und von kaum kleineren ungleichen oder in Stärke abwechselnden Spiralreifen umzogen; wo diese die Rippchen schneiden, bilden sie kleine Knötchen, so dass eine sehr hübsche Sculptur entsteht. Die Mündung ist spitz eiförmig der Aussenrand bildet am Ansatz eine Art Rinne, er ist gezähnelt und im Gaumen mit regelmässigen, nicht allzudicht stehenden Reifen sculptirt, welche kurz vor dem Rande entweder abbrechen oder sich plötzlich verbreitern, so dass in beiden Fällen ein circa 2 Nim. breiter anders sculptirter Saum entsteht. Die Spindel trägt drei starke Falten, von denen die untere mit der Abstutzung der Spindel zusammenfällt, die obere ist horizontal, die mittlere schräg. Der Callus ist oben dünn und weit ausgebreitet, mit durchscheinender Sculptur, unten dick und mit schrägen Rippen und Körnern sculptirt. Die Färbung ist gelblichweiss, mit drei verloschenen bräunlichen Binden gezeichnet, welche nur schmale Streifen der Grundfarbe zwischen sich lassen, mitunter beinahe einfarbig. Der Gaumen ist weiss, Spindelcallus und Mundrand sind rosa überlaufen. Diese Art ist, wie die abgebildete Serie zeigt, recht verånderlich, bald schlanker, bald bauchiger und auch in der Sculptur nicht sehr constant. Als Typus nehme ich das fig. 1 und 2 abgebildete grosse Exemplar, nach dem die Diagnose und Beschreibung entworfen sind. Fig 3 unterscheidet 
sich vom Typus durch die Naht, die durchaus nicht mehr rinnenförmig ist; die Längsrippen sind viel dichter und schwåcher als beim Typus. Ich nenne sie, da sie in mancher Beziehung an sinensis erinnert, var. subsinensis.

Fig. 4 ist ein schlankes, fast einfarbig erscheinendes Exemplar mit viel weniger rinnenförmiger Naht.

Fig. 5 und 6 hat die Naht durchaus nicht mehr rinnenförmig, vielmehr auch nach der Mündung hin durch Schmelz ausgefüllt; die ganze Form ist viel weniger aufgeblasen, gewissermassen schräg cylindrisch und die Spindel weicht unten viel mehr zurück. Die Sculptur stimmt aber ganz mit der von elegans überein.

Dagegen weichen die Fig. 7-9 abgebildeten Exemplare so erheblich vom Typus ab, dass man versucht sein könnte sie für eine eigene Art zu nehmen; das Gewinde ist viel höher und gethürmter, der letzte Umgang nimmt kaum mehr als die Hälfte der Gesammtlänge ein, der Nabel ist vőllig geschlossen. Ausserdem aber sind die Längsrippen in einer ganz anderen Weise entwickelt, durch breite Zwischenräume getrennt, so dass man nur 20 auf dem letzten Umgang zählt. Die Spindelbildung ist übrigens ganz wie bei der typischen elegans und ich kann mich nicht entschliessen eine neue Art dafür zu errichten. Es ist dieselbe Form welche Lischke, der diese Exemplare aus Japan erhalten hat, in seinem Werke (Japanesische Meeresconchylien Band II p. 56) erwähnt. Ich nenne sie vorläufig var. laticostata.

Aufenthalt in den ostasiatischen Gewässern. Als sicherer Fundort bekannt: Philipinen (Reeve, Lischke) die Insel Kiuschiu und die Bucht von Jedo (Coll. Lischke) Seto - Uchi, Tomo (A. Adams).

Sämmtliche abgebildete Exemplare aus meiner Sammlung.

Anmerkung. Deshayes will diese Art als Varietät zu asperella stellen; genügendes Material dürfte beweisen dass er damit Recht hal; auch melanostoma und sinensis dürften sich anschlıessen müssen.

\section{Cancellaria asperella Lamarck.}

Taf. 3. Fig. 1-4.

Testa ovata, solida, plus minusve obtecte umbilicata, spira acuminata; anfractus 7, primi 2 apicem laevem minimum formantes, sequentes convexiusculi, sutura profunde canaliculata discreti, costulis elevatis ad suturam prominentibus lirisque spiralibus reticulati, interstiis distincte decussatis. Apertura ovata, utrinque acuminata, margine dentato, faucibus distincte liratis, liris ante marginem subite abruptis; columella callo distincto, superne rectilıneo et cum labro angulum distinctum subca. naliculatum exhibente obducta, plicis tribus sicut in $\mathrm{C}$ elegante dispositis rugisque obliquis armata. Fulvida, distincte fusco trifasciata, apice saturatiore, apertura albidı-rosacea, faucibus coerulescentsbus. - 


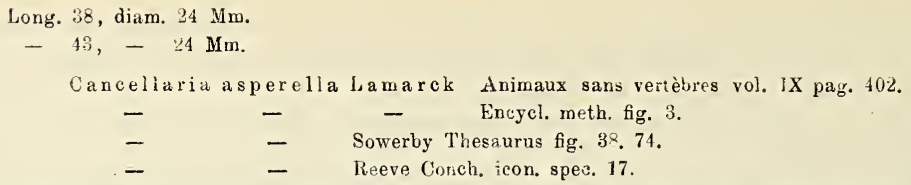

Gehäuse eiförmig mit spitzem, aber nicht allzu hohem Gewinde, mehr oder minder bedeckt genabelt, festschalig. Es sind sieben Umgänge vorhanden, die beiden ersten sind glatt und durchsichtig, die späteren sind gewölbt, durch eine tiefe rinnenförmige Naht geschieden und sehr schart sculptirt; die Längsrippen springen an der Kante stark vor und sind stärker als die Spiralreifen, welche an Stärke abwechseln und auf den Rippchen in Knoten oder scharfen Spitzen vorspringen; die Zwwischenräume erscheinen unter der Loupe deutlich gegittert. Ein Spiralreifen, welcher einen leichten Eindruck unter der Kante begränzt, ist meistens etwas stärker und tritt durch weisse Färbung noch mehr hervor. Die Mündung ist eiförmig, oben abgestutzt und an der Ecke einen Canal bildend, unten ebenfalls mit einem deutlichen Canal; der Mündungsrand ist gezähnelt, der Gaumen ist deutlich und scharf gerippt; die Rippen lassen am Mundrande einen Saum, wie bei der vorigen Art und erscheinen am Rande wieder als doppelte Zähnchen. Die Spindel trägt einen deutlichen Callus, der oben stärker ist als bej der vorigen Art, er ist oben rechtwinklig abgestutzt und bildet mit dem Aussenrande einen scharfen Winkel; unten stehen drei deutliche Falten, von denen die unterste mit der Abstutzung der Columella zusammenfällt wie bei der vorigen Art, auch die Runzeln am Aussenrande des Callus sind ebenso entwickelt. Die Färbung hat denselben Charakter wie bei elegans, drei dunkle Binden auf hellerem Grunde, sie ist aber intensiver als bei dieser und in den dunklen Binden springen häufig gelbliche oder weisse Rippen vor; der Apex ist dunkelbraun. Die Mündung ist weisslich, am Saum und am Rande des Callus rosa überlaufen, der Gaumen bläulich mit dunkleren Rippen.

C. asperella steht der elegans ziemlich nahe, so dass Deshayes diese als Varietät damit vereinigt hat. Der Hauptunterschied liegt in der dunkleren Färbung und der rauheren Sculptur, auch ist die Naht tiefer. Zwischenformen sind aber natürlich nicht ausgeschlossen und reichliches Material würde zur Vereinigung zwingen. Der Name asperella hat natürlich Priorität.

Aufenthalt an den Philippinen.

Aus meiner Sammlung. 


\title{
9. Cancellaria melanostoma Sowerby.
}

\author{
Taf. 3. Fig. 5. 6.
}

Testa ovata, subventricosa, crassa, umbilico fere omnino clauso, spira breviuscula, acuminata; anfractus 7, sutura superne fere plana, aperturam versus profunde impressa discreti, costulis obliquis elevatis sat confertim dispositis, lirisque spiralibus ad costulas leviter nodulosis decussati. Apertura ovata, labro denticulato, fancibus distincte liratis, columella subexcavata, callo superne late expanso inferne crasso, ruguloso ohtecta, plicis tribus sicut in C. Reeveana dispositis armata. Luteo albida, sed fusco fere omnino colorata, columella inferne purpureo-fusca.

Long. 30, lat. $21 \mathrm{Mm}$.

Cancellaria melanostoma Sowerky. Proc. zool. Soc. 1845 p. 137.

$$
\text { - } \quad \text { - } \quad \text { Reeve Conch. icon. sp. } 26 .
$$

Gehäuse eiförmig, leicht bauchig, festschalig, mit fast ganz geschlossenem Nabel. Gewinde ziemlich kurz, aber spitz. Die sieben Umgänge werden durch eine flache, nur nach der Mündung hin tief eingedrückte, aber nicht rinnenförmige Naht geschieden und sind fast in derselben Weise sculptirt, wie bei C. elegans; die Spiralreifen wechseln in der Stärke ziemlich regelmässig ab. Die Mündung ist oval, oben spitz, Mundrand und Gaumen ganz wie bei elegans, die Falten auf der Spindel vielleicht etwas stärker. Die Färbung ist dieselbe wie bei den beiden vorigen Arten, aber die Spindel ist unten leberbraun bis schwarz gefärbt und in derselben Nüance gesäumt.

Diese Art, von der mir übrigens nur ein Exemplar vorliegt, wird von elegans nur ein Exemplar vorliegt, wird von elegans nur durch die weniger rinnenförmige Naht und die dunkle Färbung des Spindelcallus geschieden; sie wird kaum aufrecht zu erhalten sein.

Aufenthalt nicht sicher bekannt, jedenfalls in den ostasiatischen Gewässern.

Aus meiner Sammlung.

\section{Cancellaria sinensis Reeve.}

\section{Taf. 3. Fig. 7-9.}

"Can. testa subfusiformi-ovata, imperforata, spira txserta, subobtusa, anfractibus superne convexodeclivibus, liris subtilibus granosis undique decussata; albida, rufo-fusco tincta et fasciata; apertura ovata, fauce valide lirata, columella arcuata, plicis duabus (?) mediocribus." (Reeve).

Long. 34, diam. 20 Mm. Cancellaria sinensis Reeve Conch. icon, spec. 35.

Die abgebildete Cancellaria welche ich aus der Taylor'schen Sammlung als C. sinensis Reeve erhalten habe, unterscheidet sich von Reeves Beschreibung und Abbildung in zwei Punkten. Das Gewinde ist nicht subobtusa und die Spindel hat, wie die vorher be- 
schriebenen Arten; drei deutliche Falten, allerdings steht die unterste Falte völlig am Spindelrand und ist darum wahrscheinlich von Reeve nicht mitgezählt worden und auch spira obtusa liesse sich erklären, da Reeve offenbar ein etwas abgeriebenes Exemplar vor sich hatte. In allen übrigen Punkten stimmt das vorliegende Exemplar völlig mit Reeves oben copirter Diagnose überein. Die Schale ist eispindelförmig, der Nabel bis auf eine Spur geschlossen, die Naht ist nicht vertieft, aber nach der Mündung hin durch eine ziemich breite Rampe ausgezeichnet; die Sculptur besteht aus feinen, dichtstehenden, gekörnelten Rippen und nicht minder dichtstehenden Spiralreifen, welche eine sehr dichte Gitterung erzeugen. Die Spindel ist im wesentlichen wie bei den vorstehenden Arten gebildet und zeigt dieselben schrägen Runzeln wie bei diesen. Auch die Zeichnung ist ähnlich vertheilt aber von mehr röthlicher Färbung.

Jedenfalls hat C. sinensis nicht mehr Recht auf Anerkennung als eigene Art, als die beiden vorigen und elegans. Diese vier Formen bilden eine für die ostasiatischen Gewässer charakteristische Gruppe, die man bei reicherem Material wohl als eine Art erkennen wird, welcher der Name Cancellaria asperella bleiben muss.

Aufenthalt an China.

Aus meiner Sammlung.

\section{Cancellaria reticulata Linné.}

Taf. 4. Fig. 1-4.

Testa ovato-acuminata, imperforata vel rarius rimato-perforata, solida, ponderosa, spira exserta; anfractus 9 , primi $11 / 2$ apicem laevem minimum formantes, sequentes convexi, prope suturam breviter plano-declives, liris spiralibus planis aequalibus costulisque obliquis undique pulcherrime reticulati, undique ad decussationes lirarum subtuberculati, sutura profunde impressa discreti. Aperturs subanguste ovata, superne acuminata, inferne subcanaliculato - sinuata, labro externo tenui, acuto, intus valde lirato, liris ad 12, pariete aperturali nuda vel callo tenui obtecta, liris translucentibus, columella plicis tribus, supera maxima subhorizontali, altera oblique decurrente, tertia ad marginem canalis posita munita. Albida, rufo-fusco vel ferrugineo varie strigata et interrupte fasciata; apertura eburnea.

Alt. spec. dep. maj. 57 , lat. 36 . apert. $32 \mathrm{Mm}$.

Voluta reticulata Linné Syst. nat. XII pag. 1190.

Cancellaria reticulata Lamarck IX. p. 401 .

$\begin{array}{lcl}- & - & \text { Sowerby Conch. Illustr. N. I. } \\ - & - & -\quad \text { Genera Cancell. fig. } 1 . \\ - & - & \text { Kiener Coq. viv. t. } 2 \text { fig } 1 . \\ - & - & \text { Thesaurus pl. } 92 \text { fig. } 17 . \\ - & - & \text { Reeve Conch. icon. sp. } 3 . \\ - & - & \text { Crosse Journ. Conch. } 1 X \text { p. } 237 .\end{array}$


Gehäuse spitzeiförmig, ungenabelt oder seltener mit einem kleinen offenbleibenden Nabelritz, festschalig und schwer; Gewinde hoch, gethürmt. Von den neun Umgängen bilden die ersten ein winziges glattes, kaum vorspringendes Embryonalende, die folgenden sind gut gewölbt, nur unter der Naht eine Strecke weit horizontal abgeplattet, und mit einer sehr gleichmässigen Gittersculptur bedeckt, welche von flachen, gleichbreiten ziemlich regelmässigen Spiralreifen und feinen schrägen Faltenrippen gebildet wird; an den Kreuzungsstellen stehen häufig kleine Knötchen. Die Naht ist tief eingedrückt, nach der Mündung hin fast rinnenförmig. Die Mündung ist eng, oval, oben zugespitzt, unten stark, fast canalförmig ausgeschnitten, der Mündungsrand einfach, bei ausgewachsenen Exemplaren mit paarweise angeordneten Zähnen besetzt, im Gaumen mit etwa 12 starken Rippen sculptirt, welche plötzlich abbrechen und einen breiten glatten Saum übrig lassen. Die Mündungswand ist bald nackt, bald mit einem dünnen Callus belegt, welcher die Rippen durchscheinen lässt. Die Spindel trägt zwei sehr starke Falten; die obere ist fast horizontal, springt weit vor und läuft rückwärts bis zum Innenrand der Spindel, wo sie mitunter noch einmal knotig anschwillt und in den die Nabelgegend umfassenden Wulst übergeht; unter sie legt sich noch eine Schwiele, welche aber weniger weit vorragt; die zweite Falte schlingt sich fast bis zur Basis hinab, eine dritte wird von dem vorspringenden Rande des unteren Spindeltheiles gebildet; zwischen den beiden Oberfalten stehen am Spindelrande noch einige Knötchen. Die Färbung ist weisslich mit grossen braungelben bis fast schwärzlichen Flecken, welche striemenartig angeordnet sind und mehr oder minder unterbrochene Binden bilden, zwischen denen ein weisses Mittelband frei bleibt. Die Mündung ist elfenbeinweiss.

Aufenthalt im Antillenmeere, nicht selten.

Aus meiner Sammlung.

Anmerkung. Diese alte und wohlbekannte Art, der Typus der Gattung, ist in Färbung und Sculptur sehr veränderlich. Ihre nächsten Verwandten sind die an der anderen Seiten des Isthmus von Panama lebenden glätteren Arten ovata, obesa, acuminata, eburnaeformis, die man wohl von demselben Stamme ableiten kann, aber doch nicht mit ihr vereinigen darf. Es besteht also hier dasselbe Verhältniss das wir bei so vielen Gattungen finden, welche diesseits und jenseits des Isthmus durch nah verwandte, aber nicht identische Formen repräsentirt werden.

\section{Cancellaria buccinoides Sowerby. Taf. 4 Fig. 5. 6.}

Testa fusiformi-oblonga, imperforata, spira turrita, basi recurva, solidula, parum crassa; anfractus 8 , primi 2 minuti, laevigati, caeteri superne angulati, supra angulum planati; $d+i n$ convexi, liris spiralibus planis inaequalibus costulisque oblique decurrentibus distantibus decussati, costulis ad intersectionem lirarum noduliferis, ad angulum seriem duplicem nodorum exhibentibus. Apertura irregulaIV. 4. 
riter ovata, superne late sinuata, inferne late canaliculato - effusa, labro subincrassato, faucibus vix sulcatis, parrete aperturali callo tenui, supra incrassato obtecta, columella plicis duabus obliquis armata. Livido carnea, denticulis albidis, faucibus violascescentibus.

Alt 42 , diam. 23. alt apert. $24 \mathrm{Mm}$.

- $38,-24$, - -25

Cancellaria buccinoides Sowerby. Proc. zool. Soc. 1832 p. 54 - Thesaurus pl. 92 fig. 10. 11.

\section{- $\quad$ - $\quad$ Reeve Conch. icon. spec. 15. 16. \\ - $\quad$ - C Crosse Journ. de Conch. IX p. 237.}

Gehäuse eiförmig-spindelförmig mit ziemlich hohem gethürmtem Gewinde und etwas zurückgekrümmter Basis, undurchbohrt, festschalig, doch nicht besonders dick. Von den acht Umgängen bilden die beiden ersten das winzig kleine Embryonalende, die folgenden zeigen oben eine ebene Abflachung und eine etwas vorspringende Kante, dann sind sie gut gewölbt und zeigen eine scharfe Gittersculptur aus scharf vorspringenden oben flachen, ungleich breiten Spiralreifen und schwächeren schrägen Faltenrippchen, welche Knötchen bilden, wo sie die Streifen schneiden, und namentlich an der Kante eine Reihe stärkere oft auch heller gefärbter Doppelknötchen bilden. Die Mündung ist unregelmässig eirund oben deutlich ausgebuchtet, unten mit canalartigem, zurückgebogenem Ausguss; der Aussenrand ist leicht verdickt und mit Zähnchen besetzt, zwischen denen leichte Furchen ihren Ursprung nehmen, die aber bald verschwinden, so dass der Gaumen ganz glatt ist Die Spindelwand trägt einen dünnen, nach oben schwielig verdickten Callus, die Spindel hat zwei schräge, fast gleiche Falten. - Die Färbung scheint sehr wechselnd. Von den beiden vorliegen Exemplaren ist das eine einfarbig gelblich, die Mündung ebenso bis auf die Falten, Schwielen und die Zähnchen des Mundrandes, die weisslich bleiben; das andere (Fig. 5) ist braun mit einer ziemlich deutlichen hellen Binde um die Mitte und helleren Knötchen; die Mündung ist braun gesäumt mit weissen Zähnchen und deutlicher weisser Binde, die Spindel leberfarben mit weissen Falten, der Gaumen violett überlaufen. Reeve nennt sie schmutzig fleischfarben, undeutlich gebändert.

Aufenthalt an der Westküste von Centralamerika; Iquique, Real Llejos, Callao, Puerto Potrero, auf sandigem Schlammboden von 7-15 Faden Tiefe von Cuming gedrakt.

Aus meiner Sammlung.

\section{Cancellaria decussata Sowerby. Taf. 4. Fig. 7. 8.}

Testa obtecte umbilicata, ovato-acuminata, spira subturrita, acuta, solida, crassa; anfractus 7-8, apice laevi, minuto, caeteri anguste impressi. inferi subangulato-excavati, dein convexiusculi, liris spiralibus costisque obliquis distincte cancellati, ad intersectionem lirarum subtuberculati. Apertura ovata, angusta, supra subcanaliculata, inferne in tanalem recurvum angustum desinens, margine 
externo tenui, crenulato, intus mox incrassato et valde lirato; paries aperturalis callo late expanso, tenui obtecta, sculptura translucenti, columella plicis tribus, supera horizontali minore, tertia ad mar-

ginem columellae, truncaturam simulante, armata. Unicolor fulvescens, ad suturam nec non in umbilico albida. -

Alt. 33 , diam. 22, alt. apert. $20 \mathrm{Mm}$.

Cancellaria decussata Sowerby Proc. zool. Soc. 1832 p. 55 - Thesaurus pl. XCII fig. 3.

$$
\begin{array}{lll}
- & - & \text { Reere Lonch. icon. sp. } 23 . \\
\text { - } & - & \text { Crosse Journ. Conch. IX p. } 237 .
\end{array}
$$

Gehäuse genabelt, aber der Nabel von dem Spindelumschlag fast überdeckt, eiförmig mit spitzem gethürmtem Gewinde, dessen einzelne Umgänge aber doch etwas in einander versenkt erscheinen, mit winzig kleinem spitzem, glattem Apex. Die Naht ist_unfangs rinnenförmig, später schliesst sich an sie eine ziemlich breite Aushöhlung. Die Umgänge sind hübsch gewölbt und mit einer scharfen Gitersculptur aus vorspringenden Spiralreifen und etwas schwächeren schrägen Rippchen überdeckt; die Kreuzungsstellen sind leicht knotig verdickt und da Rippchen und Reifen fast gleich weit von einander entfernt sind, erscheinen die Zwischenräume beinahe regelmässig quadratförmig. Die Mündung ist eng, unregelmässig spitzeiförmig, oben mit einer, durch eine Schwiele auf der Mündungswand noch mehr hervorgehobenen Rinne, uuten mit einem deutlichen, relativ langen, zurückgekrümmten canalartigen Ausguss; der Aussenrand ist dünn, scharf gezähnelt, innen bald verdickt und mit starken Rippen sculptirt, die Mündungswand ist mit einem weit ausgebreiteten Callus überdeckt, durch den die Sculptur durchschimmert; sein Aussenrand steigt bis zur Basis fast senkrecht herunter und überdeckt den Nabel, lässt indess noch einen ziemlich weiten Eingang offen; die Spindel trägt drei Falten, die beiden oberen, von denen die erste bei weitem stärker, horizontal, die unterste mit dem Spindelrand zusammenfallend und eine plötzliche Abstutzung der Spindel bewirkend. Die Färbung ist ein einfarbiges Fahlgelb, die Vertiefung an der Naht und die Nabelgegend sind weisslich, das Gewinde ist intensiver gefärbt, die Mündung weisslich, hier und da fleischfarben gesäumt.

Aufenhalt bei Panama, von Cuming in 10-13 Faden Tiefe gedrakt.

Aus meiner Sammlung.

\section{Cancellaria ovata Sowerby.}

Taf. 5. Fig. 1. 2.

Testa ovata, solida, ponderosa, imperforata, rufescenti-fusca, lirarum interstitiis intensius coloratis, spira breviter conoidea, apice acutissimo. Anfractus 7 parum convexi, sutura lineari distincta discreti, superi costellis numerosis obliquis lirisque spiralibus reticulati, ultimus permagnus, spirae longitudinem fere triplo superans, liris spiralibus planiusoulis undique obductus, prope suturam tantum 
corrugatus. Apertura ovato-acuminata, sat angustą, labro acuto, integro vel leviter denticulato, columella callosa, plicis duabus distinctissimis prominentibus, supra parietem continuatis munito.

Long. 48, lat. max. $30 \mathrm{Mm}$.

Cancellaria ovata Sowerby Proc. zool Soc. 1832 p. 53.

- $\quad$ - Thesaurus Conchyl. p. 441 Nr. 7 pl. 92 fig. 2.

Gehäuse eiförmig mit kurz kegelförmigem, aber ganz spitz zulaufendem Gewinde, dickschalig und schwer, undurchbohrt, röthlich braun, meist mit intensiver gefärbten Furchen, und porzellanweisser Mündung. Die sieben Umgänge sind nur wenig gewölbt und werden durch eine linienförmige deutliche Naht geschieden; die oberen sind deutlich durch Längsrippchen und Spiralleisten gegittert, auf dem letzten, welcher dreimal so lang ist wie das Gewinde, sind Rippchen nur unter der Naht zu erkennen, sonst nur die Anwachsstreifen und flache Spiralleisten. Die Oeffnung ist schmal eiförmig, oben spitz, der Aussenrand scharf, ungezähnelt, oder nach unten hin leicht gezähnelt, im Gaumen stark gerippt, aber ohne dass die Rippen den Rand erreichen; die Spindel hat einen starken, in der Mitte nach aussen nicht scharf begränzten Callus mit zwei sehr starken, lamellenartig vorspringenden Falten, welche sich auf die Spindelwand fortsetzen; der untere ausgeschnittene Rand der Spindel scheint eine dritte Falte zu bilden.

Aufenthalt an West-Columbien; bei St. Elena von Cuming in 8-10 Faden Tiefe auf Sandboden gedrakt. -

Aus meiner Sammlung.

\section{Cancellaria eburnaeformis Reeve.}

Taf. 5. Fig. 3. 4.

Testa ovato-oblonga, imperforata, solidula, albida, ferrugineo-rufo indistincte trifasciata et variegata; spira acuminata, apice acuto. Anfractus 7 sutura lineari discreti, convexi, sed infra suturam planati vel leviter concavi, spiraliter lirati, liris planis, parum prominulis, supremi tantum costellis reticulati, anfractus ultimus spiram plus quam duplo superans. Apertura ovato-acuminata, sat angusta margine integro, acuto, faucibus liratis, liris marginem haud attingentibus; columella callosa, distinctissime biplicata. -

Long. §6, diam. max. $22 \mathrm{Mm}$.

Cancellaria eburnaeformis Reeve Conchol, icon. sp. 21.

Gehäuse langeiförmig, undurchbohrt, ziemlich festschalig, doch nicht allzuschwer, weisslich mit drei breiten nicht sehr deutlichen rostbraunen Binden und allerhand undeutlichen Zeichnungen derselben Farbe, Gewinde erheblich höher, als bei der vorigen Art, 
mit spitzem Apex. Die sieben Umgänge werden durch eine linerare Naht geschieden; sie sind ziemlich gewölbt, aber unter der Naht erkennbar abgeflacht oder selbst etwas ausgehöhlt; nur auf den obersten Umgängen ist eine Gitterung erkennbar, die späteren, sowie der letzte, der nicht viel über doppelt so lang ist wie das Gewinde, zeigen nur flache, wenig auffallende Spiralreifen. Die Mündung ist ziemlich genau wie bei der vorigen Art, schmal eiförmig, oben spitz, mit ganzrandigem scharfen Aussenrand, nicht ganz durchlaufend geripptem Gaumen und schwieliger Spindel mit zwei starken Falten.

Aufenthalt unbekannt, wahrscheinlich auch an der Westküste Centralamerikas.

Aus meiner Sammlung.

Diese Art unterscheidet sich von obesa durch das Zurücktreten der Rippung, das höhere Gewinde und die Abflachung der Umgänge unter der Naht, ist aber schwerlich mehr als eine Varietät davon.

\section{Cancellaria solida Sowerby.}

Taf. 5. Fig. 5. 6.

Testa subgloboso-ovata. imperforata, solida, crassa, ponderosa, unicolor aurantio-spadicea, spira brevissima, apice acuto. Anfractus 7, sutura impressa discreti, supremi subtilissime decussati, sequentes laeves, lineis incrementi subtilibus tantum sculpti, ultimus permagnus, inflatus, basin versus contractus et crista distincta interdum umbilicum simulante munitus. Apertura ovata, subangusta, alba, aurantio limbata, labro acuto, faucibus liratis, liris marginem haud attingentibus, pariete aperturali callosa, subtriplicata, plica supera majore.

Long. 43, diam. max. $31 \mathrm{Mm}$.

Cancellaria solida Sowerby Proc. zool. Soc. 1832 p. 52.

- $\quad$ - Reeve Conch. icon. sp. 2.

- $\quad$ - Sowerby Thes. Conch. p. 440 sp. 5 tab. 92 fig. 4.

Gehäuse bauchig eiförmig, fast kugelig, undurchbohrt, festschalig, dick und schwer, einfarbig fahl orangegelb. Gewinde sehr kurz mit spitzem Apex. Die sieben Umgänge werden von einer eingedrückten Naht geschieden; nur die obersten zeigen eine feine Gittersculptur, die folgenden sind glatt, nur mit ganz feinen Anwachsstreifen. Der letzte ist gross und aufgeblasen und nimmt bei weitem den grössten Theil des Gehäuses ein, er ist unten $\mathrm{zu}$ einer Art Stiel zusammengezogen und zeigt eine kammartige Kante, welche mitunter eine Art falschen Nabel bildet, oder aber auch dicht um die Spindelschwiele herumläuft. Die Mündung ist eiförmig, ziemlich schmal, oben spitz, weiss, aber der Aussenrand orange gesäumt und der Spindelcallus ebenso überlaufen. Der Mundrand ist dünn und scharf, der Gaumen scharf gerippt, doch die Rippen nicht bis zum Rande durchlaufend. Die Spindel mit starker Schwiele und zwei deutlichen, häufig auch einer dritten undeutlichen Falte; die obere ist bedeutend grösser. 
Aufenthalt an der Westküste von Centralamerika; Real Llejos (Cuming). Das abgebildete Exemplar aus meiner Sammlung.

\title{
17. Cancellaria acuminata Sowerby.
}

\author{
Taf. 5. Fig. 7. 8.
}

Testa oblongo-ovata, imperforata, solida, albida, rufofusco indisticto fasciata et variegata, unicolor fuscescens; spira exserta, apice acuto. Anfractus 7 convexi, spiraliter plane lirati, superi costellis numerosis decussati, ultimus spirae longitudinem duplo superans, liris spiraiibus prope suturam nec non ad basin distinctioribus, infra suturam levissime planatus. Apertura ovato-acuminata, sat angusta, margine integro, acuto, faucibus liratis, liris marginem haud attingentibus, callo parietali crasso, distincte biplicato. -

Long. spec. dep، 36, diam. max. $21 \mathrm{Mm}$.

Cancellaria ac uminata Sowerby Proc. zool. Soc. 1832 p. 53.

- $\quad$ - Reeve Conch. icon. sp. 4.

- $\quad$ - $\quad$ Sowerby Thes. Conch. p. 458 Nr. 68 pl. 92 fig. 1.

Gehäuse lang eiförmig, undurchbohrt, festschalig, weisslich mit drei undeutlichen braunrothen Binden, oder mit Flammenzeichnungen, oder auch einfarbig hellbräunlich, dio Spitze ist hoch und schlank mit ganz spitzem Apex, die sieben Umgänge sind ziemlich gut gewölbt und werden durch eine einfache deutliche Naht geschieden; die oberen sind durch Spiralreifen und dichte Rippchen gegittert; der letzte ist doppelt so lang wie das Gewinde, oben etwas abgeflacht, ausser den Anwachslinien nur mit flachen Spiralreifen skulptirt, die unter der Naht und am Stiel deutlicher sind. Die Mündung ist spitzeiförmig, ziemlich schmal, weiss oder etwas bräunlich überlaufen. Der Mundrand ist scharf, ganz, der Gaumen mit starken, nicht ganz durchlaufenden Rippen; die Spindel schwielig mit zwei starken Falten.

Aufenthalt an der Westküste von Centralamerika; bei Guacamoya in 12 Fåden Tiefe auf schlammigem Sandboden von Cuming gedrakt.

Das abgebildete Exemplar meiner Sammlung habe ich von dem verstorbenen Sowerby als seine Canc. acuminata erhalten und stimmt dasselbe auch mit der Figur im Thesaurus ganz befriedigend überein. Allerdings besteht dann der einzige Unterschied von C. eburnaeformis in der stärkeren Skulptur und der geringeren Abflachung unter der Naht; eine besondere Aehnlichkeit mit C. reticulata ist nicht zu finden. Wahrscheinlich hat Sowerby aber den betreffenden Passus seiner Beschreibung von Reeve entlehnt, der allerdings eine grössere Schale $(53 \mathrm{Mm}$. lang) abbildet, die eine unverkennbare Aehnlichkeit mit der westindischen C. reticulata, namentlich in der Mündungsbildung hat. $\mathrm{Ob}$ sie noch hierherzu- 
ziehen, wage ich nach der Abbildung nicht zu entscheiden. Jedenfalls gehört C. acuminata Sow. in die nächste Verwandtschaft von ovata und ist schwerlich mehr als eine Varietät davon.

\title{
18. Cancellaria tuberculata Sowerby.
}

\author{
Taf. 6. Fig. 1-4.
}

Testa umbilicata, subgloboso-conoidea, obliqua, crassiuscula, haud ponderosa, unicolor albido-lutescens; spira breviter conoidea, subgradata, apice acuto. Anfractus 6, primi convexiusculi, laeves, sequentes spiraliter lirati, infra suturam concavo-angulati, carina nodulosa cincti, dein convexi, supra carinam laminis elevatis, oblique super carinam descendentibus armati. Anfractus ultimus permagnus, oblique dilatatus, seriebus tribus nodorum et crista compressa circa umbilicum infundibuliformem munitus, striis lamellosis obliquis usque in umbilicum decurrentibus. Apertura ovato-trigona, obliqua, ampla, labro simplici, faucibus laevibus, columella concava, callosa, late reflexa, plicis duabus parum prominentibus. -

Long. 46, diam. max. $40 \mathrm{Mm}$.

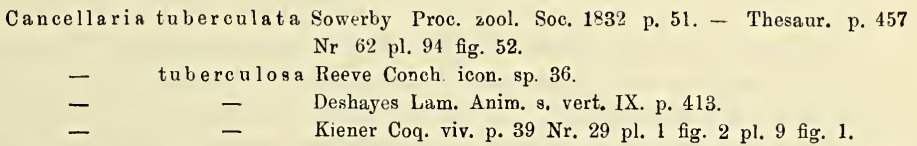

Gehäuse trichterförmig und tief genabelt, unregelmässig schief kegelförmig bis fast kugelig, nicht sehr dickschalig, einfarbig gelblich weiss. Das Gewinde ist niedrig kegelförmig, treppenartig aufgebaut, mit spitzem Apex. Von den reichlich sechs Umgängen sind die beiden ersten leicht gewölbt und glatt, die anderen flach spiral gereift, unter der Naht etwas ausgehöhlt, dann mit einer knotigen Kante umgeben, unter dieser gewölbt. Der Raum über der Kante ist von vorspringenden Anwachslamellen durchzogen, von denen eine Anzahl in schräger Richtung über die Knoten hinweg zur nächsten Naht und auf dem letzten Umgang bis in den Nabeltrichter hinein laufen. Der vordere zeigt unter der Kante noch eine Höckerreihe, der letzte, welcher stark aufgeblasen und in schiefer Richtung nach aussen verbreitert ist, noch drei und ausserdem eine deutliche Kante um den Nabel. Die Mündung ist unregelmässig dreieckig, etwas an den Ecken abgerundet, der grosse Durch messer ganz schräg nach aussen gerichtet, der Mundrand einfach, der Gaumen glatt, die Spindel konkav, stark nach links vorgezogen, schwielig, umgeschlagen mit zwei wenig auffallenden, mehr eingeschnittenen als vorspringenden Falten. 
Aufenthalt an der Westküste von Centralamerika; bei Iquique in Peru von Cuming in 7 Faden auf Sandboden gedrakt.

Die abgebildeten Exemplare aus meiner Sammlung.

\title{
19. Cancellaria bullata Sowerby.
}

\author{
Taf. 6 . Fig. $5-8$.
}

Testa ovato-conoidea, subobliqua, inflata, tenuiuscula, profunde et infundibuliforme umbilicata, unicolor sordide fulva; spira subexserta, gradata, apice acuto. Anfractus 6 supra profunde excavatocanaliculati, dein angulati, ad angulum carina nodulosa, nodulis obliquis; spiraliter lirati, liris obtusis, subrugosis, costulisque nonnullis oblique decurrentibus irregularibus sculpti; ultimus permagnus, oblique dilatatus, seriebus 2-3 nodulorum parum distinctis cingulatus, crista compressa circa umbilicum munitus. Apertura obliqua rotundato-trigona vel cordiformis, basi subcanaliculata, labro simplici, faucibus laevibus, collumella callosa, concava, late reflexa, plicis duabus parum conspicuis. -

Long. 46, diam. $37 \mathrm{Mm}$.

Cancellaria bullata Sowerby Proc. zool. Soc. 1832 p. 51. - Thes. Conch. p. 457 Nr. 61 tab. 94 fig. 56.

\section{- $\quad$ - Reeve Conch. Icon. sp. 5. -}

Gehäuse etwas schief eiförmig kegelförmig, aufgeblasen, ziemlich dünnschalig, tief und trichterförmig genabelt, einfarbig schmutzig braungelb. Das Gewinde ist ziemlich hoch, treppenförmig, mit spitzem Apex. Die sechs Umgänge sind obenher zu einer tiefen Rinne ausgehöhlt, dann mit einer knotigen Kante umgeben, nachher gewölbt; die Skulptur besteht aus etwas rauhen stumpfen Spirallinien und schief verlaufenden Anwachsstreifen, sowie einzelnen stärkeren, mit den Streifen verlaufenden Rippchen wie bei der vorigen Art. Auch der sehr grosse, schräg verbreiterte letzte Umgang hat dieselbe Skulptur wie bei tuberculata, 2-3 Knotenreihen und eine Kante um den Nabel, aber viel weniger in die Augen fallend, wie überhaupt das ganze Gehäuse leichter und dünnschaliger ist. Mündung unregelmässig dreieckig, fast herzförmig, unten zu einer Art Rinne zusammengedrückt; Aussenrand einfach, Gaumen glatt; Spindel konkav, schwielig, weit umgeschlagen, mit zwei eingeschnittenen Falten.

Aufenthalt an der Westküste von Centralamerika, von Cuming im Golf von Nicoya auf Schlammboden in 12 Faden Tiefe gedrakt.

Die abgebildeten Exemplare aus meiner Sammlung.

Diese Art unterscheidet sich von C. tuberculata durch die tiefere Nahtrinne, die im ganzen schwächere Skulptur und die dunklere Färbung; trotzdem ist sie sehr wahrscheinlich durch Zwischenformen mit ihr verbunden. 


\section{Cancellaria spirata Lamarck.}

Taf. 6. Fig. 9. 10.

Testa ovata, vix rimata, solida, albido-fulva, interdum serie macularum rufarum quadratarum infra angulum ornata; spira parum elevata, gradata, apice acuto. Anfractus 6 parum convexi, supra profunde canaliculato-excavati, striis spiralibus ad basin anfractus ultimi distinctioribus undique sculpti, superi costulis indistinctis subclathrati, anfractus ultimus longitudinis $3 / 5$ vix superans. Apertura ovatoangulata, basi subcanaliculata, labro simplici, faucibus liratis, columella rectiuscula, callosa, triplicata.

Long. 24, diam. max. $14 \mathrm{Mm}$.

Cancellaria spirata Lamarck Anim. sans vert. ed. II. IX. p. 408.

- $\quad$ - Kiener Coq. viv. p. 38 Nr. 28 pl. 4 fig. 3.

- $\quad$ - Sowerby Conchol. Illustr. fig. 25. - Thesaurus Conch. p. 449 Nr. 34 pl. 93 fig. 22 .

- $\quad$ - Reeve Conch. icon. sp. 56.

Gehäuse eiförmig, kaum geritzt, festschalig, gelblich weiss, mitunter mit einer Reihe rothbrauner, quadratischer Flecken unter der Kante; Gewinde niedrig, treppenförmig, mit spitzem Apex. Die sechs Umgänge sind nur leicht gewölbt, oben kantig und darüber tief rinnenförmig ausgehöhlt; die oberen haben eine schwache Gitterskulptur, die folgenden sind nur von feinen Spirallinien umzogen, die nach der Basis hin deutlicher werden. Der letzte Umgang macht etwas über drei Fünftel der Gesammtlänge aus. Die Mündung ist eckig eiförmig, oben abgestutzt, unten rinnenförmig zusammengedrückt, mit einfachem Mundrand und geripptem Gaumen; die Spindel ist ziemlich gerade, schwielig, mit drei deutlichen Falten.

Aufenthalt an Westaustralien, am Swan River.

Das abgebildete Exemplar aus meiner Sammlung.

\section{Cancellaria Spengleriana Deshayes.}

Taf. 7. Fig. $1-8$.

Testa fusiformi-turrita, spira exserta, acuta, basi rectiuscula; imperforata, solidula, fulva, rufo maculata vel indistincte fasciata. Anfractus 7-8 superne declivi-angulati, costis obliquis ad angulum nodiferis vel tuberculatis lirisque spiralibus alternantıbus confertis sculpti, irregulariter varicosi. Apertura mediocris, anguste ovata, supra plus minusve angustata, labro crenulato; fauces liris brevibus tantum pone labrum sculptae; columella callo subexpanso, supra tenui, sculpturam haud occultante infra crassiore rugifero, triplicato induta: plica supera horizontali, media valde obliqua, infima brevi subhorizontali.

Alt. ad $65 \mathrm{Mm}$.

IV. 4. 
Cancellaria Spengleriana Deshayes Encycl. method. Vers. vol. II. p. 185. - Anim. sans vert. II. vol. IV p. 414.

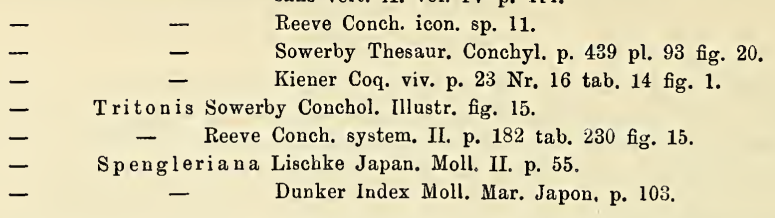

Gehäuse gethürmt spindelförmig mit gethürmtem, spitz zulaufendem Gewinde und kaum zurückgebogener Basis, fest, doch nicht allzudickschalig, undurchbohrt, braungelb mit röthlichen Zeichnungen, häufig undeutlieh gebändert, oder mit einer Fleckenreihe über der Kante; andere Exemplare sind livid blaugrau mit hellen Binden. Die 7-8 Umgänge sind oben kantig, über der Kante flach oder leicht eingedrückt, unter derselben schwach gewölbt; sie sind mit starken schrägen Rippen sculptirt, welche auf der Kante Knoten oder kurze spitze Höcker bilden und nach der Mündung hin undeutlich werden oder in unregelmässige Varices übergehen. Die Spiralsculptur ist sehr wechselnd, meist besteht sie aus dichtstehenden, ungleichen, aber in der Stärke regelmässig wechselnden Spiralreifen, zwischen welche sich feinere Linien einschieben, mitunter lassen sich aber auch nur eingeritzte Spirallinien oder ganz breite, flache, dicht aneinander gerückte Reifen erkennen. Die Mündung ist mittelgross, eirund, oben meist etwas zusammengedrückt, unten canalförmig ausgeschnitten, stark nach hinten zurückweichend, der Mundrand ist stark, doch nicht besonders verdickt, gefältelt, innen nur mit ganz kurzen unterbrochenen Rippchen; die Spindel hat einen nicht sehr ausgebreiten Callus, der oben ganz dünn ist und die Sculptur durchscheinen lässt, unten etwas dicker und stark gekörnelt und runzelig ist; sie trägt drei mittelstarke Falten; die oberste ist fast horizontal, die zweite sehr schräg nach unten gerichtet, die unterste kurze unmittelbar am Spindelausschnitt gelegene horizontal.

Aufenthalt im indochinesischen Meere, von den Philippinen bis China und Japan, nicht allzuselten.

Die abgebildeten Exemplare in meiner Sammlung.

A. Adams hat Gelegenheit gehabt das Thier zu untersuchen und beschreibt es in Ann. Mag. Nat. Hist. Februar 1864 p. 143. 


\title{
22. Cancellaria nodulifera Sowerby.
}

\author{
Taf. 8. Fig. 1. 2.
}

Testa ovato-ventricosa, quoad genus magna, rapanaeformis, spira gradata, brevi, apice obtusulo, basi contorta, recurva, unicolor luteo-fulvescens, interdum liris saturatioribus et fascia angusta albida versus basin ornata. Anfractus 6 ad suturam late et profundecanaliculati, dein infra liram latam breviter excavati et angulati, ad angulum serie nodulorum armati, plicis obliquis parum elevatis lirisque numerosis distinctis sat distantibus et alternatim majoribus, ad plicas subnoduliferis cingulati, interstitiis subtilissime striatis. Apertura lata, irregulariter ovata vel subquadrangularis, labro obtuso, crenulato, intus vix lirato, columella callo appresso, super parietem fere rectangulatim expanso, plicis duabus vix prominentibus granulisque nonnullis munita.

Alt. 60, diam. $45 \mathrm{Mm}$.

Cancellaria nodulifera Sowerby Tankerville Catalogue Appendix p. 15. - Conchol. Illustr. fig. 21. - Thesaurus Conchyl. p. 440 t. 94 fig. 57.

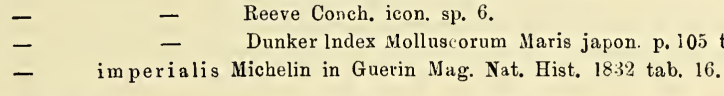

Gehäuse für die Gattung gross, bauchig eiförmig, in der Gestalt an eine Rapana erinnernd, jüngere Exemplare mehr birnförmig, festschalig und schwer, mit kurzem treppenförmigem Gewinde, leicht abgestutztem Apex und gedrehter, zurückgebogener Basis, bald deutlich genabelt, wie bei dem abgebildeten Exemplare, bald ungenabelt, wie Reeve angibt. Die Färbung ist braungelb, meist mit etwas dunkleren Spiralrippen und mitunter auch mit einer helleren Binde gegen den Nabel hin. Die sechs Umgänge sind kantig, oben abgeflacht und mit einer breiten, tief ausgeböhlten Rinne längs der Naht, welche nach aussen durch eine breite, aber kaum knotige Spiralrippe begrenzt wird, dann folgt eine schmale concave Fläche und unterhalb derselben eine zweite, knotige Spiralrippe, unterhalb deren die eigentliche Wölbung beginnt. Von der zweiten Rippe an laufen schräge, breite, gerundete, wenig vorspringende Falten nach unten, sie werden von starken, vorspringenden, entferntstehenden Spiralreifen, welche an Stärke fast regelmässig abwechseln und auf den Falten als Knötchen vorspringen, geschnitten; die Zwischenräume zeigen feine, dichte, nach der Mündung hin lamellenartige Anwachsstreifen, aber keine Gitterung. Die Mündung ist weit, unregelmässig eiförmig oder fast viereckig, oben an der Kante mit einer Art Ausguss, der Aussenrand ist stumpf, aber den Falten entsprechend gebuchtet, Spiralleisten sind im Gaumen kaum deutlich. Die Spindel hat einen starken, nicht allzubreiten, oben rechtwinklig über die Mündungswand vorgezogenen Callus mit zwei stumpfen, kaum vorspringenden Falten und einigen Körnern über dem Ende der unteren. 
Aufenthalt an Südjapan.

Das abgebildete Exemplar von dort direct an Lischke gesandt, jetzt in meiner Sammlung.

\title{
23. Cancellaria cassidiformis Sowerby.
}

\author{
Taf. 8. Fig. $3-6$.
}

Testa quoad genus magna, ovato-ventricosa, in junioribus pyriformis, imperforata, spira brevi acuminata, aurantio-fulva vel aurantia, liris saturatioribus, cingulo albo latiore versus basin plerumque ornata. Anfractus 7 sutura profunda irregulari anguste canaliculata discreti, angulati, supra angulum concavi, ad angulum nodis acutis submuricatis, in spirae anfractibus in plicas utrinque decurrentibus armati, lirisque planis spiralibus irregularibus, quarum 6-8 in anfractu ultimo majoribus et colore saturatiore distinctis, confertim sculpta. Apertura spirae longitudinem fere duplo superans, oblongoovata, sat smpla, rosāeea, labro externo in junioribus acuto, in adultis subobtuso, interdum subcrenulato, intus liris distantibus marginem haud attingentibus sculpto; columella callo crasso late expanso obducta plicisque tribus crassiusculis, tertia infra parum conspicua, tuberculisque nonnullis super finem plicae medianae sitis armata.

Alt. 58, diam. $44 \mathrm{Mm}$.

Cancellaria cassidiformis Sowerby Proc. Zool. Soc. 1832 p. 53.

- $\quad$ - $\quad$ Reeve Conch. icon. sp. 8.

- - $\quad$ Sowerby Thes. Conch. p. 439 t. 92 fig. 15.

Gehäuse für die Gattung gross, festschalig und schwer, bauchig eiförmig, jüngere Exemplare unten verschmälert und dadurch mehr spindelförmig, undurchbohrt, mit kurzem, aber spitzem Gewinde. Die sieben Umgänge werden durch eine tiefe, schmal rinnenförmige, unregelmässige Naht geschieden, sie sind kantig, oberhalb der Kante eingedrückt, an derselben mit einer Reihe spitzer Höcker besetzt, welche an den oberen Umgängen beiderseits in Rippen auslaufen, während auf dem letzten Umgang dies nur seltener und meist nicht bei sämmtlichen Knötchen der Fall ist. Die Spiralsculptur besteht aus flachen dicht stehenden, unregelmässigen Spiralreifen, von denen auf dem letzten Umgang 6-8 erheblich breiter sind und auch durch intensivere Färbung besonders hervorgehoben werden. Die Färbung ist ein helleres oder dunkleres Orangebraun bis Orangegelb; auf dem letzten Umgang ist bei dreien der vier mir vorliegenden Exemplare unten eine weisse Binde deutlich erkennbar. - Die Mündung ist über doppelt so lang als das Gewinde, lang eirund, ziemlich weit, ohne deutlichen Canal; der Aussenrand ist bei jüngeren Exemplaren scharf und mitunter den stärkeren Spiralreifen entsprechend leicht gezähnelt, bei dem Fig. 3 abgebideten ausgewachsenen Stück aber stumpf; innen stehen ziemlich weitläufige, den Rand nicht erreichende Leisten. Die Spindel ist von einem starken, glänzen- 
den, festangedrückten, weit ausgebreiteten, wie die ganze Mündung rosa überlaufenen Callus bedeckt, welcher zwei starke und am Spindelausschnitt eine dritte schwächere, doch deutlich erkennbare Falte trägt; die Mittelfalte ist plötzlich schräg nach unten gebogen und über ihrem allmählig auslaufenden Ende stehen einige kleine Höcker; die Falten erreichen den Callusrand bei weitem nicht.

Aufenthalt an der Westküste von Centralamerika, bei Panama in 16 Faden auf schlammigem Sandboden von Cuming gedrakt.

Anmerkung. Eine der schönsten und grössten Arten, ihren Character festhaltend, nur in der Sculptur einigermassen abändernd, durch ihren Cassis-artigen Habitus mit keiner anderen zu verwechseln.

\section{Cancellaria pyrum Adams et Reeve.}

\section{Taf. 8. Fig. 7. 8.}

„Testa ovato-piriformis, solida, imperforata, spira brevissima, subimmersa, valide cancellata, anfractu ultimo rotundato, laevi, supra liris nonnullis parnm conspicuis, ad basin alteris distinctioribus sculptus, unicolor fulvo-fuscescens; apertura oblonga, angusta, columella superne late callosa, ad basin granoso-costata, plicis tribus, suprema acuta, prominente, faucibus laevibus."

Alt. $38 \mathrm{Mm}$.

Cancellaris pyrum Adams et Reeve Voy. Samarang Mollusca p. 42 pl. 10 fig. 16. - $\quad-\quad$ Reeve Conch. icon. sp. 14.

Gehäuse etwas birnförmig eiförmig, festschalig, undurchbohrt, mit kurzem, fast eingesenktem - bei dem mir allein vorliegenden unausgewachsenen Exemplare ziemlich gethürmtem und nicht eingesenktem - Gewinde. Die oberen Umgänge sind mit scharfen dichtstehenden concentrischen Falten sculptirt und durch dichte deutliche Querreifen gegittert, mit dem Beginne des ietzten Umganges brechen die Falten ganz plötzlich ab und der Umgang erscheint in der Mitte, obschon feine Spirallinien vorhanden sind, glatt und glänzend; unterhalb der Naht und an der Basis sind eine Anzahl deutlicherer Spiralleisten erkennbar. Mein Exemplar zeigt obenher eine leichte Abflachung, die auch an Reeves Abbildung augedeutet ist. Die Mündung ist länglich, ziemlich schmal, der Aussenrand einfach, scharf, der Gaumen anscheinend nicht gereift; die Spindel ist mit einem starken, oben weit ausgebreiteten Callus belegt, der unten eine Anzahl Höckerchen trägt und mit drei Falten bewaffnet ist, von denen die oberste scharf und vorspringend ist.

Aufenhalt in dem chinesischen Meere.

Das abgebildete Exemplar aus der Taylor'scben Sammlung erworben, die Mündungsansicht nach Reeve ergänzt; ob ganz ausgewachsen? 


\section{Cancellaria bifasciata Deshayes.}

Taf. 9. Fig. 1. 2.

Testa oblongo-fusiformis, basi attenuata, spira exserta, imperforata, rufescenti-spadicea, fasciis duabus pallidis cincta. Anfractus 7 parum convexi, minime angulati, liris costulisque undique dense decussati. Apertura oblongo-ovata, supra acuminata, infra anguste emarginata, haud canaliculata; labrum integrum, mox incrassatum, distincte liratum; columella arcuata, inferne valde emarginata, callo superne tenui, inferne crassiore, ruguloso, triplicato munita.

L.ong. 48, diam. $24 \mathrm{Mm}$.

Cancellaria oblonga Kiener Coquilles viv. pl. 3 fig. 3 , nec Gray.

bifasciata Deshayes Encycl. meth. Vers vol. II. p. 181. - Anim. sans vert. IX. p.

- $\quad$ - $\quad$ Reeve Conch. icon. sp. 27

- oblong a Sowerby Conchol. Illustr. fig. 19. - Tankerv. Catalog Appendix p. 15. - Thesaurus Conch. p. 447 Nr. 28 tab. 93 fig. 25. -

Gehäuse langeiförmig, fast spindelförmig, unten verschmälert, aber nicht zurückgekrümmt, mit langgezogenem Gewinde, undurchbohrt, hell röthlichgelb mit zwei helleren Binden und einer hellen Linie längs der Naht. Die sieben Umgänge sind schwach gewölbt, nicht kantig, durch eine deutliche, an den unteren Umgängen mit weissem Schmelz bezeichnete Naht geschieden, mit beinahe gleich starken Radiärfalten und Spiralreifen sehr dicht gegittert. Die Mündung ist lang eiförmig, oben spitz, unten nicht in einen Canal übergehend; der Aussenrand ist einfach, nach innen schnell verdickt und mit starken Rippen sculptirt, die Spindel ist gebogen, unten stark ausgeschnitten, sie hat oben einen ganz dünnen, durchscheinenden Callus; unten ist derselbe dicker, gerunzelt und mit drei Falten besetzt.

Aufenthalt im mittleren indischen Ocean; in der Macassarstrasse auf grobem Sand von Hinds gedrakt.

Anmerkung. Diese Art gehört zur Sippschaft der elegans und sinensis, unterscheidet sich aber genügend durch die fast spindelförmige Gestalt.

\section{Cancellaria buccinoides Sowerby.}

Taf. 9. Fig. 3. 4.

Testa fusiformi-oblonga, imperforata, spira turrita, apice acuto, basi subrecurva; livido-carnea vel fusca, obscure fasciata, vel alba fasciis coeruleo-nigricantibus. Anfractus 6 convexi, superne angulati, costis obliquis lirisque spiralibus ad intersectionem costarum nodosis rude decussata, liris 2 ad 
angulum plerumque magis approximatis. Apertura ovata, supra ad angulum sinuata, labro leviter crenulato, acuto, dein subincrassato et leviter lirato, faucibus fusco vel livide-coeruleo strigatis et maculatis, infra canaliculato-emarginata; columella strictiuscula, parum callosa, inferne plicis duabus et granulis nonnullis munita.

Long. 31, diam. 18 Min.

Cancellaria buccinoides Sowerby Proc. zool. Soc. 1832 p. 54.

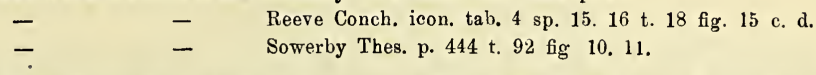

Gehäuse eispindelförmig, undurchbohrt, mit gethürmtem Gewinde und spitzem Apex, die Basis leicht zurückgekrümmt. Die Färbung ist verschiedenartig, bald livid fleischfarben oder bräunlich mit undeutlichen Binden, bald weiss mit einigen breiten schwarzblauen Binden unterhalb der Kante. Die sechs Umgänge sind gut gewölbt und mehr oder minder deutlich kantig, mitunter ganz scharfkantig, sie tragen schräge Rippenfalten und starke Spiralreifen, welche auf den Rippen zu Knötchen anschwellen. Die beiden Reifen an der Kante stehen dichter beisammen und bilden eine doppelte Perlenreihe. Nach der Mündung hin verschwinden die Falten manchmal, bei anderen Exemplaren tritt dort ein Varix auf. Die Mündung ist eirund, oben abgestutzt und an der Kante mit einer Ausbuchtung, die Aussenlippe ist gefältelt, scharfrandig, aber dann verdickt und mit wenig auffallenden Rippen versehen; der Gaumen ist weisslich mit dunklen Striemen und Flecken, deren Farbe der Oberflächenfärbung entspricht. Die Spindel ist ziemlich gestreckt, nur schwach belegt und unten mit zwei deutlichen Falten versehen, zwischen denen noch ein paar Körner sitzen.

Aufenthalt an der Westküste von Südamerika, von Cuming an zahlreichen Punkten (Real Llejos, Iquique, Callao, Puerto Potrero) auf sandigem Schlamm in 7-15 Faden Tiefe gefunden.

Anmerkung. Diese Art variirt erheblich in der Bildung der Kante und der Färbung; Reeves Figuren stellen ganz scharfkantige Stücke dar, b i meinen.bciden ist die Kante weniger entwickelt und fehlt bei dem einen ganz.

\section{Cancellaria indentata Sowerby.}

\section{Taf. 9. Fig. $5-8$}

Testa rhomboideo-oblonga, vix umbilicata, spira brevi, acuminata, cauda sibrecurva, unicolor rufescente-fusca; anfractus 7 angulati, supra angulum concavo-declives, infra planoconvexi, costis obliquis ad angulum nodosis lirisque spiralibus vix minoribus, ad intersectiones magis prominulis distincte clathrati, ultimus pone aperturam plerumque distincte varicosus. Apertura anguste ovata, plicis dentibusque coarctata, subtus canaliculato-emarginata; labro crenulato, mox incrassato, intus 
liris fortibus antice dentiformibus sculpto; columella vix callosa, inferne plicis tribus, duabus superis rudibus, tertia parva basali armata.

Alt. 34, diam. $21 \mathrm{Mm}$.

Cancellaria indentata Sowerby Proc. Zool. Soc. 1832. p. 54.

- - Reeve Conch. icon. sp. 41.

- $\quad$ - $\quad$ Sowerby Thes. Conch. p. 444 t. 92 fig. 7 t. 95 fig. 80.

- cremata Hinds Voy. Sulph. Zool. p. 42.

Gehäuse rhombisch-eiförmig, schwach oder gar nicht genabelt, festschalig, mit kurzem aber spitzem Gewinde, und leicht zurückgekrümmter Basis, einfarbig röthlichbraun. Die sieben Umgänge sind meist nur undeutlich, mitunter aber auch scharf kantig, über der Kante concav eingedrückt, unter derselben schwach gewölbt, mit fast gleichstarken schrägen Rippenfalten und Spiralreifen scharf und ziemlich weitläufig gegittert, an den Kreuzungsstellen stehen kleine Knötchen. Die Mündung ist schmal eirund, oben etwas abgestutzt, unten mit einem fast canalförmigen Ausguss; der Aussenrand ist gefaltet, aussen meist mit einem varixartigen Wulst, auch innen mit einer Verdickung, auf welcher die Enden der starken Gaumenrippen zahnartig vorspringen. Durch diese Zähne und die Falten ist die Mündung erheblich verengt. Die Spindel hat oben einen ganz dünnen, nur an der Färbung erkennbaren Schmelz; unten trägt sie drei Falten, die von oben nach unten an Stücke abnehmen; die dritte ist klein und steht dicht am Ausschnitt der Spindelbasis.

Bei typischen Exemplaren, wie dem Fig. 5. 6 abgebildeten, ist die Kante undeutlich, aber durch eine stärkere, etwas knotige Spiralleiste bezeichnet. Fig. 7. 8 ist ein scharf kantiges Exemplar mit förmlichen Stacheln und bedeutend weitläufigerer Gittersculptur; die Zähne sind sehr stark. Diese Form ist gewissermassen das eine Extrem einer Formenreihe, deren anderes Ende, bei dem die Kante gänzlich verschwindet, von C. affinis Sow. gebildet wird.

Aufenthalt bei Panama.

A nmerkung. Sowerby hat mit dem Namen die starke Bezahnung der Lippe andeuten wollen; k'assisches Latein ist das gerade nicht und bedeutet ungefähr das Gegentheil von dem, was der Autor susdrücken wollte.

\section{Cancellaria urceolata Hinds.}

Taf. 10. Fig. 1-7.

Testa solida, ovato-subfusiformis, spira exserta, unicolor fulvescenti-straminea, apice saturatiore, ad suturas pallidior; anfractus 7 convexi, superne obtuse angulati, deinde plano-convexi, plicis numerosis liriformibus obliquis $18-20$ in anfractu penultimo lineisque elevatis sat distantibus subirregularibus 
spiraliter sculpti, nltimus spirae longitudinem parum superans. Apertura parva, eburnea, anguste ovata, canali breviusculo, sat lato, labro acuto, inferne distincte sinuato, intus valde lirato; columella plicis duabus compressis elevatis, usque ad marginem calli productis, supera horizontali, prope marginem humiliore et dein iterum altiore munita, basi excisa et pliculam tertiam simulante.

Alt. 36, diam. $22 \mathrm{Mm}$.

Cancellaria urceolata Hinds Voy. Sulphur, Moll. p. 41 pl. 12 fig. 7.8.

$$
\begin{array}{lll}
\text { - } & \text { - } & \text { Reeve }^{*} \text { ) Conch. icon. sp. } 23 . \\
\text { - } & \text { - Sowerby }
\end{array}{ }^{* *} \text { ) Thes. Conch. p. } 443_{2} \text { t. } 94 \text { fig. } 48 .
$$

Gehäuse festschalig, leicht spindelförmig-eiförmig mit vorspringendem etwas treppenförmigem, mitunter leicht gethürmtem Gewinde, einfarbig strohgelb bis hellbräunlich mit dunklerem Apex und hellerer Nahtgegend. Die sieben Umgänge sind oben eine kurze Strecke weit flach, dann ganz stumpf kantig und darunter flach gewölbt; sie tragen zahlreiche schmale, fast leistenförmige, schräg verlaufende Falten, von denen man auf dem vorletzten Umgang 18-20 zählt; sie stehen auf den oberen Umgängen dichter, auf dem letzten weitläufiger und werden nach der Mündung hin unregelmässiger; die Spiralsculptur besteht aus feinen erhabenen Linien, welche auf den oberen Umgängen stärker sind und eine Gitterung hervorbringen; auch auf dem letzten springen sie mitunter da, wo sie die Falten schneiden, als kleine Knötchen vor. Die Mündung ist verhältnissmässig klein, schmal eirund, unten mit kurzem, ziemlich weitem Canal; der Aussenrand ist dünn und scharf, unten mit einer deutlichen Bucht, innen mit scharfen Rippen; die Spindel hat einen glänzend weissen, weit über die Mündungswand ausgebreiteten Callus und zwei starke zusammengedrückte Falten, die bis zum Aussenrande des Callus reichen; die obere ist fast horizontal, vor dem Rande etwas niedriger, dann noch einmal scharf vorspringend; der ausgeschnittene Basalrand der Spindel bildet eine dritte scheinbare Falte. Die Nabelgegend ist von einer starken Wulst umgeben und zeigt bei meinen beiden Exemplaren eine deutliche Perforation, während Reeve*), dessen Diagnose nicht als sehr genau bezeichnet werden kann, die Schale ausdrücklich imperforata nennt.

Aufenthalt an der Westküste von Centralamerika; im Papagayo-Golf und bei San Blas von Hinds in 7-14 Faden Tiefe gedrakt.

Anmerkung. Diese Art gehört, trotz ihrer stärkeren Sculptur, zur nächsten Verwandtschaft von ovata und obesa, mit denen sie auch das Vaterland theilt.

*) Cancellaria testa subfusiformi-turrita, solidiuscula, imperforata, spira exserta; anfractibus superne anguste obtuse angulatis, deinde plano-convexis, oblique longitudinaliter corrugato-liratis, sulcis spiralibus linearibus decussatis; fulvescente-straminea; apertura parviuscula, plicis duabus angustis subprominentibus, Reeve.

**) C. testa subcylindrica, laevigata, epidermide fusca induta; spira acuminata, anfractibus angulatis, longitudinaliter costatis, costis decussatis, ultimi anfractus distantibus, complanatis; anfractu ultimo antice coarctato, ad columellam umbilicato; apertura interne leviter costata, labio externo antice flexuoso, ad canalem leviter emarginato; columella biplicata. Sow.

IV. 4 . 


\title{
29. Cancellaria textilis Kiener.
}

\author{
Taf. 10. Fig. 5-8.
}

Testa elongato-ovata, turrita, plus minusve umbilicata, spira elongato-turrita, subgradata, apice acnto; anfractus 7-8 ad suturam impresso-excavati, plicis numerosis oblique decurrentibus, quam interstitia angustioribus, jad angulum prominentibus lirisque spiralibus parum prominulis, ad plicas levissime tuberculatis sculpti; saturate rufo-castanea, nodulis hic illic albis. Apertura parva, subtriquetra, labro continuo, inferne emarginato, externo acuto, dein labiato et creberrime lirato, columella callo tenui concolore, supra sculpturam baud occultante obtecta, plicis tribus obliquis parum prominentibus rugulisque nonnullis ad marginem munita, faucibus luteo-fuscis.

Alt. 39 , diam. $18 \mathrm{Mm}$.

Cancellaria textilis Biener Coq. viv. Canc. p. 10 pl. 7 fig. 1.

- $\quad-\quad$ Sowerby Thesaur. Conch. p. 455 t. 93 fig. 34.

- $\quad$ - Reeve Conch. icon. sp. 28.

Gehäuse langeiförmig, gethürmt, mehr oder minder deutlich genabelt, mit langgethürmtem, etwas treppenförmigem Gewinde und ganz spitzem Apex. Es sind beinahe acht langsam zunehmende Umgänge vorhanden; dieselben sind obenher ausgehöhlt, dann kantig, und mit zahlreichen schrägen Falten sculptirt, welche schmäler als die Zwischenräume sind und an der Kante höckerartig vorspringen. Die Spiralsculptur besteht aus regelmässig, aber ziemlich entfernt stehenden Spiralreifchen, welche auf den Falten etwas stärker vorspringen. Die Färbung ist ein tiefes Braunroth, das nur wenig heller auch die Mündung einnimmt; einzelne Knötchen an der Kante, namentlich die zunächst der Mündung, sind glänzend weiss; auch auf den Rippen bleiben hier und da einzelne Knötchen weiss. Die Mündung ist klein, fast dreieckig; der Mundrand von der Spindel nur durch einen Ausschnitt getrennt, ohne Canal; der Aussenrand ist scharf, aber dann rasch verdickt und mit gedrängten feinen Leisten besetzt; die Spindel hat oben einen ganz dünnen, braunen, rechtwinklig auf die Mündungswand vorgezogenen Callus, welcher die Sculptur durchscheinen lässt; unten trägt er drei mittelmässige Falten und ein paar Runzeln.

Aufenthalt an den Molukken. Die abgebildeten Exemplare aus meiner Sammlung.

\section{Cancellaria cancellata Linné sp. Taf. 11. Fig. 1-9.}

Testa ovato-acuminata, spira breviuscula, apice acuto, basi recurva, contorta, solida; albida, plerumque fusco variegata et bi-vel trifasciata. Anfractus 8 convexi, supra subangulati, plerumque

*) Can. testa subpyramidali, subumbilicata, spira acuminato-turrita, anfractibus ad suturam impresso-excavatis, deinde oblique longitudinaliter costatis, liris spiralibus subobscuris decussatis; rufo-castanea, super costas hic illic albipunctata; apertura parva, plicis tribus, mediocribus. Reeve. 
irregulariter varicosi, costis obliquis angustis lirisque spiralibus vix angustioribus aequalibus sat distantibus, ad intersectiones noduliferis vel subspinosis cancellati, interstitiis striatis; sutura distincta, subirregularis. Apertura mediocris, irregulariter ovata, infra subcanaliculata, alba; labrum expansum, distincte crenatum, faucibus valde liratis; columella superne callo tenui expanso albo sculpturam haud occultante induta, inferne plicis tribus albis prominentibus, supera majore, armata.

Alt. 40-45, diam. ad. $30 \mathrm{Mm}$.

Le bivet Adanson Coq. Senegal p. 123 t. 8 fig. 16.

Voluta eancellata Linné Syst. nat. ed. XII p. 1191.

Cancellaria cancellata Lamarck ed. II vol. IX p. 405.

\begin{tabular}{|c|c|c|}
\hline- & - & Kiener Coq. Viv. t. 7 fig. 2. \\
\hline - & - & Reeve Conch. icon. sp. 13. \\
\hline- & - & Sowerby Thesaur. Conch. p, 451 t. 94 fig. 51 . \\
\hline- & - & Chenu Manuel I fig. 1822. \\
\hline- & - & Sowerby Conchol. Illustr. fig. 38. \\
\hline- & - & Weinkauff Mittelmeerconch. II p. 171. \\
\hline - & - & Jeffreys Proc. Z. Soc. Lond. 1885 p. 49. \\
\hline - & - & Kobelt Conchylienbuch vol. 1 p. 102 t. 38 f. 20 . \\
\hline
\end{tabular}

Gehäuse spitzeiförmig mit ziemlich niedrigem, aber spitz auslaufendem Gewinde und gekrümmter, zurïckgebogener Basis, festschalig, bald undurchbohrt, bald mehr oder minder deutlich geritzt, aber mit deutlichem, oft schuppigem Nabelwulst, weisslich, meist mit drei braunen Binden, von denen die beiden unteren dunkler sind als die oberen, häufig auch nur mit braunen Flecken und Marmorirungen, seltener rein weiss. Es sind nahezu 8 Umgänge vorhanden; auf dem letzten stehen meistens zwei Varices, der eine dicht hinter der Mündung, der andere einen halben Umgang zurück; die Umgänge sind gut gewölbt und mehr oder minder deutlich kantig und tragen eine sehr htibsche Gittersculptur, welche sich aus schmalen, schrägen Rippenfalten und kaum schwächeren, etwas enger zusammenstehenden, doch immer noch ziemlich weitläufigen Spiralreifen zusammensetzt; an den Kreuzungsstellen stehen kleine Knötchen, mitunter aber auch kurze spitze Dornen; die länglich viereckigen Zwischenräume lassen nur die Anwachsstreifen erkennen. Die Naht ist deutlich, etwas unregelmåssig. Die Mündung ist mittelgross, unregelmässig, oval, oben bäufig etwas rinnenfồrmig verengt, unten mit einem, nach aussen unvollständigen, ziemlich langen, zurückgebogenen Canal; der Aussenrand ist umgeschlagen, stark gefaltet, innen gelippt und mit starken Reifen sculptirt; die Spindel hat oben einen ausgebreiteten, dünnen Beleg, welcher die Sculptur durchscheinen lässt; unten stehen drei starke, vorspringende weisse Falten.

Aufenthalt im westlichen Mittelmeer und an der afrikanischen Küste herab bis zum Senegal, nordwärts längs der atlantischen Küste von Portugal und Spanien bis zur Gascogne hinauf, wo sie de Folin fand.

Fossil von dem Miocän an weit verbreitet, im Wiener, im südfranzösischen Becken 
und im Subappenin; pliocän bis nach Dänemark (Mörch teste Jeffreys) und auf den Capverden (Rochebrune).

Anmerkung. Die Veränderlichkeit diese Art zwingt uns ihr eine ganze Tafel zu widmen. Fig. 1-3, ferner 4, 7-9 stellen die bei Algier und überhaupt im Mittelmeer häufigste Form mit drei intensiven schwarzen Binden vor und variiren hauptsächlich nur im Verhältniss der Höhe zur Breite und in der Ausprägung der Gitterung; die schlankste und zugleich am längsten gestielte ist Fig. 4, mit $35 \mathrm{Mm}$. Länge und nur $21 \mathrm{Mm}$. Breite. Eine höchst eigenthümliche Form ist Fig. 5, deren Fundort leider nicht sicher bekannt ist; sie ist auffallend dickschalig und schwer mit auffallend̉ verdicktem Mundsaum; die Umgänge zeigen kaum eine Spur von Schulterung, sondern sind beinahe ganz regelmässig gewölbt; von der Färbung sind nur gelbliche unterbrochene Binden übrig geblieben. Fig. 6 endlich führt durch ihre kurze bauchige Gestalt und die gerundeten nicht mehr gestachelten Rippen schon ein gutes Stück zu Cancellaria similis hinüber; die Schulterbildung ist auch bei ihm wenig deutlich.

Jeffreys nennt den Apex "trochiform and quite different from that of the other species"; ich kann das nicht finden, ob wohl mir eine bedeutende Serie mit tadellos erhaltenem Apex vorliegt.

Es ist eine alte Streitfrage, ob diese Art von der folgenden getrennt gehalten werden kann. Dass die Typen genügend verschieden sind, kann keinem $\mathrm{Z}_{\text {weifel unterliegen, die }}$ bauchigere, fast kugelige Form, die geringere Grösse, die ungestachelten Rippen scheinen zur Unterscheidung zu genügen. So lange C. similis für auf den Senegal beschränkt gehalten wurde, glaubte ich den Unterschied aufrecht erhalten zu können. Seit ich sie aber 1881 von Algesiras und 1884 auch von Algier mit C. cancellata zusammen erhielt, bin ich schwankend geworden und neige mich der Ansicht Weinkauffs zu, dass C. cancellata die Form des festen Sandbodens, C. similis die des Schlammgrundes sei.

\section{Cancellaria similis Sowerby.}

Taf. 12. Fig. 1-6.

Testa globoso-ovata, basi contorta, recurva, spira brevi, acuminata, solida; anfractus 7 converi, interdum obscure subangulati, plicis elevatis numerosis, circa 10 in anfr. ultimo, obliquis, interdum varices simulantibus, et liris spiralibus funiculatis pulcherrime clathrati; alba, rufo-fusco fasciata et lineata. Apertura haud magna, anguste ovata, superne acuminata, in canalem angustum valde recurvum desinens, eburnea; labrum acutum, levissime crenulatum intus mox incrassatum et liris elevatis distincte sculptum; columella supra callo tenui sculpturam haud occultante late expanso induta, infra distincte triplicata.

Alt. 28, dism. $21 \mathrm{Mm}$. 
Cancellaria similis Sowerby Conchol. Illustr. Nr. 41 Fig. 38.

- similaris Reeve Conch. icon. sp. 10.

- $\quad$ imilis Sowerby Thes. Conch. p. 450 t. 94 fig. 42.

Gehäuse kugelig bis kugelig eiförmig, festschalig, mit kurzer, gedrehter, zurückgebogener Basis und ziemlich kurzem, aber spitzem Gewinde; die flach trichterförmige, von einem starken Wulst umgebene Nabelgegend zeigt bald einen leichten Ritz, bald ist sie gänzlich geschlossen. Die sieben Umgänge sind stark gewölbt oder selbst undeutlich kantig und mit starken gebogenen, hohen Rippenfalten sculptirt, von denen auf dem letzten Umgang meistens 10 stehen, einige sind meistens stärker und varixartig, wie bei C. cancellata. Die Spiralsculptur besteht aus ziemlich dichten, fadenförmigen Streifen, welche auf den Falten stärker vorspringen; zwischen sie schiebt sich meist noch eine feinere Linie ein. Die Färbung ist ein bläuliches oder gelbliches Weiss, meist mit 2-3 braunrothen oder rothen Binden, mitunter sind auch die Spiralreifen braun gefärbt. Die Mündung ist ziemlich klein, schmal eiförmig, oben spitz, unten in einen kurzen, engen, zurückgebogenen Canal auslaufend; der Aussenrand ist scharf, aber dann rasch verdickt und mit scharfen, hohen Rippen dicht sculptirt; die Spindel trägt oben eine dünne, ziemlich durchscheinende, weit ausgebreitete Platte und unten drei starke, hohe Falten; die ganze Mündung ist weiss.

Aufenthalt am Senegal, bis zum Eingang des Mittelmeeres emporreichend, bei Algier mit C. cancellata zusammen vorkommend.

Anmerkung. Ueber das Verhältniss dieser Form zu C. cancellata siehe bei dieser Art. Die Variabilität ist eher noch grösser, als bei dieser.

\section{Cancellaria chrys ostoma Sowerby. Taf. 12. Fig. 7-9.}

Testa ovato-subglobosa, umbilicata, solidula, spira subpyramidali, leviter contabulata ; anfractus 7 superne angulati, sutura irregulari haud impressa discreti, costis crassis numerosis obliquis lirisque distinctis ruditer sculpti ; albida, liris et costis sparsim castaneo-maculatis. Apertura rotundato-expansa, labro crenulato, faucibus valde liratis, vivide aurantio limbatis; columella callo crasso aurantio supra valde rugoso, infra distincte triplicato obtecta.

Alt. ad 36, diam. $27 \mathrm{Mm}$.

Cancellaria chrysostoma Sowerby Proc. zool. Soc. 1852 p. 54. Conchol. Illustr. fig. 39.

$$
\begin{array}{lll}
- & - & \text { Sowerby Thesaur. Conch. p. } 451 \text { t. } 98 \text { fig. } 39 . \\
- & - & \text { Reeve Conch. icon. sp. } 31 . \\
- & - & \text { Kiener Coq. vivantes p. } 18 \text { pl. } 8 \text { flg. } 2 . \\
- & - & \text { Deshayes ")-Lam. Anim. sans vertèbres vol. IX p. } 414 .
\end{array}
$$

-) C. testa globoso-pyramidali, albicante, fusco fasciata, ore surantiaco; spira brevi, acumins- 
Gehäuse fast kugelig eiförmig, bei meinen beiden Exemplaren trichterförmig genabelt, nach Reeve kaum genabelt, festschalig, mit kurzem, pyramidalem, leicht treppenförmigem Gewinde. Die sieben Umgänge sind oben kantig und werden durch eine kaum eingedrückte wellenförmige Naht geschieden; sie sind mit zahlreichen, starken, etwas schräg verlaufenden Rippen und starken rauhen Spiralreifen grob sculptirt. Die Farbe ist ein bläuliches Weiss; die Spiralreifen sind mehr oder minder braun gegliedert. Das eine abgebildete Exemplar hat die Rippen oberhalb der Kante intensiv dunkel gefärbt. Die Mündung ist rundeiförmig, nach aussen erweitert, unten mit einem engen, nach rechts und hinten gerichteten Canal; der Aussenrand ist stark gefaltet, breit orangeroth gesäumt, innen stark gerippt; die Spindel ist mit einem dicken, ebenfalls orangerothen Callus bedeckt, welcher eine Anzahl starker Runzeln und Körner und unten drei deutliche, weissliche, vorspringende Falten trägt.

Aufenthalt an der Westküste von Centralamerika, bei Panama und St. Elena von Cuming in 8-10 Faden auf Sandboden gedrakt.

Von den fünf vorliegenden Exemplaren ist seltsamer Weise nicht ein einziges auf der Rückseite unversehrt, alle sind mehr oder minder zerfressen.

\section{Cancellaria haemastoma Sowerby. Taf. 12. Fig. 10. 11.}

Testa conica-ovata, solida, subanguste umbilicata, spira gradata, obtuse turrita; anfractus 6 , supra angulati, costis crassis ad angulum rude nodosis sulcisque angustis profundis spiralibus sculpti; albida, fascia lata castanea infra angulum alteraque minore basali ornata. Apertura parva, rotundatoovata, canali angusto, recurvo, labro incrassato, plicatulo, sanguineo limbato, faucibus valde liratis, albis; columella callo distincto rugoso sanguineo-limbato plicisque tribus compressis distinctis albis munita.

Alt. ad. $30 \mathrm{Mm}$.

Cancellaria haemastoma Sowerby Proc. Zool. Soc. 1852 p. 54.

$$
\begin{array}{llll}
- & - & - & \text { Thesaur. Conch. p. } 452 \text { t. } 94 \text { fig. 53-55. } \\
- & - & \text { Reeve } & \text { ( ) Conch. icon. sp. } 30 .
\end{array}
$$

Gehäuse kegelförmig-eiförmig, festschalig, ziemlich eng, doch deutlich genabelt, mit

tiuscula; anfr. 6 rotundatis, spiraliter sulcatis, longitudinaliter costatis, costis plurimis obtusis, prope suturam elevatis; apertura subrotundata, infra in canalem brevem, reflexum desinente; peritremate crenato, labro externo inte dulcato; interno corrugato; columella triplicata, umbilico mediocri, margine elevato. Desh.

*) Can. testa pyramidali-ovata, solida, subanguste umbilicata, spira obtuse turrita, anfractibus superne rude angulatis, longitudinaliter crassicostatis, sulcis linearibus spiralibus decussatis; lutescente-alba, rufo-fusco maculata et fasciata; apertura parva, fauce lirata et corrugata, vivide sanguinea, plicis tribus angustis. Reeve. 
treppenförmigen, gethürmtem, leicht abgestumpftem Gewinde. Die sechs Umgänge sind oben kantig und werden durch eine ziemlich deutliche, wellenförmige Naht geschieden, sie sind mit starken, gerundeten, an der Kante knotige Höcker bildenden Falten sculptirt, welche von schmalen tiefen Spiralfurchen geschnitten werden. Die Färbung ist weisslich mit einer breiten kastanienbraunen Binde unter der Kante und einer eben solchen schmäleren weiter unten. Die durch ihre blutrothe Färbung auffallende Mündung ist viel kleiner, als bei der vorigen Art, die Spindel weniger ausgehöhlt und auch der Aussenrand weniger nach aussen gezogen, sonst analog gebildet; der Mundrand ist scharf, gefältelt, der Gaumen scharf gerippt und breit roth gesäumt, der Spindel trägt einen starken gerunzelten rothen Callus mit drei deutlichen, scharfen, weissen Falten.

Aufenthalt au den Gallapagos, die abgebildeten Exemplare in meiner Sammlung.

Diese Art ist in ausgeprägten Exemplaren von der vorigen leicht zu unterscheiden durch die weniger aufgeblasene Gestalt, kleinere Mündung, höheres Gewinde und abweichende Sculptur; grösseres Material wird sie aber wahrscheinlich doch als eine Localform derselben erkennen lassen.

\section{Cancellaria rugos a Lamarck. \\ Taf. 12. Fig. 12. 13.}

Testa subglobosa, solida, spira parum elevata; anfractus 6 , superne angulati, plicis validis obliquis, ad angulum tuberculatim productis $8-9$ in anfractu ultimo lirisque elevatis crassis ruditer sculpti, albida vel pallide straminea, interdum ad angulum aurantio-rufo tincta. Apertura ovata, alba labro crasso crenato, faucibus distincte liratis, columella callo crasso albo rugoso obtecta, infra plicis tribus, suprema majore, armata.

Alt. $25 \mathrm{Mm}$.

Cancellaria rugosa Lamarck*) Animaux sans vertèbres ed. II vol. IX p. 408.

$$
\begin{array}{lll}
- & - & \text { Encycl. meth. t. } 373 \text { fig. } 8 . \\
- & - & \text { Kiener Coq. viv. pl. } 6 \text { fig. } 3 . \\
\text { - } & - & \text { Sowerby Thesaur. Conch. p. } 451 \text { t. } 94 \text { fig. } 44 . \\
\text { - } & - & \text { Reeve* }{ }^{* *} \text { Conch. icon. sp. } 60 .
\end{array}
$$

Schale fast kugelig mit nicht hohem kegelförmigem Gewinde, festschalig, nur schwach geritzt oder ganz undurchbohrt, aber mit trichterförmiger, von einer starken Kante umgebenen Nabelgegend. Die sechs Umgänge sind oben kantig und mit starken, runden,

*) C. testa ovali, ventricosa, longitudinaliter costata, transversim sulcata, albida; costis crassis rugaeformibus; columella suquadriplicata. Lam.

**) C. testa subglobosa, solida, imperforata, anfractibus rotundatis, superne obtuse angulatis, oblique rude tuberculato-costatis, spiraliter sulcatis; pallide straminea, ad angulum aurantio-rufo tincta; apertura ovata, subexpansa, fauce valide lirata, columella triplicata. Reeve. 
etwas unregelmässig doppelt gebogenen, an der Kante leicht höckerartigen Rippenfalten 8-9 auf dem letzten Umgang - sculptirt, welche mitunter weiter unten noch eine zweite höckerartige Anschwellung zeigen. Darüberhin laufen rauhe starke Spiralreifen; die Zwischenräume sind deutlich gestreift. Die Färbung ist weiss oder ganz blassgelb, mitunter mit orangerothen Flecken an der Kante. Die Mündung ist ziemlich klein, eirund, nach aussen und unten etwas ausgebreitet; der Mundsaum ist dick, gezähnelt, innen sehr scharf gerippt; die Spindel ist mit einer dicken Platte belegt, welche genau wie bei den beiden vorigen Arten stark gerunzelt ist und unten drei mittelstarke Falten trägt. Die Mündung ist rein weiss.

Aufenthalt in den chinesischen Gewässern; die abgebildeten Exemplare aus meiner Sammlung.

Anmerkung. Diese Art steht den beiden vorigen sehr nahe, scheint aber stets eine ungefärbte Mündung zu haben.

\section{Cancellaria undulata Sowerby. \\ Taf. 13. Fig. 1-3.}

Testa ovato-turrita, haud umbilicata, solida, spira turrita, subgradata; anfractus 7, embryonalibus 2 laevibus, sequentibus spiraliter sulcatis vel lineatis, obtuse angulatis, super angulum planatis, infra convexiusculis, costis concentricis crassis, quam interstitia angustioribus, ad angulum vix nodosis. Unicolor fulvo-spadices vel obscure fasciata. Aperturs irregulariter ovata, parva, spadicea; columella callo lato appresso induta, triplicata, basin versus granulosa; labrum haud incrassatum, integrum, liris brevibus faucium marginem haud attingentibus.

Long. 43, diam. 26, alt. apert. $26 \mathrm{Mm}$.

Extat specimen minus, turritum, sculptura spirali multo distinctiore, anfractibus vix angulatis, faucibus haud liratis (Fig. 3).

Long. 32, diam. 19 , alt. apert. $18 \mathrm{Mm}$.

Cancellaria undulata Sowerby Proc. Zool. Soc. 1848 p. 136.

- $\quad$ - Reeve Concholog. icon. sp. 9.

- $\quad$ - $\quad$ Sowerby Thesaurus Conchyl. p. 443 t. 92 fig. 12 t. 95 fig. 79.

In meiner. Sammlung liegen zwei Exemplare, welche beide von der Reeve'schen Figur und Diagnose einigermassen abweichen. Das grössere, in der allgemeinen Gestalt ziemlich gut stimmend, kann so wenig wie Reeve's Figur subanguste turrita genannt werden, ist vielmehr gethürmt eiförmig, mit verhältnissmässig kurzem treppenförmigem Gewinde, es ist festschalig und zeigt keinerlei Nabel. Die sieben Umgänge sind mit Aus-

*) Canc. testa subanguste turrita, imperforata, spira acute acuminata, anfractibus spiraliter lineari-sulcatis, longitudinaliter costatis, superne planulatis, costis ad angulum subnodatis, fulvospadicea, obscure fasciata; apertura parva, plicis duabus minutis. Reeve. 
nahme der beiden glatten embryonalen von eingedrückten Spirallinien umzogen, die ziemlich gleichweit von einander entfernt sind, und nirgends regelmässige Abwechselung in der Entfernung zeigen; sie sind stumpfkantig und mit concentrischen starken Rippen versehen, welche durch breitere $\mathrm{Zwischenräume} \mathrm{getrennt} \mathrm{sind;} \mathrm{sie} \mathrm{springen} \mathrm{an} \mathrm{der} \mathrm{Kante}$ durchaus nicht, wie Reeve sagt, höckerartig vor. Die Färbung ist ein fahles Braungelb mit undeutlichen dunkleren Binden. - Die Mündung ist unregelmässig eiförmig, relativ klein, kaum heller als das Gehäuse; die Spindel ist mit einem breiten, ziemlich dünnen Callus überdeckt und trägt drei Falten, welche übrigens die Reeve'sche Abbildung auch zeigt, obschon er sie biplicata nennt; die unterste Falte fällt freilich mit dem Spindelrande zusammen; der Aussenrand ist nicht verdickt und ungekerbt; die entferntstehenden Gaumenfalten erreichen nicht den Rand.

Das zweite, Fig. 3 abgebildete Stück ist viel kleiner und könnte für unausgebildet gelten, wenn es nicht die vollständige Windungszahl hätte; es ist viel schlanker, hat viel weniger ausgeprägte Rippen, dafür aber um so schärfere Spiralskulptur, die aus deutlichen, wenn auch flachen in der Stärke wechselnden Spiralreifen besteht; der Gaumen ist fast glatt und dunkler gefärbt, als bei der anderen Form, von der es übrigens unmöglich getrennt werden kann.

Aufenthalt an Tasmanien und Südaustralien. - Nach Sowerby auch an den Philippinen.

Diese Art könnte höchstens mit C. Spengleriana verglichen werden, ist aber durchaus nicht mit ihr zu verwechseln. - Sowerby bildet Thes. fig. 79 aus der Cuming'schen Sammlung eine gedrungenere Varietät von den Philippinen ab, die ich mir bis jetzt nicht habe verschaffen können.

\section{Cancellaria Bocageana Crosse et Debeaux. Taf. 13. Fig. 4-6.}

Testa elongato-pyramidalis, plus minusve rimata, interdum perforata, crassiuscula, solida, spira pyramidali, tabulata; anfractus $61 / 2$, embryonales 2 laeves, rotundati, sequentes supra angulati, super angulum excavati, costis concentricis distantibus rotundatis, ad angulum parum productis, usque ad anfractum anteriorem continuis muniti, spiraliter vix striati vel omnino laeves. Anfractus ultimus spira paullum minor, basi contractus, dein crista distincta circumdatus. Alba, fasciis angustis cinnamomeis numerosis confluentibus, fascias albas superam, medianam et inferam tantum relinquentibus ornata. Apertura oblongo-triangularis, patens, faucibus livida, albofasciata; columella callosa, cum labro plus minusve distincte continua, triplicata, plicis parallelis, supera msjore, basin versus leviter granulata, appressa; labrum crassum, effusum, labio dentato lirisque usque ad marginem productis munitum, ad limbum cinnsmameo maculatum, supra angulatum, ad angulum sinuatum et dente valido subintrante munitum.

Long. 31, lat. $20 \mathrm{Mm}$.

IV. 4 .

n 29, , 16 n 
Cancellaria Bocageana Crosse et Debeaux Journal de Conchyliologie vol. XI 1863 p. 77 tab. 9 fig. 3.

$\begin{array}{lll}- & - & \text { Lischke Japan. Meeresmoll. vol. } 3 \text { p. } 41 \text { tab. } 2 \text { fig. } 12-14 . \\ \text { - } & \text { - } & \text { Durker Index Moll. mar. Japon. p. } 105 .\end{array}$

Gehäuse mehr oder weniger schlank pyramidal, bald nur undeutlich geritat, bald deutlich geritst und selbst durchbohrt, festschalig, das Gewinde pyramidal und deutlich treppenförmig. Es sind sechs bis sieben Umgänge vorhanden, die beiden embryonalen glatt, die folgenden oben kantig und über der Kante ausgehöhlt, dann gewölbt; eine eigentlich rinnenförmige Naht ist nicht vorhanden; sie sind mit entfernstehenden, glatten, gerundeten, an der Kante kaum vorgezogenen, bis zum vorigen Umgang durchlaufenden concentrischen Rippen skulptirt, eine Spiralstreifung ist nur in den Zwischenräumen, und auch da nur schwach, vorhanden, oft selbst mit der Lupe kaum erkennbar. Die Grundfarbe ist weiss, aber zahlreiche braune schmale Spiralbinden stehen so dicht angeordnet, dass sie über und unter der Mitte zu zwei breiten Binden verschmelzen und ausser einer schmalen, aber scharf begränzten Mittelbinde nur den Raum oberhalb der Kante und am letzten Umgang den deutlichen Nabelkiel freilassen. Der letzte Umgang ist etwas niedriger, als das Gewinde. Die Mündung ist rundlich dreieckig und offen; der Gaumen ist braun mit weisser Mittelbinde; , der Rand weiss, nur aussen am Saum braungefleckt. Die verdickte, fest angedrückte, durch einen mehr oder minder starken Callus mit dem Oberrand verbundene Spindelplatte ist fast senkrecht, am offenen Canal ausgeschnitten, mit drei deutlichen, etwas schrägen, gleichlaufenden Falten, von denen die oberste am grössten ist, und nach der Basis hin mit kleinen Höckern am Aussenrand; der Aussenrand ist verdickt, nach aussen gedreht, innen besonders bei jüngeren Exemplaren mit einer gezähnelten Leiste, über welche die Gaumenrippen bis zum Rand hinweglaufen; oben an der Kante ist eine deutliche Bucht und nach innen davon ein starker, kurzer Höckerzahn.

Aufenthalt an China und Südjapan, in neuerer Zeit in den Sammlungen weniger selten geworden.

\section{Cancellaria piscatoria Gmelin sp. \\ Taf. 13. Fig. 7-9.}

Testa ovato-acuta, obtecte perforata, spira brevi, subexserta, scalata, solidula, parum crassa; anfractus 6-7 acute angulati, supra excavati, infra convexiusculi, liris spiralibus, quarum 2 in anfractibus superis, 6 in ultimo majoribus, costisque ad intersectiones lirarum acute nodosis, ad angulum tuberculo spinoso subite terminatis; anfractus ultimus spiram fere duplo superans, basi vix contractus, leviter contortus. Albida, vel cinerea, livido olivaceo vel aurantiacs late bifasciata, rarius omnino alba. Apertura ovata vel subtriangularis, csnali brevi; columella callo tenuiusculo, ad umbilicum subsoluto induta, plica unica cristae umbilicari respondente, interdum subbiplicata; labrum acutum tenue, 
crenulatum, supra auriculatum, limbo albo, laevi, fancibus vel liratis, vel laevibus, fasciis externis translucentibus.

Long. 30, diam. 20-22 $\mathrm{Mm}$.

Le Solat Adanson Coq. Sénégal p, 112 t. 8 fig. 15.

Y a rtin i Conchyl. Cabinet vol. 4 t. 124 fig. 1151. 1152.

Buccinum piscatorium Gmelin Syst. nat. ed. XIII p. 3496.

C'ancellaria nodulosa Lam. Anim. sans vert. ed II vol. 9 p. 404.

- $\quad$ - Kiener Coq. viv. p. 15 pl. 6 fig. 1.

- piscatoria Deshayes-Lam. vol. 9 p. 404 note.

- piscatorum Sowerby Thesaurus Conch. p. 446 pl. 93 fig. 33.

- piscatoria Reeve Conchol. iconica sp. 55.

Gehäuse spitzeiförmig, bedeckt durchbohrt, mit kurzem, aber vorspringendem treppenförmigem Gewinde, festschalig, wenn auch ziemlich dünnschalig. Die 6-7 Umgänge sind mit Ausnahme der embryonalen nahe der Naht kantig, obenher abgeflacht und etwas ausgehöhlt, unter der Kante gewölbt, von ungleichen Spiralreifen umzogen, von denen auf den oberen Umgängen zwei, auf dem letzten meistens 6 stärker vorspringen $;_{s}^{\infty}$ sie werden von schwarhen schrägen Rippen gekreuzt und an den Schnittpunkten stehen spitze, an den oberen Reihen leicht schuppenförmige Knötchen; an der Kante bilden die Rippen noch einen scharfen zurückgekrümmten Stachel und brechen dann plötzlich ab, so dass auf dem abgeflachten Raum höchstens noch flache lamellenartige schräg zur Naht laufende Leistchen übrig bleiben. Der letzte Umgang ist ziemlich doppelt so lang, wie das Gewinde, unter der Kante leicht abgeflacht, die drei obersten Knötchenreihen stehen weiter auseinander, als die unteren; er ist unten nur von vorn nach hinten aber nicht seitlich zusammengedrückt und leicht gedreht. Die Färbung ist sehr wechselnd; von meinen drei Exemplaren ist das eine rein weiss, das andere hat zwei breite orangefarbene, das dritte zwei schmutzig olivenbraune Bänder, die ein weisses Band zwischen sich lassen und auch in der Mündung sichtbar sind. Die Mündung ist ziemlich gross, rundeiförmig, etwas dreieckig, unten mit einem etwas zurückgekrümmten Canal; die Spindelplatte ist dünn, an der Perforation etwas gelöst, meist nur mit einer kleinen, dem Nabelwulst genau entsprechenden Falte, seltener mit noch einer schwächeren darunter; der Aussenrand ist dünn, scharf, buchtig, oben mit einer der Kante entsprechenden Schuppe, innen mit einem hellen Saum; der Gaumen, in welchen die Binden intensiv auftreten, ist bei einem meiner Exemplare ganz glatt, beim zweiten scharf gerippt, beim dritten nur mit einigen Rippenspuren.

Aufenthalt an Senegambien; die abgebildeten Exemplare aus meiner Sammlung.

*) C. testa ovato-acuta, ventricosa, longitudinaliter costata, transversim striata, rufescente; costis per totam longitudinem nodulosis; anfractibus convexis, superne angulatis, supra planis; columella uniplicata. Lamarck. 


\title{
38. Cancellaria hystrix Reeve.
}

\author{
Taf. 13. Fig. 10. 11.
}

Testa globoso-ovata, imperforata, basi recurva, spira brevi sed acute acuminata, solida; anfractus 7, embryonales 2 et sequentes 1-2 laeves, inferi supra planati et ad suturam distincte excavati, angulati, infra angulum convexi, sprraliter lirati et costis obliquis angustis erectis numerosis, ad angulum acute tuberculato-spinosis et ad intersectiones lirarum pulcherrime muricatis, anfractum superiorem haud attingentibus sculpti; anfractus ultimus globoso-inflatus, spiram fere duplo superans. Albida, livido bifasciata. Apertura trigono-ovata, faucibus bifasciatis, liratis, liris interdum saturatius tinctis, versus labium patulum crenulatum abrupte obsolescentibus; columella excisa, callo tenuisculo appresso, plicis tribus distinctis irregularibus munita, basin versus granulosa; labrum ad angulum auriculatum, sinuatum, dein callo albo intrante munitum.

Alt. 26, diam. $19 \mathrm{Mm}$.

Cancellaria hystrix Reeve ${ }^{\star}$ Conchol. iconica sp. 67.

Gehäuse etwas kugelig eiförmig, undurchbohrt, mit zurückgekrümmter Basis und kurzem, aber ganz spitz zulaufendem Gewinde, ziemlich festschalig. Von den sieben ziemlich rasch zunehmenden Umgängen sind die beiden embryonalen völlig glatt, die beiden folgenden nur ganz schwach skulptirt; die unteren haben hoch oben eine scharfe Kante und sind darüber abgeflacht; in Folge davon, dass die Rippen vor der Naht plötzlich abbrechen, erscheint diese tief rinnenförmig; unter der Kante sind die Umgänge gut gewölbt und dicht mit Reifen von abwechselnder Stärke umzogen, sowie mit schräg gerichteten, schmalen, hohen, dichtstehenden concentrischen Rippen, 17 auf dem letzten Umgang, versehen. Diese sind an der ${ }_{s=}^{i c}$ Kante und an der Stelle wo sie vor der Naht abbrechen, stark gestachelt; auch wo die stärker en Spiralreifen über sie hinlaufen, springen sie stachelig vor, so dass eine prächtige Skulptur entsteht. Der letzte Umgang ist etwas aufgeblasen und macht beinahe zwei Drittel des Gehäuses aus. Die Färbung ist weisslich mit zwei breiten lividen Binden, welche die Kante und eine scharfbegränzte Mittelbinde freilassen. Die Mündung ist eiförmig dreieckig, offen, der Gaumen mit zwei braunen Binden und scharfen Rippen, welche dunkel gefärbt sind und am Beginn des geöffneten Mundsaumes plötzlich an einer Art Lippe schwächer werden. Die Spindel ist stark gebogen, mit oben ganz dünnem, fest angedrückten, unten etwas stärkerem und leicht lostretendem Callus belegt, mit drei deutlichen Falten, von denen die oberste horizontal verläuft, die beiden untersten etwas enger beisammen stehen und nach innen convergiren; zwischen

*) Can. testa globoso-ovata, imperforata, spira breviuscula, acute acuminata, anfractibus ad suturam anguste angulatis, oblique longitudinaliter dense costatis, costis erectis, angustis, undique pulcherrime muricato-serratis; albida, livido-fuscescente pallide tincta; apertura ovata, fauce rufilineata, columella arcuata, plicis tribus irregularibus. Reeve. 
der ersten und zweiten stehen nahe dem Innenrande eine Anzahl deutlicher Körner. Der Mundrand ist scharf, erst in einiger Entfernung von dem gekerbten Rande verdickt, nach aussen gewandt, an der Kante ohrförmig vorgezogen und ausgebuchtet, und daneben mit einem leistenartig nach innen fortgesetzten Höcker versehen. Der Canal ist mehr ein Ausguss.

Aufenthalt an Mauritius, ziemlich selten. Das abgebildete Stück in meiner Sammlung.

\section{Cancellaria tessellata Sowerby.}

Taf. 13. Fig. 12. 13.

Testa subcylindraceo-oblonga, imperforata, solidiuscula, spira brevi, conica, apice obtusulo. Anfractus vix 5, sutura primum parum, dein distinctius impressa discreti, plano-convexi, liris spiralibus alternantibus striisque incrementi pulcherrime decussata vel quasi punetis impressis ornata; anfractus ultimus permagnus, fere $3 / 4$ longitudinis occupans, basi vix attenuatus. Albida, purpureoferrugineo trifasciata et interdum tessellata. Apertura anguste oblonga, supra acuminata, infra leviter dilatata, peritremate continuo, basi vix emarginato; columella callo crasso, distincte circumscripto obducta, plicis duabus validis munita, basin versus granoso-ragosa; labrum vix arcuatum, obtusum, integrum vêl subtilissime crenulatum, faucibus distincte liratis, liris marginem haud attingentibus; cailus lutuscens.

Long. $22 \mathrm{Mm}$.

Cancellaria tessellat a Sowerby Proc. Zool. Soc. 1832 p. 51.

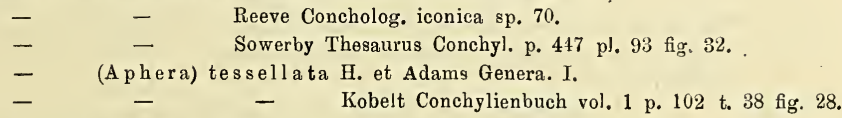

Gehäuse länglich eirund, fast cylindrisch, undurchbohrt, ziemlich festschalig, mit kurzem kegelförmigem Gewinde und relativ auffallend stumpfem Apex. Es sind knapp fünf Umgänge vorhanden, welche durch eine anfangs kaum, dann wenigstens bei meinem Exemplare immer tiefer eingedrückte, zuletzt breit rinnenförmige Naht geschieden werden, sie sind nur wenig gewölbt und durch dichte, auf dem letzten Umgang in Stärke ziemlich regelmässig abwechselnde Spiralreifen und die wenig schwächeren Anwachslinien ganz eigenthümlich gitterförmig skulptirt, so dass bei dem abgebildeten Stücke die Maschen des Gitters wie eingestochene Punkte erscheinen. Der letzte Umgang nimmt beinahe drei Viertel der Gesammtlänge ein und ist unten kaum verschmälert. Die Färbung ist weisslich mit drei breiten rostbraunen oder ins Purpurne spielenden, bisweilen in Flecken

*) Can. testa cylindrico oblonga, solidiuscula, imperforata, spira brevi, conica, sutura parum impressa, anfractibus plano-convexis, granoso-decussatis; albida, purpureo-ferrugineo fasciata et interdum tessellata; apertura anguste oblonga, fauce lirata, columella valide biplicata, late encaustica. Reeve. 
aufgelösten Binden. Die Mündung ist lang und schmal, oben spitz, unten breiter, mit zusammenhängendem, unten kaum leicht ausgeschnittenem Rand; die Spindelplatte ist dick, Echarf begränzt und gegen den letzten Umgang abgesetzt, wie bei [manchen Cassis-Arten, mit zwei starken Falten, - der Canalrand ist durchaus nicht faltenartig - und einigen leichten länglichen Höckern im unteren Theile. Der Mundrand ist wenig gewölbt, stumpf, ganzrandig oder ganz leicht gezähnelt, der Gaumen trägt scharfe Reifen, die aber in einiger Entfernung vom Rande plötzlich abbrechen. Die ganze Mündung ist schwach gelblich gefärbt.

Diese Art steht durch ihre ganze Gestalt, die geringe Zahl ihrer Umgänge und den stumpfen Apex sowie die Mündungsbildung überhaupt den übrigen Cancellarien so eigenthümlich gegenüber, dass die Gebrüder Adams sie zum Typus einer eigenen Untergattung Aphera gemacht haben.

Aufenthalt an Westamerika, wo sie Cuming bei Caraccas, Santa Elena und Xipixapi auf sandigen Schlamm in 7-11 Faden Tiefe fand. Das abgebildete Exemplar habe ich aus der Taylor'schen Sammlung erworben.

\section{Cancellaria Cumingiana Petit. \\ Taf. 14. Fig. 1. 2.}

Testa oblongo-ovata, ad basin attenuata, subumbilicata, spira breviuscula, obtusa, rude oblique convoluta, anfractibus ad suturam canaliculatis, deinde rotundatis, undique anguste sulcatis et liratis; spadiceo-fusca; apertura ovata, plicis tribus, infima fere obsoleta.

Alt. 48 , diam. $35 \mathrm{Mm}$.

Cancellaria Cumingiana Petit in Guérin Magasin de Zoologie.

- $\quad$ - Reeve Conchologia iconica sp. 1.

- $\quad$ - Sowerby Thesaurus Conchyl. p. 440 t. 93 fig. 20.

Gehäuse länglich eiförmig, unten verschmälert, kaum genabelt, mit kurzem abgestumpftem Gewinde, aber wenigstens der Abbildung nach feinem und spitzem Apex. Die Umgänge sind an der Naht rinnenförmig ausgehöhlt, dann gewölbt und dicht mit starken Spiralreifen umzogen. Die Färbung ist einfarbig fahlbraun mit weisser Mündung. Die Mündung ist oval, mit weitem canalartigem Ausguss, innen anscheinend leicht gefurcht; die Spindel ist mit einer dicken Platte belegt und trägt drei Falten, von denen die unterste fast obsolet ist.

Eine eigenthümliche Form, welche meines Wissens Unicum der Cuming'schen Sammlung geblieben ist und die ich somit kopiren muss. Reeve kennt den Fundort nicht, aber Sowerby nennt Payta an der südamerikanischen Westküste. 


\section{Cancellaria ventricos a Hinds.}

Taf. 14. Fig. 3. 4.

Testa oblongo-ovata vel subiusiformis, spira turrita, acuminata, imperforata vel anguste perforata, parum crassa; anfractus $6-77_{\infty}^{*}$ ad suturas breviter planati, dein convexiusculi, liris spiralibus distantibus costisque obliquis vix latioribus undique decussati; anfractus ultimus inflatus, spirae longitudinem fere duplo superans, supra leviter contractus. Rufo-fusca, plerumque albido bifasciata. Apertura ovata, subtus canali brevi recurvo; columella callo tenuissimo obducta, triplicata, plica supera subhorizontalis, prominens, media et infera marginalis parallelae, obliquae; labrum tenue, denticulatum, intus indistincte sulcatum, faucibus lividis, fascia mediana albida.

Long. 30, lat. vix $20 \mathrm{Nim}$.

Cancellaria ventricosa Hinds Proc. Zool. Soc. 1843 p. 47. Voy. Sulph. Zool. pl. 12 fig. 11. 12 .

$\begin{array}{lll}- & - & \text { Reeve Conchol. iconica sp. } 47 . \\ - & -\quad \text { Sowerby Thesaurus Conchyl. p. } 443 \text { t. } 95 \text { f. } 77 .\end{array}$

Gehäuse langeiförmig bis spindelförmig mit gethürmtem, ganz spitz auslaufendem Gewinde, undurchbohrt oder, wie bei dem abgebildeten Exemplare, ganz eng durchbohrt, nicht dickschalig, doch fest. Die sechs oder sieben Umgänge sind mit Ausnahme des glatten Embryonalendes obenher ganz schmal aber horizontal abgeplattet, dann gut gewölbt; sie sind durch ziemlich entferntstehende Spiralreifen und kaum stärkere, etwas weitläufiger stehende schräg gerichtete Rippen sehr hübsch gegittert. Der letzte Umgang ist aufgeblasen, etwa doppelt so lang, wie das Gewinde, obenher eigenthümlich eingeschnürt, was auch bei der Reeve'schen Figur $47 \mathrm{~b}$ deutlich erkennbar ist. Die Färbung ist rothbraun, bei meinem Exemplar mit zwei weissen Binden, einer schwächeren oberen und einer deutlichen unteren. Die Mündung ist eiförmig, nicht gerade gross, unten mit einem deutlichen zurückgekrümmten Canal; die Spindel hat nur unten einen deutlichen Beleg, während oben die Skulptur völlig sichtbar ist; sie trägt drei deutliche Falten; die obere springt stärker vor und läuft horizontal; die mittlere und die untere, welche dem Rand des Canals entlang läuft, sind schräg nach unten gerichtet und convergiren etwas; zwischen der oberen und der mittleren stehen am Rand des Callus ein paar schwache Höcker. Der Mundsaum scheint bei meinem, wie bem Reeve'schen Exemplar nicht ganz ausgebildet; er ist dünn, den Spiralreifen entsprechend gefurcht, am Rande leicht gebuchtet, der Gaumen glatt, livid, mit durchscheinender weisser Binde.

Aufenthalt an der Westküste Centralamerikas, wo sie Hinds bei Real-Lejos und im Golf von Magdalena entdeckte. Das abgebildete Exemplar in meiner Sammlung. 


\title{
42. Cancellaria granosa Sowerby.
}

\author{
Taf. 14. Fig. 5. 6.
}

Testa ovato-subfusiformis, spira exserta, turrita, scalata, cauda brevissima, recta, obtecte perforata, solida, unicolor fulvescenti-spadicea vel maculis rufis ornata. Anfract. 7, (embryonal. exceptis) supra angulati et super angulum plano-excavati, dein rotundati, ad suturam leviter contracti, costis subobliquis numerosis $13-14$ in anfractu ultimo lirisque spiralibus latiuscuils ad costas granosis, ad angulum lira duplici, sculpti, ultimus spiram fere aequans. Apertura sat anguste ovata, basi in canalem recurvum contracta, concolor, labro obtusulo, vix crenulato, faucibus plus minusve liratis, labio columellari callo tenui, granoso, triplicato, plicis parvis, oblique intuenti tantum conspicuis.

Long. 34, diam. $18 \mathrm{Mm}$.

Cancellaria granos a Sowerby Conchological Illustrat. Nr. 15 fig. 17. Thesaurus Conchyl. p. 443 pl. 93 fig. 58. 59 .

- $\quad$ - Reeve Concholog. icon. sp. 20.

Gehäuse langeiförmig, fast spindelförmig, mit hohem, gethürmtem, treppenförmigem Gewinde und ganz kurzem Stiel, bedeckt durchbohrt oder auch gänzlich entnabelt, festschalig, einfarbig gelblich, mitunter mit rothen Zeichnungen, weisslich. Es sind sieben Umgänge vorhanden, welche mit Ausnahme der beiden embryonalen oben eine Kante haben und über derselben flach ausgehöhlt und glatt erscheinen; unter derselben sind sie gewölbt, an der unteren Naht etwas zusammengezogen, und mit zahlreichen starken rundlichen Rippen - 13-14 auf dem letzten Umgang, - und mit Spiralreifen skulptirt, welche auf den Rippen gekörnelt sind; der der Kante entsprechende Reifen ist doppelt. Der letzte Umgang ist ungefähr so hoch, wie das Gewinde. Die Mündung ist ziemlich klein, schmal eirund, unten in einen deutlichen engen zurückgekrümmten Canal zusammengezogen, mit dem Gehäuse gleichfarbig; der Aussenrand ist ziemlich stumpf, nur ganz leicht gezähnelt, der Gaumen mehr oder minder deutlich gerippt. Die Spindel trägt eine ziemlich dünne, gekörnelte Platte mit drei schwachen Falten, welche beim Sehen gerade von vornen kaum sichtbar sind.

Aufenthalt nach Sowerby an Tasmanien, nach Reeve an Peru.

Ich habe nur das abgebildete Exemplar, das sich früher in der Taylor'schen Sammlung befand, erwerben können; nach den Figuren bei Reeve und Sowerby zu schliessen, ist die Art ziemlich veränderlich.

*) Can. testa subpyramidali, obtecte umbilicata, spira acuminato-turrita, anfractibus superne anguste planatis, deinde longitudinaliter costatis, liris obtuse granatis spiraliter decussatis; flavescentespadicea, rufo sparsim maculata; apertura parviuscala, plicis tribus parvis. Reeve. 


\section{Cancellaria laevigata Sowerby.}

Taf. 14. Fig. 7. 8.

Testa elongato-ovata, spira breviuscula, acuminata, cauda brevissima, imperforata; solidula, sed haud crassa. Anfractus 7, sutura impressa subcrenulata discreti, supra anguste planati, dein convexiusculi, superi obsoletissime concentrice plicati, ultimus fere omnino laevigatus, liris spiralibus obsoletissimis tantum cingulatus, quam spira duplo longior, ad aperturam indistincte varicosus. Albida vel carneo-fuscescens, saepe ad angulum fusco maculata. Apertura ovata, sordide albida, infra effusa, columella callo angusto appresso induta, triplicata, plicis parum prominentibus, subaequalibus; labro obtuso, integro, faucibus valde liratis, livido limbatis.

Long. 30, lat. 19,5 $\mathrm{Mm}$.

Cancellaria laevigata Sowerby Conchological Illustrations fig. 24.

$\begin{array}{lll}- & - & \text { Reeve }^{*} \text { Conchol. iconica sp. } 34 . \\ - & - & \text { Sowerby Thes. Conchyl. p. } 448 \text { pl. } 92 \text { f. } 46 \text { pl. } 96 \text { f. } 81 . \\ \text { - } & - & \text { Kobelt Conchylienbuch vol. } 1 \text { p. } 102 \text { t. } 38 \text { fig. } 21 .\end{array}$

Gehäuse langeiförmig, mit kurzem, aber spitz zulaufendem Gewinde und kurzer undurchbohrter nicht zurückgebogener Basis, festschalig, doch nicht allzudickschalig. Die sieben Umgänge werden durch eine eingedrückte, leicht crenulirte Naht geschieden und sind unter derselben anfangs schmal rechtwinklig abgeflacht, dann Jeicht gewölbt; an den oberen erkennt man undeutliche dichte Rippenfalten, auf dem letzten nur ganz undeutliche flache Spiralleisten. Der letzte Umgang ist etwa doppelt so lang wie das Gewinde und trägt längs des Mundrandes eine Art Varix. Die Färbung ist weisslich oder auch ziemlich dunkel fleischfarben mit dunkleren unbestimmten Zeichnungen, meist mit dunklen viereckigen Flecken unter der Naht. Die Mündung ist unregelmässig oval, unten etwas geöffnet und mit einem kurzen breiten Ausguss; die Spindel hat einen schmalen fest angedrückten Callus und trägt drei ziemlich gleich vertheilte und gleich starke Falten, die von vornen gesehen nur wenig vorspingen, von der Seite her aber stärker erscheinen; die unterste fällt mit dem Spindelrande zusammen. Der Aussenrand ist stumpf, ungezähnelt, dunkel gesäumt, der Gaumen mit zahlreichen Reifen skulptirt, welche kurz vor dem Rande abbrechen.

Aufenthalt an Neu-Süd-Wales, das abgebildete Exemplar in meiner Sammlung, früher in der Taylor'schen.

Diese Art erinnert, wie C. spirata und excavata, auffallend an Eburna australis. Das bei Reeve abgebildete Cuming'sche Exemplar weicht ausser in der Zeichnung namentlich durch den aussen mehr herabgezogenen Mundrand von dem meinigen ab.

*) Can. testa ovata, imperforata, spira breviuscula, exserta, anfractibus superne anguste obtuse angulatis, ad angulum obsolete plicato-nodulatis, deinde laevigatis; alba, carneo-fuscescente obscure tincta et ad angulum maculata; apertura ovata, fauce dense lirata, plicis tribus prominentibus. Reeve.

IV. 4 . 


\section{Cancellaria trigonos toma Lamarck. \\ Taf. 15. Fig. 1. 2.}

Testa eleganter pyramidali-turbinata, scalariformis, perampliter perspective umbilicata, spira perattenuata, anfractibus 10, acute trigonis, spiraliter obsolete liratis, ad angulum exteriorem spinosis; roseo-alba; apertura parva, trigona, columella biplicata, plicis tenuibus. Reeve.

Le Bordstrappe Favanne Conch. pl. 79 f. C. C.

Delphinula trigonostoma Lamarck Anim. sans vert. vol. VII. p. 37.

Cancellaria trigonostom a Deshayes Encycl. vers t. 1 p. 180.

$\begin{array}{lll}- & - & \text { Deshayes Anim. sans vert. IX p. } 409 . \\ - & - & \text { Sowerby Conchol. Illustrat. fig. } 44 . \\ - & - & \text { Kiener Coq. vivantes p. } 41 \text { pl. } 1 \text { fig. } 1.1 \mathrm{a} . \\ - & - & \text { Reeve Concholog. icon. sp. } 51 . \\ - & - & \text { Sowerby Thesaurus Conchyl. p. } 457 \text { t. } 94 \text { fig. } 45.46 . \\ - & - & \text { Chenu Nanuel vol. I fig. } 1828 . \\ - & - & \text { Kobelt Conchylienbuch vol. } 1 \text { p. } 102 \text { t. } 38 \text { f. } 17 .\end{array}$

Gehäuse scalarid ausgezogen, lang pyramidal-kreiselförmig, mit sehr weitem, perspectivischem, von einer gezahnten Kante umgebenem Nabel, nicht sehr dickschalig, einfach weisslich oder rosa, mitunter mit undeutlichen bräunlichen Binden. Es sind zehn Umgänge vorhanden, von dreieckigem Querschnitt und so aufgewunden, dass sie sich nur mit einer Kante berühren; sie sind mit entferntstehenden, wenig deutlichen Spirallinien und mit ebenfalls wenig vorspringenden senkrechten Rippenfalten skulptirt, welche an der Kante ein Knötchen oder eine Schuppe bilden; der Raum über der Kante ist glatt. Der letzte Umgang ist kürzer als die Hälfte des Gehäuses, um den Nabel herum zu einer scharfen, grob gesägten Kante zusammengedrückt. Die Mündung ist dreieckig, innen bräunlich, unten mit einem schwachen Ausguss; Mundsaum zusammenhängend, nur wenig verdickt, der Spindelrand dünn, nur am Ansatz etwas zurückgeschlagen, mit zwei schwachen Falten.

Aufenthalt nicht sicher bekannt; Kiener giebt Ceylon an.

Eine altbekannte Art, aber immer noch die seltenste und gesuchteste der Gattung. Die wenigen bekannten Arten scheinen sämmtlich aus alten Holländischen Sammlungen zu stammen, in neuerer Zeit ist sie meines Wissens nicht in den Verkehr gekommen und darum bezweifle ich, dass sie an Ceylon vorkommt. Sie mag eher von einer in neuerer Zeit seltener besuchten Insel des holländischen Indien stammen. Ich habe mir sie nicht verschaffen können und gebe darum die Abbildung nach Reeve. 


\section{Cancellaria Sowerbyi Crosse. \\ Taf. 15. Fig. 3-5.}

Testa fusiformi-elongata, imperforata, ad basin attenuato-recurva, spira turrita, apice acuto; rufo-fusco aut nigricante unicolor tincta. Anfractus 8-9 superne declivi-angulati, super angulum concaviusculi, costulis et liris fere aequalibus ad intersectiones granosis pulcherrime clathrati, lira una ad angulum majore, liris ad labium elevatis et serratis. Apertura anguste ovata, superne acuminata, infra in canalem brevem recurvum desinens, labro serrato, faucibus coeruleis versus marginem tantum breviter liratis; columella vix callosa, biplicata, plicis albidis, compressis, parvis.

Long. (ex. icon, Reeveano) 50, diam. $20 \mathrm{Mm}$.

Cancellaria mitriformis Sowerby*) Proc. zool. Soc. London 1832 p. 51. Thesaurus Conchyl. p. 445 t. 93 fig. 24.

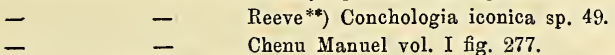

- $\quad$ - Chenu Manuel vol. I fig. 277.

- Sowerbyi Crosse in Journal de Conchyliologie vol. IX p. 242.

- $\quad$ - Kobelt Conchylienb. vol. I p. 102 t. 38 fig. 26.

Non Cancellaria mitriformis Brocchi Conch. foss. subappenn. II p. 645 t. 15 fig. 13 (1814).

juv. $=$ Cancellaria uniplicata Sowerby Proc. zool. Soc. London 1832 p. 173. Thesaurus Conchyl. fig. 35 .

Gehäuse lang spindelförmig, undurchbohrt, nicht sehr dickschalig, unten verschmälert und zurückgebogen, mit gethürmten Gewinde und spitzem Apex. Die Färbung ist einfarbig rothbraun bis schwärzlich. Es sind beinahe neun Umgänge vorhanden; dieselben sind oben kantig, über der Kante eingedrückt, an derselben, sowie dicht unter der Naht von je einem stärkeren, sehr hübsch geperlten Reifen umzogen; zwischen beiden liegt nur ein schwacher ungeperlter Spiralreifen und weicht somit der Raum oberhalb der Kante von dem Rest der Schale in der Skulptur ziemlich erheblich ab. Der Rest der Schale erscheint durch ziemlich dichstehende, fast gleichstarke und gleichweit von einander entferntstehende Rippen und Spiralreifen, welche an den Kreuzungsstellen perlenartig anschwellen, prachtvoll gegittert; die Rippchen setzen sich auch in den Raum über der Kante fort. Der letzte Umgang ist kaum aufgeblasen, unten etwas in einen kurzen, zurückgekrümmten Stiel verschmälert, auf dem die Rippen schwächer werden; bei erwachsenen Exemplaren springen die Leistchen am Mundrand zahnartig vor, so dass derselbe säge-

*) C. testa oblonga, costis longitudinalibus et transversis numerosis, subnoduliferis cancellata; spira acuminata; anfractibus angulatis; apertura laevi; labio externo dentato, emarginato; columella antice producta, crenulata, irregulariter biplicata; colore brunneo, variat nigricante. Sow.

**) Can. testa fusiformi-elongata, imperforata, ad basin attenuato-recurva, spira turrita, anfractibus superne declivi-angulatis et concavis, liris nodulatis undique dense decussatis, liris spiralibus ad labrum elevatis et serratis; rufo-fusca aut nigricante; apertura subangusta, columella uniplicata. Reeve. 
förmig gezackt erscheint. Die Mündung ist schmal eiförmig, oben spitz, unten in einen kurzen, stark zurückgebogenen Canal auslaufend; der Mundrand ist gesägt, der Gaumen nur ganz am Rande mit kurzen Rippchen, im Innern glatt, bläulich mit dunklerem Saum. Die Spindel hat nur einen ganz dünnen, durchscheinenden Beleg und trägt unten wenigstens bei meinem Exemplar zwei deutliche zusammengedrückte Falten.

Aufenthalt bei Panama, von Cuming entdeckt. Eine der seltensten Arten, von welcher ich mir nur das Fig. 5 abgebildete unausgewachsene Exemplar, früher in der Taylor'schen Sammlung, habe verschaffen können. Ich gebe darum in Fig. 3 und 4 die Copie der Reeve'schen Abbildung des Cuming'schen Originals. Der Name ist wegen der gleichnamigen Brocchi'schen fossilen Art von Crosse geändert worden. Die Adams rechnen sie zu ihrer Untergattung Narona, Crosse bildet für sie und C. clavatula die Gruppe III Mitraeformes. Dass C. uniplicata nur auf unausgewachsene Exemplare mit weniger deutlicher zweiter Falte gegründet sei, gibt Sowerby selbst zu.

\section{Cancellaria clavatula Sowerby. \\ Taf. 15. Fig. 6-9.}

Testa elongato-turrita, basi recurva, imperforata, spira acuminato-turrita, varicibus crassis irregularibus hic illic munita. Anfractus 7-8 leniter crescentes, sutura obliqua juncti, supra planati, dein leviter convexi, costis concentricis numerosis parum prominentibus lirisque spiralibus inaequalibus, illa ad angulum interdum majore, sculpta. Albida, rufo-fusco trifasciata, fascia mediana latiore. Apertura elongato-ovata, basi late canaliculata, canali contorto, columella callo tenui angusto munita, fere sigmoidea, biplicata; labrum acutum, crenulatum, faucibus indistincte liratis, limbo laevi.

Long. ad $35 \mathrm{Mm}$.

Cancellaria clavatula Sowerby Proc. Zool. Soc. 1832 p. 52. Conchol. Illustr. fig. 12.

- $\quad$ - $\quad$ Reeve*) Conchologia iconica sp. 52.

- $\quad$ - $\quad$ Sowerby Thesaurus Conchyl. pl. 13 pl. 95 f.67. fig. 92.

- $\quad$ - $\quad$ Kiener Coq. viv. p. 31 pl. 5 fig. 2.

- $\quad$ - Deshayes-Lam. Anim. sans. vert. vol, IX p. 416.

- $\quad$ - Chenu Manuel I fig. 1850.

Gehäuse gethürmt, fast spindelförmig, an manche Pleurotomiden erinnernd, die Basis zurückgekrümmt und undurchbohrt, das gethürmte Gewinde spitz zulaufend und durch ein paar unregelmässig vertheilte starke Varices sofort auffallend. Es sind sieben oder acht Umgänge vorhanden, welche langsam zunehmen und durch eine sehr schräg verlaufende leicht eingedrückte Naht verbunden sind; sie sind oben abgeflacht, dann leicht

*) Canc. testa elongato-turrita, ad basin recurva, imperforata, spira acuta, hic illic valide irregulariter varicosa, anfractibus plano-convexis, obtuse longitudinaliter costatis, spiraliter striatis; rufofusca, albo maculata et fasciata; apertura parva, columella biplicata. Reeve. 
gewölbt, so dass eine undeutliche Kante entsteht; die Skulptur wird von zahlreichen wenig vorspringenden Rippen und dichtstehenden, häufig durch eine Furche getheilten Spiralreifen gebildet. Die Färbung ist weisslich mit drei braunen Spiralbinden, von denen die mittelste besonders breit ist, so dass nur schmale, weisse Binden übrig bleiben. Die Mündung ist langeiförmig, kürzer als das Gewinde, unten mit deutlichem, breitem, zurückgekrümmtem Kanal; die fast s-förmig gebogene Spindel hat nur einen dünnen ganz schmalen Beleg und zwei feine, aber deutlich vorspringende Falten, der Aussenrand ist scharf, leicht gezähnelt, der Gaumen ist im Innern leicht gerippt, doch erreichen die Rippen den Rand nicht.

Aufenthalt bei Panama, von Cuming in sandigem Schlamm in sieben Faden Tiefe gedrakt. Aus meiner Sammlung. Deshayes nennt sie von Payta.

\section{Cancellaria obtusa Deshayes.}

Taf. 16. Fig. 1. 2.

C. testa globosa, spira brevi, obtusissima, luteola, transversim rugosa, superne subplicata; apertura alba, magna, ovata; columella superne callosa, in medio biplicata, umbilico minimo perforata. Deshayes.

Long. 30, lat. $25 \mathrm{Mm}$.

Cancellaria obtusa Deshayes Encycl. meth. Vers. vol. 2 p. $187 \mathrm{Nr}, 19$. Cuvier Regn. anim. Nouv. edit. Moll. pl. 52 fig. 6. Animaux sans, vert. ed II vol. IX p. 417 , nec Kiener.

- $\quad$ - Reeve *) Conchol, icon. sp. 37.

- $\quad$ - Chenu Manuel tome 1 fig. 1844.

Gehäuse fast kugelig mit ganz kurzem oben abgestumpftem Gewinde, einfarbig gelblich, aus fünf rasch zunehmenden, spiral gefurchten Windungen bestehend, welche durch eine leicht eingedrückte Naht geschieden werden. Der letzte Umgang macht fast allein dass ganze Gehäuse aus und zeigt flache, nur durch ganz schmale Furchen geschiedene breite Spiralreifen und nur oben zunächst der Naht ein paar undeutliche kurze Rippen. Der Nabel ist nur durch eine schwache Ritze angedeutet. Die Mündung ist gross, oval, oben und unten verengt, unten mit einem ganz leichten Ausguss, innen weiss. Der Mundrand ist scharf, innen schräg gefurcht; die Spindel ist mit einem breiten Callus belegt und trägt zwei kleine, wenig schräge Falten.

Aufenthalt unbekannt. Diese Art beruht meines Wissens immer noch auf dem einzigen Exemplar, das früher in der Deshayes'schen, später in der Cuming'schen Sammlung lag und mit dieser ins British Museum gelangt ist. Die Abbildung aus Reeve kopirt.

*) Can. testa globosa, minute umbilicata, spira brevissima, obtusa, sutura subimpressa, anfractibus rotundatis, longitudinaliter subobsolete plicatis, spiraliter regulariter sulcatis, luteo-spadicea; apertura ovata, subampla, columella arcuata, plicis duabus parvis. Reeve. 


\section{Cancellaria semidisjuncta Sowerby. Taf. 16. Fig. 3. 4.}

Testa oblique ovata, pervie umbilicata, umbilico infundibuliformi, spira brevi, scalata, apice obtuso; spadicea, aurantio-fusco strigata et maculata. Anfractus 5, celeriter crescentes, supra compresso-angulati, super angulum profunde excavati, dein convexi, costis concentricis vix conspicuis, sed liris spiralibus duplicibus et interstitiis angustioribus profundis cingulati et liris subtilibus longitudinalibus ubique pulcherrime granulati. Anfractus ultimus $3 / 5$ longitudinis aequans, basi in cristam distinctam umbilicum cingentem compressus, antice omnino solutus. Apertura triangularis, margine undique soluto, labro tenui, crenato, faucibus sulcis externis translucentibus, columella tenuis, subverticalis, plicis duabus parvis munita.

Long. ad $25 \mathrm{Nm}$.

Cancellaria semidisjuncta Sowerby*) Proc. zool. Soc. 1848 p. 137. Thesaurus Conchyl. p. 458 pl. 95 fig. 62.63 .

$\begin{array}{lll}- & - & \text { Reeve**, Concholog. icon. sp. } 58 . \\ - & - & \text { Chenu Manuel vol. I fig. } 1839 .\end{array}$

Gehäuse schief eiförmig, mit trichterförmigem, bis zur Spitze durchgehendem Nabel, kurzem ineinander gesenktem treppenförmigem Gewinde und stumpfem Apex, gelblich mit orangebraunen Striemen und Flecken. Es sind nur fünf Umgänge vorhanden, die ziemlich rasch zunehmen, sie haben mit Ausnahme der embryonalen nahe der Naht eine zusammengedrückte, stumpfe Kante und sind über derselben tief und ziemlich breit ausgehöhlt, unter ihr schön gerundet; concentrische Rippen sind nur flach angedeutet, doch vorhanden und namentlich in der Nahtrinne so deutlich, dass diese stellenweise gekammert erscheint; die Spiralskulptur, welche über der Kante fehlt, besteht aus breiten, steil abfallenden Reifen, welche durch eine Mittelfurche oder auch durch zwei doppelt oder dreifach erscheinen und durch tiefe, etwas schmälere Zwischenräume geschieden werden; sie wie ihre Zwischenräume werden durch schräge leistenartige Rippchen geschnitten und erscheinen dadurch ganz eigenthümlich gekörnelt; die Zwischenräume sind in den Vertiefungen zwischen der concentrischen flachen Rippen viel tiefer. Der letzte Umgang nimmt ungefähr zwei Fünftel der Gesammtlänge in Anspruch und ist vornen für eine kurze Strecke völlig gelöst; an der Basis ist er in einen stumpfen Kamm zusammengedrückt, welcher den Nabeltrichter umgibt. Die Mündung ist ganz gelöst, dreieckig, und macht an

*) C. testa ovali ventricosa, turrita (?), spiraliter sulcata; anfractibus angulatis, ad suturam profunde disjunctis, ultimo disjuncto; umbilico maximo, costato; apertura triangulari; columella triplicata, colore fulvo, fusco longitudinaliter fasciata. Sow.

**) Can. testa ovata, latissime aperte umbilicata, spira laxe exserta, anfractibus ad suturam latissime excavato-angulatis, angulo obtuso, spiraliter liratis et excavate sulcatis, liris sulcisque im. presso-striatis; spadicea, aurantio-fusco tincta et maculata; apertura trigona, columella biplicata. Reeve. 
meinem Exemplar, sowohl wie auf den mir bekannten Abbildungen bei dem Mangel jeder Verdickung einen unfertigen Eindruck; sie ist unten zu einer Ausgussrinne zusammengezogen; der Aussenrand ist einfach, důnn, gezähnelt, im Gaumen erscheinen die Spiralreifen der Aussenseite als Furchen; die Spindelplatte ist dünn, fast senkrecht aufgerichtet, mit zwei sehr schwachen Falten. Sowerby gibt drei an, aber seine Abbildung zeigt nur zwei.

Aufenthalt an den Philippinen; Cuming fand sie bei Cagayan auf Mindanao in 25 Faden auf sandigem Schlamm. Das abgebildete Exemplar meiner Sammlung stammt von Taylor.

\section{Cancell aria lamellosa Hinds.}

Taf. 16. Fig. 5. 6.

Testa ovato-acuminata, umbilicata, umbilico infundibuliformi, sublato, mox contracto, spira acute acuminata, scalata; anfractus 7 , superne angulati, super angulum excavati, spiraliter lirati, oblique costati, costis numerosig, acutis, pulcherrime serratis, ad angulum squamoso-uncinatis; anfractus ultimus subinflatus, spirae longitudinem superans. Alba, ad angulum rufo maculata vel interrupte late fasciata. Apertura alba, trigono-ovata, subtus subcanaliculata; columella distincte triplicata; fauces liratae, liris marginem acutum, crenulatum, pone angulum costa intrante munitum haud attingentibus.

Long, 19, lat. $13 \mathrm{Mm}$.

Exstat varietas testa graciliore, costis numerosis, confertius dispositis, quarum nonnullis ad modum varicium crassioribus, apertura multo minore, maculis olivaceis ad angulum nec non prope basin fasciam albam relinquentibus. Long. 17, lat. $12 \mathrm{Mm}$. An C. serrata Reeve sp. 63 ?

Cancellaria lam ellos a Einds Zool. Voy. Sulphur Moll. p. 43 pl. 12 fig. 15. 16.

- - Reeve*) Conchol. iconica sp. 65.

- - $\quad$ Sowerby Thesaur. Conchyl. pl. 94 f. 47 pl. 96 . fig. 106.

Gehäuse spitz eiförmig mit trichterförmigem, mittelweitem, von einer gesägten Kante umgebenem, meist bald zu einer Perforation verengtem Nabel und ziemlich hohem, ganz spitz zulaufendem, treppenartigem Gewinde, nicht allzu festschalig. Die sieben Umgänge haben mit Ausnahme der beiden embryonalen oben nahe der Naht eine scharfe Kante und sind über derselben ausgehöhlt, unter ihr gut gewölbt; sie nehmen ziemlich rasch zu. Es ist eine deutliche Spiralskulptur vorhanden, doch fallen mehr die schrägen, bohen, schmalen, lamellenartigen Rippen in die Augen, welche am Rande prächtig gezähnt und an der Kante zu einem schuppigen Stachel ausgezogen sind. Der letzte Umgang ist etwas

*) Can. testa ovata, anguste umbilicata, spira, acute turrita, anfractibus superne sublate excavato-angulatis, tenue longitudinaliter costatis, costis acute fimbriato-serratis; albida, livido-olivacea tincta, medio albifasciata; apertura trigono-ovata, fauce lirata, columella triplicata. - Hab. ? Reeve. 
aufgeblasen und hat 11 Rippen, er ist höher als das Gewinde. Die Farbe ist ein reines Weiss, mit ausgedehnten rothen Flecken unter der Kante, welche bisweilen den Charakter einer unterbrochenen Binde annehmen. Die Mündung ist eiförmig dreieckig mit kanalartigem Ausguss, weiss, die Spindel trägt eine deutliche unten lostretende Platte und drei ziemlich gleiche Falten; der Gaumen ist scharf gerippt, aber die Rippen erreichen den scharfen leicht gezähnelten Mundrand nicht, sondern brechen vorher plötzlich ab; oben über der Kante steht eine eindringende Falte.

Ausser zwei schönen typischen Exemplaren dieser hübschen Art liegt in meiner Sammlung noch ein von Taylor erworbenes eigenthümlich abweichendes Exemplar, das ich später abbilde. Es ist etwas schlanker und trägt zahlreichere aber unregelmässige Rippen, - 16 auf dem letzten Umgang, - von denen eine Anzahl varixartig stärker erscheinen; die Mündung ist erheblich kleiner, im Uebrigen ebenso gebildet; die Flecken sind olivenbraun und man erkennt auch, obschon blass, eine zweite untere Fleckenreihe, welche, wie die obere, im Gaumen durchscheint; zwischen beiden bleibt eine weisse Binde. Es könnte das ganz gut C. serrat a Reeve sein, obschon die Abbildung eine etwas abweichende Gestalt zeigt. Leider habe ich mir diese Art noch nicht verschaffen können.

Aufenthalt im indischen Ocean.

\section{Cancellaria macrospira Adams et Reeve. Taf. 16. Fig. 7. 8.}

C. testa acuminato-turrita, semipellucida, minute umbilicata, spira elongata, hic illic varicosa, anfractibus ad suturam anguste plano-excavatis, deinde convexis, liris subtilibus crenulatis decussatis; pellucido-alba; apertura minuta, labro varicose incrassato, labro columellari expanso, plicis tribus tenuibus. Reeve.

Long. 24, diam. $11 \mathrm{Mm}$.

Cancellaria macrospira Adams et Reeve*) Voy. Samarang Mollusca p. 41 pl. 10 fig. 2.

$\begin{array}{lll}- & - & \text { Reeve Concholog. icon. sp. } 50 . \\ - & - & \text { Chenu Manuel vol. I fig. } 1818 .\end{array}$

Gehäuse lang gethürmt, halbdurchscheinend, weisslich, nur fein geritzt, mit sehr langem Gewinde, das einige unregelmässig angeordnete Varices trägt. Es sind 8-9 Umgänge vorhanden, welche an der Naht eine schmale flache Aushöhlung und dann eine

*) Canc. testa acuminato-turrita, solidiuscula, vix umbilicata, spira valde exserta, suturis planoexcavatis, anfractibus 8, convexis, apicem versus plicato-costatis, hic illic undique obscure varicosis liris tenuibus longitudinalibus et transversis, subobsolete crenulatis, eximie clathratis, columella tenuiter triplicata, apertura parva, labro incrassatim varicoso, superne producto; cereo-albicante. Adams et Reeve. 
Kante zeigen und im Uebrigen leicht gewölbt sind; sie sind mit feinen Spiralreifen umzogen, welche durch die Anwachsstreifen crenulirt erscheinen, so dass eine schwache Gitterskulptur entsteht. Der letzte Umgang nimmt etwas über zwei Fünftel der Gcsammtlänge ein. Die Mündung ist klein, gerundet dreieckig, der Aussenrand durch einen deutlichen Varix verdickt, der Spindelrand ausgebreitet, fest angedrückt, mit drei kleinen Falten, der Gaumen gereift.

Aufenthalt in den ostasiatischen Gewässern, selten. Ich habe mir diese Art nicht verschaffen können und gebe die Abbildung nach Reeve.

\section{Cancellaria antiquata Hinds. Taf. 16. Fig. 9. 10.}

Testa scalata, latissime et pervie umbilicata, tenuis, solidula, spira brevi sed turrita, apice parvo, laevi, pellucido, alba vel detrita inter costas purpureo translucens. Anfractus 7, supra profunde excavati, dein carinati, ad suturam inferiorem coarctati, sub lente liris subtilissimis spiralibus striati, costis tenuibus sed acutis distantibus ad carinam muricatis sculpti; anfractus ultimus basi in carinam alteram muricatam umbilicum infundibuliformem usque ad apicem pervium cingentem compressus. Apertura parva, trigona, ad basin indistincte canaliculata, peristomate continuo, supra et extus costa ultima ad modum varicis incrassato; columella tenuis, fere omnino soluta, haud reflexa, plicis duabus profundis munita.

$\begin{array}{ccc}\text { Cancellaria antiquat a Hinds Voy. Sulphur Moll. p. } 43 \text { pl. } 12 \text { f. } 17.18 . \\ - & - & \text { Reeve*) Conchologia iconica sp. } 74 . \\ - & - & \text { Sowerby**) Thesaurus Conchyl. p. } 458 \text { pl. } 93 \text { f. } 27 . \\ - & - & \text { Chenu Manuel vol. I fig. } 1835 .\end{array}$

Gehäuse ausgeprägt treppenförmig, weit und durchgehend genabelt, dünnschalig, doch ziemlich fest, mit nicht hohem aber gethürmtem Gewinde und kleinem, glattem, durchscheinendem Apex, rein weiss, in abgeriebenem Zustand zwischen den Rippen purpurroth durchscheinend. Die sieben Umgänge sind mit Ausnahme der embryonalen obenher tief ausgehöhlt und dann mit einer zusammengedrückten, sich auch gegen die Rinne hin scharf absetzenden Kante umzogen, dann leicht gewölbt, aber nach der unteren Naht hin deutlich zusammengeschnürt; sie sind nicht, wie Reeve angibt, glatt, sondern zeigen, wie Sowerby richtig bemerkt, eine allerdings nur mit der Loupe erkennbare Spiralreifung;

*) Can. testa ovata, perampliter et profunde umbilicata, spira turrita, anfractibus ad suturam late declivi-excavatis, ad angulum carinatis et muricatis, deinde acute plicato-costatis, laevigatis; alba; apertura parva, trigona, columella subobsolete biplicata. - Reeve.

*) Testa ovata, acuminata, contabulata, albida; anfractibus septenis, planulatis, costatis, trans. versim striatis; costis acutis, superne spinis cavis desinentibus; apertura trigona; labro reflexo; columella plicis tribus minimis; umbilico maximo. - Sow.

IV. 4. 
ausserdem sind sie mit auffallenden, schmalen, hohen Rippen skulptirt, die an der Kante und auch im Umfang des Nabels in Stacheln oder Schüppchen vorspringen. Bei meinem Exemplare sind sie weiter entfernt, als bei dem von Reeve abgebildeten, es stehen auf dem letzten Umgang nur 8, bei dem Reeve'schen anscheinend 13-14. Der letzte Umgang zeigt um den tiefen bis zur Spitze durchgehenden Nabel herum eine zweite zusammengedrückte Kante, auf welcher die Rippen ebenfalls stachelig vorspringen. Die Mündung ist klein, rein dreieckig, nur unten etwas zu einer Rinne zusammengedrückt, der Mundsaum zusammenhängend, oben und aussen durch die letzte Rippe varixartig verdickt, die Spindel dünn, fast in ihrer ganzen Ausdehnung gelöst, kaum zurückgebogen, mit zwei kleinen Falten; der Gaumen ist deutlich gerippt und zeigt hinter dem Mundsaum eine verdickte Lippe.

Aufenthalt an Neu Guinea, wo sie Hinds auf grobem Sand in 22 Faden Tiefe drakte. Das abgebildete Exemplar meiner Sammlung von Taylor erworben.

Diese Art steht jedenfalls von allen bekannten Arten der seltenen C. trigonostoma am nächsten, doch ist ganz abgesehen von der Grösse die Skulptur eine ganz andere.

\section{Cancellaria foveolata Sowerby. Taf. 16. Fig. 11-13.}

Testa pyramidali-ovata, perforata, spira exserta, turrita, distincte scalata, apice obtusula; tenuis sed solida; anfractus $6 \frac{1}{2}$ infra suturam profunde excavati, dein carinato-angulati, infra convexiusculi, costis albidis distantibus vix prominentibus, ad angulum levissime tuberculatis et striis spiralibus irregularibus, sub lente vix conspicuis sculpti, saepe detriti, laevigati; anfractus ultimus spirae longitudinem vix superans. Carnea, angulo et costis albidis, fasciis et lineis pallide fuscescentibus cingulata, super angulum maculata. Apertura trigono-ovata, subtus vix canaliculata, peritremate continuo; columella angusta, triplicata, labrum extus varicoso-incrassatum, obtusum, integrum, album, faucibus laevibus lividis. - Exstat varietas omnino unicolor luteo-fusca.

Long. 22, lat. $14 \mathrm{Mm}$.

Cancellaria foveo lat a Sowerby Proc. zool. Soc. 1848 p. 137.

- $\quad$ - Reeve ${ }^{*}$ ) Concholog. iconica sp. 71.

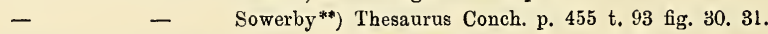

Gehäuse eiförmig pyramidal, fast spindelförmig, eng genabelt oder richtiger durch-

*) Can. testa pyramidali-ovata, anguste umbilicata, spira exserta, anfractibus ad suturam profunde declivi-excavatis, ad angulum obtuse carinatis, deinde plano-convexis, laevibus; carneo fulva, lineis pallide fuscescentibus cingulata, aurantio-fusco ad angulum cingulata; apertura trigono-ovata, labro urasse varicoso, columella arcuata, triplicata. - Reeve.

**) C. testa oblongo-ovali, turrita, laevigata; obsolete costata, spira producta; anfr. angulatis, ad suturam excavatis, ad angulum subcoronatis; apertura triangulari, laevi; columella triplicata; umbilico mediocri; colore fusco vel fulvo taeniato. - Sow. 
bohrt, mit hohem, gethürmtem, deutlich treppenförmigem Gewinde, aber ziemlich stumpfem Apex, dünnschalig, aber fest. Es sind gegen sieben Umgänge vorhanden, welche nächst der Naht tief ausgehöhlt und dann von einer kielartigen Kante umgeben sind; unter derselben sind sie leicht gewölbt. Abgeriebene Exemplare, wie sie meist iu den Handel kommen, sind fast glatt, wie Reeve angibt; gute zeigen aber, wie auch auf seiner $\mathbf{A b}$ bildung deutlich zu erkennen, weissliche wenig erhabene, aber an der Kante deutlich vorspringende Rippen und auch eine, wenn auch schwache und unregelmässige Spiralskulptur. Der letzte Umgang ist etwas höher, als das Gewinde. Die Färbung ist meist fleischfarben; die Kielkante und die Rippen, sowie der Mundsaum bleiben weiss; ausserdem sind bräunliche, bei abgeriebenen Exemplaren auch orangegelbe Linien und Binden vorhanden, von denen eine unter der Kante, eine andere auf der Peripherie deutlicher hervorzutreten pflegen. Das aus der Taylor'schen Sammlung stammende, Fig. 13 abgebildet, Exemplar ist bis auf den Mundrand einfarbig braungelb. Die Mündung ist eiförmig dreieckig unten mit einem kanalartigen Ausguss; der Mundrand ist zusammeuhängend; die schmale schwielige Spindelplatte trägt drei Falten, von denen die unterste mit dem Spindelrand zusammenfällt; der Aussenrand ist varicös verdickt, stumpf, ungekerbt, weiss, der glatte Gaumen bräunlich, bei Fig. 13 mit weissem, braungestreiftem Saum.

Aufenthalt an der Südspitze Afrikas bis nach Natal hinauf. - Aus meiner Sammlung.

\section{Cancellaria Cumingii var. suboblusa Crosse. Taf. 17. Fig. 1.}

Testa subobtusa, brevior, magis globosa, ad basin minus attenuata, validius subumbilicata; anfr. 4 (embryonalibus $1 \frac{1}{2}$ laevibus, albis), margine dextro et margine basali colore luteo tinctis, limbo brunneo-violascescente, epidermide olivacea induta.

Long. 38, diam. max. $29 \mathrm{Mm}$.

Cancellaria Cumingii var. subobtusa Crosse Journal de Conchyliologie vol. 111863. p. 62 t. 2 fig. 9 .

Crosse bildet unter obigem Namen eine sehr interessante Form ab, welche gewissermassen einen Uebergang von Cancellaria Cumingii Petit zu Cancellaria obtusa Deshayes bildet und die Vermuthung erweckt, dass diese beiden Arten nur die Extreme eines und desselben Formenkreises sind. Sie steht übrigens der C. Cumingii näher als der obtusa und unterscheidet sich wesentlich nur durch die kugeligere, kürzere Form, die geringere Verschmälerung der Basis und den etwas weiteren Nabel. Auch die Färbung ist etwas verschieden; Aussenrand und Basis sind orangegelb gesäumt mit schmalem braunviolettem Rand. Spuren einer dünnen olivengrünen Epidermis sind vorhanden.

Aufenthalt bei Payta in Peru. Abbildung und Beschreibung nach Crosse 1. c. 


\title{
54. Cancellaria Semperiana Crosse.
}

\author{
Taf. 17. Fig. 2. 3.
}

„T. imperforata, globoso-turrita, pärum crassa, cinnamomea; spira elongata, apice rotundato, obtusiusculo; anfr. $61 / 2$, duobus primis embryonalibus laevibus, pallide castaneis; caeteris longitudinaliter et irregulariter plicato-costatis, spiraliter frequentissime striato-sulcatis, striis inaequalibus, imprimis ad basin undulatis, aliis tenuibus, numerosis, aliis validioribus, ad occursum costarum longitudinalium nodulosis; anfr. penultimo et ultimo obtuse subcarinatis, ultimo anfractu ventricoso, inflato, spira multo majore, colore squalide albo fasciato supra carinam et ad suturam albo variegato; columella crassiuscula, valide callosa, nitide candida, triplicata; apertura satis ampla, ovato-rotandata, fauce lirata, cinnamomeo-albida; margine dextro acuto, flexuoso, postice abeunte. - Long. 37, diam. max. 25, long. anfr. ult. 24 Mm." - (Crosse).

Cancellaria Semperiana Crosse Journ. Conch. XI. 1863 p. 65 t. 2 fig. 7.

Gehäuse undurchbohrt, kugelig mit gethürmtem Gewinde, nicht gerade dickschalig, zimmetbraun, Apex knopfförmig, stumpf, hell kastanienbraun, aus 2 glatten Umgängen bestehend. Die übrigen Umgänge sind mit unregelmässigen Rippenfalten sculptirt, welche von zahlreichən, unregelmässigen, nach der Basis hin welligen Spiralreifen geschnitten werden und an den Schnittstellen leichte Knötchen tragen. Der vorletzte und der letzte Umgang sind undeutlich kantig, der letzte ist aufgeblasen, viel höher als das Gewinde, undeutlich weiss gebändert und gescheckt. Die Mündung ist ziemlich weit, rundeiförmig, mit geripptem bräunlichem Gaumen; die Spindel trägt einen starken glänzend weissen Callus mit drei Falten; der Aussenrand ist scharf, etwas gebogen, unten zurückweichend.

Aufenthalt an Neucaledonien. Ich habe mir diese Art nicht verschaffen können und gebe Abbildung und Beschreibung nach Crosse.

\section{Cancellaria obliquata Lamarck.}

\author{
Taf. 17. Fig. 4. 5.
}

Testa oblique globosa, anguste sed profunde umbilicata, spira parva, acuta, subscalata, solidula, albida vel fulvescenti alba, plerumque rufo-fuscescente sparsim punctulata. Anfractus 7, praeter embryonales 2 supra sublate excavati, angulati, infra angulum convexi, costis tenuibus acutis obliquis, ad angulum submuricatis striisque spiralibus distantibus elevatis, super costas nodulosis sculpti. Anfractus ultimus inflatus subglobosus, ad aperturam varice interdum latissimo munitus. Apertura irregnlariter ovata vel subtriquetra, basi contracta, effusa, labro acuto, integro, effuso, slbo; faucibus valde liratis; columella callo tenui, infra soluto, angusto, triplicato obtecta.

Long. 26, diam. 19 Mm. 
Cancellaria obliquat a Lamarck*) Anim. sans vert. ed. II vol, 9 p. 408.

\begin{tabular}{|c|c|c|}
\hline- & - & $\begin{array}{l}\text { Sowerby Concholog. Illustrations fig. } 26 . \text { - Thesaurus Conchy- } \\
\text { lior. p. } 458 \text { pl. } 96 \text { fig. } 82.83 \text {. }\end{array}$ \\
\hline$\alpha$ & - & Reeve Concholog. icon. sp. 61 \\
\hline & - & Kiener Coq. viv. p. 19 pl. 6 fig. 3. \\
\hline
\end{tabular}

Gehäuse etwas schräg kugelig, eng aber tief genabelt, mit kurzem aber ganz spitz zulaufendem Gewinde, das leicht treppenförmig gebildet ist, festschalig, weiss oder gelblich weiss, meist mit braunrothen Zeichnungen und Flecken, mitunter die Rippen mehr oder minder deutlich gegliedert. Es sind aieben rasch zunehmende Windungen vorhanden; sie sind mit Ausnahme der beiden embryonalen oben kantig und darüber ziemlich schmal ausgehöhlt, darunter gut gewölbt; die Skulptur besteht aus schmalen, schrägen, scharfrückigen, an der Kante stachelig vorspringenden Rippen, von denen ich auf dem letzten Umgange 12-14 zähle, und aus feinen erhabenen ziemlich entfernt stehenden Spiralreifen, welche auf den Rippen knotig verdickt und mitunter braun gegliedert sind. Der letzte Umgang ist fast doppelt so hoch, wie das Gewinde, aufgeblasen, hinter den Mundrand mit einem breiten, starken, auch noch oben erheblich über die Naht vorspringenden Varix. Die Mündung ist unregelmässig eiförmig oder fast dreieckig, unten zu einem kanalförmigen Ausguss verengt, mit scharfem, kaum gezähneltem, etwas nach aussen geöffnetem Rand und scharf geripptem, doch nach dem Rande hin glattem Saum; der Spindelcallus ist dünn, unten lostretend, schmal, mit drei fast gleichen und gleichlaufenden Falten; oben dicht vor der Kante steht gleichfalls ein glänzend weisser Höcker.

Aufenthalt an den Philippinen; das abgebildete Exemplar aus meiner Sammlung.

\section{Cancellaria Angasi Crosse.}

\section{Taf. 17. Fig. 6. 7.}

Testa imperforata, elongata, spira turrita, scalata, tenuis; anfractus 7 , embryonales $11 / 2-2$ laeves, rotundati, cornei, sequentes acute angulati, supa angulum planati, infra vix convexi, ad suturam contracti, parce et obsolete spiraliter striati, costis validis angustis distantibus ad angulum acute tuberculatis, usque ad anfractum superiorem prolongatis muniti. Anfractus ultimus quam spira vix brevior, basi contractus et lira spirali ab insertione marginis dextri oriente quasi bicarinatus. Alba,

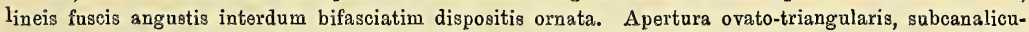
lata; columella callo tenui, angusto, livido induta, plicis duabus tenuibus munita; labrum album, leviter incrassatum, integrum, faucibus laevibus.

Long. 18, lat. $10 \mathrm{Mm}$.

*) C. testa ovato-scuta, ventricosa, umbilicata, albido-fulva; costis longitudinalibus obliquis crebris asperulatis; striis transversis tenuissimis ; columella triplicata. - Lam. 
Cancellaria Angasi (rosse*) in Journal de Conchyliologie vol. XI 1863 p. 64 tab. 2 fig. 8 .

Gehäuse undurchbohrt, langkegelförmig, mit gethürmtem treppenförmigem Gewinde, dünnschalig und durchscheinend; es sind sieben Umgänge vorhanden, wovon $11 / 2-2$ auf das Embryonalende kommen. Diese sind glatt, gerundet, dunkel hornfarben, die folgenden sind scharfkantig, über der Kante stark abgeflacht, unter ibr nur wenig gewölbt und nach der nächsten Naht hin verschmälert, nur hier und da undeutlich gestreift, mit starken aber schmalen, ziemlich entferntstehenden Rippen - 9 auf dem letzten Umgang - skulptirt, welche auf der Kante höckerartig spitz vorspringen und bis zum vorhergehenden Umgang durchlaufen. Der letzte Umgang ist kaum kürzer als das Gewinde, unten eingezogen; am Beginn der Verschmälerung läuft eine eigenthümliche Spiralleiste vom Ansatz des Aussenrandes aus, gewissermassen eine zweite Kante bildend. Crosse nennt die Art einfarbig weiss, aber mein Exemplar ist auf dem letzten Umgang von gelbbraunen, zu zwei Bändern angeordneten Spirallinien umzogen; das eine der auf den Rippen besonders deutlichen Bänder liegt etwas unter der oberen Kante, das andere dicht über der unteren, in der Mündung sind sie kaum sichtbar. Die Mündung ist etwas dreieckig eirund, klein, weiss, der Spindelcallus ist schwach, schmal, mit zwei schwachen Fältchen; der Aussenrand ist weiss, leicht verdickt, ungekerbt, der Gaumen glatt, weiss.

Aufenthalt nicht sicher bekannt, obschon die Art neuerdings mehrfach in die Sammlungen gekommen ist. Das abgebildete Exemplar in meiner Sammlung.

\section{Cancellaria articularis Sowerby.}

Taf. 17. Fig. 8-11.

Testa ovato-acuminata, subobliqua, profunde perforata, spira exserta, leviter scalata, apice acuto, solidula, carnea, costis fusco articulatis. Anfractus 7, superne angulati, super angulum excavati, dein convexiusculi, costis numerosis crenulatis, ad angulum nodoso-muricatis, quam interstitia plus quam dimidia angustioribus sculpti, spiraliter lirati; ultimus subinflatus, spirae longitudinem superans, circa perforationem in cristam dentatam compressus, supra cristam leviter coarctatus. Apertura ovato-triangularis, basi distincte effusa, albido-rosacea; peristoma continuum; labro supra ad angulum subcanaliculato et lira forti intrante munito, externo acuto, integro, extus varice lato crasso munito,

*) T. imperforata, elongato-turrita, subscalariformis, tenuis, albida, spira elongata, apice rotundato, obtusiusculo; anfractus $61 / 2$ (embryonales $\left.11\right|_{2}$ laeves, nigricantes, rotundati), acute carinati, parce et obsolete spiraliter striati, immpressi, longitudinaliter costis validis, ad angulum carinae acutis, subspinosis; anfr. ultimus bicarinatus, (carina altera minore ad insertionem marginis dextri sita,) spiram fere aequans; columella biplicata, callo parvo munita, alba; apertura trigono-subquadrata, fauce alba; apertura trigono-subquadrata, fauce alba, non lirata, nitida. - Long. 15, diam. max 8, long. anfr. ult. 7, spirae $8 \mathrm{Mm}$. - Crosse. 
intus primum laevi, dein labro dentato incrassato, faucibus costatis; columella ad perforationem tantum reflexiuscula, triplicata, callo parietali tenui.

Long. 20, lat. 15, alt. apert. $13 \mathrm{Mm}$.

Cancellaria articularis Sowerby *) Concholog. Illustr. fig. 32. - Thesaurus Conchyl. p. 454 t. 96 fig. 90.91 .

$\begin{array}{lll}- & - & \text { Kiener Coq. vivantes p. } 22 \text { pl. } 6 \text { fig. } 2 . \\ - & -\quad \text { Reeve }\end{array}$

Gehäuse spitzeiförmig, etwas schief, tief, aber ziemlich eng durchbohrt, mit erhobenem, leicht treppenförmigem Gewinde und spitzem Apex, ziemlich festschalig, fleischfarben oder rosa mit bräunlich gegliederten Rippen. Die sieben Umgänge sind mit Ausnahme der embryonalen oben kantig und über der Kante ausgehöhlt, darunter leicht gewölbt; sie sind mit zahlreichen, nur wenig schrägen, beiderseits steil abfallenden Rippen skulptirt, welche an der Kante in spitze Höcker ausgezogen sind, sie werden von feinen, gleichmässigen, ziemlich weitläufigen Spirallinien geschnitten und erscheinen dadurch leicht crenulirt. - Der letzte Umgang ist länger, als das Gewinde, etwas aufgeblasen, unten um den Eingang der Perforation herum zu einer gezahnten Kante zusammengedrückt und über dieser leicht doch erkennbar eingeschnürt. Die Mündung ist abgerundet dreieckig, weiss mit einem Stich in rosa, der Mundsaum zusammenhängend, unten mit einem deutlichen, etwas zurückgebogenen Ausguss; der Aussenrand ist oben an der Kante auch mit einer Art Kanal versehen, davor steht eine starke, eindringende Leiste. Der Aussenrand ist scharf, ganz, dünn, aussen mit einem breiten, starken Varix, innen erst glatt, dann mit einer gezähnelten Lippe, im Gaumen gereift. Die Spindel ist nur an Eingang der Perforation etwas umgeschlagen, sonst senkrecht, mit drei deutlichen Falten, der Callus auf der Mündungswand sehr dünn.

Aufenthalt an Ceylon, die beiden abgebildeten Exemplare mit zwei fast gleichen in meiner Sammlung.

Ich sehe nicht recht ein, warum diese Art von C. obliquata abzutrennen ist; der einzige Unterschied ist die etwas schlankere Gestalt; die gegliederte Zeichnung kommt bei beiden Formen vor.

*) C. testa ovali, subventricosa; costis numerosis, crenulatis, ad angulum anfractuum in angulum obtusum productis, ultimo prope marginem in varicem elevato; interstitiis obsolete striatis; spira turrita, producta; anfractibus angulatis, ad suturam excavatis; apertura postice canalifera et uniplicata, interne laevi, prope marginem sulcata, margine laevi; canali antico brevi; umbilico sulcato; colore roseo, costis fusco punctatis. - Sow.

*) C. testa ovato-conoidea, anguste profunde umbilicata, spira acute exserta, anfractibus ad suturam anguste subprofunde excavatis, deinde convexis, oblique longitudinaliter subtiliter costatis, spiraliter obscure liratis, costis minute nodulatis, nodulis ad angulum prominentioribus; livido-carnea, nodulis albidis; apertura trigono-ovata, subexpansa, fauce valide lirata, columella triplicata. - Reeve. 


\title{
58. Cancellaria Lamberti Souverbie.
}

\author{
Taf. 17. Fig. 12. 13.
}

Testa late et profunde perforata, ovato-elongata, spira scalata, subturrita, apice acuto, solida, crassiuscula, alba vel carneola costis albis, interdum obscure bifasciata, spiraliter lirata, oblique costata, costis crassiusculis, ad intersectiones lirarum nodulosis, interstitiis quam costae multo latioribus, ad angulum acute tuberculatis. Anfractus $\left.5^{1}\right|_{2}-6$ leniter crescentes, convexiusculi, suprà angulum excavati et a costis anfractum superiorem attingentibus profunde concamerati; anfractus ultimus obliquus, spirae longitudinem vix superans, basi circa perforationem in cristam serratam compressus. Apertura trigono-ovata, basi compressa et effusa, peristomate continuo albido; labro acuto, subpatulo, mox intus incrassato et denticulato, faucibus liratis, fuscis; margine supero tuberculo pliciformi munito; columella fere verticalis, distincte triplicata, supra super perforationem subreflexa.

Long. 14, diam. 10, alt. apert. 8,5 $\mathrm{Mm}$.

Cancellaria Lamberti Souverbie*) in Journal de Conchyliologie vol. XVIII 1870 p. 428 tab. 14 fig. 2 .

Gehäuse weit und tief durchbohrt, langeirund mit treppenförmigem ziemlich gethürmtem Gewinde und spitzem Apex, für ihre Grösse dick und festschalig, weiss oder wenigstens zwischen den Rippen lebhaft fleischfarben, bei einem meiner Exemplare auch undeutlich gebändert, mit deutlichen Spiralreifen und mit starken schrägen Rippenfalten skulptirt, welche viel schmäler als ihre Zwischenräume und an den Schnittstellen knotig verdickt sind; sie springen auf der Kante in spitzen Schuppenhöckern vor und laufen dann etwas niedriger bis zum vorhergehenden Umgang, so dass der Raum über der Kante hübsch gekammert erscheint. Es sind knapp sechs Umgänge vorhanden, die langsam zunehmen; mit Ausnahme der embryonalen sind sie oben scharf kantig und über der Kante ausgehölht, unter ihr gut gewölbt; der letzte Umgang ist kaum länger, als das Gewinde, schief, an der Basis zu einer gesägten, die Perforation umgebenden Kante zusammengedrückt. Die Mündung ist abgerundet dreieckig, unten zu einem Ausguss zusammengedrückt, der Mundsaum zusammenhängend, der Aussenrand scharf, etwas geöffnet, innen mit einer verdickten Lippe, weisslich, der Gaumen gerippt, bräunlich; der Oberrand trägt eine starke eindringende Höckerfalte; die Spindel ist fast senkrecht gerichtet, leicht ausgehöhlt, nur über den Eingang der Perforation leicht zurückgeschlagen, mit drei deutlichen weissen Falten.

*) Testa umbilicata, ovato-subelongata, subcrassa, scalariformis, longitudinaliter et suboblique costato-plicata, spiraliter subcostulata; alba vel albo-subcarneola; anfr. $5^{1} / 2$ cylındrico-subconvexi, superne angulati, supra subplano-concavi, ad angulum ob exasperationem costarum tuberculis parviusculis coronati; ultimus obliquus, dimidium longitudinis testae non aequans; apertura trigono-semilunaris, intus sulcata, superne uniplicata; labro subcampanulato, margine dextro reflexo, sinistro ad umbilicum sublatum, profundum et carina circumdatum reflexo; columella subobliqua vel verticalis triplicata. Souv. 
Aufenthalt im neucaledonischen Archipel. Das abgebildete Exemplar aus meiner Sammlung. Sie dürfte bei reichem Material sich auch als ein Glied desselben Formenkreises erweisen, welchem obliquata und articularis angehören.

\section{Cancellaria Souverbiei Crosse.}

Taf. 17. Fig. 14. 15.

„T. umbilicata, elongato-pyramidata, sat nitida, costis longitudinalibus subobliquis, granulosis, ad angulum unfractuum obtuse muricatis, et striis spiralibus obsoletis, subdistantibus impressa, violaceo-cinnamomea, fulvido transversim multilineata; spira elongata, apice obtusulo, sutura late et sat profunde excavata; anfr. 7, embryonales primi 2 laeves, rotundati, luteo-castanei, sequentes angulati, non convexi, ultimus spiram subaequans, circa umbilicum mediocriter amplum, profundum luteo-albidus; apertura ovato-triangularis, intus liris brunneis impressa; peristoma simplex, album, margine columellari triplicato, externo intus subincrassato, versus limbum acuto, castaneo-maculato, ad angulum intus unidentato. - Long. 17, diam. maj. $10 \mathrm{Mm}$, apert. cum perist. 9 Mm. longa, 5 lata." Cancellaria Souverbiei Crosse Journ. Conch. XVI 1868 p. 272 t. 9 fig. 5.

Gehäuse genabelt, länglich pyramidal, ziemlich glänzend, mit etwas schrägen gekörnelten Rippen skulptirt, welche an der Kante der Umgänge als leichte Höcker vorspringen; die Spiralskulptur besteht aus ziemlich weitläufigen undeutlichen Linien. Die Färbung ist zimmetbraun mit einem Stich ins Violette; nach dem Mundrand hin erkennt man einige braune Striemen; die Rippen heben sich heller ab. Das Gewinde ist ziemlich hoch, die Naht breit und tief ausgehöhlt; die Rippen laufen bis zum vorhergehenden Umgang durch und bilden eine Anzahl Kämmerchen längs der Naht. Es sind beinahe sieben Umgänge vorhanden, von denen zwei auf den glatten braunen Apex kommen; die folgenden sind oben kantig, dann gewölbt, der letzte ist ungefähr so hoch wie das Gewinde und um den tiefen, mässig weiten Nabel herum weisslich. Die Mündung ist rundlich dreieckig, im Gaumen gerippt, mit braunen Zwischenfurchen; Mundrand scharf, weiss, am Rande leicht braun gefleckt, oben mit einem Höcker im Raum zwischen Kante und Spindel; diese letztere trägt drei Falten.

Aufenthalt unbekannt, Abbildung und Beschreibung nach Crosse.

Ich besitze kein Exemplar, das die Crosse'sche Abbildung genau deckt, aber nach dem Bilde sehe ich keinen rechten Unterschied zwischen dieser Art und Canc. Lamberti; etwas schlankere Gestalt, leicht abweichende Färbung und ein Umgang mehr können kaum einen Artunterschied begründen. Im Fall einer Vereinigung hat übrigens der Crosse'sche Name die Priorität.

IV. 4. 


\section{Cancellaria Moutrouzieri Souverbie. \\ Taf. 18. Fig. 1. 2.}

„T. anguste umbilicata, ovato-turrita, scalaris, crassa, nitidiuscula, pallide cinnamomea, hic illic longitudinaliter rufo-fasciata; anfr. $51 / 2$ (embryonalibus $11 / 2$ laevibus, pallidioribus) superne biplanis et obtuse bicarinatis, infra carinam inferiorem usque ad ultimum anfractum dorso convexum et spiram superantem subobconicis, plano-subconvexis, longitudinaliter et suboblique dense costatis, spiraliter plicatulo-costulatis et minute impresso-striatis; carınis ad occursum costularum undulatis; columella verticalis candida, oblique et aequidistanter triplicata; apertura mediocris, semiovalis, alba, in fundo subcinnamomeo tincta, fauce longilirata; margine dextro crasso, extus acuto, inferne ad canalem subsinuoso; columellari extus brevissime lamelloso, superne ad umbilicum angustum, punctiformem fornicatim reflexo. - Long. 15, lat. $10 \mathrm{Mm}$; apert. $9 \mathrm{Mm}$. longa, 5 lata." (Souv.).

Cancellaria Montrouzieri Souverbie Journ. Conch. XI 1863 p. 163 t. 5 fig. 8.

Gehäuse eng genabelt, gethürmt eiförmig, mit treppenförmigem Gewinde, festschalig, etwas glänzend, blass zimmetbraun mit undeutlichen röthlichen Binden; es sind $5^{1} /_{2} \mathrm{Um}$ gänge vorhanden; die $1 \frac{1}{2}$ embryonalen sind glatt und heller, die folgenden obenher abgeflacht, die Abflachung wegen eines auf derselben laufenden Kieles doppelt erscheinend, dann stumpfkantig, schwach gewölbt, unten zusammengezogen, so dass sie verkehrt kegelförmig erscheinen, mit etwas schrägen dichtstehenden Faltenrippen skulptirt und von feineren Spiralreifen und eingedrückten Linien umzogen; der letzte Umgang ist aufgeblasen und länger als das Gewinde. Die Mündung ist mittelgross, halbeirund, weiss, in dem geripptem Gaumen bräunlich; der Aussenrand ist scharf, aber nach innen rasch verdickt, unten am Eingang des Kanales leicht ausgebuchtet; die Spindel ist fast senkrecht mit einem weissen kurz abstehenden Callus belegt, welcher sich über den punktförmigen engen Nabel tütenförmig zurückschlägt; sie trägt drei gleichweit von einander abstehende schräge Falten.

Aufenthalt an der neucaledonischen Insel Art; Abbildung und Beschreibung nach Souverbie.

Diese Art ist von Souverbie auf ein einzelnes Exemplar hin gegründet worden und meines Wissens existirt noch kein zweites. Allem Anschein nach handelt es sich hier nur um eine Abnormität der folgenden, ungleich häufigeren Art; der Hauptunterschied liegt in der Kante, welche die Abflachung unter der Naht noch einmal theilt.

\section{Cancellaria Forestieri Montrouzier,}

\section{Taf. 18. Fig. 3. 4.}

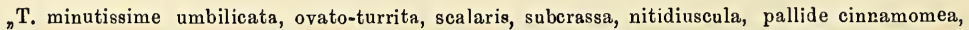
hic illic longitudinaliter subrufulo-fasciata vel maculata; anfr. $51_{2}^{1}$ (embryonalibus $11 / 2$ laevibus, palli- 
dioribus), superne acute carinatis, supra carinam plano-concavis, infra usque ad ultimum anfractum subventricosum et spiram superantem cylindraceis plano-subconvexis, longitudinaliter et suboblique plus minusve dense costatis, spiraliter subplicatulo-costulatis et minute impresso-striatis; costis longitudinalibus carinam crenulantibus et ad suturam obliquissime radiantibus. Columella verticalis, candida, obliquissime et inaequidistanter triplicata; apertura satis ampla, truncato-semilunaris, alba, in fundo subcinnamomeo tincta; fauce ad marginem brevilirata; margine dextro acuto, inferne ad canalem subsinuoso, columellari extus brevissime lamelloso, subreflexo; umbilicum minimum suboccultante et in rimulam mutante. - Alt. $\left.17^{1}\right|_{2}$, lat. $11 \mathrm{Mm}$., apert. $\left.101\right|_{2} \mathrm{Mm}$. alta, $\left.51\right|_{2}$ 1ata." (Montr.).

Cancellaria Forestieri Montrouzier Journ. Conch. XI 1863 p. 161 t. 5 fig. 7.

Gehäuse ganz eng genabelt, gethürmt eiförmig, mit treppenförmigem Gewinde, ziemlich festschalig, etwas glänzend, blass zimmetbraun mit undeutlichen rothen Flecken und Striemen. Von den $5 \frac{1}{2}$ Umgängen sind die $1 \frac{1}{2}$ embryonaleu glatt und heller, die folgenden oben scharf kantig, über der Kante leicht ausgehöhlt, dann etwas gewölbt, mit schrägen dichten Längsrippen versehen, welche an der Kante höckerig vorspringen und dann schräg zur Naht verlaufen; die Spiralskulptur besteht aus feinen dichten eingedrückten Linien und stärkeren Reifen. Die Spindel ist senkrecht, weiss, mit drei ungleichen und in ungleichen Abständen stehenden schrägen Falten. Die Mündung ist verhältnissmässig gross, abgestutzt halbmondförmig, weiss mit zimmtbraunem Gaumen, der Aussenrand scharf, innen mit einer Reihe kurzer Rippchen, unten am Kanal leicht ausgebuchtet, die Spindelplatte ist unten gelöst und leicht über den Nabel zurückgeschlagen; so dass nur ein feiner Ritz bleibt.

Aufenthalt an der neukaledonischen Insel Art. Abbildung und Beschreibung nach Montrouzier 1. c.

Wahrscheinlich nur eine Varietät des Formenkreises der Canc. scalata.

\section{Cancellaria Rougeyroni Souverbie.}

Taf. 18. Fig. 5. 6 .

„T. umbilicata, ovato-elongata, subventricosa, scalaris, sat crassa, longitudinaliter et suboblique costata, spiraliter subplicato-costulata et impresso-striata, albo-subflavidula, spiraliter cinnamomeoplurifasciata; anfr. $\left.61\right|_{2}$ superne angulati, supra plano-concavi, ad angulum tuberculis coronati, primi $11 / 2$ laevigati, albi, ceteri usque ad ultimum turgidulum, inferne attenuatum et dimidiam longitudinis testae superantem cylındraceo-subconvexi; apertura trigono-semilunaris, alba, intus fere usque ad limbum sulcata, superne tuberculata, margine dextro acuto, sinistro superne appresso, inferne lamellose erecto; columella verticalis, obliquissime triplicata; umbilicus angustissimus, profundus. - Long. 28 , lat. $\left.181\right|_{2} \mathrm{Mm}$.. apert. $16 \mathrm{Mm}$. longa, 10 lata." - (Souverbie).

Cancellaria Rougeyroni Souverbie Journ. Conch. XVIII 1870 t. 14 fig. 1. 
Gehäuse genabelt, lang eirund mit gethürmtem treppenförmigem Gewinde, ziemlich dickschalig, mit schrägen stumpfen zahlreichen Rippen skulptirt, welche von Spiralreifen und eingedrückten Linien geschnitten werden. Es sind $6 \frac{1}{2}$ Umgänge vorhanden, von denen $1 \frac{1}{2}$ auf den glatten Apex kommen; die folgenden sind oben abgeflacht und dann von einer höckerigen Kante umzogen, dann schwach gewölbt, cylindrisch, der letzte nimmt über die Hälfte der Gesammtlänge ein und ist obenher etwas aufgetrieben, nach der Basis hin verschmälert. Die Mündung ist gerundet dreieckig, weiss, innen scharf gerippt, oben mit einem starken Höcker, der mitunter gespalten erscheint; Aussenrand schneidend, nach innen rasch verdickt; die Spindel ist senkrecht; der oben angedrückte, unten lostretende Spindelcallus trägt drei sehr schräge Falten, von denen die unteren kleiner sind und nach aussen convergiren. Die Färbung ist weisslich mit zahlreichen schmalen braunen Bändern.

Aufenthalt an der Insel Art. Abbildung und Beschreibung nach Souverbie.

Ich habe mir diese Art nicht verschaffen können; nach der Abbildung möchte ich sie trotz der fast doppelten Grösse und des Umganges mehr für eine Varietät der vorigen halten.

\section{Cancellaria littorinaeformis Sowerby.}

Taf. 18. Fig. 9. 10. 13. 14.

Testa ovata vel globoso-ovata, spira brevi, apice acuto, late et profunde perforata, tenuicula sed solida, unicolor rufescens vel rufescenti-castanea; anfractus 6 rapide crescentes, primum ad suturam planati, dein convexi, liris spiralibus et concentricis undique decussati, ultimus globosus, inflatus, spirae longitudinem fere duplo superans, circa umbilicum leviter compressus. Apertura ovato-trigona, basi subcanalıculato-effuea, labro simplici, subtilissime crenulato, faucibus liratis, columella distincte triplicata, super perforationem reflexo, ad parietem aperturalem tenuissima.

Long. spec. depicti 17 , diam. 14, alt. apert. 16,5 Mm.

- icon. Reeveani 24, diam. 19, alt. apert. $14 \mathrm{Mm}$.

Cancellaria littorina eformis Sowerby*) Conchological Illustrations fig. 14. Thesaurus Conchylior p. 450 pl. 92 fig. 5. 6. 9 .

Reeve*) Conchologia iconica sp. 62.

Gehäuse eiförmig bis eiförmig kugelig mit kurzem Gewinde und spitzem Apex, weit und tief durchbohrt, nicht dickschalig doch fest, einfarbig rothbraun bis kastanienbraun;

*) C. testa rotundata, minute granulatim decussata; spira obtusa; sutura nonnunquam sub. scalata; apertura interne costata, columella triplicata, umbilicata; colore fusco. -

**) Can. testa ovata, profunde umbilicata, tenuicula, anfractibus superne anguste angulatis, deinde declivi-convexis, undique decussatim striatis; rufescente-castanea; apertura subanguste ovata, columella triplicata. - Reeve. 
es sind sechs rasch zunehmende Umgänge vorhanden, welche mit Ausnahme der embryonalen unter der Naht abgeflacht, dann gut gewölbt sind, sie erscheinen durch Spiralreifen und feine concentrische Rippchen gegittert. Der letzte Umgang ist kugelig, aufgeblasen, ziemlich noch einmal so lang wie das Gewinde, um den Nabel herum leicht zu einer stumpfen Kante zusammengedrückt. Die Mündung ist rundlich dreieckig, unten mit deutlichem rinnenförmigem Ausguss; der Mundsaum ist einfach, scharf, nur ganz fein gezähnelt, der Gaumen deutlich gerippt; die Spindel trägt drei deutliche Falten, von denen die untere am Beginn der Rinne horizontal nach innen vorspringt, während die beiden oberen mehr schräg verlaufen; die Spindelplatte schlägt sich oben über den Eingang der Perforation zurück und ist auf der Mündungswand kaum sichtbar.

Aufenthalt an Ceylon, das Fig. 9. 10 abgebildete Exemplar in meiner Sammlung.

C. littorinaeformis bildet den Mittelpunkt für eine Gruppe, zu welcher C. Verreauxi Kiener, coctilis Reeve und nassa Deshayes gehören, bei grösserem Material werden sie wohl als Varietäten einer Art erkannt werden. Das vorliegende Exemplar entspricht zwar in der Skulptur ganz der Sowerby'schen resp. Reeve'schen Diagnose, ähnelt aber in der Gestalt und Färbung schon viel mehr der C. Verreauxi, welche sich aber wieder durch gröbere Skulptur unterscheidet. Mein Exemplar stellt nicht ganz den Typus dar, ich gebe darum auch eine Copie der Sowerby'schen Figur. (Fig. 13. 14).

\section{Cancellaria Verreauxi Kiener.}

Taf. 18. Fig. 7. 8.

Testa ovata, perforata, spira breviter turrita, apice acuto, solidula, unicolor fusco-vel castaneorufa. Anfractus 6 infra suturam impressi, angulati, dein convexi, plicis obliquis et liris distantibus ad costas nodosis sculpti, interstitiis spiraliter striatis, lira ad angulum duplici; anfractus ultimus subinflatus, spirae longitudinem superans, circa umbilicum vix compressus. Apertura ovato-subırıgona, basi effusa, labro acuto, simplici, denticulato, faucıbus liratis, columella triplicata, ad insertionem super perforationem reflexo, callo parietali tenuissimo.

Long. 19, diam. 14, alt. apert. 11,5 $\mathrm{Mm}$.

Cancellaria Verreauxi Kiener Coq. vivantes p. 17 t. 8 fig. 3.

- $\quad$ - Reeve Concholog iconica sp. 59.

- $\quad$ - Sowerby Thesaurus Conchyl p. 450 t. 93, f. 28.

Gehäuse eiförmig oder etwas gethürmt, durchbohrt, mit kurz gethürmtem Gewinde und spitzem Apex, festschalig, einfarbig heller oder dunkler braunroth; die sechs bis sieben Umgänge sind unter der Naht abgeflacht und etwas eingedrückt, dann kantig und unter der Kante gut gewölbt, und mit schrägen concentrischen Rippenfalten und ziemlich entfernt stehenden Spiralreifen hübsch gegittert; die Schnittstellen sind knotig verdickt, 
in den Zwischenräumen verlaufen schwächere Spirallinien; der Spiralreif an der Kante ist meistens doppelt. Der letzte Umgang erscheint etwas aufgeblasen, ist länger als das Gewinde und um die Perforation herum kaum zusammengedrückt. Die Mündung ist eiförmig, etwas dreieckig, unten zu einem Ausguss verengt, der Mundrand einfach, scharf, leicht gezähnelt, im Gaumen gerippt. Die Spindel trägt drei deutliche Falten, genau wie bei C. littorinaeformis, und ist in derselben Weise über den Eingang der Perforation zurückgeschlagen; der Beleg auf der Mündungswand ist ganz dünn.

Aufenthalt unbekannt, das abgebildete Evemplar aus meiner Sammlung.

C. Verreauxi unterscheidet sich von littorinaeformis nur durch gröbere Skulptur.

\section{Cancellaria coctilis Reeve.}

Taf. 18. Fig. 11. 12.

Testa ovato-globosa, lato perforata, spira breviuscula, apice acuto, unicolor rufescens, solidula; anfractus 7 tumiduli, supra planati et leviter obtuse angulati, spiraliter lirati et costis concentricis ad intersectiones lirarum nodosis sculpti, ultimus $3 / 5$ longitudinis occupans, circa umbilicum vix compressus. Apertura irregulariter ovata, basi effusa, labro tenui, leviter crenulato, faucibus tenuiter liratis, columella tenui triplicata, super umbilicum reflexa, callo ad parietem aperturalem vix conspicuo.

Long. 16, lat. 11 , alt. apert. $10 \mathrm{Mm}$.

Cancellaria coctilis Reeve*) Concholog. icon. sp. 79.

Gehäuse eiförmig kugelig mit kurzem aber spitzem Gewinde, weit und tief durchbohrt, einfarbig röthlich, ziemlich dünnschalig, doch fest. Die sieben stark gewölbten, fast aufgeblasenen Umgänge sind mit Ausnahme der embryonalen nächst der Naht abgeflacht und haben dann eine stumpfe undeutliche Kante; sie sind mit Spiralreifen umzogen und tragen zahlreiche deutliche Rippen, welche da, wo sie die Reifen schneiden, knotig verdickt sind. Der letzte Umgang nimmt drei Fünftel der Gesammtlänge ein und ist um den Nabel herum nur leicht zusammengedrückt. Die Mündung ist unregelmässig eirund, unten mit leichtem Ausguss; der Aussenrand ist dünn, leicht gezähnelt, der Gaumen schwach gerippt; die Spindel ist dünn, mit drei deutlichen Falten, an ihrem Ansatz ist sie über die Pertoration zurückgeschlagen, auf der Mündungswand ist ein Callus kaum erkennbar.

Eine seltene Art unbekannten Fundortes. Mein einziges, aus der Taylor'schen Sammlung erworbenes Exemplar unterscheidet sich von der Reeve'schen Abbildung durch bedeutendere Grösse, - jene ist nur $11 \mathrm{~mm}$ hoch, - geringere Abplattung an der Naht und schwächere Skulptur; es führt dadurch schon ganz entschieden zu C. littorinaeformis hinüber, die offenbar die nächste Verwandte unserer Art ist und deren Vaterland, den vorderen indischen Ocean, speciell Ceylon, sie wohl theilen wird. 


\section{Cancellaria funiculata Hinds.}

Taf. 18. Fig. 15. 16.

Testa acuminato-ovata, umbilicata, spirae suturis profunde impressis, anfractibus 6 ad 7 subangustis, rotundatis, prominentibus, longitudinaliter costatis, costis elevatis, compressis, distantibus, e suturis descendentibus, liris tenuibus spiraliter regulariter sculptis, linea elevata interveniente; columella triplicata, plica antica subobsoleta; apertura trigono-ovata, parva, subeffusa; albicans, costis pallide fuscescentibus. - Ad. et Reeve.

Alt. (ex icone) 20, diam. 13, alt. apert. $9 \mathrm{Mm}$.

Cancellaria funiculata Hinds**) Zoolog. Voy. Sulph. Moll. p. 43 tab. 12 fig. 5. 6. Sowerby Thes. Conch. p. 454 pl. 96 fig. 96.97.

- lyrata Adams et Reeve Voy. Samarang Zool. Moll. p. 42 pl. 10 fig. 4.

- funiculata Reeve Conchol. icon. sp. 68.

Gehäuse ziemlich spitz eiförmig, mit offenem, von einer Kante umgebenem Nabel und tief eingedrückter Naht, weisslich mit hellbräunlichen Rippen. Es sind sechs bis sieben gewölbte, oben kantige Umgänge vorhanden, welche mit ziemlich schmalen, entferntstehenden, aber hohen, gewölbten Rippenfalten, die unverändert, bis zur Naht durchlaufen, skulptirt sind und von regelmässigen Spiralreifen umgeben werden, zwischen welche sich immer noch eine schwächere Linie einschiebt. Die Mündung ist dreieckig eiförmig, unten nur zu einem Ausguss zusammengedrückt, verhältnissmässig klein, im Gaumen stark gefurcht, die schwielige Spindel mit drei Falten, von denen die unterste am kleinsten ist. Aufenthalt nach Hinds im Golf von Nicoya an der Westküste von Centralamerika, nach Adams und Reeve im chinesischen Meere.

Ich habe mir diese Art nicht verschaffen können und gebe die Beschreibung nach Adams und Reeve. Für die Identität mit C. lyrata verbürgt sich Crosse und in der That bieten Abbildung und Diagnose keinerlei Anhalt für ihr Abtrennung; bezüglich der Vaterlandsangabe kann wohl ein Irrthum untergelaufen sein. Reeve nennt auch Centralamerika, speciell den Golf von Magdalena, also wird diese Angabe wohl die richtige sein. Für alle Fälle habe ich die Figur der Voy. Samarang und die des Thesaurus kopiren lassen; die letztere ist etwas kleiner und schlanker. Bei Reeve zeigt die Vorderansicht die Spiralskulptur nur auf den Rippen, die Rückenansicht auch in den Zwischenräumen.

*) Can. testa ovato-globosa, anguste profunde umbilicata, spira breviuscula, acuta; anfractibus tumidis, superne obtuse angulatis, rude nodoso-costatis, transversim liratis; rulescente; apertura subquadraro-ovata, ad basin attenuata, columella trıplicata. -

**) C. testa ovali, elongata; anfractibus senis, costatis, superne subangulatis; costis subdistantibus, elevatis rotundatis, nodulosis, lineis elevatis decussatis; sutura profunda; labro intus sulcato; columella plicis tribus parvis; umbilico marginato; canali subnullo - Hinds. 


\section{Cancellaria elata Hinds. Taf. 18. Fig. 17. 18.}

Teeta ovata, elongata, acuminata, anfractibus septenis, costatis, soperneangulatis, lineis elevatis decussatis; sutura profunda; apertura ovali, peritremate superne disjuncto; labro intus sulcato; columella triplicata; plıca inferiore maxima; umbilico parvo subocculto; canali inflexo. - Hinds.

Alt. (ex icone) 17, diam. 9, alt. apert. 7,5 $\mathrm{Mm}$.

Cancellaria el ata Hinds Zoology Voy. Sulphur Moll, p. 43 pl. 12 fig. 3. 4.

- $\quad$ - Sowerby Thesaur. Conchyl. p. 454 pl. 96 fig. 94.95.

- $\quad$ - Reeve Conchol. icon. sp. 83.

Gehäuse verlängert eiförmig, zugespitzt, mit deutlichem zurückgebogenem Stiel, aus sieben oben scharfkantigen Umgängen bestehend, welche mit ziemlich dicht stehenden, an der Kante höckerigen Rippen und erhabenen Spiralreifen skulptirt sind und durch eine tiefe Naht geschieden werden. Die Mündung ist unregelmässig eiförmig mit deutlichem, zurückgebogenem Canal, der Mundrand oben nicht zusammenhängend, (die Abbildung lässt das nicht erkennen), der Gaumen ist gefurcht; der Stiel hat einen engen, fast verdeckten Nabel.

Aufenthalt bei Panama, in etwa 30 Faden Tiefe. Ich habe mir diese Art nicht verschaffen können und gebe Abbildung und Beschreibung nach Sowerby. Auch Reeve hat die Art nie gesehen.

\section{Cancellaria scalata Sowerby.}

Taf. 19. Fig. 1-6.

Testa ovato-turrita, spira producta, scalata, tenuiuscula, albida, rosea vel fulva unicolor; anfr. $6{ }^{1} / 2$, embryonales 2 laeves, rotundati, sequentes angulati, super angulum plano-excavati, infra convexıusculi, ad suturam coarctati, costis longitudinalibus parum elevatis, ad angulum subtuberculatis, super eum evanescentıbus, lirisque spiralibus distantibus super costas leviter granosis sculpti, interstitiis sub lente decussatis; anfractus ultimus tumidus, basi attenuatns, plerumque rimatus. Apertura ovato-angulata, alba, faucibus subtilissime sulcatis, labro simplice, vix incrassato, super angalum costa intrante munito; columelı callo tenui, angusto, triplicato, rarius quadriplicato.

Long. 24, diam, 15, alt. apert. $12 \mathrm{Mm}$.

Cancellaria scalata Sowerby*) Concholog. Illustrations fig. 27. Thesaurus Conchyl. p. $455 \mathrm{Nr}, 55 \mathrm{pl}, 93 \mathrm{fig} .26$.

*) C. testa turrita; costis numerosis, noduliferis; spira producta; anfractibus angulatis, ad suturam excavatis; apertura postice canalifers et uniplicata, interne costata; columella triplicata; umbilico parvo; colore fulvo, apertura alba. Sow. 
$\begin{array}{ccl}\text { Cancella ria scalata } & \text { Reeve Concholog. icon. sp. } 19 . \\ - & - & \text { Kiener Coq. vivantes tab. } 7 \text { fig. } 4 . \\ - & - & \text { Deshayes*) Lam. Anim. sans vert. ed II tome } 9 \text { p. } 411 .\end{array}$

Gehäuse gethürmt eiförmig, mit ziemlich hohem, treppenförmigem Gewinde, ziemlich dünnschalig, weisslich, rosa oder hellbraun, meist einfarbig, doch auch mit einzelnen unregelmässigen orangefarbenen Flecken. Es sind über sechs Umgänge vorhanden; die beiden ersten embryonalen sind winzig klein, glatt und gerundet; die folgenden haben eine auffallende, von der Naht ziemlich weit abliegende Spiralkante und sind oberhalb derselben wagerecht abgeflacht oder selbst ausgehöhlt, unterhalb derselben leicht gewölbt und an der Naht eingeschnürt; die Skulptur besteht aus zahlreichen schwachen gerundeten Rippenfalten, welche an der Kante höckerig vorspringen und von da bis zur Naht meistens verkümmern, und aus ungefähr ebensoweit von einander abstehenden Spiralreifen, welche auf den Rippen sich zu einem Knötchen oder einem schwachen Höcker verdicken; die fast quadratischen Zwischenräume erscheinen unter der Loupe durch Spirallinien und die Anwachsstreifen fein gegittert. Im einzelnen variirt diese Skulptur aber ungemein. Beim Typus (Fig. 1. 2) sind die Rippen und die Reifen fast gleichstark, wie auch bei dem von Sowerby abgebildeten Exemplar, das nur etwas grösser ist (alt. $28 \mathrm{Mm}$.). Bei dem zweiten (Fig. 3. 4) treten die Spiralreifen fast ganz zurück, während die Rippen breiter sind, bei dem dritten besonders lebhaft gefärbten sind die Rippen scharf und hoch, die Spiralreifen aber zu feinen Linien geworden, welche trotzdem deutliche Knötchen bilden. Der letzte Umgang ist aufgeblasen, unten verschmälert; er hat meistens einen deutlichen Nabelritz oder eine enge Perforation. Die Mündung ist gerundet dreieckig oder eckig eirund, unten zu einer Ausgussrinne zusammengedrückt, oben bei ganz ausgebildeten Exemplaren in Folge der Entwicklung einer starken eindringenden Höckerleiste oberhalb der Kante des Aussenrandes auch mit einer Art Canal, der aber bei schwachschaligen Stücken häufig fehlt; der Gaumen ist weiss, nur fein gestreift. Der Aussenrand ist einfach, stumpf, kaum verdickt, die Spindel trägt einen schmalen dünnen Callus mit drei deutlichen und häufig noch einer undeutlicheren schwachen obersten Falte.

Aufenthalt im vorderen indischen Ocean, speciell an Ceylon, von wo auch die drei abgebildeten Exemplare meiner Sammlung stammen sollen.

**) C. testa ovato-acuta, scalariformi, fuscescente, transversim albo-lineolata, longitudinaliter costato-crenulata; anfractibus superne canaliculatis; apertura alba, ovata; labro tenui, intus sulcato; columella quadriplicata. Long. 20, diam, $12 \mathrm{~mm}$. Desh.

IV. 4. 


\title{
69. Cancellaria s calata Sowerby var.?
}

\author{
Taf. 19. Fig. 7. 8.
}

Differt a typo testa minore, graciliore, costis numerosis, ad angulum bituberculatis, colore rufopurpurea, ad angulum maculis albis ornata.

Alt. 21, diam. 13, alt. apert. $12 \mathrm{Mm}$.

Im meiner Sammlung befindet sich das abgebildete, von mir aus der Taylor'schen Sammlung erworbene Exemplar, das auf den ersten Blick weit von Cancellaria scalata verschieden erscheint, sich aber doch schliesslich nicht wohl, namentlich nicht von dem Fig. 5. 6 abgebildeten Exemplare trennen lässt. Die Färbung ist dunkel purpurbraun, auch der Gaumen braun, die Nabelkante ist heller und an der oberen Kante sind die deutlich doppelten Höcker der Rippen weiss, besonders nach der Mündung hin; auch die Spiralreifen heben sich etwas heller ab. Das ganze Gehäuse ist kleiner, schlanker, die Rippen sind zahlreicher, schärfer, die obere Kante ist, was übrigens auch schon bei dem Fig. 5. 6 abgebildeten Exemplare zu erkennen ist, deutlich doppelt. Die Spindelbildung ist ganz wie beim Typus, mit vier Falten.

Ein genauer Fundort ist mir nicht bekannt.

Reeve's Abbildung von C. scalata stellt ein Exemplar dar, welches erheblich von meinen und den Sowerby'schen abweicht; es ist $32 \mathrm{~mm}$ lang, die Skulptur auffallend stark mit vorspringenden Knötchen an den Kreuzungsstellen. Es scheint kaum möglich, sie zu derselben Art zu rechnen, wie die hier beschriebene Varietät.

\section{Cancellaria costifera Sowerby.}

Taf. 19. Fig. 9-14.

Testa turrita, oblongo-fusiformis, spira acuminata, scalata, solida, albida, pallide fulvo late bifasciata et lineis aurantiacis geminatis ornata. Anfractus 7, superi 2 embryonales laeves rotundati, sequentes supra distincte angulati, super angulum subexcavati, infra convexiusculi, costis distantibus vel rotundatis vel subcrenulatis, ad angulum acute tuberculatis et usque ad suturam continuatis sculpti, sculptura spirali obsoletissima; ultimus spiram haud aequans, basi compressus. Apertura ovato-triangularis, supra truncata, basi effusa, labro acuto sed mox valde incrassato, super angulum callo valido intrante munito, faucibus liratis; columella subplanata, callo appresso induta, triplicata, plica supera majore.

Long. spec. dep. 21, diam. 12, alt. apert. $10 \mathrm{Mm}$.

*) C. testa turrita, oblongo-ovali; costis distantibus, subcrenulatis, validis, ad angulum anfractuum elevatis; spira acuminata, anfractibus acute angulatis; apertura interne obsolete costata; postice subangulata, colore pallide fulvo, vel interstitiis rosea, vel fusca. Sow. 
Cancellaria costifera Sowerby ) Conchol, Illustr. fig. 31 . - Thesaurus Conch. p. 456 pl, 95 fig. 65. 66. 71 .

Reeve ${ }^{*}$ ) Conchol. icon. sp. 57.

Gehäuse gethürmt eiförmig, spindelförmig mit spitzem treppenförmigem Gewinde, festschalig, weisslich mit zwei breiten, nur durch einen schmalen Streifen getrennten Binden, in welchen zahlreiche orangefarbene Linienpaare laufen. Von den sieben Umgängen, sind die beiden embryonalen glatt und gerundet, die tolgenden obenher deutlich gekantet und über der Kante ausgehöhlt, unter derselben gewölbt, mit gerundeten oder leicht gekerbten Rippen skulptirt, welche an der Kante höckerartig vorspringen zur Naht durchlaufen; sie stehen ziemlich entfernt von einander; eine Spiralskulptur ist

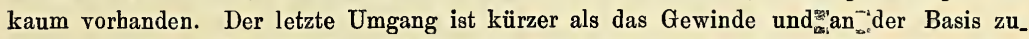
sammengedrückt. Die Mündung ist eiförmig dreieckig, oben horizontal abgestutzt, unten zu einem Ausguss verengt; die Aussenlippe ist scharf, aber dann rasch innen verdickt, oben über der Kante mit einem starken eindringenden Wulst; der Gaumen ist scharf gerippt; die Spindel erscheint eigenthümlich abgeflacht und ist mit einem fest angedrückten Callus belegt, welcher drei Falten trägt, von denen die oberste am stärksten ist.

Aufenthalt im chinesischen Meer und an den Philippinen; das abgebildete Exemplar mit einem fast gleichen in meiner Sammlung, von Taylor erworben.

Diese Art scheint äusserst variabel. Sowerby bildet im Thesaurus drei Exemplare ab, von denen Fig. 71 bis auf etwas grössere Breite ganz meinen beiden entspricht. Die beiden anderen (Fig. 65 und 66) weichen aber so erheblich ab, dass ich mich veranlasst sehe, sie der Vollständigkeit halber (Fig. 11 und 12) zu kopiren. Auf Fig. 66 (unsere Fig. 11) lassen sich, die Grösse abgerechnet, zwei ganz gleiche Exemplare beziehen, welche ich ebenfalls aus der Taylor'schen Sammlung als C. costifera var. erwarb und von denen ich das eine Fig. 13. 14 abbilde. Dieselben sind erheblich kleiner, nur $14 \mathrm{Mm}$. hoch und zeichnen sich durch schäfere, mehr zusammengedrückte, am Rande leicht gekerbte Rippen, deutlichere Spiralskulptur und reichere Färbung aus; die Färbung ist übrigens nach dem. selben Princip angeordnet, wie bei dem oben beschriebenen Exemplare. Sowerby scheint der unten kopirten Diagnose nach die schärfer skulptirten Exemplare als Typus zu nehmen. Reeve's Figur entspricht in der Färbung beinahe meiner kleinen Form, ist aber $24 \mathrm{~mm}$ lang.

*) C. testa ovata, late superficialiter umbilicata, spira turrita, anfractibus superne late excavato-angulatis, oblique longitudinaliter costatis, spiraliter substriatis; livido-purpurea, lineis rufis interruptis cingulata, angulo costisque hic illic albis; apertura trigono-ovata, columella arcuata, triplicata. - Reeve. 


\section{Cancellaria taeniata Sowerby. Taf. 19. Fig. 15. 16.}

Testa oblonga, turrita; costis numerosis, transverse striatis, ad angulum anfractuum acute angulatis; spira acuminata, apice mammillifera; apertura interne laevigata, margine acuto, columella laevi, biplicata. Colore pallidissime fulvo, fusco taeniato. - Sow.

Long. (ex icon.) 21, diam. 11, alt, apert. $9 \mathrm{Mm}$.

Cancellaria taen i ta Sowerby Thesaur. Conchyl. p. 445 pl. 95 fig. 75.76. - $\quad$ - Reeve ${ }^{*}$ ) Conchol. icon. sp. 81.

Gehäuse länglich, gethürmt, aus sieben kantigen Umgängen bestehend, welche mit zahlreichen an der Kante in spitzen Höckern vorspingenden Rippen skulptirt und spiral gestreift sind; das Gewinde ist gethürmt mit zitzenförmigen Apex. Die Färbung ist ein ganz helles Braun mit zahlreichen schmalen braunen Binden. Die Mündung ist unregelmässig eiförmig ohne deutlichen Kanal, mit scharfem, innen glattem Aussenrand, die Spindel mit zwei schwachen Falten.

Aufenthalt unbekannt, die Zugehörigkeit zu Cancellaria mir nicht ganz zweifellos. Abbildung und Beschreibung nach Sowerby.

\section{Cancellaria obesa Sowerby. Taf. 20. Fig. 1.}

Testa ovata, crassa, ponderosa, imperforata, spira breviuscula, acuminata, anfractibus convexis, superne declivibus, laevibus, obscure spiraliter striatis, versus apicem minute reticulatis; albida, aurantio-fusco pallide nebulata; apertura oblonga, subangusta, superne sinuata, fauce validissime lirata, plicis duabus crassissimıs prominentibus. - Reeve.

Alt. 60 , diam. $40 \mathrm{Mm}$.

C ancellaria obesa Sowerby Proc. Zool. Soc. Lond. 1832 p. 52. - Thesaurus Conchyl. p. 441 pl. 93 fig. 37.

- Reeve Conch. icon. sp. 7.

Gehäuse gross, schwer, eiförmig mit kurzem spitzem Gewinde, undurchbohrt, mit gewölbten, oben leicht abgeflachten Umgängen; die obersten sind fein gegittert, die folgenden nur noch spiral gefurcht, der letzte beinahe glatt. Die Färbung ist weisslich mit undeutlichen orangefarbenen Striemen. Die Mündung ist ziemlich schmal eiförmig, oben zu

* C. testa subfusiformi-turrita, imperforata, spira subgracili, anfractibus superne plano-angulatis, longitudinaliter anguste costatis, subobsolete decussatim liratis; fulvo-rufescente, fusco taeniata; columella biplicata. - Reeve. 
einer kanalartigen Bucht verengt, im Gaumen stark gerippt, die Spindel mit zwei auffallend stark vorspringenden Falten.

Aufenthalt an der Westküste von Centralamerika, im Golfo Dulce von Cuming gedrakt.

Ich kenne diese Art nur aus den Abbildungen, kann aber aus diesen keinen Grund entnehmen, sie von C. ovata (cfr. Taf. 5 Fig. 1. 2) zu trennen; sie ist ein klein wenig bauchiger und glätter, die Gitterskulptur verschwindet früher und die Falten sind ein wenig stärker. Die Art scheint übrigens auch nur auf wenigen Exemplaren zu beruhen.

\section{Cancellaria bulbulus Sowerby.}

Taf. 20. Fig. 2. 3 .

Testa oblongo-piriformis, subventricosa, solida, imperforata, basi anguste attenuata, spira parva, valide decussatim plicata, sutura rude impressa, anfractu ultimo superne declivi, laevigato; fulva; apertura anguste oblonga; columella triplicata, plica suprema validissima. - Reeve.

Alt, 58, diam. $25 \mathrm{Mm}$.

Cancellaria bulbulus Sowerby*) Proc. Zool. Soc. Lond. 1832 p. 55. - Thesaurus p. 440 pl. 95 fig. 64.

- $\quad$ - Reeve Conchol. icon. sp. 85 .

Gehäuse langrund, fast birnförmig, oben bauchig, festschalig und schwer, undurchbohrt, an der Basis zu einer Art Stiel verschmälert, mit kurzem, stark gefaltetem und spiral gereiftem Gewinde, die Naht ist unregelmässig, rauh eingedrückt; der letzte Umgang bildet fast allein das Gehäuse und ist obenher abgeflacht; nach Sowerby trägt er noch obeu und am Stiel Spiralreifen und die Abbildung zeigt auch am grössten Umfang kurze Rippenfalten; nach Reeve ist er vollkommen glatt. Die Färbung ist einfarbig braungelb. Die Mündung ist schmal eiförmig, oben spitz, unten mit deutlichem Kanal, die Aussenlippe scharf, unten am Eingang des Kanals leicht ausgeschnitten, der Gaumen glatt oder undeutlich gereift; die Spindel trägt drei Falten, von denen die oberste besonders stark ist.

Aufenthalt an der Westküste von Centralamerika, die beiden Abbildungen nach Sowerby (2) und Reeve (3).

Ich kann diese Art nur für eine unausgewachsene $\mathrm{C}$ solida - mit der sie zusammen vorkommt - halten; das Reeve'sche Exemplar ist etwas älter, als das Sowerby'sche.

*) C. testa subturbinata, subovali, laevi; spira acuminata, anfractibus superioribus decussatim costatis; ultimo prope suturam et antice spiraliter striato; apertura pirformi; plicis columellae tribus, prima acuta; labro externo acuto, ad canalem paululum emarginato; colore fulvo. - Sow. 


\section{Cancellaria affinis Reeve.}

Taf. 20. Fig. 4. 5.

Testa fusiformi-ovata, minute umbilicata, spira mediocri, anfractibus superne angulato-declivibus deinde planulatis, liris obliquis et spiralibus undique clathratis; fulva, liris rufescentibus; apertura subangusts, plicis tribus mediocribus. - Reeve.

Alt. 28, diam. $17 \mathrm{Mm}$.

Cancellaria af $\mathrm{fin}$ is Reeve Concholog. icon. sp. 39.

Gehäuse eiförmig-spindelförmig, ganz eng durchbohrt, "mit mittelhohem Gewinde', in der Skulptur der C. indentata sehr ähnlich, mit fast gleichstarken Rippen und Spiralreifen gegittert, die Umgänge obenher abgeflacht, doch nicht mehr' eigentlich scharfkantig, wenig gewölbt, bräunlich mit röthlichen Reifen. Die Mündung ist ziemlich= schmal, der Gaumen glatt oder undeutlich gerippt, die Spindel trägt drei Falten, welche bei weitem nicht so stark sind, wie bei C. indentata.

Aufenthalt nicht sicher bekannt, wahrscheinlich an der Westküste von Centralamerika. Die Abbildung und Beschreibung nach Reeve.

Ueber das Verhältniss dieser Art zu der sehr nahe verwandten C. indentata siehe oben p. 32.

\section{Cancellaria crispata Sowerby.}

Taf. 20. Fig. 6. 7.

Testa ovata, imperforata, spira acute exserta, anfractibus superne anguste angulatis, oblique longitudinaliter costatis, costis crassis ad angulum muricato-uncinatis, striis spiralibus decussatis; albida, lineis fasciisque castaneo-fuscis cingulata; apertura ovata, parva, fauce tenuilirata, plicis tribus parvis. - Reeve.

Alt. 28, diam. $18 \mathrm{Mm}$.

Cancel laria crispata Sowerby Concholog. Illustr. fig. 20. - Thesaurus Conch. p. 452 pl. 96 fig. 89 .

Reeve Conchol. icon. sp. 43.

Gehäuse spitzeiförmig, undurchbohrt, mit spitzem vorspringendem Gewinde, weisslich mit kastanienbraunen Spirallinien und schmalen Binden. Die sechs bis sieben Umänge sind oben abgeflacht und nahe der Naht kantig, spiral gereift und mit starken hohen Rippen skulptirt, welche an der Naht hakenförmig vorspringen. Die Mündung ist dreieckig eirund, ziemlich klein, mit gereiftem Gaumen, die Spindel mit drei kleinen Falten. 
Aufenthalt an den Philippinen, bei Negros in 5 Faden Tiefe von Cuming gedrakt. Abbildung und Beschreibung nach Reeve.

Diese Art, die ich mir nicht verschaffen konnte, dürfte nur eine Lokalform von C. crenifera sein.

\title{
76. Cancellaria serrata Reeve.
}

\author{
Taf. 20. Fig. 8. 9 .
}

Testa ovata, anguste umbilicata, spira acute turrita, anfractibus superne sublate excavato-angulatis, tenue longitudinaliter costatis, costis acute fimbriato-serratis; albida, livido-olivaceo tincta, medio albifasciata; apertura trigono-ovata, fauce lirata, columella triplicata. - Reeve.

Alt. 20, diam. $13 \mathrm{Mm}$.

Cancellaria serrata Reeve Conchol. icon. sp. 63 , nec Brocchi.

Crossei Semper Palaeont Untersuch. p. 91.

Gehäuse eiförmig mit kurzem, aber spitzem und gethürmtem Gewinde, eng genabelt, die Umgänge oben ziemlich breit ausgehöhlt, dann kantig, mit feinen, schmalen, aber hohen Lamellenrippen skulptirt, welche am Rande zierlich gekraust sind. Spiralskulptur wird in der Diagnose nicht erwähnt, ist aber auf der Abbildung angegeben. Die Färbung ist livid olivenbraun mit einer weissen Mittelbinde. Die Mündung ist eiförmig dreieckig mit geripptem Gaumen, die Spindel mit drei Falten.

Aufenthalt unbekannt, Abbildung und Beschreibung nach Reeve. - Auch diese Art dürfte nur eine Varietät von C. crenifera sein, und kann als solche den Reeveschen Namen behalten.

\section{Cancellaria mangelioides Reeve. Taf. 20. Fig. 10. 11.}

Testa acuminato turrita, imperforata, spira acuta, anfractibus superne angulatis, longitudinaliter costatis, costis compressis, distantibus, transversim striatis; candida; apertura trigono-ovata, labro subexpanso, columella triplicata. - Reeve.

Long. 18, diam. $11 \mathrm{Mm}$.

Cancellaria mangelioides Reeve Conchol. icon. sp. 69.

Gehäuse plump spindelförmig, etwas gethürmt, undurchbohrt, mit spitzem Gewinde, einfarbig weiss. Die 6-7 Umgänge sind oben kantig und mit zusammengedrückten, ziemlich entferntstehenden Rippen skulptirt, welche quer gestreift sind. Die Mündung ist eiförmig dreieckig mit leicht ausgebreitetem Aussenrand; die Spindel trägt drei Falten.

Aufenthalt unbekannt; Abbildung und Beschreibung nach Reeve. 


\title{
78. Cancellaria corrugata Hinds.
}

\author{
Taf. 20. Fig. 12. 13.
}

Testa oblongo-piriformis, imperforata, spira exserta, subobtusa, anfractibus declivi-convexis, longitudinaliter obsolete corrugatis, lineis impressis decussatis; fulvo-olivacea; apertura anguste oblonga, fauce lirata, columella subattenuata, biplicata. - Reeve.

Long. 22, diam. $12 \mathrm{Mm}$.

Cancellaria corrugat a Hinds*) Proc. Zool. Soc. Lond. 1843 p. 48.

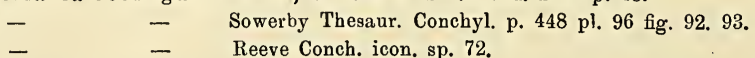

Gehäuse birnförmig, undurchbohrt, mit niederem, doch vorspringendem Gewinde und leicht abgestumpftem Apex: die 4 Umgänge sind erst leicht abgeflacht, dann gewölbt, durch feine concentrische Längsrunzeln und eingedrückte Spirallinien fein decussirt, einfarbig olivenbraun. Die Mündung ist lang nnd schmal, unten zusammengezogen, der Gaumen gerippt, die Spindel schmal mit zwei Falten.

Aufenthalt bei Guayaquil; die Abbildung nach Reeve. (Weder die Abbildung bei Sowerby noch die bei Reeve zeigen die Skulptur der Beschreibung entsprechend). $\mathrm{Ob}$ ausgewachsen?

\section{Cancellaria coronata Scacchi. \\ Taf. 21. Fig. 1.}

Testa oblongo turrita, subimperforata, longitudinaliter costulata, transversim striata; anfractus 7 superne angulati, supra plani, angulo costarum excurrentium mucronibus coronato. Apertura $2 / 5$ totius longitudinis occupans, angulato-ovata, dilatata; plicae columellae duae, parum elevatae; labrum intus obsoletıssime striatum.

Alt. 18. diam. $9 \mathrm{Mm}$.

Cancellaria coronata Scacchi Notizie p. 34 tab. 1, fig. 15.

\begin{tabular}{|c|c|c|}
\hline - & - & Philippi Enum. Moll. Sicil. II p. 177 tab. 25, fig. 24. \\
\hline - & varicosa & Philippi Enum. I p. 201. \\
\hline & coronata & Tryon Manual p. 76 pl. 4 fig. 68. \\
\hline & - & Monterosato Enumer. e Sinon. p. 37. \\
\hline
\end{tabular}

Gehäuse gethürmt eiförmig, fast undurchbohrt, aus sieben Umgängen bestehend, welche oben flach, dann kantig sind und nach der unteren Naht hin leicht eingeschnürt

*) T. bucciniformis, fusca; anfractibus quaternis, subventricosis, rugis parvis longitudinalibus indutis, lineis impressis decussatis; apertura oblonga, fusca; labro intus sulcato; columella plicis duabus albidıs instructa; umbilico nullo; canali mediocri. - Hinds. 
erscheinen, sie sind spiral gestreift und mit Längsrippen skulptirt, welche oben an der Kante als stachelige Dornen vorspringen. Die Mündung nimmt ungefähr zwei Fünftel der Gesammtlänge ein; sie ist eckig eirund, etwas erweitert; die Spindel trägt zwei wenig vorspringende Falten; die Aussenlippe ist innen glatt oder nur ganz fein gestreift.

Zuerst fossil aus den süditalienischen Tertiärschichten beschrieben, seitdem von Jeffreys auch lebend in dem Mittelmeer gefunden. Abbildung und Beschreibung nach Philippi.

\section{Cancellaria pusilla $H$. Adams.}

\section{Taf. 21. Fig. 2.}

C. testa imperforata, ovato-turrita, albida, longitudinaliter obtuse nodoso-costata et filis remotis cincta; spira elata, sutura leviter impressa; anfr. 5 convexiusculis, ultimo 1/3 longitudinis testae; apertura oblonga, antice vix canaliculata; labio antice sinuato, plicis duabus validis instructo; labro simplici, intus valde lirato.

Long. 6, lat. 2,5 $\mathrm{Mm}$.

Cancellaria pusilla H. Adams Proc. Zool. Soc. London 1869 pag. 274 tab. 19 fig. 12, nec Sowerby.

- mitraeform is Brocchi var. Jeffreys ibid. 1885 pag. 49.

- pusilla Tryon Man. t. 3 f. 46.

- $\quad$ - Kobelt Prodromus faunae europ. p. 125.

Gehäuse undurchbohrt, gethürmt eiförmig, weisslich, mit schwachen, stumpfen, knotigen Rippenfalten und entferntstehenden Spiralleisten skulptirt; das Gewinde ist ziemlich hoch, die Naht leicht eingedrückt. Es sind fünf ziemlich gewölbte Umgänge vorhanden, von welchen der letzte etwa zwei Drittel der Gesammtlänge einnimmt. Die Mündung ist länglich, unten in einen wenig deutlichen Canal zusammengezogen, die Spindel ist ausgebuchtet und mit zwei deutlichen Falten versehen, die Aussenlippe ist einfach, innen tief gefurcht.

Aufenthalt im lusitanischen Meer von dem Meerbusen von Biscaya bis zu den Canaren.

Diese Art steht der fossilen Cancellaria mitraeformis Brocchi nec Sow. so nahe, dass Jeffreys sie unbedenklich als Varietät mit ihr vereinigt. Ich habe kein lebendes Exemplar gesehen und copire die Abbildung nach H. Adams.

\section{Cancellaria minima Reeve.} Taf. 21. Fig. 3. 4.

T. subfusiformis, imperforata, spira subelongata, anfractibus rotundatis, oblique costatis, costis saperne obtuse nodosis, interstitiis nitide cancellatis; alba, interdum fuscescens; columella obsolete biplicats. - Reeve.

IV. 4. 
Alt. (ex icone Reeverno) $5 \mathrm{Mm}$.

Cancellaria minima Reeve Conch. icon. sp. 77.

- $\quad$ - Jeffreys Pr. Zool. Soc. 1855 p. 49.

An = Cancellaria subangulosa Searles Wood Crag Mollusca t. 7 f. 20.

Gehäuse fast spindelförmig, undurchbohrt, mit ziemlich hohem Gewinde, die Umgänge sind gerundet oder oben leicht kantig und. sind mit oben knotigen Rippen skulptirt, deren Zwischenräume deutlich gegittert erscheinen. Die Färbung ist weisslich, mitunter ganz leicht bräunlich; die Spindel trägt zwei undeutliche Falten. Nach Jeffreys ist die Skulptur in ihrer Ausprägung sehr wechselnd und kommt mitunter der fossilen Cancellaria subangulosa Wood aus dem englischen Crag sehr nahe.

Diese kleine Art, deren Aufenthalt Reeve nicht kannte, ist bei den neueren Tiefseeforschungen nach Jeffreys in der Tiefe des lusitanischen Meeres bis nach Madera hin gefunden worden. - Abbildung nach Reeve.

\section{Cancellraia candida Sowerby.}

\section{Taf. 21. Fig. 5 .}

T. subfusiformi-ovata, ventricosa, basi contorta, imperforata, spira acute acuminata, anfractibus rotundatis, ad suturam parum planatis, undique dense nodoso-reticulatis, candida; apertura subangusta, fauce valide lirata, plicis duabus, fortibus valde prominentibus. - Reeve.

Alt. (ex icone Reeveano) 33, diam, $20 \mathrm{Mm}$.

Cancellaria candida Sowerby Conch. Ill. sp. 2 fig. 1. - Thes. Conch. t. 92 f. 8.

- $\quad$ - Reeve Conch. icon. sp. 46.

Gehäuse etwas spindelförmig eiförmig, gedrungen und kräftig, unten mit einem deutlichen etwas gedrehten Stiel und ziemlich hohem spitzem Gewinde; es sind 7-8 gerundete Umgänge vorhanden, die nur unter der Naht leicht abgeflacht sind; sie erscheinen durch starke Längsrippen und etwas schwächere Spiralreinfen, welche an den Schnittstelle knotig verdickt sind, gegittert; die Färbung ist weiss. Die Mündung ist relativ schmal, die Aussenlippe unten dem Stiel entsprechend etwas eingezogen, im Gaumen scharf gerippt, die Spindel mit zwei starken, vorspringenden Falten, von denen die obere am stärksten ist.

Aufenthalt in Polynesien. Abbildung und Beschreibung nach Reeve.

Diese Art ist der C. indentata am nächsten verwandt und bildet mit C. ventricosa und den folgenden Arten einen Formenkreis, dessen Arten theils an der Westküste von Centralamerika, theils in Polynesien bis nach Australien hin wohnen. Sie sind in den Sammlungen alle sehr selten und ich habe mir keine Exemplare verschaffen können. 


\section{Cancellaria australis Sowerby.}

Taf. 21. Fig. 6.

Testa ovata, imperforata, spira acuminata, sutura impressa, anfractibus rotundatis, costis longitadinalibus confertis obliquis lirisque tenuibus spiralibus; candida; apertura parviuscula, columella arcuata, plicis tribus mediocribus. - Reeve.

Long. (ex icone) $23 \mathrm{Mm}$.

Cancellaria australis Sowerby Conch. Ill. f. 29. Thesaurus Conch. fig. 72. 73.

- - Reeve Conch. icon. sp. 44.

- $\quad$ - Crosse Journal de Conchyliologie IX. p. 236.

Gehäuse oval, undurchbohrt, mit spitzem Gewinde und eingedrückter Naht. Die Umgänge sind gerundet, mit dichten schrägen Rippen und feinen Spirallinien skulptirt. Die Färbung ist einfarbig weisslich. Die Mündung ist ziemlich klein, die Spindel gebogen mit drei mittelstarken Falten.

Aufenthalt an Neusüdwales. Abbildung und Beschreibung nach Reeve.

\section{Cancellaria albida Hinds.}

Taf. 21. Fig. 7.

T. subfusiformi-oblonga, solida, imperforata, basi contorta, spira acuminata, anfractibus planoconvexis, ad suturam anguste plicatis, deinde declivi-angulatis, liris funiculatis undique eleganter reticulatis; candida, apertura angusta, plicis duabus, subprominentibus. - Reeve.

Long. (ex icone) $27 \mathrm{Mm}$.

Cancellaria albida Hinds Proc. Zool. Soc. 1843 p. 47.

- $\quad$ - Reeve Conch. icon. sp. 45.

Gehäuse langeiförmig, fast spindelförmig, festschalig, undurchbohrt, mit mehr oder minder deutlich abgesetztem gedrehtem Stiel und spitzem Gewinde. Es sind sieben Umgänge vorhanden, die dicht unter der Naht eine stärkere, knotige Leiste haben und dann leicht ausgehöhlt und kantig sind; die Skulptur ist gegittert, wie bei der vorigen, doch an den Schnittstellen nicht so deutlich knotig. Die Färbung ist gleichfalls weiss. Die Mündung ist eng, im Gaumen scharf gerippt, die beiden Falten sind schwächer und mehr schräg nach unten gerichtet, als bei der vorigen Art.

Zuerst von Hinds im Sulphur, dann auch von Cuming an der Westküste von Centralamerika bei Panama, Veragua und Guayaquil in 7-23 Faden Tiefe gesammelt. Abbildung und Beschreibung nach Reeve. 


\section{Cancellaria lactea Deshayes. \\ Taf. 21. Fig. 8.}

T. ovata, ventricosa, acuta, tenuis, transiucida, candidissima vel luteola, laevigata; anfractibus 6-7 turgidulis; apertura ovato-acuta, labro tenui intus non striato; columella triplicata. - Desh. Alt. 22-25, diam. 13-15 Mm.

Cancellaria lactea Deshayes Encycl. meth. II. p. 180. - Anim. sans vert. vol. IX. p. $412 \mathrm{Ni}, 17$.

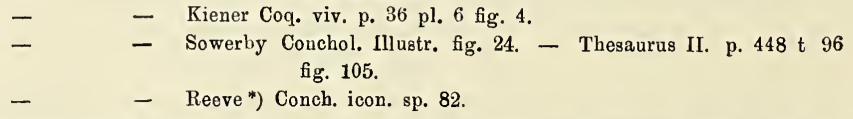

Gehäuse mittelgross, eiförmig bis fast kugelig, ziemlich dünnschalig, aus $6-7$ gerundeten und durch eine einfache Naht geschiedenen Umgängen bestehend, von denen der letzte fast allein das ganze Gehäuse ausmacht, glänzend weiss bis rahmfarben, glatt; die Mündung ist halbeirund, unten mit einem undeutlichen, kaum ausgeschnittenen Kanal ; die Spindel ist fast senkrecht und trägt drei schräge ziemlich gleiche Falten, von denen die oberste ein wenig stärker vorspringt. Der Aussenrand ist dünn, scharf, nicht im geringsten verdickt, innen völlig glatt.

Aufenthalt unbekannt, die Art überhaupt ziemlich verschollen. Ich gebe die Abbildung nach Reeve, der übrigens den Gaumen im Gegensatz zu Deshayes gerippt nennt. Möglicherweise handelt es sich um ein unausgewachsenes gerolltes Exemplar von Cancellaria laevigata.

\section{Cancellaria gemmulata Sowerby.}

Taf. 21. Fig. 9. 10.

T. globoso-ovata, solida, imperforata, spira brevi, acuta; anfractibus superne vix angulatis, plano-convexis, costis nodulatis lirisque dense conspicue decussatis; alba; apertura subexpansa, plicis tribus mediocribus. - Reeve.

Alt. (ex icone Reeveano) $26 \mathrm{Mm}$.

Cancellariag emmulata Sowerby Proc. Zool. Soc. 1832 p. 55. - Thesaurus Conchyl.

II. p. 446 t. 92 f. 14 .

- - $\quad$ - Reeve Conchol, icon. sp. 48.

Gehäuse eiförmig kugelig, festschalig, undurchbohrt, mit kurzem spitzem Gewinde, die Umgänge sind oben ganz leicht kantig, dann ziemlich flach gewölbt, mit Rippen und

*) Can. testa oblongo-ovato, tenui, pellucida, imperforata, spira subobtusa, anfractibus superne declivi-convexis, laevigatis; lactea; apertura ovata, fauce lirata; columella valide triplicata. - Roeve. 
Spirallinien, die an den Schnittstellen hübsch gekörnelt sind, sehr schön gegittert. Die Färbung ist, wie bei den anderen Arten der Gruppe, weisslich. Mündung mit etwas ausgebreitetem, innen scharf geripptem Mundsaum; die Spindel scheint im Gegensatz zu den vorigen drei Falten zu tragen, doch kommt das nur daher, dass die zweite etwas höher steht und dadurch der Spindelrand am Kanaleingang auch als Falte erseheint.

Aufenthalt an der Westküste von Centralamerika, im Golf von Nicoya von Cuming entdeckt. Abbildung und Beschreibung nach Reeve.

\section{Cancellaria clathrata A. Adams. \\ Taf. 21. Fig. 12. 13.}

„C. testa oblongo-ovali, anguste umbilicata, albida, fasciis duabus pallide rufescentibus ornata; anfractibus 7 postice vix angulatis regulariter clathratis, apertura subquadrata, columella recta tuberculato-granosa, triplicata, plica postica valida, plica media unisulcata, plica antica bisulcata, labro intus valde lirato." - A. Adams.

Long. (ex icone Reeveano) $22 \mathrm{Mm}$.

Cancellaria clathrata A. Adams Proc. Zool. Soc. 1855 p. 123, nec Lamarck.

- corrosa Reeve*) Conch. icon. sp. 64.

- $\quad$ - Tryon Manual p. 67 t. 1 fig. 9.

Gehäuse länglich eiförmig bis fast kugelig, eng genabelt, weisslich mit zwei undeutlichen blassröthlichen Binden; die sieben Umgänge sind oben nur ganz wenig kantig, durch ziemlich gleich starke Längs- und Spiralrippen regelmässig gegittert; die Mündung ist fast viereckig, die Spindel höckerig und mit drei starken Falten bewaffnet, von denen die oberste am stärksten ist; die mittlere ist durch eine Furche getheilt, die untere durch zwei; der Gaumen ist innen stark gerippt.

Aufenthalt unbekannt. Ich habe mir auch diese Art nicht verschaffen können und gebe die Abbildung nach Reeve. Die Aenderung des Namens ist unnöthig, da Cancèllaria clathrata Lamarck in die Synonymie von hirta Brocchi fällt.

\section{Cancellaria parva Philippi.}

\section{Taf. 21. Fig. 11.}

„T. oblongo-fusiformis, longitudinaliter costata et cingulis spiralibus ornata; costis, ubi a cingulis secantur granuliferis, cingulis in anfractibus superioribus tribus, in ultimo circa 6 ; cauda di-

*) Can. testa subgloboso-ovata, crassiuscula, minute umbilicate, spira acuta, anfractibus rotundatis, ad suturam parum angulatis, liris funiculatis undique nitide clathratis; fulvescente; apertura parviuscula, plicis tribus fortibus. 
stincta, subimperforata, apertura spiram aequante; columella biplicata; labro plicis 4 intus munito. - (Phil.)

Alt. 12, alt. apert. $6 \mathrm{Mm}$.

Cancellaria parva Philippi Reise in die Wiste Atacama p. 187 t. 7 fig. 18.

- $\quad$ - Tryon Manual p. 73 t. 3 fig. 44.

- $\quad$ - Crosse Journal de Conchyologie XI. 1883 p. 67.

Gehäuse lang eiförmig, fast spindelförmig, der Länge nach gerippt und mit breiten Spiralgürteln umzogen, welche da, wo sie die Längsrippen schneiden, knötchenartige Körner bilden; man zählt auf den oberen Umgängen drei, auf dem letzten sechs Gürtel. Der letzte Umgang ist nach unten in einen deutlichen Stiel ausgezogen, kaum durchbohrt. Die Mündung ist so hoch wie das Gewinde; die Spindel trägt zwei Falten, der Mundrand innen 4 kurze Fältchen (die Figur zeigt deren 6-7).

Diese eigenthümliche kleine Art, welche Philippi am chilenischen Strand sammelte, ist mir unbekannt geblieben; ich gebe Abbildung und Beschreibung nach Philippi l. c.

\section{Cancellaria Stimpsoni Calkins. \\ Taf. 22. Fig. 1. 2.}

T. ovato-subglobosa, tenuis, solidula, umbilicata, albida, epidermide fuscescente induta; spira brevi, scalata, apice acuto; anfractus 6 , superi tres laeves, rotundati, inferi super angulum compressum coronatum profunde excavati, spiraliter lirati, liris irregularibus, $3-4$ in ultimo plus minusve noduliferis; ultimus basi compressus, umbilico infundibuliformi crista circumdato. Apertura subtriangulariovata, basi vix emarginata, haud canaliculata, labro tenui, ad liras irregulariter flexuoso, faucibus laevibus, lamella columellari tenui, super umbilicum fornicatim reflexa, plicis duabus fere medianis parum prominulis armata.

Alt. 21, diam. 16, alt. apert. $13 \mathrm{Mm}$.

Cancellaria Stimpsoni Calkins Proc. Davenport Acad. N. S. 1878 p. 250 t. 8. fig. 4. 5 .

Tryon Manual p. 79 t. 5 fig. 87.

Aus Paetels Sammlung liegt mir durch die Güte des Besitzers eine Cancellaria vor, welche ich unbedingt für eine Zwergform von Cancellaria bullata genommen haben würde, wenn ich mich nicht einer freilich arg verzeichneten Figur in Tryon's Manual erinnert hätte, welche die noch kaum bekannt gewordene Cancellaria Stimpsoni von Florida darstellt und welche, wenn richtig gestellt, wie mein Freund Kobelt im Vertrauen auf seine Erfahrung im Conchylienzeichnen gethan, vollkommen mit dieser Schnecke übereinstimmt. Auch was Tryon sagt (der Aufsatz von Calkins ist mir nicht zugänglich), stimmt vollständig: Whorls shouldered, the angle nodulous, surface below it covered with irregular nodules, which do not appear to be developed in the lines of longitudinal ribs, but rather from revolving sculpture; columella with two plates, whitish. Long. $17 \mathrm{Mm}$. 
Auch wenn Calkins nicht ganz bestimmt angäbe, dass seine neue Art von Sable Cape in Florida stamme, könnte das vorliegende Stück doch nicht ohne Weiteres mit C. bullata vereinigt werden, da es zweifellos ausgewachsen ist, C. bullata aber in ausgewachsenem Zustand reichlich doppelt so gross ist. Es scheint also hier wieder einer der Fälle vorzuliegen, wo wir an beiden Seiten des Isthmus von Panama eng verwandte einander vertretende Formen finden, wie bei Pyrula melongena und patula und anderen mehr.

\section{Cancellaria bicolor Hinds.}

Taf. 22. Fig. 3. 4.

T. ovato-ventricosa, late et profunde umbilicata, spira breviuscula, turrita; anfractibus ad suturam late excavatis, acute angulatis, longitudinaliter remote costatis, tenue spiraliter liratis; rufo castanea, versus apicem alba (in anfr. ult plerumque bicolor, supra rufo-castanea, infra alba); apertura trigono-ovata, basi sinuata, plicis tribus subprominentibus. - Reeve.

Alt. $26 \mathrm{Mm}$.

Cancellaria bicolor Hinds Zool. Voy. Sulphur, Mollusca p. 43 t. 12 fig. 13 . 14.

- $\quad$ - Reeve Conchol. icon. sp. 29.

Gehäuse bauchig eiförmig mit kurzem aber treppenförmig gethürmtem Gewinde, weit und tief genabelt; die Umgänge sind oben scharfkantig und darüber breit ausgehöhlt; ihre Skulptur besteht aus entferntstehenden starken Rippen, welche bis in den Nabel hinein laufen, und aus feinen Spirallinien. Der letzte Umgang ist entweder ganz oder zur Hälfte dunkel braunroth, das Gewinde weiss; die Mündung ist gerundet dreieckig, unten zu einer Rinne zusammengedrückt, die Spindel trägt drei mittelstark vorspringende Falten.

Aufenthalt an der philippinischen Insel Samar. Abbildung und Beschreibung nach Reove.

\section{Cancellaria tenuis A. Adams.}

Taf. 22. Fig. 5. 6.

C. testa ovato-ventricosa, tenuicula, sordide earneola, anguste umbilicata, spirae suturis profunde impressis, anfr. 6 planiusculis, longitudinaliter costatis, costis tenuibus crenulatis fusco articulatis, liris spiralibus regulariter sculptis, postice angulatis, productıs, lamellatis; columella triplicata, labro tenui. - A. Adams.

Long. ?

Cancellaria tenuis A. Adams Proc. zool. Soc. 1855 p. 123.

- $\quad$ - Reeve *) Conch. icon. sp. 75.

scalata Sow. var. fide Tryon.

*) Can. testa ovata, tenuiuscula, anguste profunde umbilicata, spira subpyramidali, anfractibus 
Gehäuse bauchig eiförmig, ziemlich dünnschalig, schmutzig fleischfarben, eng genabelt, mit tief eingedrückter Naht; die sechs Umgänge sind nur wenig gewölbt, fein und regelmässig spiral gestreift und mit dünnen, hohen, etwas gezähnelten Längsrippen skulptirt, welche meistens braun gegliedert sind und an der Kante schuppig vorspringen. Die Mündung ist oval, unten verschmälert, mit dünnem Aussenrand, der nur eine schmale Lippe mit kurzen Fältchen hat; die Spindel hat drei kleine Falten.

Eine etwas verdächtige Art unbekannten Fundortes, die ich mir nicht habe verschafien können und nach Reeve kopire. Tryon zieht sie einfach zu C. scalata.

\section{Cancellaria nitida A. Adams. \\ Taf. 22. Fig. 7. 8.}

C. testa acuminato-ovali, imperforata, alba, nitida, spira acuta suturis valde impressis; anfr. 7 planis, longitudinaliter costatis, costis elevatis, compressis, distantibus, crenulatis, postice alatis, productis, liris tenuibus spiralibus regulariter sculptis; apertura ovata, columella triplicata. - A. Adams.

Long. $9 \mathrm{Mm}$.? (ex icone).

Cancellaria nitida A. Adams Proc. zool. Soc. 1855 p. 123.

- $\quad$ - Tryon Manual p. 82 t. 7 fig. 16.

- $\quad$ - Reeve*) Conch. icon. sp. 78.

Gehäuse spitz eiförmig, undurchbohrt oder nur ganz oberflächlich genabelt, mit spitzem Gewinde; die sieben Umgänge sind obenher schmal, aber tief eingedrückt, dann kantig, mit regelmässigen feinen Spiralreifen und mit hohen lamellenartigen, am Rande gezähnelten und oben schuppig vorgezogenen Längsrippen skulptirt; sie ist weiss oder fleischfarbig überlaufen. Die Mündung ist eckig eirund, im Gaumen gerippt, die Spindel mit drei deutlichen Falten.

Aufenthalt an den Philippinen; Abbildung und Beschreibung nach Reeve.

\section{Cancellaria purpurif ormis Valenciennes.}

Taf. 22. Fig. 9. 10.

T. oblongo-ovata, imperforata, spira exserta, subobtusa; anfractibus $t ;$ plano-convexis, longitudinaliter obsolete plicatis, transversim lineari-sulcatis; fuscescente-alba; apertura ovata ; columella arcuata, triplicata. - Reeve.

ad suturam anguste declivi-excavatis, longitudinaliter laminato-costatis, transversim tenuiliratis; fulvescente; apertura ovata, ad basin attenuata, columella triplicata.

*) Can. testa ovato-turrita, superficialiter umbilicata, spira acuta, anfractibus ad suturam anguste angulatis, costatis, costis compressis, valde prominentibus, acutis, interstitiis laevigatis; albs carneo tincta; apert. subquadrato-ovata, fauce lirata, columella conspicue triplicata. 
Alt. $18 \mathrm{Mm}$.

Cancellaria purpuriformis Valenciennes in Kiener Coq. vir. pl. 7 fig. 4.

$$
\text { - } \quad \text { - } \quad \text { Reeve Conch. icon. sp. } 76.9
$$

Gehãuse lang eirund, undurchbohrt, mit erhobenem, gethürmtem, aber oben abgestutztem Gewinde, aus sechs flach gewölbten Umgängen bestehend, welche von feinen eingedrũckten Furchenlinien umzogen werden und undeutliche Längsfalten zeigen; die Mündung ist eiförmig, unten kaum ausgeschnitten, die Spindel gebogen, mit drei Falten, der Gaumen innen nur ganz fein gereift.

Aufenthalt unbekannt. Ich kenne diese Art nicht und gebe Abbildung und Beschreibung nach Reeve.

\title{
94. Cancellaria pulchra Sowerby.
}

\author{
Taf. 23. Fig. 1.2.9.10.
}

T. ventricoso-ovata, tenuiuscula sed solida, albicans, brunneo varie fasciata et lirata; spira breviuscula, turrito-acumixata, apice acuto; anfractus 6 inflati, supra planati, dein angulati, costis distantibus angustis obliquis ad intersectiones lirarum spiralium muricato-aculeatis sculpti; spinis ad angulum majoribus; apertura ovata, canali distincto curvato, labro margine dentato-crenato; faucibus sulcatis; columella triplicata, plicis 2 inferioribus magis approximatis.

Alt. $25-30 \mathrm{Mm}$.

Cancellaria pulchra Sowerby*) Proc. Zool. Soc. 1832 p. 50. - Thesaurus Conchgl. p. 451 tab. 94 fig. 41.

Gehäuse bauchig eiförmig, ziemlich dünnschalig aber fest, weisslich, gewöhnlich mit einer tiefbraunen Binde über der Kante und einer anderen unter der Verschmälerung des letzten Umganges, oft auch mit braunen Spiralreifen; das Gewinde ist kurz, aber gethürmt, und mit spitzem Apex; der enge Nabel ist von einer schuppigen Kante umgeben. Die sechs Umgänge sind stark gewölbt, der letzte erheblich aufgeblasen; sio sind obenher deutlich abgeflacht und haben dann eine durch eine stärkere Dornenreihe bezeichnete Kante; die Skulptur ähnelt sehr der von Cancellaria cancellata L.; schiefe, entferntste-

*) C. testa aubovata, albicante, brunneo fasciata; spira breviuscula, acuminata; anfractibus 6 ventricosis, costatis; costis muricato-aculeatis, lineis elevatis spiralibus decussatis; apertura ovats; intus sulcata; peritremate crenato; columella triplicata, plica intermedia minore; labro externo ruguloso; urabilico mediocri, margino elevato, canali recurvo. - Sow.

**) Can. testa ovato-globosa, vix umbilicata, spira acute conoidea; anfractibus convexis, superne subangulatis, costis obliquis longitudinalibus lirisque spiralibus spinosis undique clathratis; albida, castaneo-fusco fasciata et lineata; aperturs parviuscula, fauce valde lirata, plicis tribus mediocribus. Reeve.

IV. 4. 
hende, zusammengedrückte Längsrippen sind da, wo sie von den etwas dichter stehenden Spiralreifen geschnitten werden, in Stacheln vorgezogen; an der Kante sind, wie schon erwähnt, die Stacheln länger. Die Mündung ist eiförmig, ziemlich weit, unten in einen deutlichen, nach rechts gekrümmten Kanal verschmälert, welcher im Innern braun gefärbt ist; die Aussenlippe ist den Dornen entsprechend gekerbt, der Gaumen bei dem vorliegenden Exemplare nur fein gefurcht, bei dem Reeve'schen, das sich auch durch bedeutendere Grösse und viel stärkere Spindelplatte als älter dokumentirt, sehr stark gerippt; die Spindel trägt drei schmale aber ziemlich vorspringende Falten; die obere ist mehr horizontal und von den beiden unteren durch einen etwas breiteren Zwischenraum getrennt; sie alle laufen auffallend weit auf die Spindelplatte vor.

Aufenthalt an Santa Elena an der Westküste Centralamerikas. Das abgebildete Exemplar aus der Sammlung des Herrn Fr. Paetel in Berlin, Fig. 9 und 10 Copie nach Reeve.

\section{Cancellaria semipellucida Adams et Reeve.}

Taf. 23. Fig. 3. 4.

"Cancellaria testa ovato-ventricosa, tenuicula, vix umbilicata, spira breviuscula, suturis profunde impressis, anfractibus 5, superne rotundatis, longitudinaliter oblique plicato costatis, liris spiralibus, costas super nodulosis, subobsolete decussatis, columella triplicata, apertura ovata effusa, labro simplici fuscescente-alba, semipellucida." - Ad, et Rve.

Long. 18, lat. $13 \mathrm{Mm}$. (ex icone).

Cancellaria semipellucida Adams et Reeve Voy. Samar. p. 42 t. 10 fig. 3. 3a.

- $\quad$ - Reeve Conch. icon. sp. 73.

Gehäuse bauchig eiförmig, dünnschalig, halbdurchscheinend, kaum genabelt, mit kurzem Gewinde und tief eingedrückter Naht. Die fünf oben gerundeten Umgänge sind der Länge nach mit schrägen Rippenfalten skulptirt und werden von wenig auffallenden, aber an den Rippen knotigen Spiralreifen umzogen. Die Mündung ist oval, offen, mit einfachem Mundrand und drei Falten auf der Spindel.

Aufenthalt in der Sulu-See. Die Abbildung nach Reeve 1. c.

\section{C ancellaria laevigat a Sowerby.}

Taf. 23. Fig. 5. 6.

Da mein Taf. 14 fig. 7. 8 abgebildetes Exemplar von dieser Art nicht unerheblich von dem Reeve'schen abweicht, gebe ich hier noch einmal die Abbildung eines etwas bauchigeren, das auch die charakteristische Nahtzeichnung und eine deutlichere Ab- 
flachung unter der Naht hat. Das Original befindet sich in der Sammlung des Herrn Paetel.

\section{Cancellaria Wilmeri Sowerby.}

Taf. 23. Fig. 7. 8.

Testa oblongs, acuminata, fusca; anfractus 7 convexiusculi, superne anguste excavati, costis numerosis noduliferis et liris transversis cancellati; spira elata; apertura oblongo-ovata, fusca; labrum concavo-depressum, arcuatum, superne emarginatum; columella curta, rectiuscula, minute triplicata. - Sow.

Long. 11, lat. $5 \mathrm{Mm}$.

Cancellaria Wilmeri Sowerby Proc. Zool. Soc. 1881 p. 638 t. 56 fig. 2.

Gehäuse gethürmt eiförmig, aussen und innen einfarbig braun mit etwas helleren Rippen und Knötchen, aus sieben etwas gewölbten Umgängen bestehend, die obenher schmal ausgehöhlt und dann von einer Kante umzogen sind. Die Skulptur besteht aus zahlreichen, dichtstehenden, an den Schnittstellen knotigen Rippen und Spiralreifen; das Gewinde ist hoch und gethürmt. Die Mündung ist unregelmässig gerundet dreieckig, innen braun, die Aussenlippe oben etwas ausgeschnitten, dann gerundet, unten flach ausgebreitet, im Gaumen gerippt; die Spindel ist kurz, fast gerade, mit drei kleinen Fältchen. Aufenthalt an den Andamanen. Ich kopire Abbildung und Beschreibung nach Sowerby l. c.

\section{Cancellaria tenera Philippi.}

C. testa ovato-oblonga, umbilicata, alba; anfractibus basi constriotis superne angulatis, supra planis, angulo nodulis coronato, infra angulum cingulo parum elevato subnodoso, ultimo vero cingulis duobus subnodosis ornato; striis transversis obsoletis; umbilico anguste infundibuliformi, margine scuto cincto; apertura subtriangulari, plicis duabus columellae minutis. - Phil.

Alt. 15, diam. 10,5, alt. apert. $9 \mathrm{Mm}$.

Cancellaria tenera Philippi Zeitschr. f. Malacozool. V. 1848 p. 25.

Species sculptura, umbilico, plicis minutis columellae valde distincta. Pars superior horizontalis anfractuum valde lata, cingulum tertium noduliferum anfractus ultimi suturam continuat; plicae longitudinales striaeque transversae obsoletae. Labrum intus laeve.

Hab. Yucatan. 


\section{Cancellaria nassa Roissy.}

C. testa subglobosa, longitudinaliter costata, transversim tenuissime striata, castanea; basi umbilicata; spira brevi, acuta; anfractibus convexis, canali angusto separatis; apertura ovata, triplicata. - Deshayes.

Alt. 20-25 $\mathrm{Mm}$.

Cancellaria nassa Roissy in Buffon Moll. VI. p. 13.

- $\quad$ - Deshayes-Lam. IX. p. 410.

- $\quad$ - Crosse Journal de Conchyliologie IX. p. 233. - Seba Mus. III. pl. 53 fig. 42. - Knorr Vergnügen der Augen IV. pl. 26 fig. 6.

Gebäuse ziemlich kugelig mit kurzem Gewinde, nur aus wenigen stark gewölbten Umgängen bestehend, welche durch eine rinnenförmige Naht geschieden werden. Sie tragen in regelmässigen Abständen scharfe schräge Rippen und werden ausserdem von dichtstehenden feinen Spirallinien umzogen. Der letzte Umgang ist sehr kugelig, unten schräg abgestutzt, mit weitem, scharf umgränztem Nabel. Die Mündung ist rundeiförmig, kurz, innen hellbraun, die Spindel mit drei schrägen Falten. Die ganze Conchylie ist einfarbig braun.

Aufenthalt unbekannt. Die Art ist seit Deshayes nicht wieder gefunden worden und muss als verschollen gelten. Vielleicht ist sie eine der Varietäten von Cancellaria littorinaeformis.

\section{Cancellaria excavata Sow. *)}

Testa oblongo-ovata, tenuicula, minutissime umbilicata, spira turrita, acuta, anfractibus ad suturam late profunde excavatis, ad angulum carinatis, deinde planulatis, laevibus, nitentibus; pellucidoalba; apertura subquadrato-ovata, fauce tenuilirata, columella arcuata, triplicata. - Reeve.

Alt. $25 \mathrm{Mm}$.

Cancellaria excavata Sowerby Proc. Zool. Soc. 1848 p. 137. - Thesaurus II p. 449 tab. 93 fig. 18.

Reeve Conchol, icon, sp. 53.
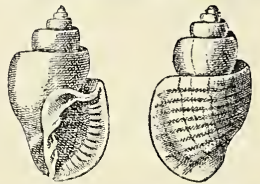

Gehäuse von dem der Cancellaria spirata Lam. nur durch breitere Aushöhlung unter der Naht und schwächere Skulptur unterschieden. Letzteres könnte Folge von Abrollung sein. Was ich als C. excavata gesehen habe, waren wenigstens immer abgerollte Stücke von spirata. Ich lasse darum die Artberechtigung dahingestellt.

Aufenthalt an Tasmanien; die Abbildung nach Reeve.

*) Diese Art ist aus Versehen nicht mit abgebildet; ich gebe darum hier eine Copie nach Reeve im Holzschnitt. 


\section{Erklärung der Tafeln.}

\section{Tafel 1.}

1. 2. Cancellaria goniostoma Sow. - 3. 4. C. brevis Sow. - 5-8. C. rigida Sow. - 9. 10. C. contabulata Sow. - 11. 11. C. goniostoma Sow. - 13-17. C. crenifera Sow. - 17. 18. C. Thomasiana Crosse. -- 19. C. brevis Sow.

Tafel 2.

1-9. Cancellaria Reeveana Crosse.

\section{Tafel 3.} Reeve.

1-4. Cancellaria asperella Lam. - 5. 6. C. melanostoma Sow. - 7-9. C. sinensis

\section{Tafel 4.} sata Sow.

1-4. Cancellaria reticulata Linné. - 5. 6. C. buccinoides Sow. - 7. 8. C. decus-

\section{Tafel 5.}

1. 2. Cancellaria ovata Sow. - 3. 4. C. eburnaeformis Rve. - 5. 6. C. solida Sow. - 7. 8. C. acuminata Sow.

Tafel 6.

1-4. Cancellaria tuberculata Sow. - 5-8. C. bullata Sow. - 9. 10. C. spirata Lam. Tafel 7.

1-8. Cancellaria Spengleriana Desh.

\section{Tafel 8.}

1. 2. Cancellaria nodulifera Sow. - 3-6. C. cassidiformis Bow. - 7. 8. C. pyrum Ad. et Reeve.

\section{Tafel 9.}

1. 2. Cancellaria bifasciata Desh. - 3. 4. C. buccinoides Sow. - 5-8. C. indentata Sow.

Tafel 10.

1-4. Cancellaria urceolata Hinds. $-5-8$. C. textilis Kiener.

\section{Tafel 11.}

1-9. Cancellaria cancellata Linné.

Tafel 12.

1-6. Cancellaria similis Sow. - 7-9. C. chrysostoma Sow. - 10. 11. C. haemastoma Sow. - 12. 13. C. rugosa Lam. 
Tafel 13.

1-3. Cancellaria undulata Sow. - 4-6. C. Bocageana Crosse et Debeaux. - 7-9. C. piscatoria Gmel. - 10. 11. C. hystrix Reeve. - 12.13. C. tessellata Sow.

Tafel 14.

1. 2. Cancellaria Cumingiana Petit. - 3. 4. C. ventricosa Hinds. - 5.6. C. granosa Sow. - 7. 8. C. laevigata Sow.

Tafel 15. vatula Sow.

1. 2. Cancellaria trigonostoma Lam. - 3-5. C. Sowerbyi Crosse. - 6-9. C. claTafel 16.

1. 2. Cancellaria obtusa Desh. - 3. 4. C. semidisjuncta Sow. - 5. 6. C. lamellosa Hinds. - 7. 8. C. macrospira Ad. et Reeve. - 9. 10. C. antiquata Hinds. - 11-13. C. foveolata Sow.

Tafel 17.

1. Cancellaria Cumingii var. subobtusa Crosse. - 2. 3. C. Semperiana Crosse. 4. 5. C. obliquata Lam. - 6. 7. C. Angasi Crosse. - 8-11. C. articularis Sow. - 12. 13. C. Lamberti Souv. - 14. 15. C. Souverbiei Crosse.

Tafel. 18.

1. 2. Cancellaria Montrouzieri Souv. - 3. 4. C. Forestieri Montr. - 5. 6. C. Rougeyroni Souv. - 7. 8. C. Verreauxi Kiener. - 9. 10. C. littorinaeformis Sow.-11. 12. C. coctilis Reeve. - 13. 14. C. littorinaeformis Sow. - 15. C. funiculata Hds. - 17. 18. C. elata Hinds.

Tafel 19.

1-8. Cancellaria scalata Sow. - 9-14. C. costifera Sow. - 15. 16. C. taeniata Sow.

Taf. 20.

1. Cancellaria obesa Sow. - 2. 3. C. bulbulus Sow. - 4. 5. C. affinis Reeve. 6. 7. C. crispata Reeve. - 8. 9. C. serrata Reeve. - 10.11. C. mangelioides Reeve. 12. 13. C. corrugata Hinds.

Tafel 21.

1. Cancellaria coronata Scacchi. - 2. C. pusilla H. Ad. - 3. 4. C. minima Reeve. - 5. C. candida Sow. - 6. C. australis Sow. - 7. C. albida Hinds. - 8. C. lactea Desh. - 9. 10. C. gemmulata Sow. - 11. C. parva Phil. - 12. 13. C. clathrata A. Ad.

\section{Tafel 22.}

1. 2. Cancellaria Stimpsoni Calkins. - 3. 4. C. bicolor Hinds. - 5. 6. C. tenuis A. Ad. - 7. 8. C. nitida A. Ad. - 9. 10. C. purpuriformis Val.

Tafel 23.

1. 2. Cancellaria pulchra Sow. - 3. 4. C. semipellucida Ad. et Reeve. - 5. 6. C. laevigata Sow. - 7. 8. C. Wilmeri Sow. - 9. 10. C. pulchra Sow. 


\section{Register.}

Cancellaria

acuminata Sow.

affinis Reeve

albida Hinds

Angasi Crosse antiquata Hinds

articularis Sow. asperella Lam.

australis Sow.

bicolor Hinds

bifasciata Desh.

Bocageana Crosse et Deb.

brevis Sow.

buccinoides Sow.

buccinoides Couth. vide Admete bucc.

bulbulus Sow.

bullata Sow.

cancellata Linné

candida Sow.

cassidiformis Sow.

chrysostoma Sow.

circumcincta Dall vide Admete circ.

clathrata Ad.

clavatula Sow.

coctilis Reeve

contabulata Sow.

coronata Scacchi

corrosa Rve.

corrugata Hinds.

costata Sow.

costifera Sow.

Couthouyi Jay vide Admete bucc.

cremata Hinds

crenifera Sow.
17. 30

1

crispata Sow. $\quad 78$

Crossei Semper $\quad 79$

Cumingiana Petit. 46. 59

decussata Sow. 18

eburnaeformis Reeve 20

elata Hinds 71

elegans Sow. 12

excavata Sow. $\quad 92$

Forestieri Montr. $\quad 66$

foveolata Sow. 58

funiculata Hinds $\quad 70$

gemmulata Sow. $\quad 85$

goniostoma Sow. 4

granosa Sow. 48

haemastoma Sow. $\quad 38$

hystrix Reeve 44

imperialis Michel. 27

indentata Sow. $\quad 31$

lactea Deshayes 84

laevigata Sow. 49. 90

Lamberti Souv. $\quad 64$

lamellosa Hinds $\quad 55$

littorinaeformis Sow. $\quad 68$

lyrata Ad. et Rve. 71

macrospira Ad et Rve. $\quad 56$

mangelioides Reeve $\quad \mathbf{7 9}$

melanostoma Sow. $\quad 15$

minima Rre. 81

mitriformis Sow. 51

mitriformis Brocchi 81

Montrouzieri Souv. $\quad 66$

nassa Roissy 92

nitida Adams $\quad 88$ 
nodosa Verrill vide Admete nod. nodulifera Sow. nodulosa Lam. obesa Sow.

obliquata Lam. oblonga Kiener obtusa Desh. ovata Sow.

parva Phil.

piscatoria Gmel. piscatorum Sow. pulchra Sow. purpuriformis Val. pusilla A. Ad. pusilla Sow. pyrum Ad. et Rve. Reeveana Crosse reticulata $\mathbf{L}$. rigida Sow. rosea Beck Rougeyroni Souv. rugosa Lam. scalarina Lam. scalata Sow.

Schythei Phil. v. Admete semidisjuncta Sow. semipellucida Ad. et Reeve Semperiana Crosse serrata Reeve similaris Sow. similis Sow.

sinensis Reeve 15

solida Sow.

Souverbiei Crosse $\quad 65$

Sowerbyi Crosse 51

Spengleriana Desh. 25

spirata Lam. 25

Stimpsoni Calkins $\quad 86$

subangulata Wood 82

subobtusa Crosse $\quad 59$

taeniata Sow. $\quad 75$

tenera Phil. $\quad 91$

tenuis A. Ad. $\quad 87$

tessellata Sow. $\quad 45$

textilis Kiener 33

Thomasiana Crosse et Deb. $\quad 10$

trigonostoma Lam. $\quad 50$

Tritonis Sow. $\quad 26$

tuberculata Sow. $\quad 23$

tuberculosa Reeve 28

unalaschkensis Dall. v. Admete un.

undulata Sow.

uniplicata Sow.

urceolata Hinds 32

varicosa Phil. $\quad 80$

ventricosa Hds. $\quad 47$

Verreauxi Kiener $\quad 69$

viridula Möll. vid. Admete

Wilmeri Sow. 


\title{
Genus A d m e te Kroyer.
}

\author{
Von
}

Dr. W. Kobelt.

Testa ovata vel ovato-turrita, tenuiuscula, unicolor griseo-albida; apertura ovata, basi vix subemarginata; labio tenui, recto; columella arcuata, oblique truncata, obsolete bi-vel triplicata; faucibus laevibus. Operculum nullum.

Die Gattung Admete wurde von Kroyer für eine nordische Art errichtet, welche sich durch verkümmerte Falten und schwächere Skulptur von Cancellaria unterscheidet und überhaupt die Kennzeichen einer hochnordischen Art an sich trägt. Es sind seitdem sowohl in den nordischen als in den antarktischen Gewässern eine Anzahl Arten aufgefunden worden und die Gattung hat ziemlich allgemeine Anerkennung gefunden, wenn auch bei einigen Autoren nur als Untergattung.

Das Thier hat nach Möller einen grossen, vorn breit abgestutzten und ausgebuchteten, hinten lang ausgezogenen Fuss, lange fadenförmige Fühler und kleine Augen, die auf Höckern aussen an der Fühlerbasis sitzen. Die Zungenbewaffnung weicht von Cancellaria übrigens so erheblich ab, dass Troschel die Gattung sogar zu einer eigenen Familie erhebt. Möller stellt die Existenz einer Zungenbewaffnung überhaupt in Abrede, Troschel hat aber einen eigenthümlichen Apparat in der Mundmasse gefunden, von dem er zweifelhaft ist, ob er ihn als einen Pfeilzahn oder als einen Kieferapparat auffassen soll. Eine drüsige Masse liegt hinter der Mundmasse, aber der Zusammenhang mit dem Zahn liess sich nicht nachweisen. Sars sagt über die Mundbewaffnung nur „Uncini imperfecte evoluti“, lässt aber die Gattung in der Familie Cancellariidae.

Die Admeten, welche wir bis jetzt mit Sicherheit kennen, gehören fast sämmtlich dem arktischen Meere an; die von Smith und von Watson beschriebenen antarktischen Arten haben mit der Gattung schwerlich etwas zu thun. Nur die beiden von Philippi beschriebenen Arten (Schythei und australis) stammen von der Magellanstrasse.

IV. 4. 


\title{
1. Admete viridula Fabricius.
}

\author{
Taf. 24. Fig. 1-7.
}

Testa ovato-ventricosa, solidula, opaca, albida, epidermide decidua tenui fusco-viridi induta, spira breviuscula conico-producta, apice parvo, laevi; anfractus 7-8 convexi sed in speciminibus typicis haud angulati, spiraliter lirati, liris subaequalibus, rarius minoribus intercedentibus, concentrice plicati, plicis ad intersectionem lirarum subnodosis, in anfractu ultimo peripheriam versus evanescentibus; anfractus nltimus tumidus, basi compressus; sutura distincta vix crenulata. Apertura ovata, estae dimidiam vix superans, basi vix canaliculata, labro expanso, tenui, intus vix sulcato; columella callo tenui diffuso obducta, plica, vix conspicua.

Alt. ad $20 \mathrm{Mm}$.

Tritonium vir idulum Fabricius Fauna groenl. p. 402.

A d m ete crispa Möller Index Moll. Groenl. p. 15.

- viridula Sars Moll. Norv. arct. p. 216 t. 13 fig. 1a.

- $\quad$ Kobelt Prodromus p. 126.

- $\quad$ - Herzenstein Murmankïste p. 685.

- $\quad$ - Aurivillius Vega Expedit. p. 329.

- $\quad$ - Friele Norske Nordh. Exp. pl. 8 fig. 27-30.

- - Middendorff Mal. Ross. II. t. 10 f. 3. 4.

Cancellaria viridula Reeve Conch. icon. sp. 85.

$$
\text { - _ Sowerby Thes. fig. } 102
$$

Var. undato-costata, testa ventricosiore, anfractibus ad suturam fere planulatis, costis elevatis, regularibus circa 15. (Fig. 6.)

Admete undato -costata Verkrüzen Jahrb. D. Mal. Ges. 1876 tab. 4 fig. 6. - Sars Moll. Norv. aret. t. 13 fig. $1 \mathrm{~b}$.

Var. producta, spira turrita, anfractibus subangulatis vel scalariformibus, sutura profunda fere. canaliculata, apertura dimidia testa multo breviore, plicis longitudinalibus fere evanidis. Long. $16 \mathrm{Mm}$.

Admete viridula var. producta Sars Moll. reg. arct. Norv. p. 217 t. 13 fig. 2.

Var. laevior, Leche in Kon. Vetensk. Akad. Handl. vol. 16 Nr. 2 p. 48. - Aurivillius Vega Exped. p. 329.

Var. distincta, Leche 1. c. p. 48 t. 1 f. 14.

Gehäuse eiförmig kugelig bis bauchig spindelförmig, nicht dickschalig, aber fest, weisslich, mit einer sich leicht abreibenden bräunlichen Epidermis überzogen, mit kurzem kegelförmigem Gewinde und kleinem glattem Apex. Die sieben bis acht Umgänge sind bei der typischen Form rein gerundet, ohne Abflachung und Kante an der Naht, von ziemlich dichtstehenden Spiralreifen umzogen und mit radialen Rippenfalten sculptirt, welche auf dem letzten Umgang von der Peripherie ab verschwinden. Das Verhältniss zwischen Reifen und Rippen ist sehr wechselnd und es entstehen dadurch die mannigfachsten Skulp- 
turvarietäten. Die Spiralreifen sind meistens ziemlich gleichmässig und dicht; nur selten schieben sich schwächere Leistchen ein oder treten die Reifen auf dem letzten Umgang nach der Basis hin weiter auseinander; die Rippen sind bald gerundet und so dicht gedrängt, dass sie nur durch schmale Furchen geschieden erscheinen, bald schmäler und durch breite $Z$ wischenräume getrennt; bei einem Exemplare meiner Sammlung aus Reikjavik sind sie kaum stärker, als die Reifen, und die oberen.Umgänge erscheinen fast rein gegittert. In anderen Fällen verkümmern sie zu kurzen Höckern unter der Naht (Fig. 1) oder auch ganz, wie bei var. laevior Leche (Fig. 3). Der letzte Umgang ist stets etwas aufgeblasen, unten zusammengedrückt, ohne einen eigentlichen Stiel zu bilden, und ungenabelt. Die Mündung ist bald höher bald niedriger als die Hälfte des Gehäuses, bei manchen Varietäten bis zu zwei Drittel ausmachend, unten zu einer breiten Ausgussrinne, nicht eigentlich einem Kanal, zusammengedrückt, die Spindel mit dickerem oder dünnerem fest angedrück̀tem Belag und kaum angedeuteten Falten; die Aussenlippe bleibt immer dünn, die äusseren Reifen scheinen mitunter durch.

Admete viridula ist eine ächt arktische Art, die nach Norden zu immer grösser und veränderlicher zu werden scheint. Durch die Güte Friele's, der mir die noch unpublicirten Tafeln seines grossen Werkes zusandte, ist es mir möglich gewesen, einige mir sonst nicht zugänglich gewordene arktische Formen abzubilden, welche erheblich von dem Typus abweichen (Fig. 1-4). Der Ausgangspunkt für alle diese Formen ist die bauchige Varietät, welche Verkrüzen als Admete undat ocostata beschrieben hat, ausgezeichnet durch die auffallend bauchige Gestalt, die aufgetriebenen, von der Naht aus fast horizontal verlaufenden Umgänge und die starke Rippenskulptur. Unmittelbar an sie an schliesst sich unsere Fig. 1, Copie nach Friele 1. c. pl. VII fig. 27, ebenfalls aufgeblasen, aber mit viel schwächerer Skulptur und auffallend niederem Gewinde, dessen Windungen der Abbildung nach nur Spiralskulptur, aber keine Rippen haben. Das Extrem erreicht diese Form in Fig. 3, Copie nach Friele Fig. 28, wo die Radialskulptur vollkommen verschwunden ist. Ein Exemplar in Paetel's Sammlung, als Admete grandis Gray, Spitzbergen, leg. Kroyer bezeichnet, schliesst sich unmittelbar an undato-costata an, hat aber auf dem letzten Umgang unter der Naht nur noch schwache Andeutungen von Falten, während sie auf dem hohen Gewinde sehr scharf ausgeprägt sind. - Eine sehr eigenthümliche Abweichung bildet Fig. 4, Copie nach Friele Fig. 29 ; sie bildet nämlich an dem letzten und vorletzten Umgange eine deutliche, durch einen stärkeren Spiralreifen bezeichnete Kante aus, während die Radialfalten bis auf geringe Andeutungen verschwunden sind; sie führt dadurch einigermassen nach Admete contabulata Friele hinüber, doch ohne in sie überzugehen. 


\section{Admete buccinoides Couthouy.}

Taf. 24. Fig. 12.

Testa ovato-conica, subturrita, corneo-lactea; anfractus 5-6 convexi, supra planati, sutura distincta discreti, lineis incrementi distinctis, prope suturam interdum costiformibus lirisque spiralibus rudibus subdeccusata; apertura dimidiam testae aequans, ovata, labro acuto, margine leviter crenulato; columella arcuata, callo tenui obducta, plicis tribus parum conspicuis obliquis munita; canalis indistinctus.

Long. $12-15 \mathrm{Mm}$.

Cancellaria buccinoides Couthouy Bost. Journ. N. H. II. p. 105 t. 3 fig. 3 , nec Sowerby.

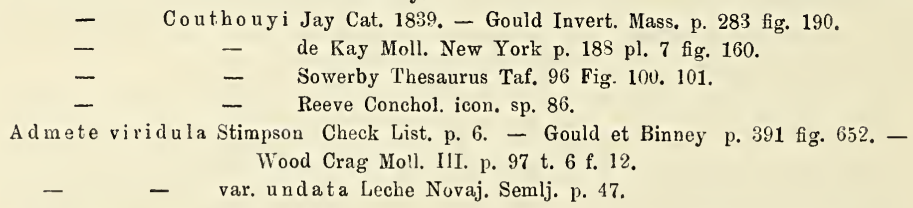

Gehäuse eiförmig-kegelförmig, mit gethürmtem, spitz zulaufendem Gewinde und kleinem Apex, milchweiss bis hornfarben. Es sind fünf oder sechs Umgänge vorhanden, von denen der letzte zwei Drittel der Gesammtlänge ausmacht; die Naht ist deutlich, mitunter tief eingedrückt; die Umgänge sind gut gewölbt, selbst aufgeblasen, obenher etwas abgeflacht, doch ohne Kante; die Skulptur besteht aus deutlichen Anwachslinien, welche unter der Naht mitunter faltenartig vorspringen, und deutlichen groben Spirallinien, welche mit den Anwachslinien eine Art Gitterung hervorbringen; starke knotige Rippen scheinen bei der amerikanischen Form nicht vorhanden zu sein. Die eiförmige Mündung nimmt ungefähr die Hälfte des Gehäuses ein; die Aussenlippe ist scharf, ihr Rand den Reifen entsprechend leicht gezähnelt; die Spindel ist mit einem dünnen Callus belegt, welcher drei leichte schräge Falten trägt; ein Kanal ist nur undeutlich vorhanden.

Aufenthalt an der amerikanischen Ostküste und an Neufundland.

Es kann keinem Zweifel unterliegen, dass die amerikanische Admete durch Zwischenformen mit der europäischen resp. nordischen verbunden ist; aber ihre schlankere Gestalt, das Zurücktreten der Rippen und die drei Falten bedingen doch ihre Anerkennung mindestens als eigenthümliche Lokalrasse 


\section{Admete borealis A. Adams.}

Taf. 24. Fig. 10. 11.

Testa ovato-oblonga, tenuis, albida, epidermide fusco-cornea induta, spira turrita, apice acuto; anfractus 6 aequaliter convexi, subtumidi, supremi obscure radiatim plicati, inferi sulcis spiralibus latiusculis sat distantibus tantum cingulati, ultimus ventricosus, circa rimulam umbilicalem in cristam subcompressus; sutura profunde impressa. A pertura sat regulariter ovata, parum lunata, labro tenui, acuto, simplici, columella valde arcuata, basi ante apicem canalis oblique subtruncata, callo tenui expanso obducta, plicis fere omnino obsoletis.

Alt. 27, diam. $18 \mathrm{Mm}$.

Admete borealis A. Adams *) Proc. Zool. Soc. Lond. 1855 p. 122.

Gehäuse für die Gattung ungewöhnlich gross, dünnschalig, weisslich mit Spuren einer hornbraunen Epidermis, die Textur ganz die der hochnordischen Arten; Gewinde gethürmt mit spitzem Apex. Die sechs Umgänge sind aufgeblasen und gleichmässig gewölbt, die oberen bei meinem Exemplare so zerfressen, dass man eine Skulptur nicht mehr erkennen kann, nach Adans leicht radial gefaltet, die unteren ohne jede Spur von Radialskulptur, die Anwachsstreifen ausgenommen, nur von breiten ziemlich entfernt und regelmässig stehenden Spiralfurchen umzogen; der letzte Umgang ist aufgeblasen und um die Nabelritze herum schwach kammartig zusammengedrückt. Die Mündung ist rein oval, nur wenig ausgeschnitten, und macht etwa $3 / 5$ der Gesammtlänge aus; ein eigentlicher Kanal ist nicht vorhanden, nur ein schiefer Ausschnitt, da die dünne scharfe Aussenlippe etwas über das Ende der unten schräg abgestutzten Spindel hinausreicht. Die Spindel ist gebogen, in der Mitte erheblich ausgeschnitten, mit einem dünnen, weit ausgebreiteten Callus belegt, auf dem kaun eine Spur von Falten zu erkennen ist.

Aufenthalt im hohen Norden, nach Adams an der Melville-Insel. Das abgebildete Exemplar erhielt ich vor Jahren von Vimont ohne bestimmte Fundortsangabe. Es stimmt mit der unten kopirten Adams'schen Diagnose so genau, dass ich über die Zugehörigkeit keinen Zweifel habe; Dimensionen hat Adams nicht angegeben. - Ich würde auch Admete (Trichotropis) inflata Friele hierherbeziehen, wenn sie nicht deutlich und tief genabelt wäre.

*) A. testa ovato-oblonga, albida, epidermide fusco-cornea induta; anfr. 6 convexis, supremis obscure longitudinaliter plicatis, ultimo ventricoso spiraliter sulcato, sulcis subdistantibus; suturis impressis; apertura ovali, labro tenui expanso, columella arcuata simplici antice subtruncata, labro margine acuto intus simplici. 


\section{Admete inflata Friele.}

Taf. 24. Fig. 17.

Testa tenuis, albida, semipellucida, ovalis; anfractibus 5 tumidis, valde crescentibus, sutura parum impressa, distincta, spira brevi, apice retuso, laevi; apertura $1 / 3$ testae longitudinem aequante, semilunata, columella recta, plicis 1 vel 2 obscuris munita, reflexa, umbilicum ex parte praecludente distinctum et profundum, canali brevissimo. Sculptura lineis densis angustis impressis spiraliter excavata, striisque incrementi plus minusve conspicuis, flexuosis. - Friele.

Long. 8, lat. 4,5 , apert. long. $5 \mathrm{Mm}$.

Trichotropis inflata Friele Jahrb. D. Mal. Gesellsch. VI. 1875 p. 275. - Norske Nordh. Fxped, pl. 8 fig. 33.

\section{- $\quad$ - Kolelt Prodromus p. 206.}

Gehäuse dünnschalig, doch fest, weisslich, halbdurchscheinend, lang eiförmig, aus fünf aufgetriebenen rasch zunehmenden Windungen bestehend, welche durch eine deutliche, aber wenig eingedrückte Naht geschieden werden; das Gewinde ist kurz mit eingewundenem glattem Apex. Die Skulptur besteht aus feinen dichtstehenden eingedrückten Linien und mehr oder minder deutlichen Anwachsstreifen. Die Mündung ist halbmondförmig, etwa zwei Drittel des Gehäuses ausmachend, mit kurzem kaum abgesetztem weitem Kanal; die Spindel ist fast gerade, der Callus über den deutlichen tiefen Nabel zurückgeschlagen, mit ein oder zwei deutlichen Falten.

Aufenthalt an Spitzbergen; Abbildung und Beschreibung nach Friele.

Friele hat diese Art ursprünglich als Trichotropis beschrieben, wofür ich keinen rechten Grund einsehe; in den Erläuterungen, die er mir mit seinen noch unpublizirten Tafeln sandte, stellt er sie dagegen zu Admete.

\section{Admete contabulata Friele.}

\section{Taf. 24. Fig. 8. 9.}

Testa albida, turrito-fusiformis, anfractibus 5 supra angulatis, parum ventricosis, contabulatis, sutura parum impressa, spira producta, apice retuso fere mamillari; apertura ovali, expansa, infra acuminato-rotundata, dimidiam testae longitudinem aequante; columella recta, plicis 2 parum conspicuis, canali brevissimo. Sculptura spiraliter costulata, costulis (in ultimo anfractu 16) ad carinam partem anfractuum supremam circumcingentem patentibus, supra nunc laevem, nunc 1 vel 2 costis haud conspicuis instructam, in anfractibus 2 mediis plicis longitudinalibus obliquis, circum carinam nodosis, in ultimo anfractu evanidis, anfractibus primariis convexis, laevibus et nitidis. - Friele.

Long. 8, lat. 4,5 $\mathrm{Mm}$.

Admete contabulata Friele Jahrb. D. Mal. Gesellsch. VI. 1879 p. 276. - Norske Nordh. Exped. pl. 8 fig. 31. 32.

Kobelt Prodromus p. 126. 
Gehäuse weisslich, gethürmt spindelförmig, aus nur fünf Umgängen bestehend, welche obenher horizontal abgeflacht und deutlich kantig, und dann leicht gewölbt sind. Die Naht ist nur wenig eingedrückt, das Gewinde vorgezogen mit fast zitzenförmigem Apex. Die Mündung ist eiförmig, unten spitz zugerundet, oben ausgebreitet, etwa halb so lang wie das Gehäuse; die Spindel ist fast gerade mit zwei wenig deutlichen Falten, der Kanal ganz kurz. Die obersten Umgänge sind glatt, glänzend, gewölbt, die folgenden von Spiralreifen umzogen, welche auch über der Kante vorhanden sind, mitunter aber auch fehlen; die beiden mittleren Umgänge haben deutlichc Rippenfalten, welche am Kiel knotig sind; auf dem letzten Umgang verschwinden sie.

Aufenthalt an Spitzbergen; Abbildung und Beschreibung nach Friele.

\section{Admete unalaschkensis Dall.}

Taf. 24. Fig. 15.

Testa gracilis, acuta, solida, alba, vestigiis epidermidis fuscae deciduae; apex minutus, alkus, lacvis. Anfractus 6 superne angulati, super angulum radiatim fortiter striati, liris crassiusculis spiralibus 3 in spirae anfractibus, 7 in ultimo cingulati, superioribus tribus nodulosis. Apertura 2/5 longitudinis aequans, alba, columella rosea, labro leviter incrassato, intusque sulcato, sulcis liris externis respondentibus; columella bi-vel triplicata; cana'is brevis, rectus, parum profundus, subangustus. Dall angl.

Long. 19, lat. $9 \mathrm{Mm}$. (ex icone).

Cancellaria (Trigonostoma) unalaschkensis Dall Proc. Cal. Soc. 1873 V. p. 13. Occasional Papers pl. 2 f. 1 (nec 2).

- unalaschkensis Tryon Manual p. 72 tab. 3 fig. 41.

Gehäuse schlank mit spitzem Gewinde, festschalig, weiss mit Spuren einer hinfälligen bräunlichen Epidermis; Apex klein, weiss, glatt. Die sechs Umgänge sind, die apicalen ausgenommen, oben kantig und mit kurzen dichtstehenden Rippenfalten, - Dall fasst die Zwischenräume als Streifen auf - skulptirt, welche die obersten drei Spiralreifen gekörnelt oder knotig erscheinen lassen; untcr der Kante laufen starke Spiralreifen, auf den oberen Umgängen drei, auf dem letzten sieben. Die Mündung nimmt etwa zwei Fünftel der Gesammtlänge ein und ist innen weiss, die Spindel rosa überlaufen, der Mundrand leicht verdickt, der Gaumen gefurcht; die Furchen entsprechen den Spiralreifen der Oberfläche; die Spindel trägt zwei oder drei schwache Falten; der Kanal ist gerade, kurz, nur wenig tief und ziemlich eng.

Aufenthalt an Unalaschka, von Dall in 50-60 Faden Tiefe gedrakt. Abbildung und Beschreibung nach Dall.

Dall rechnet diese Art zwar zu den ächten Cancellarien, aber die ganze Beschaffenheit, die Epidermis und die Heimath verweisen sie zu Admete. 


\section{Admete circumcincta Dall. \\ Taf. 24. Fig. 16.}

Testa gracilis, acuta, tenuiuscula, apice minuto, laevi; anfractus 6 rotundati, superne obsoletissime tabulati, spiraliter lirati, liris subaequalibus, sed minoribus nonnullis intercedentibus, et costellis radiantibus in spirae anfractibus conspicuis, interdum nodulosis, in ultimo obsolescentibus subdecussati. Rufescenti-rosea, liris saturatioribus. Labrum tenue, liris externis translucentibus; columella vix callosa, plicis 2-3 subobsoletis munita; canalis brevis, profundus. - Dall. angl.

Alt. 20, diam. 9,5 Mm.

Cancellaria (Trigonostoma) circumcincta Dall Proc. Cal. Soc. V. 1873 p. 13. Occasional Papers pl. 2 fig. 2.

Gehäuse schlank mit spitz zulaufendem Gewinde und kleinem glatten Apex. Die sechs Umgänge sind fast rein gerundet, nur oben abgeplattet mit einer schwachen Kante; sie werden durch ziemlich gleiche Spiralreifen, zwischen welche sich manchmal mehrere schwächere einschieben, und durch Radialrippchen, die aber auf dem letzten Umgang verkümmern, etwas gegittert. Die Färbung ist ein lebhaftes Rosa mit intensiver gefärbten Reifen. Die Mündung geht in einen kurzen, aber tiefen Kanal aus; die Aussenlippe ist dünn, so dass die Reifen durchscheinen, die Spindel hat nur einen schwachen Belag mit 2-3 verkümmerten Falten. - Das Thier ist nach Dall schieferfarben.

Aufenthalt an der aleutischen Insel Shumagin, in zehn Faden Tiefe von Dall gedrakt. Abbildung und Beschreibung nach Dall.

\section{Admete japonica Smith.}

Taf. 24. Fig. 18.

T. ovata, pyramidata, alba, crassiuscula; anfractus 7 convexi, sutura profunda divisi, costis circiter 13 in anfractu rotundatis, quam interstitia latioribus et liris spiralibus in penultimo 6-7, in ultimo 12 sculpti, apertura parva, longitudinis $3 / 8$ vix aequans; columella plicis 2 fere medianis obliquis nunita. - Smith angl.

Alt. 12, diam. $5 \mathrm{Mm}$.

Cancellaria japonica Smith Proc. Zool. Soc. 1879 p. 216 t. 20 fig. 54.

$$
\text { - } \quad \text { Kobelt Synopsis } 1879 \text { p. } 39 .
$$

Gehäuse eiförmig pyramidal, weisslich, ziemlich dickschalig, aus sieben gewölbten Umgängen bestehend, welche durch eine tiefe Naht geschieden werden; die Skulptur besteht aus gerundeten Radialrippen, welche breiter sind als ihre Zwischenräume, etwa dreizehn auf den Umgang, und aus schwächeren Spiralreifen, von denen auf dem vorletzten 
Umgang 6-7, auf dem letzten 12 stehen. Die Mündung ist klein, kaum $3 / 8$ so hoch wie das Gehäuse; die Spindel trägt fast in der Mitte zwei schwache schräge Falten.

Aufenthalt an Japan; Abbildung und Beschreibung nach Smith.

\section{Admete cancellata n. sp.}

\section{Taf. 24. Fig. 14.}

Testa parva, ovato-pyramidata, crassiuscula, cinereo-fusca; anfractus 6 convexi, supra breviter planati, costellis radiantibus quam interstitia angustioribus circa 15 in anfractu ultimo, lirisque spiralibus vix minoribus 3 in penultimo distincte clathrati, costellis ad peripheriam anfractus ultimi subite evanescentibus; apertura parva, irregulariter ovata, canali indistincto, columella medio distincte biplicata.

Alt. 9,5, diam. 5,5 $\mathrm{Mm}$.

Aus Paetel's reicher Sammlung liegt mir eine kleine Schnecke als Cancellaria japonica vor, welche mit der vorhergehenden zwar nahe verwandt ist, aber sich in der Skulptur so erheblich von derselben unterscheidet, dass ich sie vorläufig wenigstens als eigene Art ansehen muss. Die Skulptur besteht nämlich aus schmalen hohen Radialrippen, welche schmäler sind als ihre Zwischenräume, und aus beinahe ebenso starken Spiralreifen, die mit jenen eine äusserst regelmässige Gitterung mit fast rein quadratischen $\mathrm{Ma}$ schen bilden, ohne dass sie sich an den Schnittstellen verdicken; auf dem letzten Umgang brechen die Längsrippen an der Peripherie plötzlich ab, wie das ja auch bei Admete viridula nicht selten der Fall ist (cfr. Fig. 7). Im Uebrigen stimmen Gestalt, Textur und auch die Spindelfalten ganz mit Admete japonica überein und ist das Vorkommen von Zwischenformen durchaus nicht ausgeschlossen.

Aufenthalt an Japan.

\section{Admete tabulata Sowerby.}

\section{Taf. 24. Fig. 13.}

Testa oblongo-turrita, spiraliter costata, costis planato-concavis, longitudinaliter obscure plicata, albida, epidermide pallide fuscescente induta; anfractibus 7 convexis, superne angulatis, supra angu$1^{\text {um }}$ concavo-depressis; apertura oblongo-ovata; columella rectiuscula, minute plicata. - Sow.

Long. 22, diam. $10 \mathrm{Mm}$.

Admete tabulata Sowerby Pr. Z. Soc. Londen 1875 p. 128 t. 24 fig. 3. Tryon Manual pl, 7 fig. 30.

Gehäuse gethürmt langeiförmig, dicht von starken, aber flachen oder selbst leicht ausgehöhlten Spiralreifen umzogen, welche durch wenig deutliche Längsfalten gekörnelt IV. 4. 
erscheinen; unter einer dünnen hellbräunlichen Epidermis ist die Farbe weisslich. Die sieben Umgänge sind gut gewölbt, obenher kantig und über der Kante ausgehöhlt; die Rippen setzen sich anscheinend nicht über die Kante hinaus fort. Die Mündung ist langeiförmig, die Spindel gerade mit einer undeutlichen Falte.

Aufenthalt im arktischen Ocean. - Abbildung und Beschreibung nach Sowerby.

\section{1. ? Admete imbricata Watson.}

Testa ovata, lutescenti-albida, spira exserta conica, subscalari, parva; anfractus 5 bene rotundati, spiraliter lirati interstitiis latioribus, lamellis longitudinalibus appressis ruditer imbricatis sculpti, ultimus magnus, sutura impressa. Apertura semicircularis, sat magna, labro regulariter rotundato, patulo, intus distincte sulcato, columella callo tenui dilatato obducta, distincte biplicata.

Alt. $16 \mathrm{Mm}$.

Cancellaria imbricata Watson Linn. Soc. Journal Zoology vol. XVI. p. 325.

Südlich vom Cap vom Challenger gefunden, die Zugehörigkeit zu Admete nicht ganz sicher.

\section{Admete carinata Watson.}

Testa late ovata, carinata, spira brevissima, scalari, obtusa; alba; anfractus 5 medio angulati supra excavati, liris spiralibus inaequalibus cingulati, lineis incrementi rudibus subdecussati; sutura impressa. Apertura dimidiam testae superans, ovata, labro rotundato, aperto; columella contorta, callo tenui diffuso obtecta, obsolete biplicata.

Cancellaria (Admete) carinata Watson Linn. Soc. Journal Zoology vol. XVI. p. 327.

Hab. Royal Sound, Kerguelen.

\section{Admete specularis Watson.}

Testa parva, ovata, basi rotundata, spira brevi, scalari, apice obtuso; anfractus $5^{1 / 2}$ rotundati, supra leviter angulati et super angulum planati, spiraliter lirati et lineis incrementi filiformibus sculpti, ultimus basi leviter productus; sutura impressa. Apertura semicircularis, sat magna, labro regulariter arcuato, aperto, intus leviter sulcato; columella callosa, obsolete biplicata.

Alt. $9 \mathrm{Mm}$.

Cancellaria (Admete) specularis Watson Linn. Soc. Journal Zoology vol. XVI. p. 326.

Hab. Hearth Island. 


\section{Admete ovata Smith.}

"Testa ovata, tenuis, semipellucida, coeruleo-alba, anfractus $4-5$ convexi, supremi $2-3$ erosi, penultimus radiatim oblique plicatus, plicis superne suturam non attingentibus, spiraliter striatus, ultimus maximus, subglobosus, striis spiralibus circiter 20 insculptus; apertura ovata, longitudinis totius $8 / 13$ adaequans; columella arcuata, callo tenuissimo induta, basi oblique truncata." (Smith.)

Long. $61 / 2$, lat. $31 / 2 \mathrm{Mm}_{\text {, }}$ apert. $4 \mathrm{Mm}$. longa, 2 lata.

A dmete ovata Edg. Smith Ann. Mag. IV. vol. 15 p. 426 (1875).

Habitat ad Japoniam, lat. $43^{0}$ N., prof. $48 \mathrm{~F}$.

\section{Admete globularis Smith.}

„Testa parva globularis, tenuis, nivea; anfractus $41 / 2$, primi tres parvi convexiusculi sutura leviter canaliculata sejuncti, ultimus globosus magnus, omnes spiraliter tenuissime sulcati; apertura aliquanto magna subpyriformis, longitudinis totius $3 / 4$ aequans; columella callo tenui lato supra anfractum producto amicta, versus basim oblique truncata; labrum tenue, simplex." (Smith).

Long. 4, diam. $2 \mathrm{Mm}$.

Admete globularis Edg. Smith Ann. Mag. IV. vol. 15 p. 426.

Habitat ad Japoniam, lat. $43^{\circ} \mathrm{N}$., prof. $48 \mathrm{~F}$.

Anmerkung: Gleicht in der Form beinahe einer kleinen Cassis saburron. (Smith.)

\section{Admete Schythei Philippi.}

Testa imperforata, tenuis, alba, epidermide tenui, fuscescente vestita, oblongo-fusiformis, transversim profunde sulcata seu striata, ecostata; anfractibus 6 , convexis, praesertim ad suturam, ultimo spiram fere superante; apertura oblonga; plica unica columellae, esque parum distincta; labro albo nitido. - Phil.

Alt. 15 , diam, $9^{1} / 2$, alt. apert. $9 \mathrm{Mm}$.

Cancellaria Schythei Philippi Mal. Bl. IIr. 1856 p. 164.

Hab. fretum Magellanicum.

\section{Admete australis Philippi.}

Testa sübperforata, tenuis, alba, epidermide tenui fuscescente vestita, oblongo-fusiformis, transversim sulcata, in anfractibus superioribus costis frequentibus radiantibus munita, anfractibus tumidis, ad suturam fere horizontalibus, ultimo spiram euperante, superius ventricoso; apertura oblonga; la mina labiali crasea, eburnea; plicis duabus in columella. - Phil.

Alt. 12 , diam. $8^{2} / 3$, alt. apert. $71 / 2 \mathrm{Mm}$. Cancellaria australis Philippi Mal. Bl. III. 1856 p. 164.

Hab. fretum Magellanicum. 


\section{Admete limnaeaeformis Smith.}

Testa tenuissima, subdiaphana, laevis, parum nitens, vitreo-alba; anfractus 3 , primi duo parvi, convexiusculi, ultimus amplissimus, convexus; sutura simplex, aliquanto profunda; apertura ovata, superne paululum acuminata, longitudine testae totius circiter ${ }^{2} / 5$ aequans; columella leviter obliqua, vix arcuata, inferne obliqua et subabrupte truncata, superne callo tenuissimo, super anfractum expanso, labro juncta; labrum simplex, tenue.

Long. 2,5, diam. 1,5 Mm.

Admete (-?) limnaeaeformis Smith Moll. Kerguelen p. 6 t. 9 fig. 4.

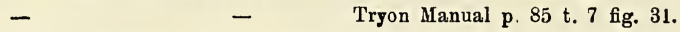

Gehäuse ganz dünnschalig, fast durchsichtig, glatt, wenig glänzend, glasartig weiss. Es sind nur drei Umgänge vorhanden, die beiden ersten klein, leicht gewölbt, der letzte sehr gross und stark gewölbt; die Naht ist einfach, ziemlich tief. Die Mündung ist eiförmig, oben spitz, etwa $3 / 5$ des Gehäuses einnehmend; die Spindel ist etwas schief, kaum gebogen, unten schräg und ziemlich plötzlich abgestutzt, oben durch einen sehr dünnen, über die Mündungswand ausgebreiteten Callus mit dem dünnen, einfachen Mundrand verbunden.

Aufenthalt an Kerguelen, in 4-5 Faden Tiefe auf Tang und Polyzoen gefunden. Sie gèhört schwerlich zu Admete und ist wahrscheinlich unausgewachsen.

\section{Admete nodos a Verrill et Smith.}

"Shell rather small thick and solid, short, stout, with coarsely ribbed and rudely nodulous, convex whorls. The spire is short and rapidly tapered, with the apex apparently blunt, but eroded in both of our specimens. Whorls apparently $4-5$, the last 2 are strongly convex with a well impressed suture. The last whorl is surrounded by 5 rows of rather large and coarse prominent nodules, joined together by low revolving ridges and situated upon about 12 broad, low, rounded or wave like ribs. On the penultimate whorl the ribs are more prominent and continue across the whorl and bear about 3 rows of nodules. The aperture is short, broad-ovate, more acute behind than in front; the canal is very short and broad flaring, widely opened and twisted a little to the left, but does not cause any interruption or constriction of the outer lip which is regularly arched, forming nearly a semicircle and has a thin flaring edge, which is strongly thickened a short distance within the aperture, anteriorly the outer lip continues round in a regular curve and joins the columella without a distinct notch; posteriorly there is a distinct rounded groove within the aperture at the junction of the lip with the body-whorl; the columella is strongly sinuous and twisted, its anterior margin forms a distinct ridge or fold and another similar fold is situated at about the middle; the inner lip is excavated in the middle and is thickened by a layer of white enamel, which is continuous from the outer lip around to the anterior margin. No operculum. Colour white. - Long. 12, diam. 8 Mm. ${ }^{\star}-$ Verrill.

Admete nodosa Verrill Transact. Connect. VI. p. 419 pl. 44 fig. 9.

Im Tiefwasser vor der Küste von Neuengland gefunden, meiner Ansicht nach wohl besser eine eigene Gattung bildend. 


\section{Erklärung der Tafel.}

\section{Tafel 24.}

1-7. Admete viridula Fabr. - 8. 9. A. contabulata Friele. - 10.11. A. borealis A. Ad. - 12. A. buccinoides Couth. - 13. A. tabulata Sow. - 14. A. cancellata n. 15. A. unalaschkensis Dall. - 16. A. circumcincta Dall. - 17. A. inflata Friele. - 18. A. japonica Smith. 


\section{Register.}

\author{
Admete Kroyer \\ australis Phil. \\ borealis A. Ad. \\ buccinoides Couth. \\ cancellata Kob. \\ carinata Watson. \\ circumcincta Dall. \\ contabulata Friele. \\ Couthouyi Jay. \\ crispa Möll. \\ globularis Smith. \\ grandis Gray.
}

\begin{tabular}{r|}
97 \\
107 \\
101 \\
100 \\
105 \\
106 \\
104 \\
102 \\
100 \\
98 \\
107 \\
99
\end{tabular}

japonica Smith. imbricata Watson. inflata Friele.

102 limnaeformis Smith. $\quad 108$ nodosa Verrill. 108 ovata Smith. 107 Schythei Phil. $\quad 107$ specularis Wats. 106 tabulata Sow. $\quad 105$ unalaschkensis Dall. 103 undato-costata Verkr. $\quad 98$ viridula Fabr. 


IV. 4 .
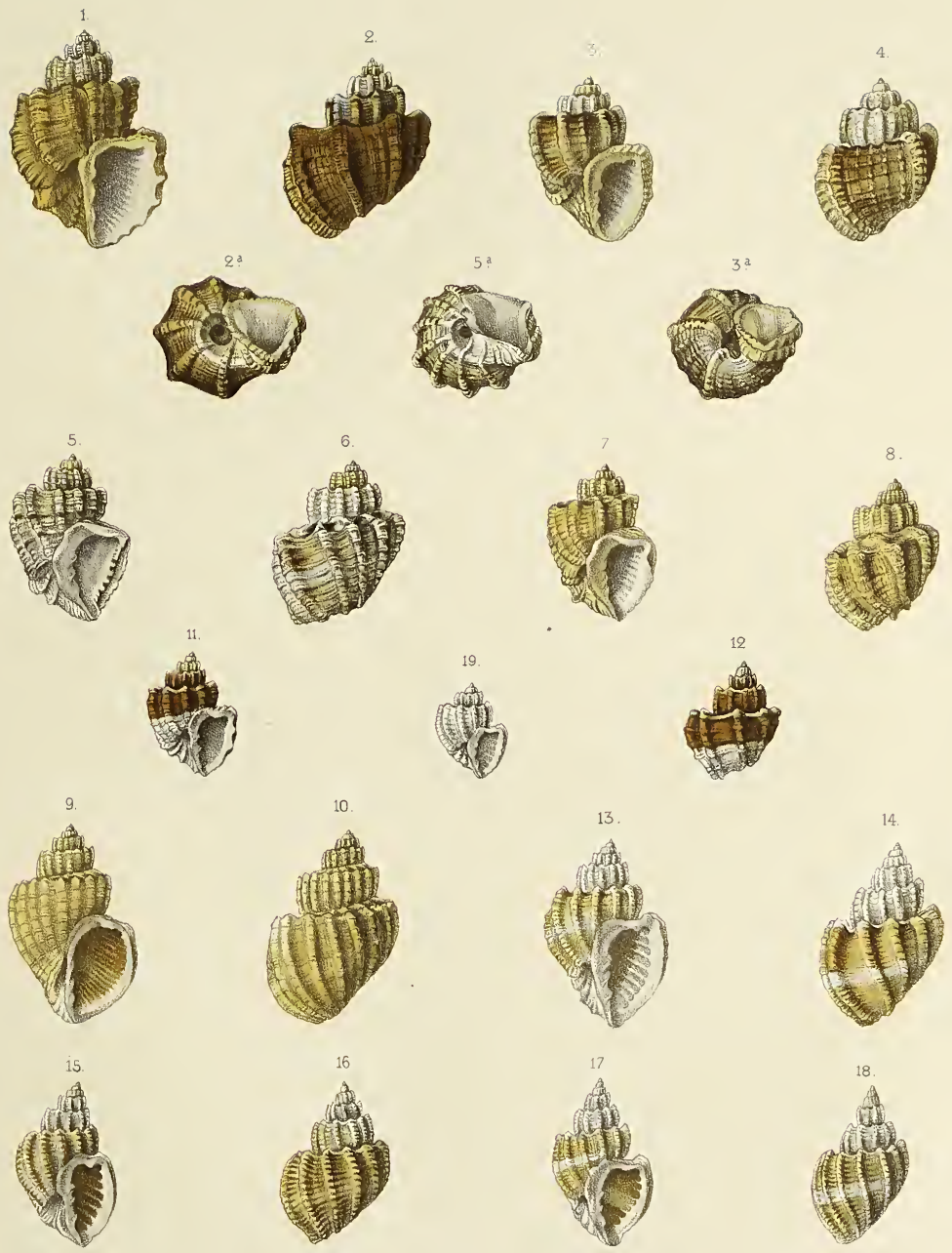


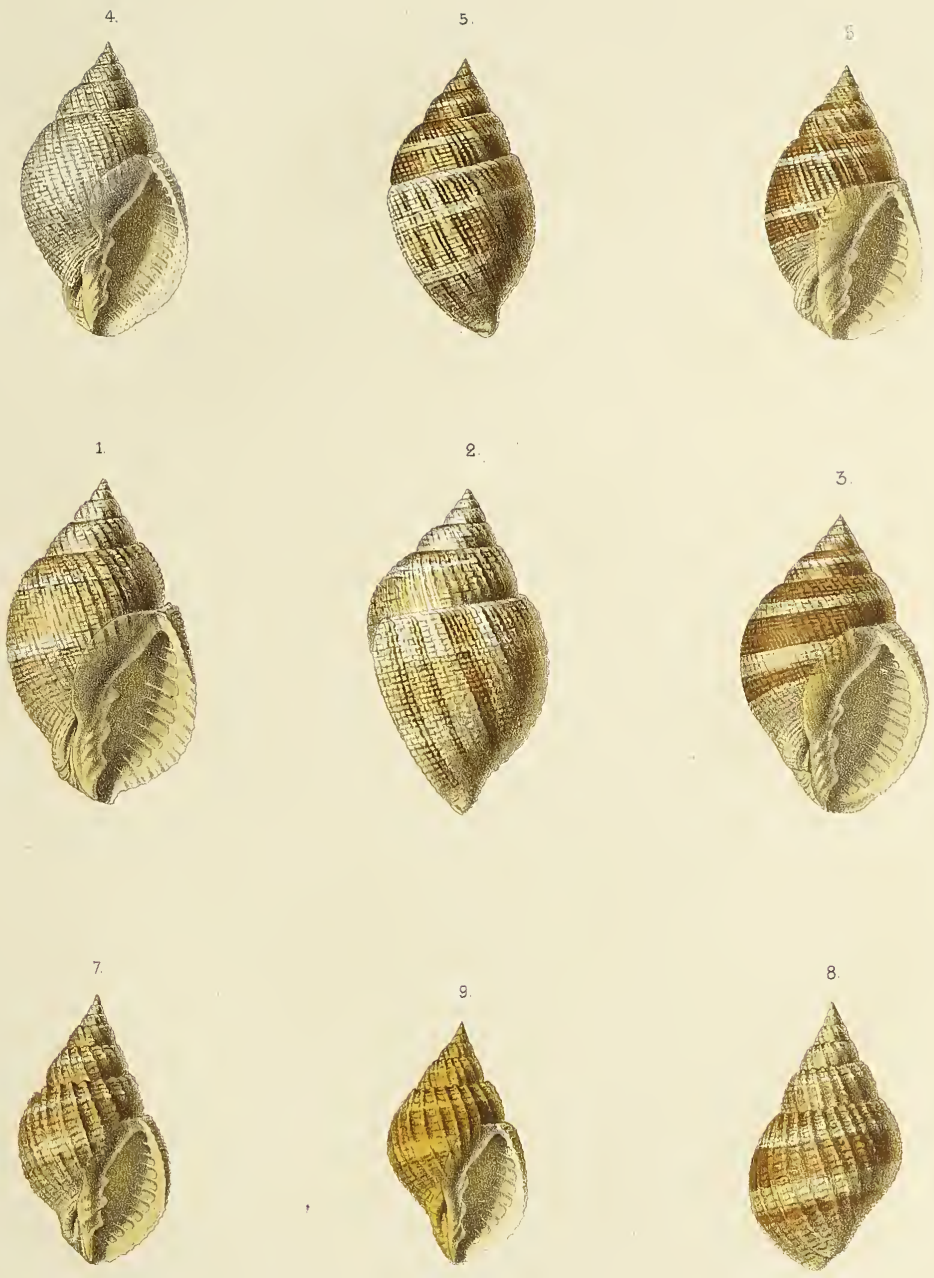

* 

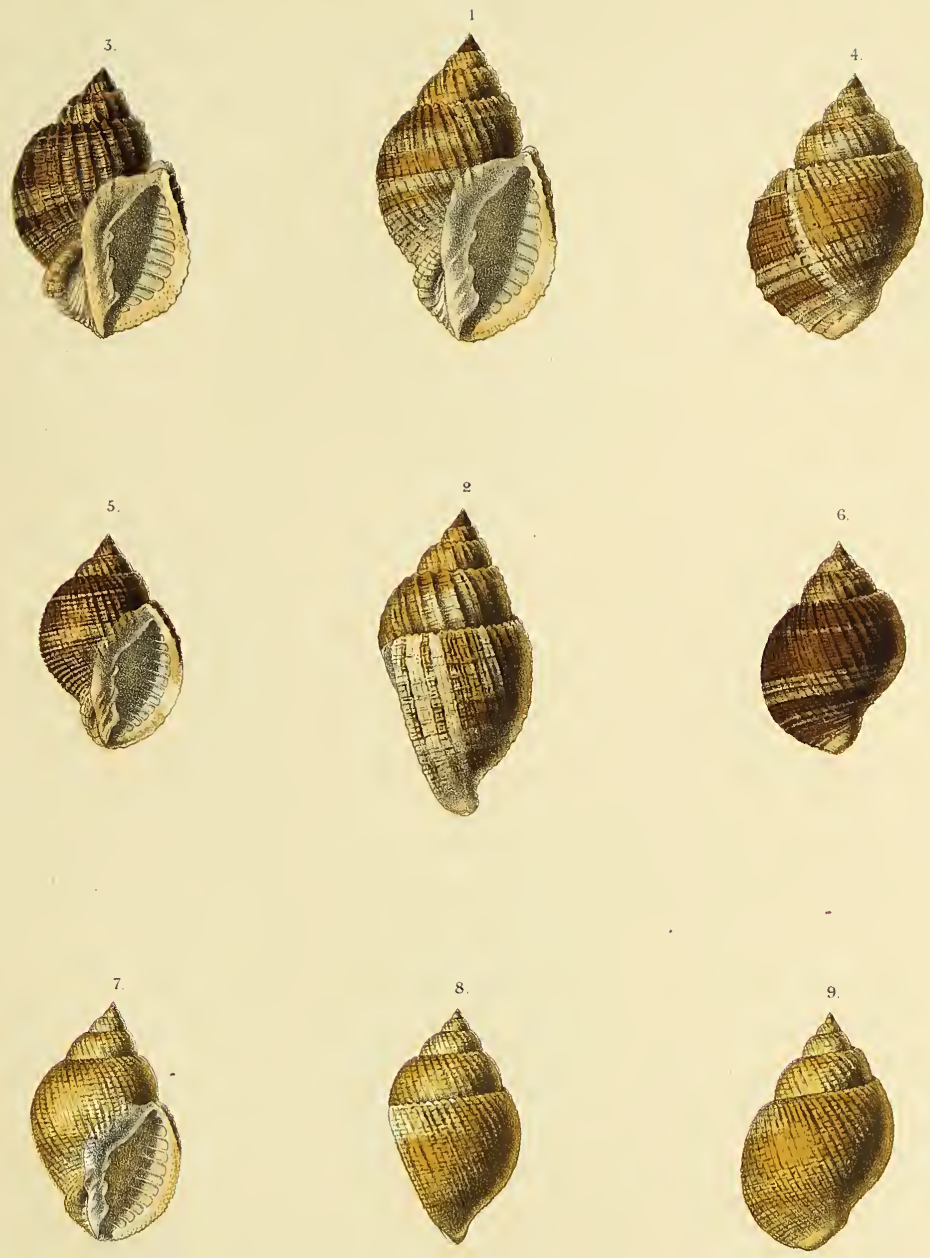

IV. 4 .
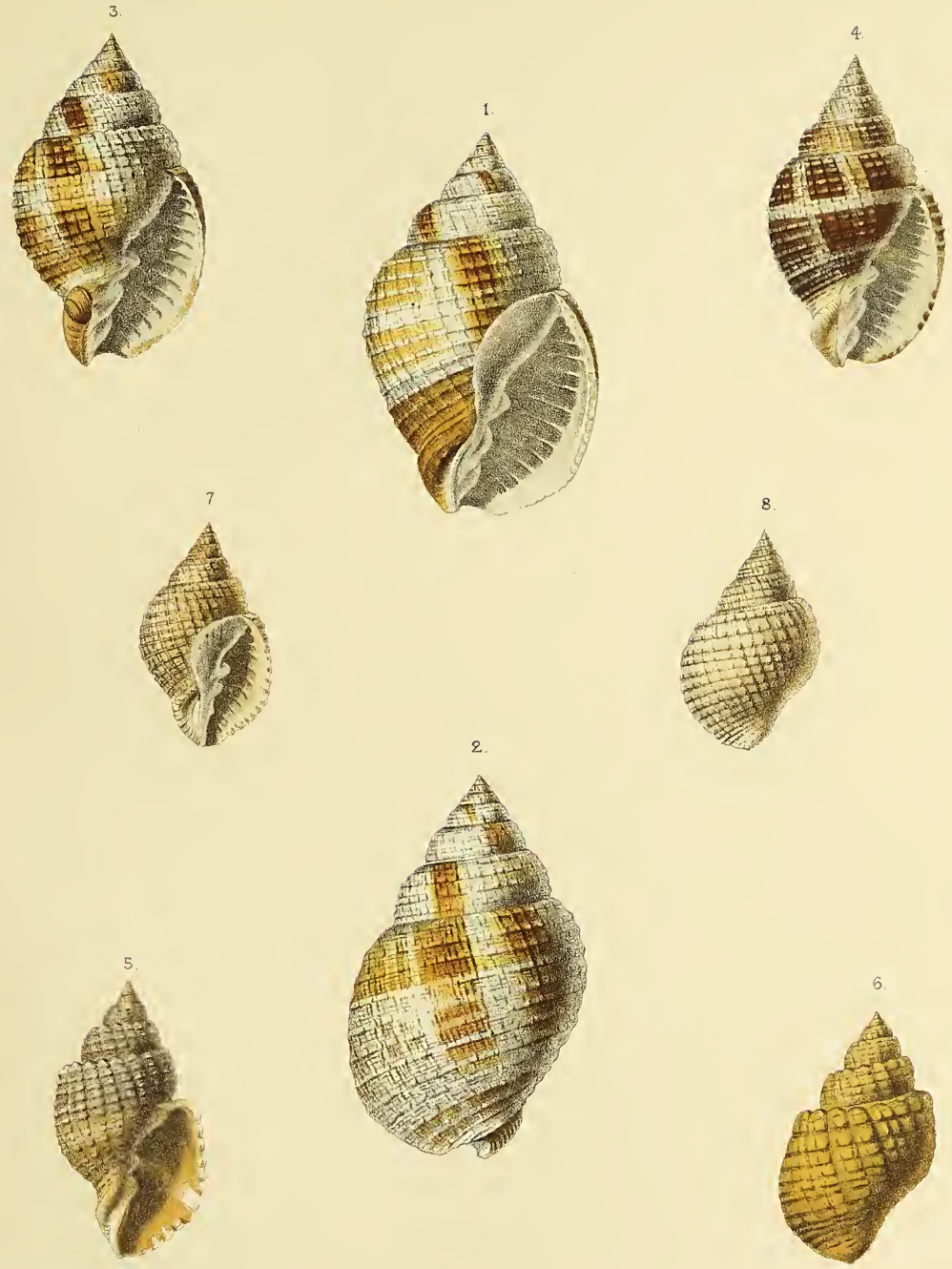


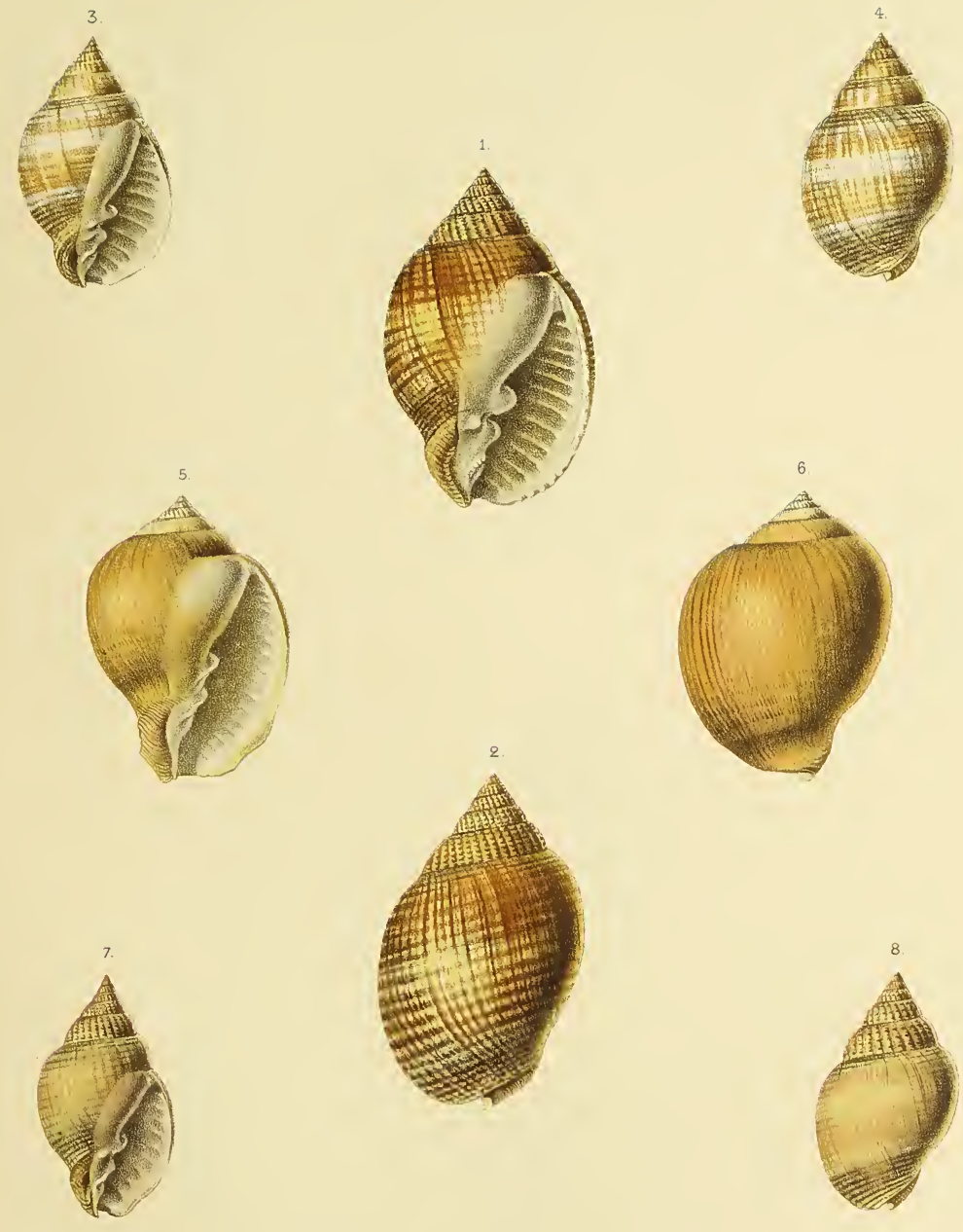

Kobelt del.

Lith $v$ Werner \& Winter Franksur! ift 

IV. 4
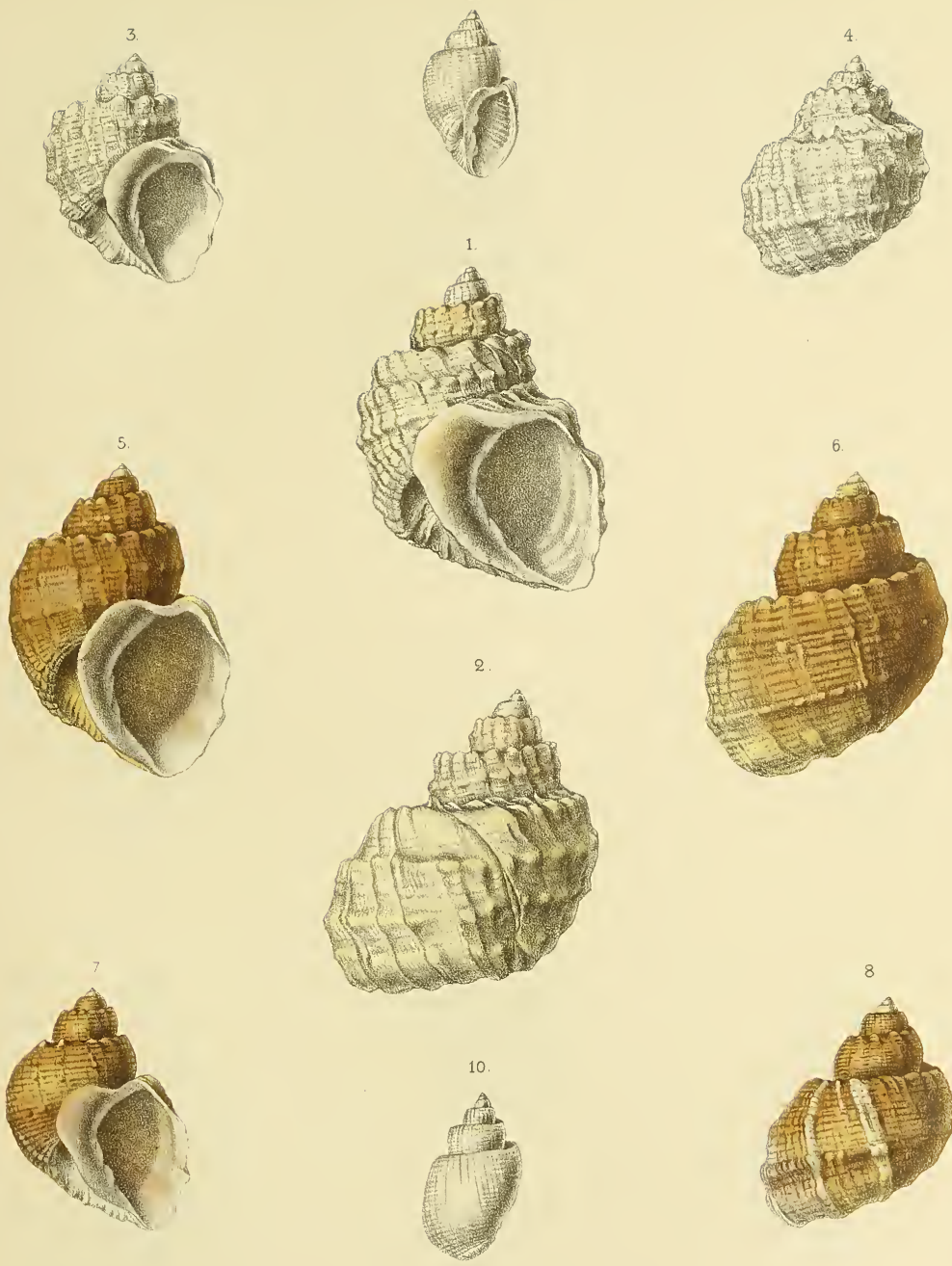

IV. 4
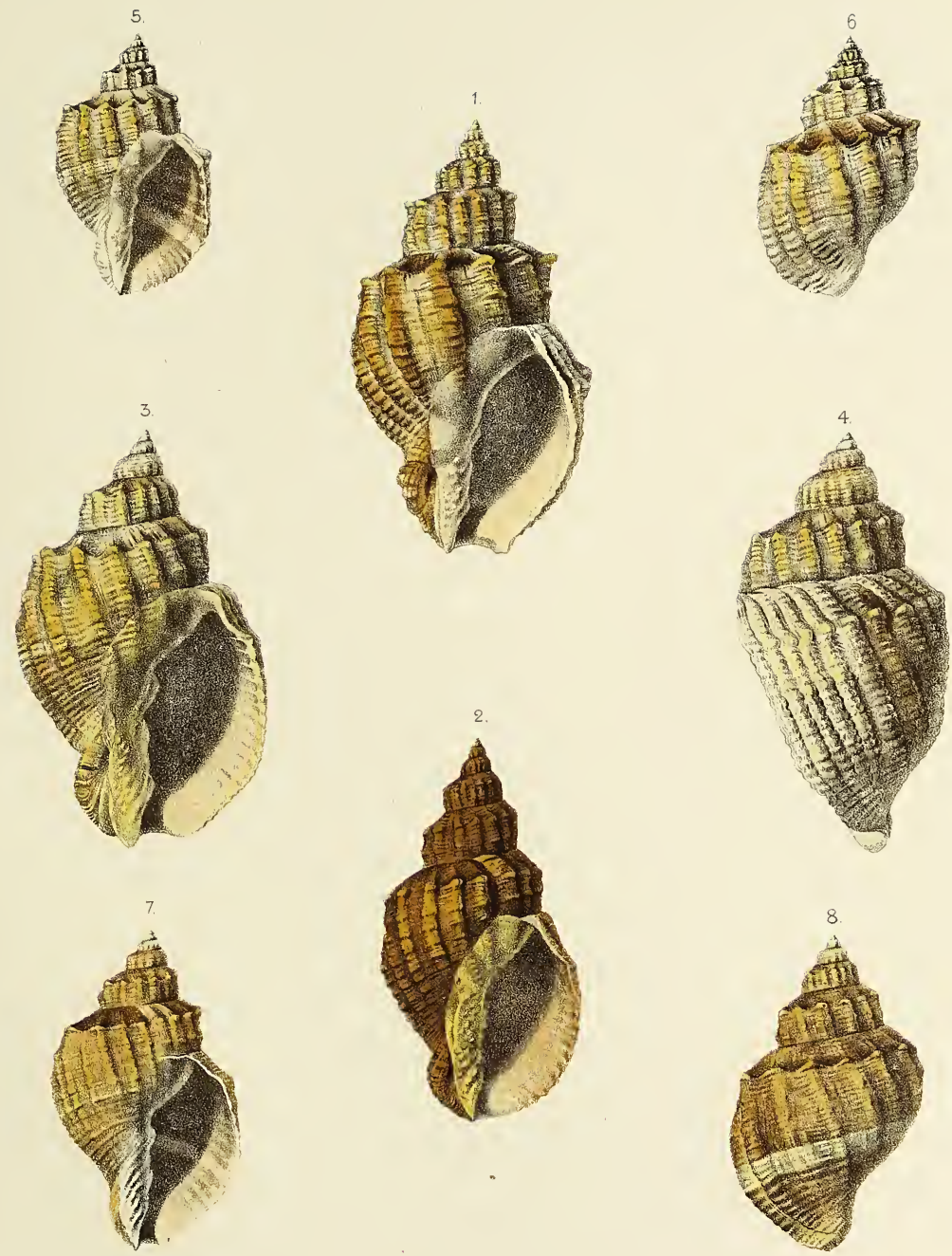

Kobelt del 


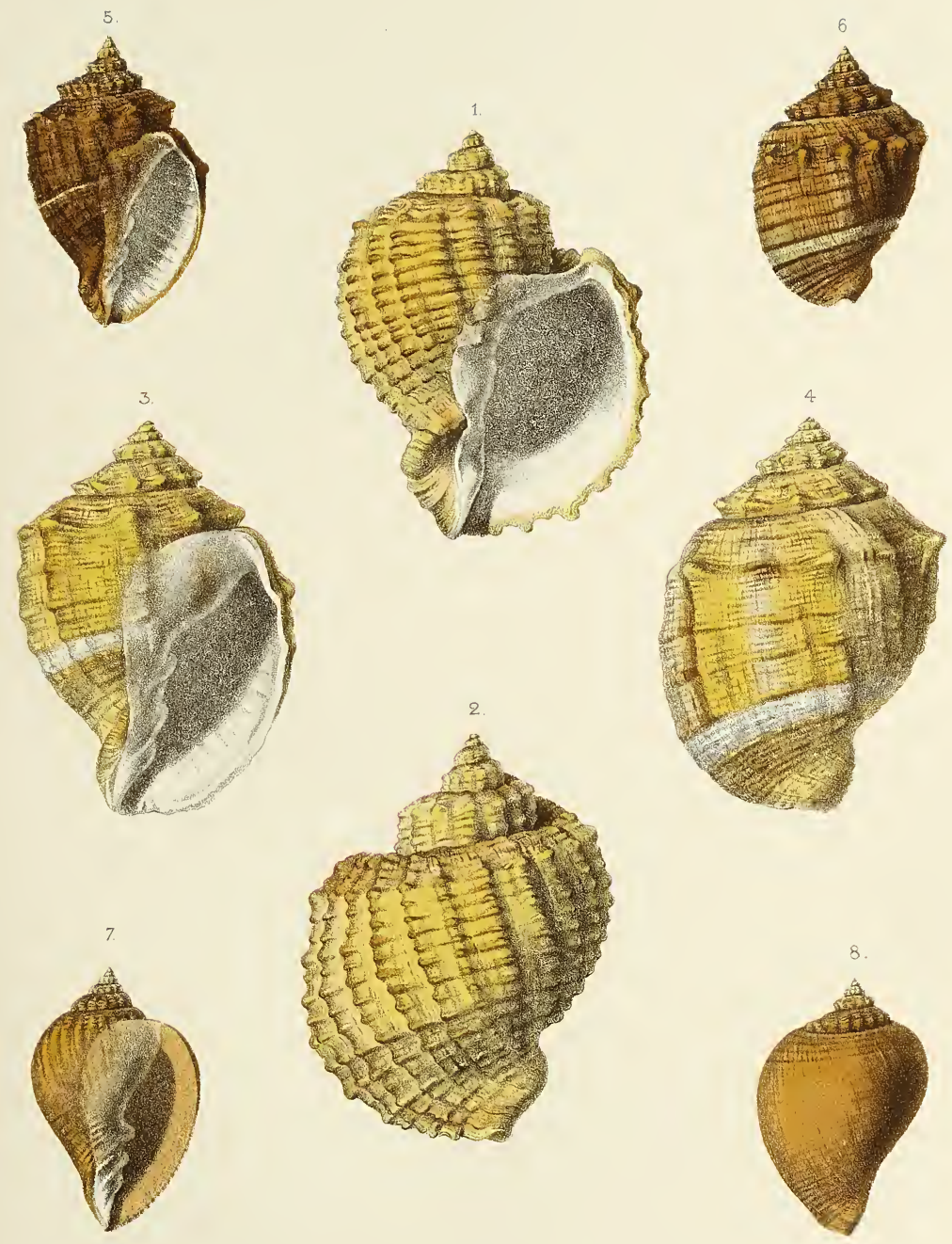

Kobeit del 
$-$ 

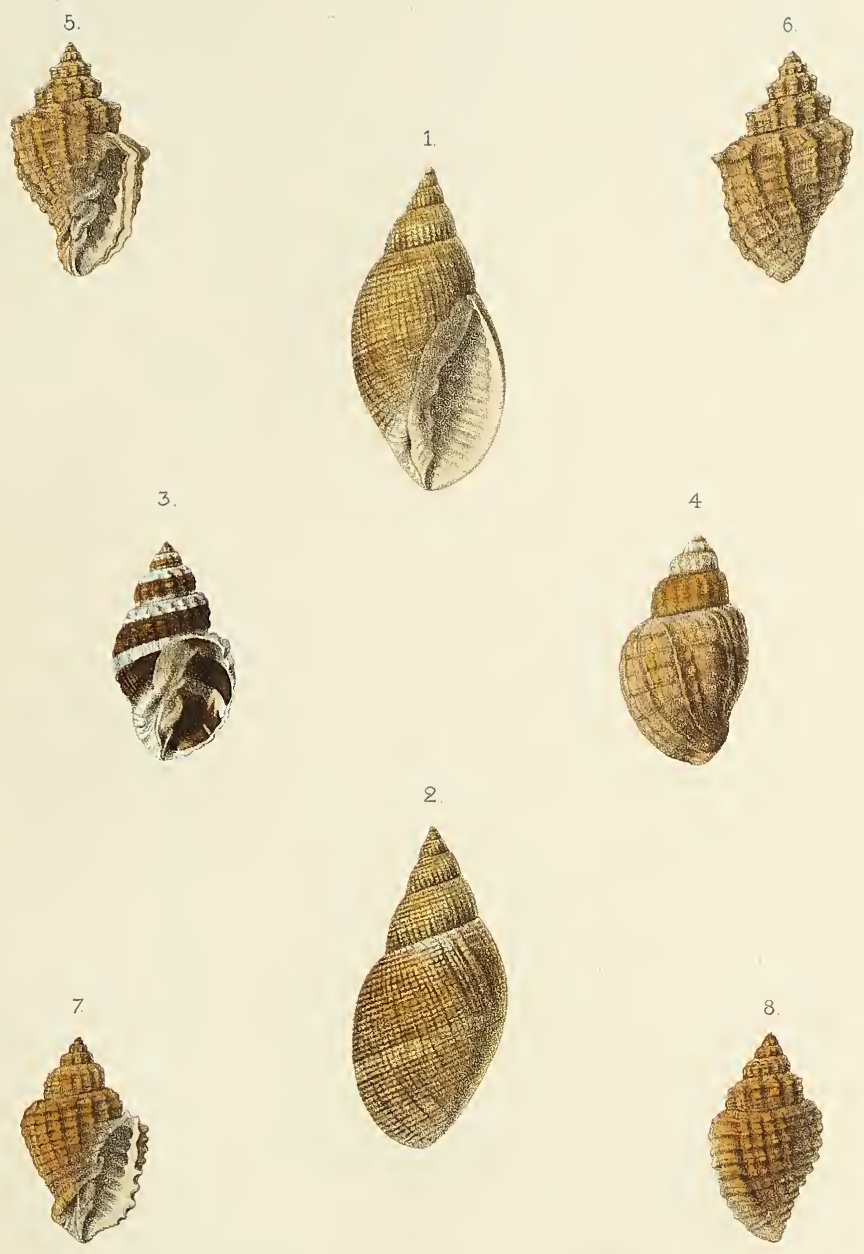

Kobelt del. 


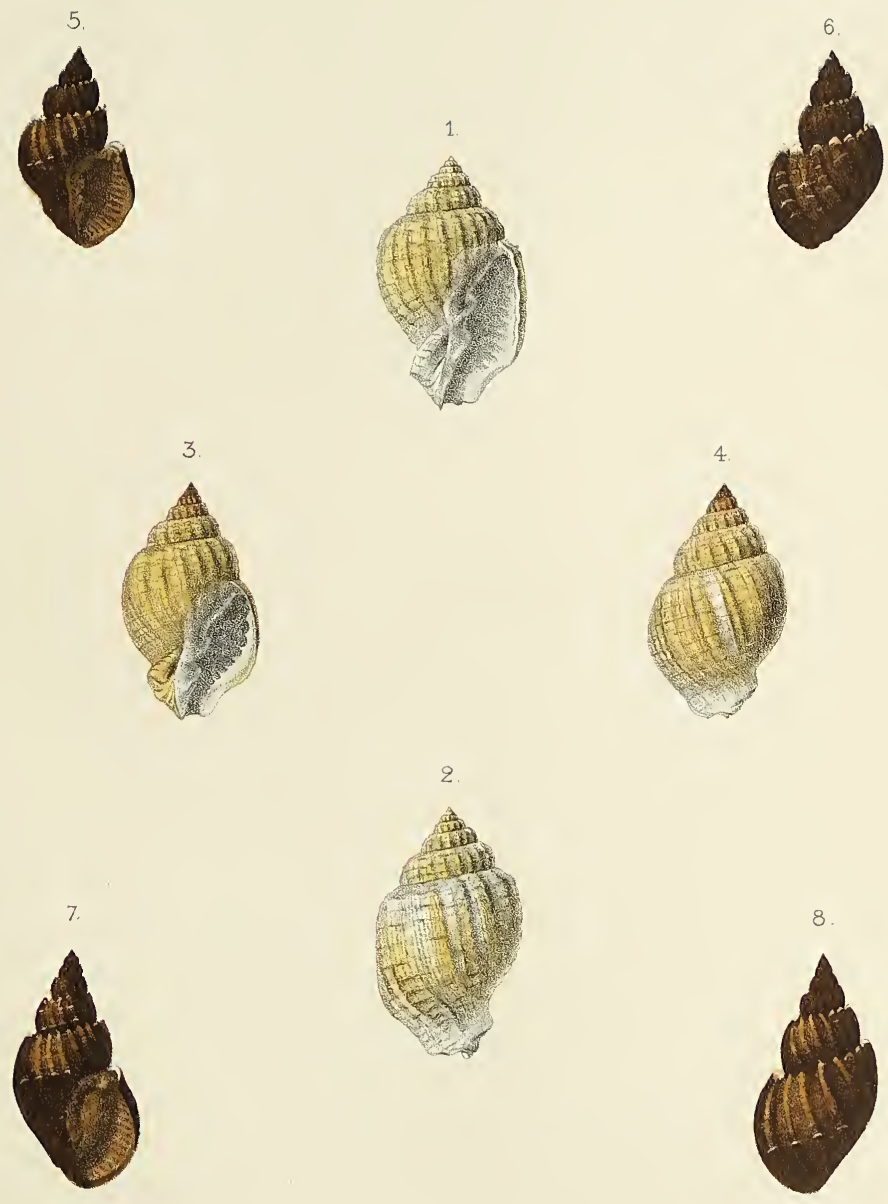

Kobelt del. 


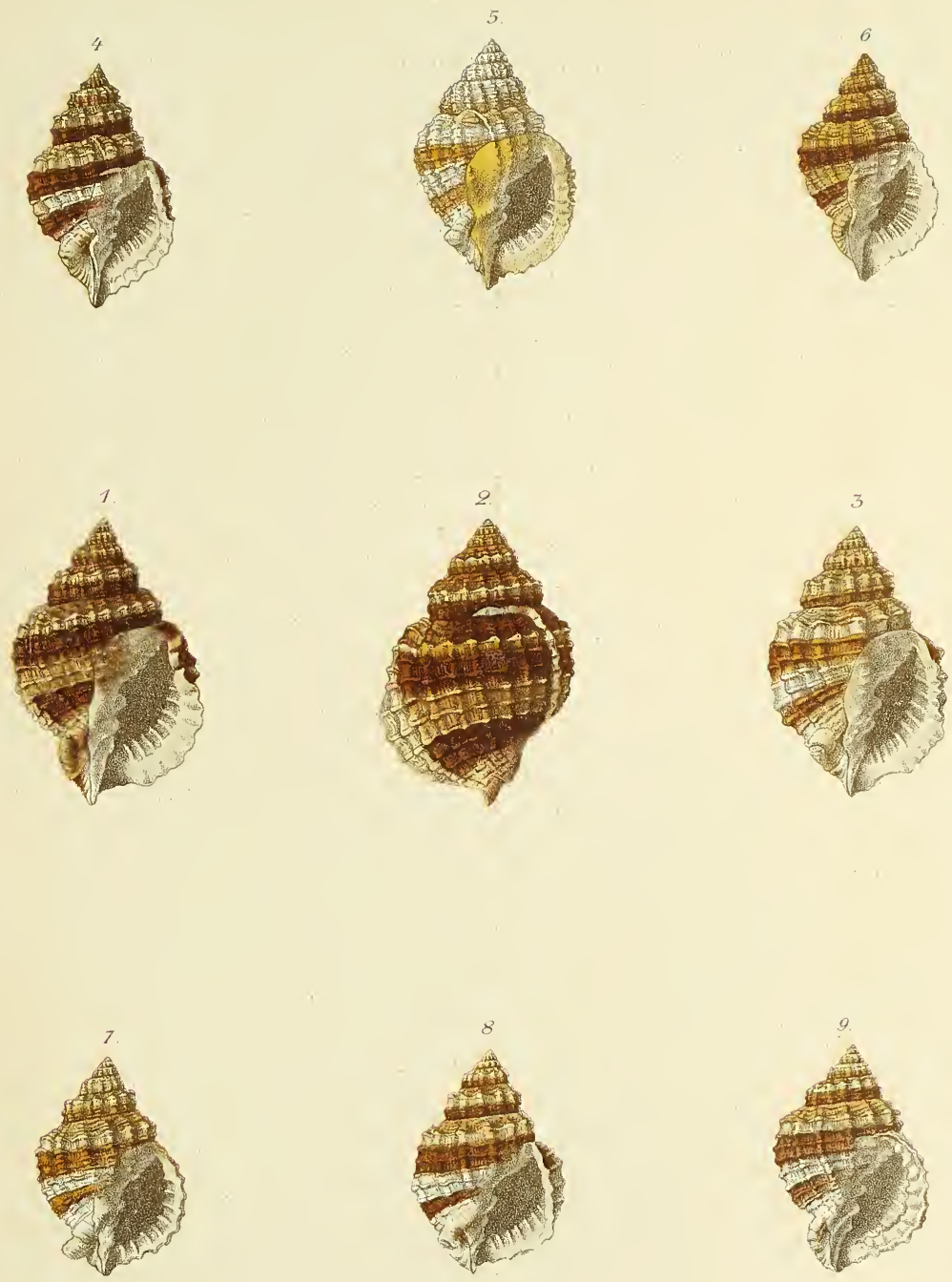


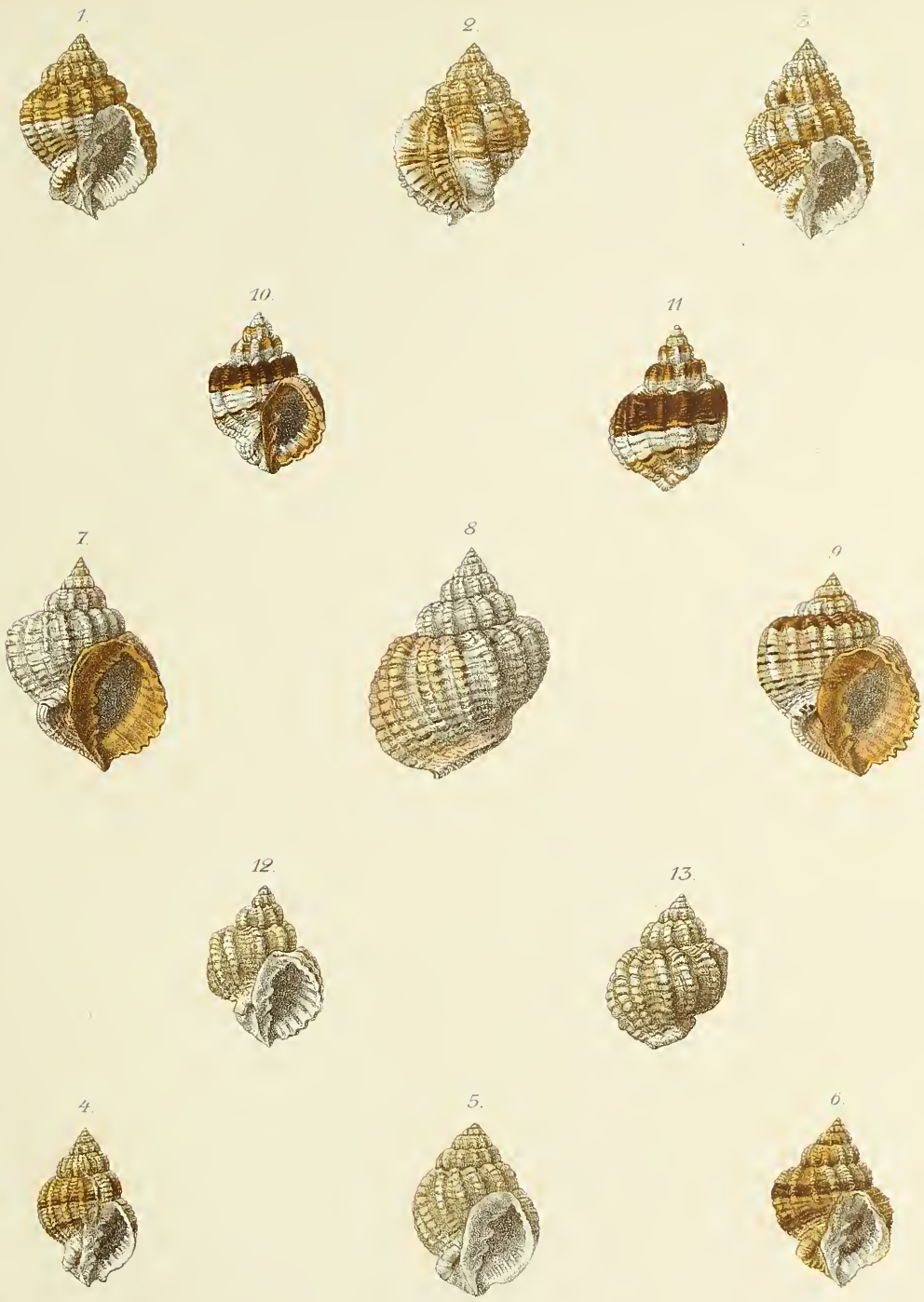


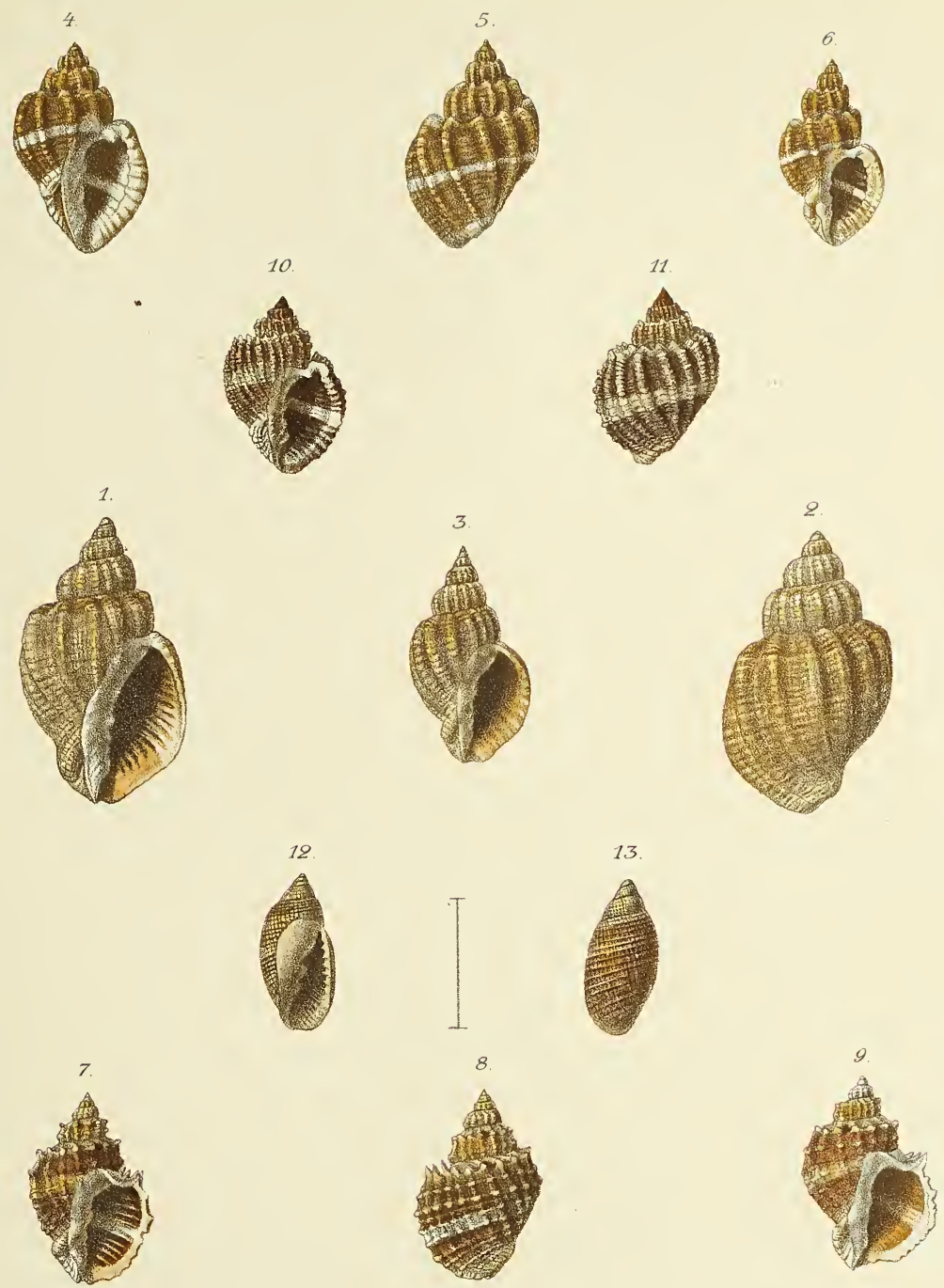


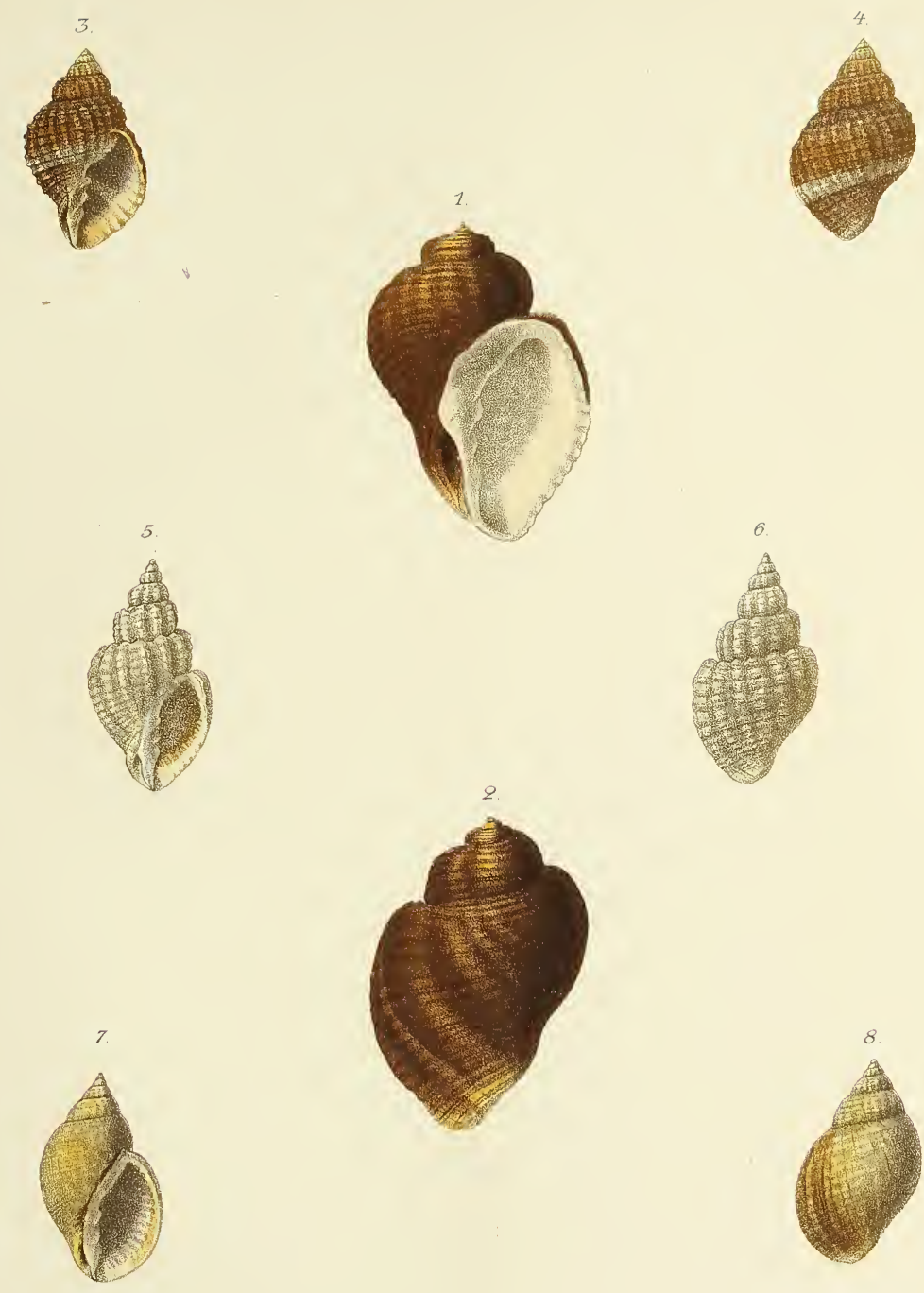


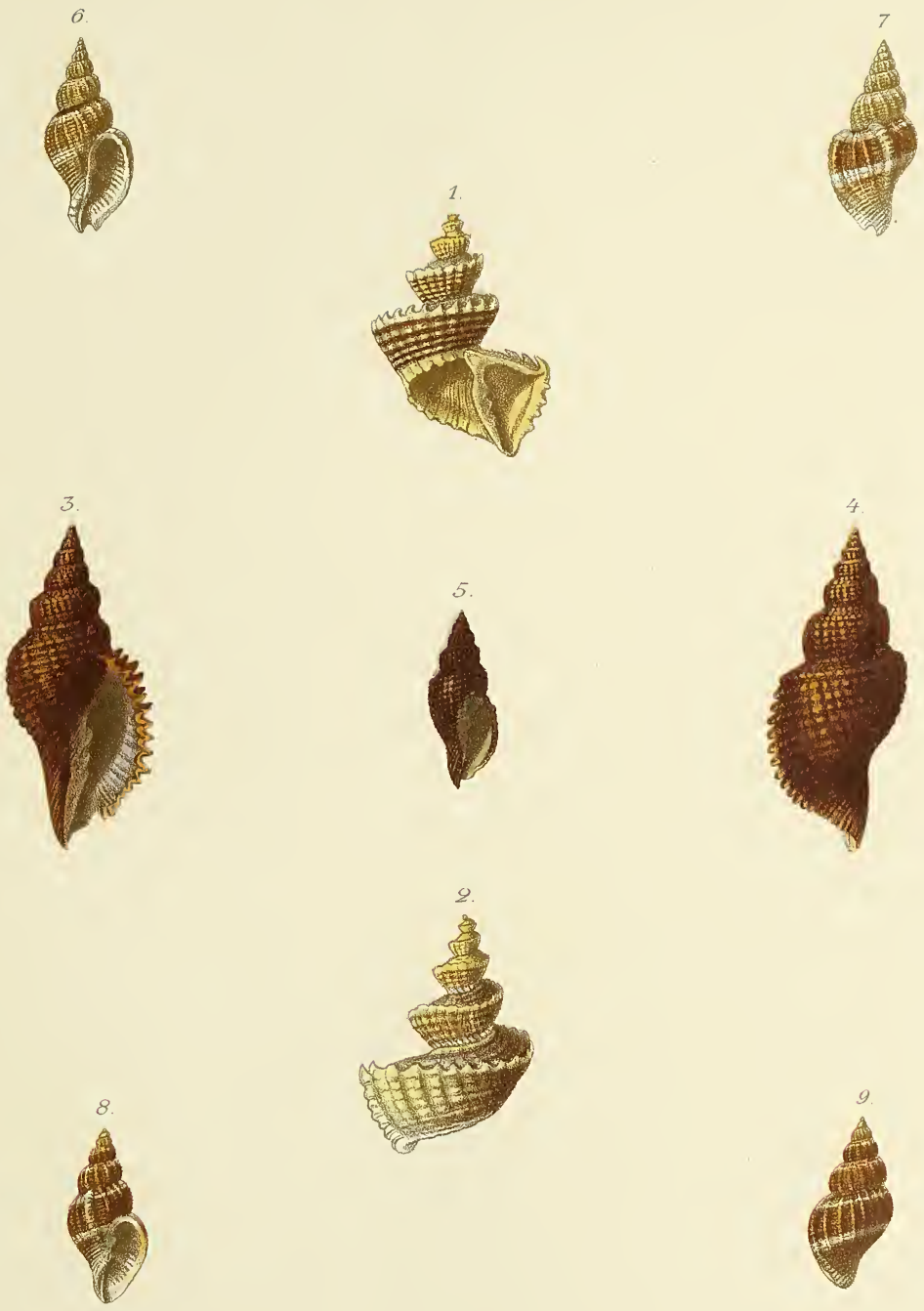
- 

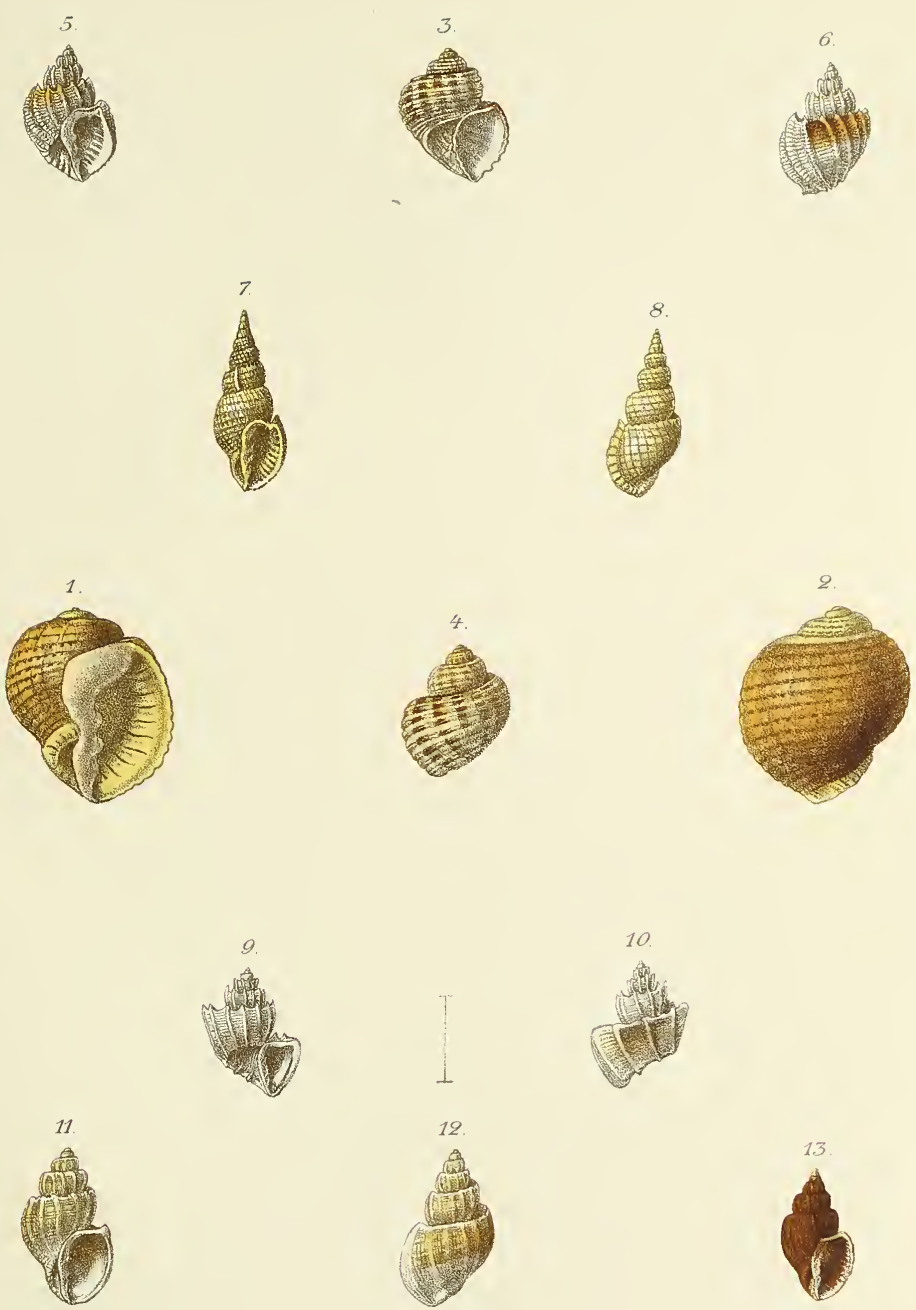


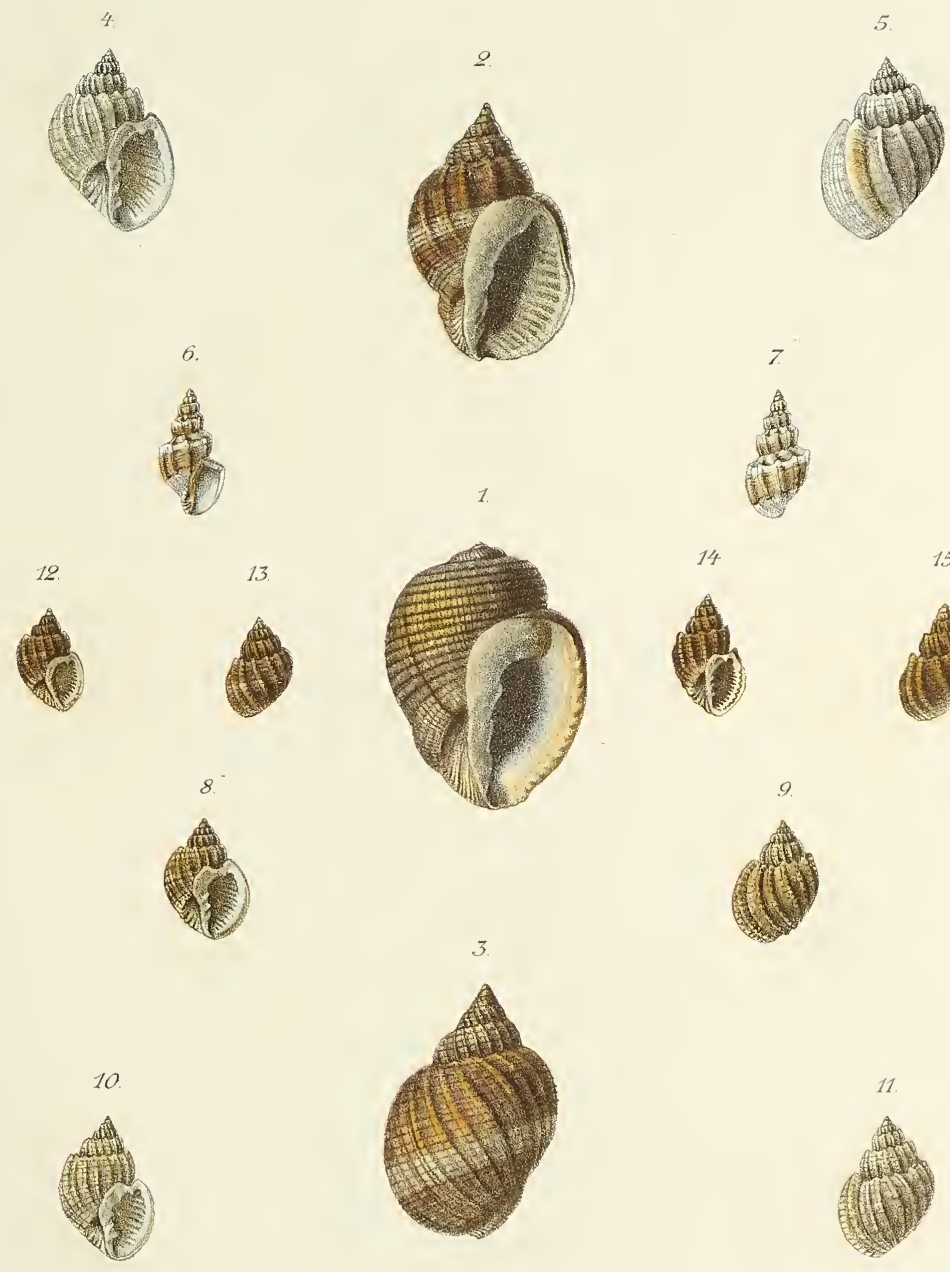


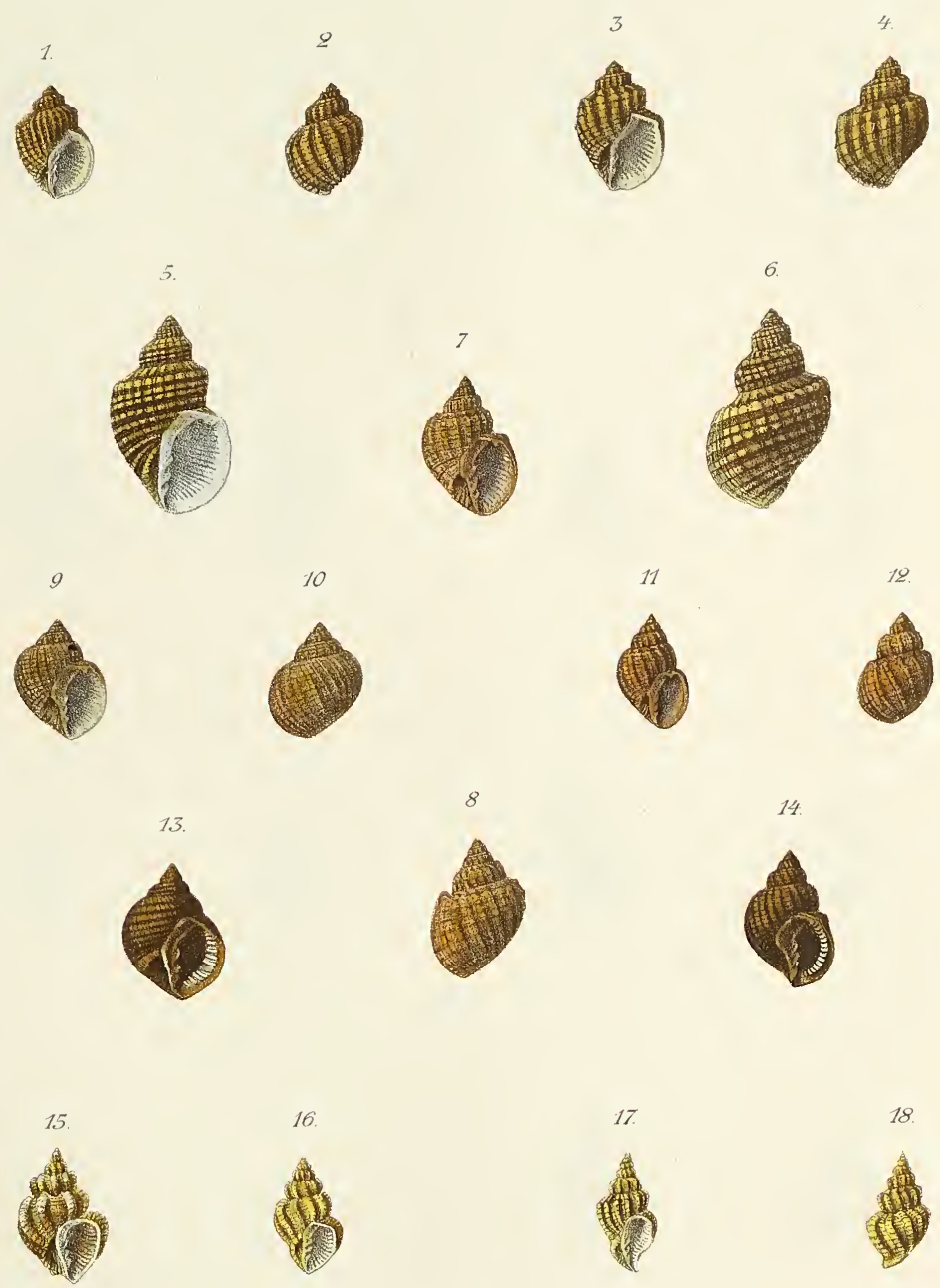


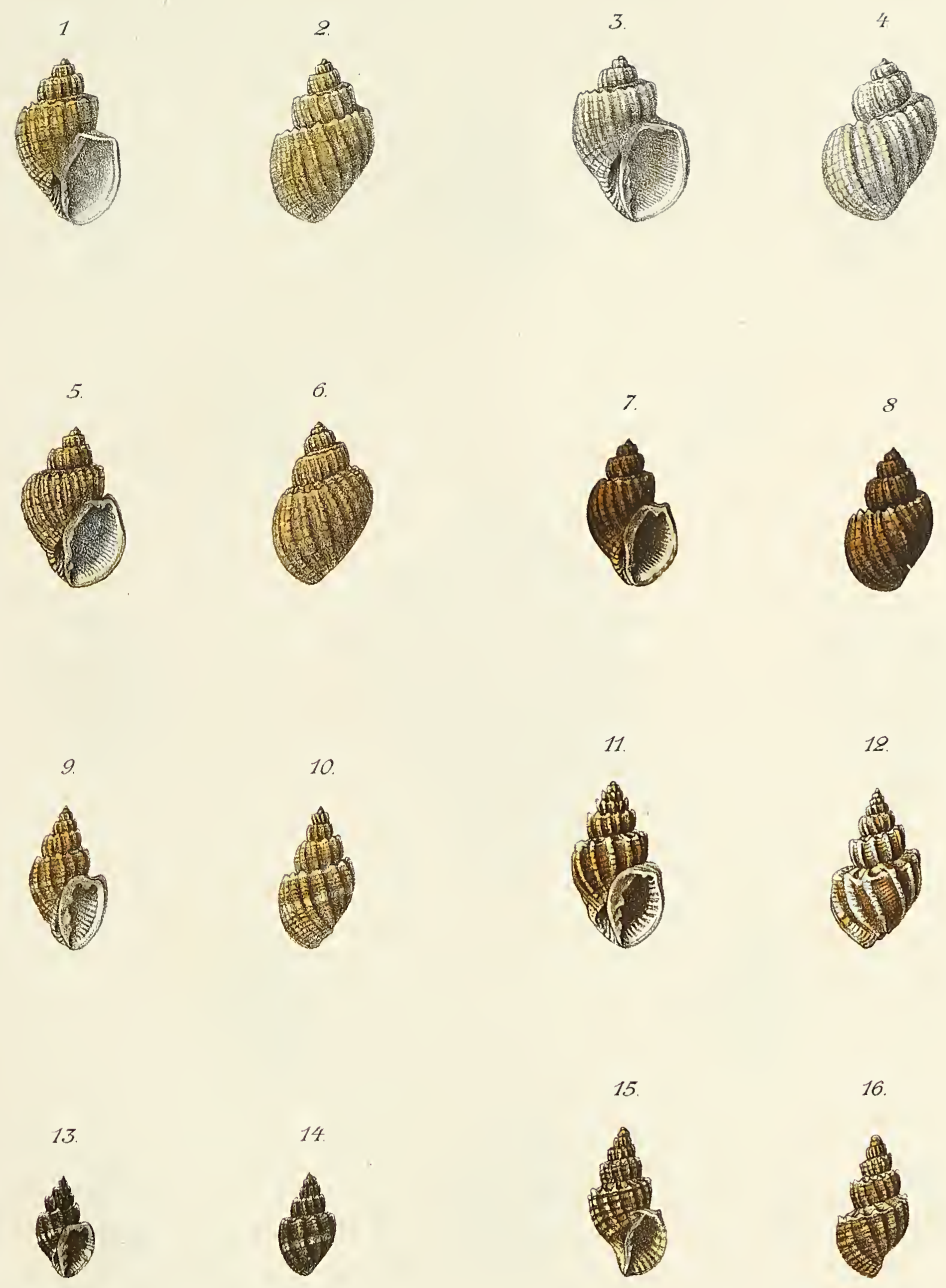


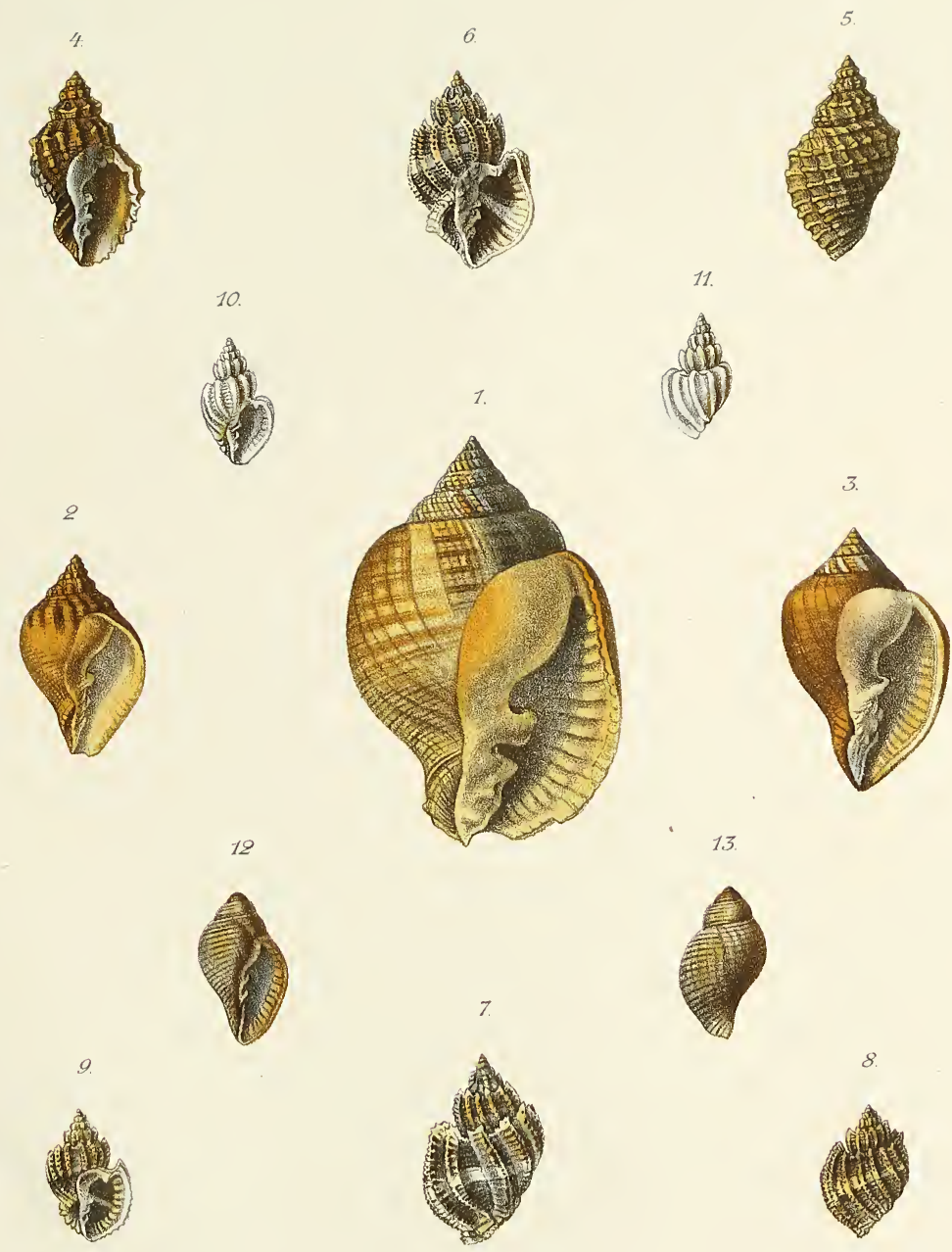


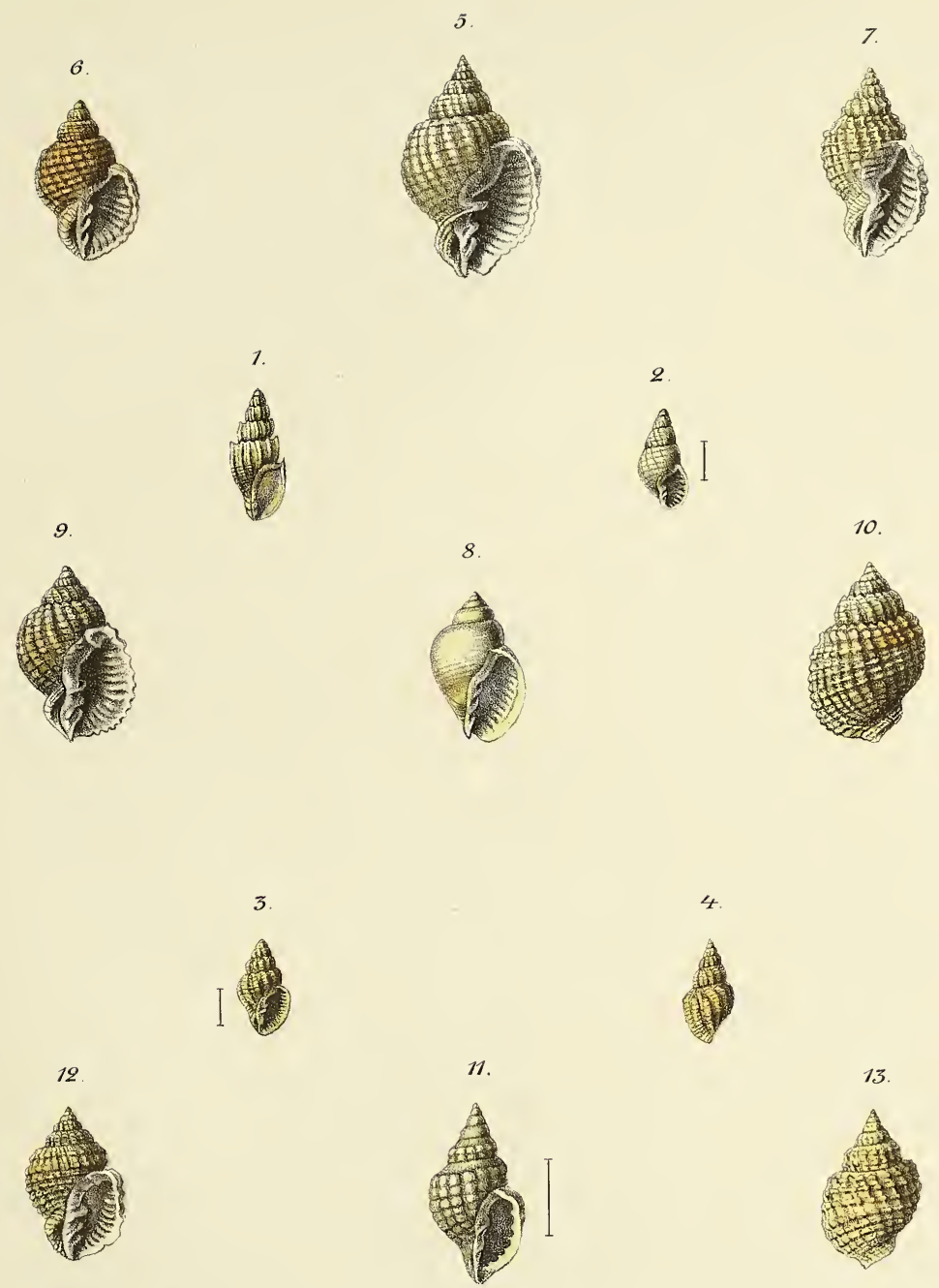

5.

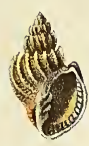

7.

(iv)

9

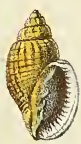

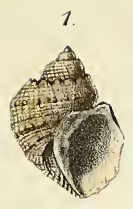

3

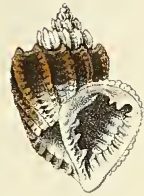

4

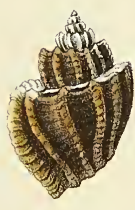

2

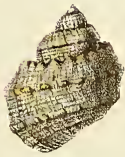

6

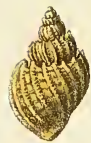

8

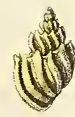

10.

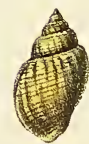



7.

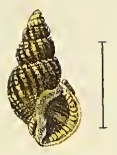

5.

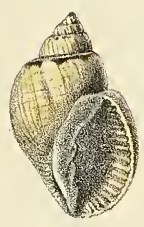

9.

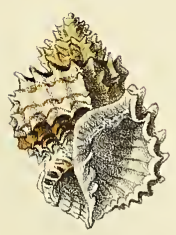

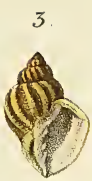

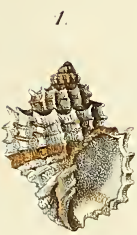

Q

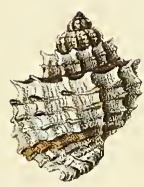

4.

(4)
8

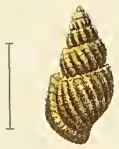

6

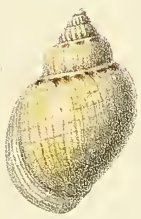

10.

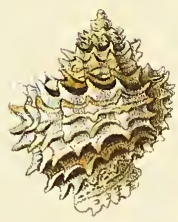




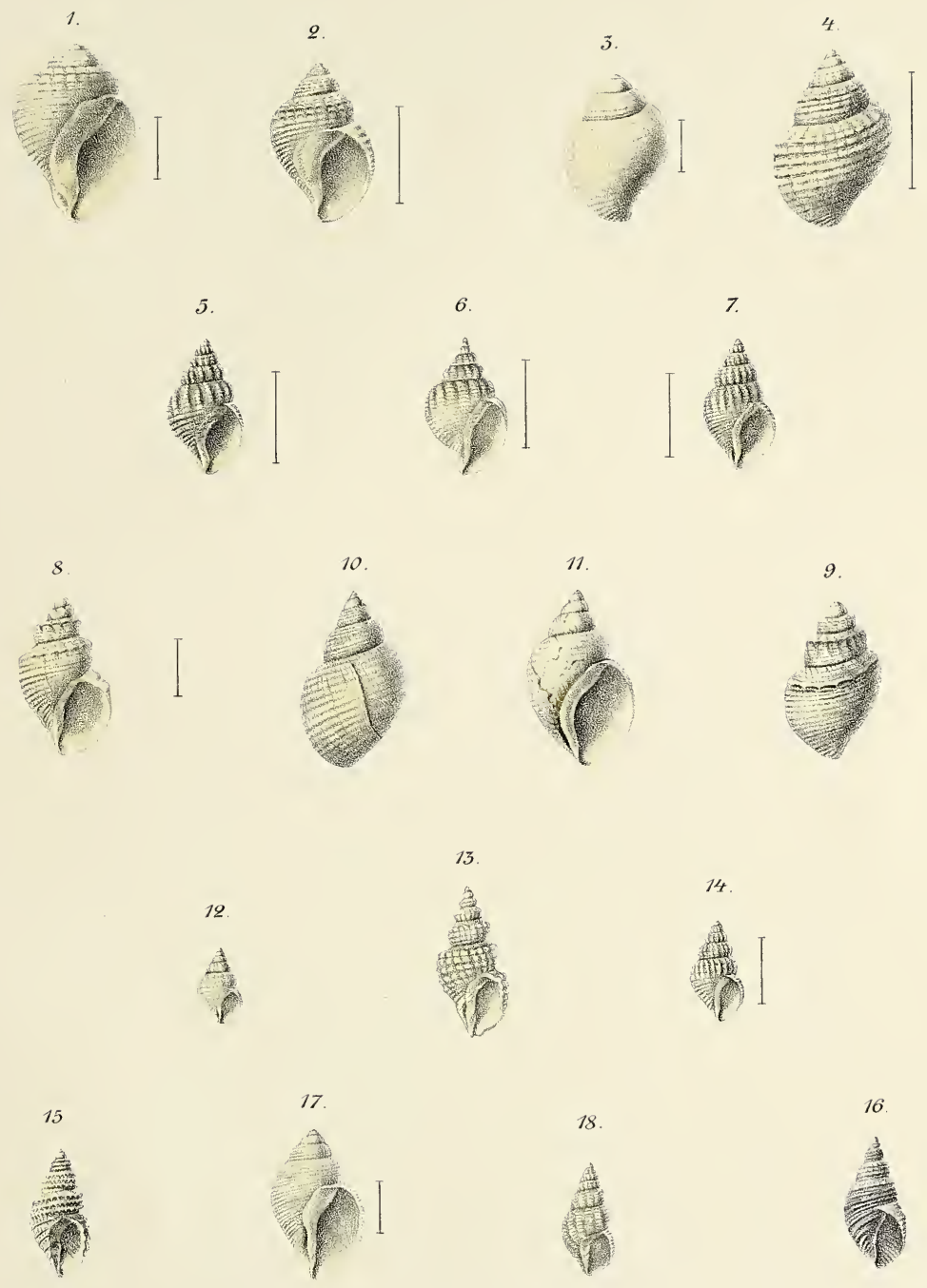
APR 46 SQR 



